Delivery of Gentamicin from Resorbable Polymeric Carriers as Anti-Infective Strategy for Implant-Associated Osteomyelitis 
The research in this thesis has been conducted between 2012 and 2016 in the Polymers Group (part of the Musculoskeletal Regeneration Program) and the Musculoskeletal Infection Program at the AO Research Institute Davos, Davos, Switzerland, and in the Biomaterials Science and Technology research group at the Institute for Biomedical Technology and Technical Medicine (MIRA), University of Twente, Enschede, The Netherlands. The research was financially supported by AO Trauma as part of the Clinical Priority Program Bone Infection.

\section{¿ AOTRAUMA}

Delivery of Gentamicin from Resorbable Polymeric Carriers as Anti-Infective Strategy as Anti-Infective Strategy for Implant-Associated Osteomyelitis

Gert-Jan ter Boo

$\mathrm{PhD}$ Thesis, with references and summaries in English and Dutch

University of Twente, Enschede, The Netherlands

Printed by: Gildeprint - Enschede, The Netherlands 


\title{
DELIVERY OF GENTAMICIN FROM RESORBABLE POLYMERIC CARRIERS AS ANTI-INFECTIVE STRATEGY FOR IMPLANT-ASSOCIATED OSTEOMYELITIS
}

\author{
DISSERTATION
}

to obtain

the degree of doctor at the University of Twente,

on the authority of the rector magnificus,

prof.dr. H. Brinksma,

on account of the decision of the graduation committee,

to be publicly defended

on Wednesday $2^{\text {nd }}$ of November 2016 at 16.45

by

\section{Gert-Jan Albert ter Boo}

Born on the $23^{\text {rd }}$ July 1985

In Hengelo(O), the Netherlands 
The dissertation has been approved by the promotors:

Prof.dr. D.W. Grijpma

Dr. D. Eglin

(C) Gert-Jan ter Boo

ISBN: 978-90-365-4231-9

DOI: $10.3990 / 1.9789036542319$ 


\section{Promotion Committee}

Chairman:

Prof.dr.ir. J.W.M. Hilgenkamp

University of Twente

Promotor:

Prof.dr. D.W. Grijpma

University of Twente

Co-promotor:

Dr. D. Eglin

AO Research Institute Davos

Referee:

Dr. T.F. Moriarty

AO Research Institute Davos

Members:

Prof.dr. H.B.J. Karperien

University of Twente

Prof.dr. D.B.F. Saris

University of Twente

Prof.dr. H.C. van der Mei

University Medical Center Groningen

Prof.dr. R.R.M. Bos

University Medical Center Groningen

Dr. S.A.J. Zaat

Academic Medical Center Amsterdam 



\section{Table of contents}

Chapter $1 \quad$ General introduction

Chapter $2 \quad$ Antimicrobial delivery systems for local infection

prophylaxis in orthopedic and trauma surgery

Chapter $3 \quad$ Hyaluronic acid derivatives and their polyelectrolyte

complexes with gentamicin as delivery system

for antibiotics

Chapter $4 \quad$ Injectable gentamicin-loaded thermo-responsive

hyaluronic acid derivative prevents infection

in a rabbit model

Chapter $5 \quad$ Local application of a gentamicin-loaded

thermo-responsive hydrogel allows fracture healing

upon clearance of a high Staphylococcus aureus load

Chapter 6

Preparation of gentamicin dioctyl sulfosuccinate loaded poly(trimethylene carbonate) matrices intended

for the treatment of orthopaedic infections

Chapter 7

Polymeric microparticles with low dispersity loaded with gentamicin sulfate and hydrophobic modified gentamicin

Chapter 8

Future perspectives

Summary

Samenvatting

Acknowledgements 

Chapter 1

General Introduction 


\section{General Introduction}

The number of patients requiring fracture fixation after trauma is increasing yearly [ 1 , 2]. In the US alone, 440 thousand fractures were reduced with internal fracture fixation implants in 2010 [3]. The insertion of orthopaedic- and trauma implants creates a localized deficiency in phagocytosis of bacteria in the vicinity of the implant. Therefore, the susceptibility to bacterial colonization of the implant substantially increases $[4,5]$.

The fixation of closed fractures results in infection rates of $0.5 \%$ to $2 \%$. However, the infection rate might exceed $30 \%$ in patients with severe open fractures $[1,6]$. On average $5 \%$ of the internal fracture fixation devices get colonized by bacteria, resulting in implant infection [2]. The socio-economic effects of implant infection are tremendous. The treatment of chronic osteomyelitis is difficult and time-consuming. A standard protocol for chronic osteomyelitis and infected non-unions may involve: identification of the bacterial species and antibiotic susceptibility testing, removal of fracture fixation devices, debridement of the infected bone and soft tissue and systemic delivery of antibiotics for a 4-6 weeks period [7]. The average cost for removing infected internal fracture fixation devices and subsequent treatment of these infections were estimated to be $\$ 15,000$ on average per case around the year 2000 in the United States [8]. A large survey performed amongst hospitals located in New York City revealed similar figures. A total of 13,550 cases of $S$. aureus infection with a total cost of $\$ 435.5$ million for treatment were reported, on average $\$ 32,100$ per case [9].

As such, the prophylactic delivery of antibiotics plays a crucial role in the prevention of infections in trauma surgery. However, systemic delivery of antibiotics is often insufficient to protect the implant site from bacterial colonization as the bony structures and local vascularity might be disturbed [10]. Furthermore, the systemic delivery of certain antibiotics is associated with toxic side effects [11, 12].

Local delivery of antibiotics by antibiotic loaded biomaterials (ALBs) can overcome the aforementioned problems, by on-site delivery of high concentrations of antibiotics. One of these ALBs that is most commonly used, either as carrier in the shape of polymeric bead chains, blocks or putty, is non-degradable 
poly(methylmethacrylate) (PMMA) [13]. A follow-up surgery is required to remove the material after its useful lifetime, involving the risk for new intraoperative infection. Other commercially available ALBs are antibiotic loaded collagen fleece [14] and antibiotic-loaded poly(lactic acid) (PLA) as a coating on fracture fixation implants. Although both biomaterials are degradable, they do not take the nature of trauma wounds into account as these materials have confined dimensions and may have limited distribution in complex wounds. Hyaluronic acid (HA) hydrogels are biocompatible and degradable and used across many biomedical applications, notably as vehicle for drug delivery systems [15]. HA hydrogels with lower critical solution temperature (LCST) behaviour can be obtained by grafting thermosensitive (co)polymers to one of the functional groups on the HA backbone. Although many polymers exhibit thermo-responsiveness, some have gained particular interest because their LCSTs are just below physiological temperature [16]. These comprise poly( $N$-isopropylacrylamide) ( $\mathrm{pN})$ and its copolymers, poly $(N, N$-diethylacrylamide), block copolymers of poly(ethylene oxide) and poly(propylene oxide) (PEO-PPO) and block copolymers of poly(ethylene oxide) and poly(lactic-co-glycolic acid) (PEOPLGA) $[16,17]$. Importantly, conjugation of $\mathrm{pN}$ onto a polymer chain yields thermoresponsive polymers with sharp phase transition [18].

\section{Scope of the studies}

In this thesis several investigations are performed. Firstly, the potential of hyaluronic acid and several HA derivatives to complex gentamicin sulfate, a commonly used antibiotic in ALBs, is investigated. Additionally, HA derivatives are prepared with 2 different polymers with LCST behaviour. The thermo-responsive behaviour of PEO/PPO grafted HA is compared with $\mathrm{pN}$ functionalized HA. Secondly, thermoresponsive hydrogels loaded with gentamicin sulfate are prepared from $\mathrm{pN}$ grafted HA (HApN) and characterized in vitro. Their potential to prevent infection in vivo is studied in a rabbit humerus model including fracture, implant and high bacterial load. Their influence on bone healing upon clearing an infection is investigated. Finally, the hydrophobic modification of gentamicin and encapsulation in hydrophobic matrices 
and particles are explored to obtain gentamicin loaded ALBs more suited for infection treatment purposes.

\section{Outline of the thesis}

In Chapter 2 an introduction to antibiotic loaded biomaterials (ALBs) is provided. Protocols for systemic antibiotic infection prophylaxis and current commercial available ALBs are described. Finally, new developments in this field are reviewed, including the incorporation of antimicrobial agents other than antibiotics into ALBs, development of improved polymeric carriers for the passive delivery of antibiotics and the description of responsive polymeric carriers for the active delivery of antibiotics.

In Chapter 3 the complexation of positively charged gentamicin with negatively charged hyaluronic acid (HA) into polyelectrolyte complexes (PECs) is investigated. Subsequently, several HA derivatives are reported that have been synthesized and characterized with respect to their thermo-responsiveness and their complexation into PECs with- and release of gentamicin.

Chapter 4 describes the preparation of a thermo-responsive hyaluronic acid poly $(N$ isopropylacrylamide) hydrogel and its loading with gentamicin sulfate. The rheological properties and in vitro release from the gentamicin-loaded $\mathrm{HApN}$ hydrogel is studied. The efficacy of prophylactic antibiotic delivery from these hydrogels is investigated in a contaminated osteotomy model with plating osteosynthesis in the rabbit humerus.

In Chapter $\mathbf{5}$ the effect of the thermo-responsive hydrogel on fracture healing is assessed. Firstly, the effect of HApN hydrogels on fracture healing is assessed and compared to normal healing in the presence of a fracture fixation implant. Finally, clearance of a high bacterial load and subsequent fracture healing in the presence of gentamicin-loaded HApN hydrogels is investigated.

Chapter 6 describes the preparation of a hydrophobic salt of gentamicin by hydrophobic ion pairing. The potency of the hydrophobic salt of gentamicin to kill bacterial species relevant to traumatology and orthopaedics, and its toxicity towards mammalian cells is investigated. Finally, both the hydrophobic and hydrophilic gentamicin salts are encapsulated within poly(trimethylene carbonate) matrices. 
In Chapter 7 the preparation of polymeric microspheres loaded with gentamicin is described by means of the double emulsion solvent evaporation technique and the preparation of monodisperse microspheres loaded with either the hydrophobic or hydrophilic salt of gentamicin by membrane emulsification is described.

Chapter 8 focuses on the future perspectives of local antimicrobials delivery 


\section{References}

[1] Trampuz A, Widmer AF. Infections associated with orthopedic implants. Curr Opin Infect Dis 2006;19:349-56.

[2] Trampuz A, Zimmerli W. Diagnosis and treatment of infections associated with fracture-fixation devices. Injury 2006;37 Suppl 2:S59-66.

[3] National Hospital Discharge Survey. Center for Disease Control and Prevention; 2010.

[4] Andriole VT, Nagel DA, Southwick WO. A paradigm for human chronic osteomyelitis. J Bone Joint Surg Am 1973;55:1511-5.

[5] Elek SD, Conen PE. The virulence of Staphylococcus pyogenes for man; a study of the problems of wound infection. Br J Exp Pathol 1957;38:573-86.

[6] Schmidmaier G, Lucke M, Wildemann B, Haas NP, Raschke M. Prophylaxis and treatment of implant-related infections by antibiotic-coated implants: a review. Injury 2006;37 Suppl 2:S105-12.

[7] Peng KT, Chen CF, Chu IM, Li YM, Hsu WH, Hsu RW, et al. Treatment of osteomyelitis with teicoplanin-encapsulated biodegradable thermosensitive hydrogel nanoparticles. Biomaterials 2010;31:5227-36.

[8] Darouiche RO. Treatment of infections associated with surgical implants. N Engl J Med 2004;350:1422-9.

[9] Rubin RJ, Harrington CA, Poon A, Dietrich K, Greene JA, Moiduddin A. The economic impact of Staphylococcus aureus infection in New York City hospitals.

Emerg Infect Dis 1999;5:9-17.

[10] Ito K, Perren SM. Biology and biomechanics in bone healing. In: Ruedi TP, Buckley RE, Moran CG, editors. AO principles of fracture management. Davos Platz: AO Publishing; 2007. p. 9-31.

[11] Deguchi T, Ishi A, Tanaka M. Binding of aminoglycoside antibiotics to acidic mucopolysaccharides. J Antibiot (Tokyo) 1978;31:150-5.

[12] Mingeot-Leclercq MP, Tulkens PM. Aminoglycosides: nephrotoxicity. Antimicrob Agents Chemother 1999;43:1003-12.

[13] ter Boo GJ, Grijpma DW, Moriarty TF, Richards RG, Eglin D. Antimicrobial delivery systems for local infection prophylaxis in orthopedic- and trauma surgery. Biomaterials 2015;52:113-25. 
[14] Kilian O, Hossain H, Flesch I, Sommer U, Nolting H, Chakraborty T, et al. Elution kinetics, antimicrobial efficacy, and degradation and microvasculature of a new gentamicin-loaded collagen fleece. J Biomed Mater Res B Appl Biomater 2009;90:210-22.

[15] Prestwich GD. Hyaluronic acid-based clinical biomaterials derived for cell and molecule delivery in regenerative medicine. J Control Release 2011;155:193-9.

[16] Qiu Y, Park K. Environment-sensitive hydrogels for drug delivery. Adv Drug Deliv Rev 2001;53:321-39.

[17] Jeong B, Kim SW, Bae YH. Thermosensitive sol-gel reversible hydrogels. Adv Drug Deliv Rev 2002;54:37-51.

[18] Schild HG. Poly(N-isopropylacrylamide): experiment, theory and application. Progress in Polymer Science 1992;17:163-249. 
Chapter 1 


\title{
Chapter 2
}

\section{Antimicrobial delivery systems for local infection prophylaxis in orthopedic- and trauma surgery}

\author{
Gert-Jan A. ter Boo ${ }^{1,2}$, Dirk W. Grijpma ${ }^{2,3}$, Thomas F. Moriarty ${ }^{1}$, Robert G. Richards ${ }^{1}$, \\ David Eglin ${ }^{1}$
}

${ }^{1} \mathrm{AO}$ research institute Davos, Clavadelerstrasse 8, CH 7270 Davos, Switzerland

${ }^{2}$ Department of Biomaterials Science and Technology, University of Twente, Enschede, P.O.

Box 217, 7500 AE Enschede, The Netherlands

${ }^{3}$ Department of Biomedical Engineering, W.J. Kolff Institute, University Medical Center

Groningen, University of Groningen, P.O. Box 196, 9700 AD Groningen, The Netherlands

* Biomaterials 52 (2015) 113-125 


\section{Abstract}

Infectious complications occur in a minor but significant portion of the patients undergoing joint replacement surgery or fracture fixation, particularly those with severe open fractures, those undergoing revision arthroplasty or those at elevated risk because of poor health status. Once established, infections are difficult to eradicate, especially in the case of bacterial biofilm formation on implanted hardware. Local antibiotic carriers offer the prospect of controlled delivery of antibiotics directly in target tissues and implant, without inducing toxicity in non-target organs. Polymeric carriers have been developed to optimize the release and targeting of antibiotics. Passive polymeric carriers release antibiotics by diffusion and/or upon degradation, while active polymeric carriers release their antibiotics upon stimuli provided by bacterial pathogens. Additionally, some polymeric carriers gelate in-situ in response to physiological stimuli to form a depot for antibiotic release. As antibiotic resistance has become a major issue, also other anti-infectives such as silver and antimicrobial peptides have been incorporated in research. Currently, several antibiotic loaded biomaterials for local infection prophylaxis are available for use in the clinic. Here we review their advantages and limitations and provide an overview of new materials emerging that may overcome these limitations.

\section{Introduction}

Developments in the field of trauma and orthopedic biomaterials have improved the life of millions of patients undergoing surgery. However, infectious complications can delay successful healing. Infection after orthopedic or trauma surgery occurs when bacteria enter the surgical site and cause pathological conditions or diseases [1]. Surgical site infections (SSI) are infections that encompass the surgical wound and all other tissues involved in the operation [2]. Clinical studies have identified several risk factors for the development of SSI, which may be classified into patient-related factors and operation-related factors (Table 2.1) [2, 3].

One of the most significant risk factors for the development of infection is the presence of an implant. The reasons why implanted medical devices are at such high risk for developing infection has been a topic of research for decades. In 1957, Elek and Conen showed that the presence of a single silk suture could reduce the number 
of bacteria required to cause an infection in human subjects by 10,000 fold [4]. Zimmerli et al. showed similar data in a guinea pig model, whereby the minimal infectious dose of Staphylococcus aureus (S. aureus) was 100,000 fold lower when a device was implanted subcutaneously compared to the situation in which no implant was inserted [5]. This increased susceptibility to infection appears to be partly due to a localized deficiency in phagocytosis of bacteria in the vicinity of an implant, and to the growth of bacteria in a biofilm on the surface of the implanted device $[6,7]$. Published infection rates of about $5 \%$ have been reported for internal fracture fixation devices (FFDs) [8]. Increased infection rates have been reported within certain high-risk groups: for example, the infection rate in patients with open fractures may exceed $30 \%$ [9], in comparison with $0.5-2 \%$ for equivalent closed fractures [9]. Similarly, the infection rate for revision of failed prosthetic joints may be up to $40 \%$ [9], whereas the rate for primary joint replacement is approximately $1-4 \%$ [3, 10-12].

A guideline document outlining best clinical practice for the prevention of SSI has been published by the U.S. department of health and human services [13]. Several key-actions for surgical personnel are described which are based upon well-designed studies that have proven to reduce the risk of SSI significantly. Most importantly, preoperative intravenous administration of antimicrobial agents that are effective against the most common species causing SSI should be provided. The timing of the administration should be such that the minimal bactericidal concentration of the antimicrobial agent for these species should be reached and that it stays above this level at least until a few hours after the incision is closed. Finally, surgical personnel should adhere to the principles of asepsis when placing intravascular devices, spinal or epidural anesthesia catheters or when providing intravenous drugs [13]. 
Table 2.1: Risk factors for surgical site infection [2, 14]

\begin{tabular}{|c|c|}
\hline \multicolumn{2}{|c|}{ Risk factors for the development of SSI } \\
\hline \multirow[t]{12}{*}{ Patient factors } & Extremes of age \\
\hline & Poor nutritional state \\
\hline & Obesity (>20\% of ideal body weight) \\
\hline & Diabetes mellitus \\
\hline & Smoking \\
\hline & Infections at sites other than the surgical site \\
\hline & Inflammatory arthritis \\
\hline & Malignancy \\
\hline & Bacterial colonization (e.g. nares colonization) \\
\hline & $\begin{array}{l}\text { Immunosuppression (steroids, } \\
\text { immunosuppressive drug use, cytotoxic drugs } \\
\text { or previous antibiotics) }\end{array}$ \\
\hline & Preoperative hospitalization \\
\hline & $\begin{array}{l}\text { Prolonged postoperative hospital stay } \\
\text { (nosocomial infection) }\end{array}$ \\
\hline \multirow[t]{14}{*}{ Operation factors } & $\begin{array}{l}\text { Too short surgical scrub (shorter than } 2 \\
\text { minutes) }\end{array}$ \\
\hline & Poor skin antisepsis \\
\hline & Preoperative shaving \\
\hline & $\begin{array}{l}\text { Type of agent used for preoperative skin } \\
\text { preparation }\end{array}$ \\
\hline & Emergency procedure \\
\hline & Length of operation \\
\hline & Antimicrobial prophylaxis \\
\hline & Operating theather ventilation \\
\hline & Inadequate instrument sterilization \\
\hline & $\begin{array}{l}\text { Traumatic or unfamiliar surgical technique } \\
\text { (hematoma, devitalized tissue, dead space, } \\
\text { electro cautery etc.) }\end{array}$ \\
\hline & $\begin{array}{l}\text { Foreign material in surgical site (orthopedic } \\
\text { implant, fracture fixation devices) }\end{array}$ \\
\hline & Surgical drains \\
\hline & $\begin{array}{l}\text { Surgical technique (hemostasis, poor closure, } \\
\text { tissue trauma) }\end{array}$ \\
\hline & Postoperative hyperthermia \\
\hline
\end{tabular}

Most infections associated with orthopedic implants are caused by opportunistic pathogens and bacteria that are regularly found within the microflora of the human skin [15]. The initial colonization of the wound tissues may occur preoperatively, in the case of open wounds, or perioperatively, i.e. after incision but before complete healing of the surgical wound [8]. Considering the large number of bacterial species 
present on the human skin, only relatively small percentages have been implicated in SSI infections involving orthopedic hardware. The staphylococci account for the majority of cases of device related infections for most classes of implants. S. aureus and various coagulase negative staphylococci such as $S$. epidermidis account for more than $50 \%$ of infection cases related to FFDs and for up to $65 \%$ of prosthetic joint infections (PJIs) [8, 16-19].

The increasing prevalence of multiple antibiotic resistant bacteria such as methicillin resistant $S$. aureus (MRSA), both in the community and in the hospital setting, has been attributed to the misuse of antibiotic agents in the medical and agricultural sector [20, 21]. This has an additional downstream impact upon the treatment of infections associated with implanted orthopedic hardware. Even when medically required, antibiotic use can have secondary consequences. For example, colonization of the hip joint with antibiotic- resistant bacteria may reach up to $88 \%$ upon hip revision surgery in which antibiotics had been used in bone cement at a previous operation [22].

Infection of the bone and bone marrow, osteomyelitis, can be divided into different types according to the origin of the condition: 1) osteomyelitis from hematogenous spread of infection, 2) osteomyelitis secondary to a continguous focus of infection, 3) osteomyelitis associated with vascular insufficiency [23] and 4) osteomyelitis from iatrogenic inoculation during surgery or trauma.

If symptoms appear early and are correctly diagnosed, treatment of acute osteomyelitis is usually successful [24]. If the diagnosis is delayed, or infection of the bone progresses without successful treatment, a significantly more challenging complication arises. Chronic osteomyelitis may involve bacterial biofilm formation on the implant and devitalized bone fragments, which become sequestra [25]. The bacterial biofilm is a central factor in implant related osteomyelitis. A biofilm consists of adherent bacteria within a polymeric matrix made out of exopolysaccharides surrounded by interstitial voids in which nutrients circulate between cells [26]. These polysaccharides are required for intercellular adhesion so that bacteria can accumulate in an adherent muli-layered biofilm [27]. Besides these polysaccharides, the extracellular polymeric substances in which bacteria live, are composed out of proteins, nucleic acids (extracellular DNA), lipopolysaccharides, glycolipids and lipids 
$[28,29]$. Biofilms readily form on surfaces such as prostheses and implants [30] as well as on the surface of dead bone and living tissue [31, 32]. The presence of bacteria in a biofilm drastically reduces their susceptibility to antimicrobial drugs and host defense cells. Reduced susceptibility seems not to be caused by limited antibiotic penetration, but the reduced growth rate of bacteria in a biofilm makes them less susceptible to growth-dependent antimicrobial killing [17, 26, 33]. Subpopulations may also differentiate into a phenotypically resistant state and bacteria might express biofilm-specific antimicrobial resistance genes [34, 35].

The treatment of chronic osteomyelitis is difficult, time-consuming and expensive. A standard treatment protocol for chronic osteomyelitis and infected non-unions may involve: identification of the bacterial species and antibiotic susceptibility testing, removal of orthopedic or fracture fixation devices, debridement of infected bone and soft tissue and systemic delivery of antibiotics for a 4 to 6 week period. Antibioticloaded spacers may be placed in the area where infected bone is removed. Irrigation with abundant antiseptic after debridement of infected bone may be an adjunct to this standard procedure [36]. Furthermore, a viable and stable soft-tissue environment has to be created and reconstruction, alignment and stabilization of the skeleton has to be performed [25].

The average costs for removing infected internal fixation devices and subsequent treatment of these infections were estimated to be $\$ 15,000$ on average per case around the year 2000 in the United States [37]. A similar figure was obtained from a large survey from hospitals located in New York City in 1995, where 13,550 cases of $S$. aureus infection were reported with a total cost of $\$ 435.5$ million for treatment; on average $\$ 32,100$ per case [38]. Treatment of SSI caused by $S$. aureus cost on average $\$ 21,800$ and treatment of osteomyelitis $\$ 35,000$ [38]. The morbidity and socioeconomic costs of implant related osteomyelitis emphasize the need for effective prophylactic measures to prevent infection in orthopedic- and trauma surgery.

Systemic antibiotic prophylaxis is mandated for certain surgical procedures, though not for all [39]. The requirement for antibiotic prophylaxis is largely based on the risk assessment of the surgeon, regular practice in the hospital in question, and 
numerous guidelines published on the topic. Antimicrobial prophylaxis is indicated for operations considered to have contamination, as these are associated with a high rate of infection [40]. When an implant is inserted during surgery, it is standard practice that perioperative antibiotic prophylaxis is provided, since the presence of a foreign material at the surgical site is an important risk factor for the development of SSI [41].

For arthroplasty, usually a single dose or $24 \mathrm{~h}$ administration of a first or second generation cephalosporin is provided [14, 42]. A similar regime is indicated for the fixation of closed fractures [14]. For the fixation of open fractures in trauma surgery, the number of antibiotic doses and the duration of administration are related to the severity of the open fracture and the status of the wound, with greater antibiotic protection required for cases with greater soft tissue damage and greater exposure of bone and higher degree of contamination [43] (Table 2.2). When there is potential fecal contamination of the wound, either piperacillin/tazobactam, or a carbapenem or a third generation cephalosporin plus metronidazole should be provided [14].

For elective surgery like an arthroplasty, the optimal effect is obtained when sufficient antibiotic tissue levels are achieved at the time of incision. The incidence of SSI during these surgeries increases to $3.8 \%$ when prophylaxis is given too early $(>2 \mathrm{~h}$ before surgery) or to $3.3 \%$ when prophylaxis is given too late ( $>3 \mathrm{~h}$ after surgery) in comparison with $0.6 \%$ when prophylaxis is given just before surgical incision is made [44]. In the case of severe trauma with open fractures after an accident, one would like to give antibiotic prophylaxis as soon as possible, since the possibility of bacterial colonization of the wound increases over time. In surgical practice, however, the antibiotics are administered upon arrival in hospital.

One of the problems related to systemic delivery of antibiotics is that insufficient concentrations are reached at vascular compromised locations, such as a fracture site or other compromised tissues. In fractures, the bony structure may be affected and the local vascularity may be disturbed [45] making it impossible to achieve appropriate local antibiotic concentrations via systemic delivery via the bloodstream. Increasing the dose of systemically delivered antibiotics is not a suitable approach since high concentrations of antibiotics over an extended period might cause 
systemic toxicity problems; e.g. like ototoxicity for aminoglycosides [46] and nephrotoxicity for aminoglycosides [46-48], glycopeptides [48, 49], polymyxins [4850], quinolones, rifampicin and sulfonamides [48].

Table 1.2: Guidelines for antibiotic prophylaxis according to AO principles [14]

\begin{tabular}{|c|c|c|c|c|}
\hline $\begin{array}{l}\text { Open fracture } \\
\text { classification }\end{array}$ & $\begin{array}{c}\text { Fracture } \\
\text { description }\end{array}$ & $\begin{array}{c}\text { Likely } \\
\text { bacterial } \\
\text { pathogen }\end{array}$ & $\begin{array}{l}\text { Antibiotic } \\
\text { course (IV) }\end{array}$ & $\begin{array}{c}\text { Duration } \\
\text { following } \\
\text { wound } \\
\text { closure }\end{array}$ \\
\hline I. & $\begin{array}{c}\text { Skin wound more } \\
\text { than } 1 \mathrm{~cm} \text {, Clean, } \\
\text { Simple fracture } \\
\text { pattern }\end{array}$ & $\begin{array}{c}\text { Gram positive } \\
\text { cocci }\end{array}$ & $\begin{array}{c}1^{\text {st }} \text { or } 2^{\text {nd }} \\
\text { generation } \\
\text { cephalosporin }\end{array}$ & $24 \mathrm{~h}$ \\
\hline II. & $\begin{array}{c}\text { Skin wound less } \\
\text { than } 1 \mathrm{~cm} \text {, Soft } \\
\text { tissue damage not } \\
\text { extensive, } \\
\text { No flaps or } \\
\text { avulsions, } \\
\text { Simple fracture } \\
\text { pattern }\end{array}$ & $\begin{array}{l}\text { Gram } \\
\text { positive } \\
\text { cocci }\end{array}$ & $\begin{array}{c}1^{\text {st }} \text { or } 2^{\text {nd }} \\
\text { generation } \\
\text { cephalosporin }\end{array}$ & $24 \mathrm{~h}$ \\
\hline $\begin{array}{l}\text { III. } \quad \text { A } \\
B \\
\text { C }\end{array}$ & $\begin{array}{c}\text { High-energy injury } \\
\text { involving extensive } \\
\text { soft tissue damage, } \\
\text { Or multifragmentary } \\
\text { fracture, segmental } \\
\text { fractures, or bone } \\
\text { loss irrespective of } \\
\text { the size of skin } \\
\text { wound, } \\
\text { Or severe crush } \\
\text { injuries, } \\
\text { Or vascular injury } \\
\text { requiring repair, } \\
\text { Or severe } \\
\text { contamination } \\
\text { including farmyard } \\
\text { injuries }\end{array}$ & $\begin{array}{c}\text { Gram positive } \\
\text { cocci + Gram } \\
\text { negative rod }\end{array}$ & $\begin{array}{c}\text { Amoxicillin / } \\
\text { clavulanic acid } \\
\text { or ampicillin/ } \\
\text { sulbactam or } 3^{\text {rd }} \\
\text { generation } \\
\text { cephalosporin }\end{array}$ & $120 \mathrm{~h}$ \\
\hline
\end{tabular}




\section{Local antibiotic infection prophylaxis}

Local delivery of antibiotics maximises target tissue concentration, and minimizes systemic toxicity risks. Any drug delivery device intended for prophylactic use should have a broad-spectrum antibiotic incorporated in order to prevent both a wide of Gram-positive (e.g. Staphylococcus aureus and S. epidermidis) and Gram-negative (e.g. Pseudomona aeruginosa and Escherichia coli) bacteria from colonizing the surgical site.

Aminoglycosides are broad-spectrum antibiotics covering the species most frequently encountered in trauma surgery such as $S$. aureus and $S$. epidermidis [51]. Aminoglycosides have two mechanisms of action. First of all, aminoglycosides inhibit protein synthesis in bacteria. Sensitive bacteria accumulate aminoglycosides on the 30 s subunit of ribosomes associated with the cell membrane. Secondly, aminoglycosides destroy the cytoplasmic membrane [52]. The ability of aminoglycosides to destabilize the outer membrane by creating holes in the cell wall is probably the most important ability of this class of antibiotics, since bacteria are killed even before protein synthesis is disrupted [52]. The aminoglycosides gentamicin and tobramycin, and the glycopeptide vancomycin are the most commonly used antibiotics in local delivery vehicles $[53,54]$.

Gentamicin has a broad-spectrum of activity, rapid concentration-dependent bactericidal effect, a low rate of resistance and low cost [52]. Gentamicin is available for intramuscular and intravenous injection, in antibiotic impregnated poly(methylmethacrylate) PMMA beads, in sponge-like collagen implants and as antibiotic component in a coating on intramedullary nails for tibial fracture fixation [53, 54]. Tobramycin and the glycopeptide vancomycin are also used in PMMA bone cement. The aminoglycosides activity is reduced at low $\mathrm{pH}$, at low oxygen-containing environment, in the presence of calcium and magnesium ions, and in the case of hyperosmolarity [52, 55-57]. The suggested mechanism is that an acidic $\mathrm{pH}$ impairs gentamicin transport into bacteria, this is because of its larger ionization at lower $\mathrm{pH}$, since the pKa values of the amino groups of gentamicin are between 5.5 and 9 [56]. 
Vancomycin is active against Gram-positive bacteria such as Staphylococci (including MRSA), Streptococci and Enterococci [2]. Vancomycin interferes with cell wall synthesis in Gram-positive bacteria [58]. It targets the terminal D-Ala-D-Ala of the staphylococcal peptidoglycan stempeptide and inhibits the elongation of the sugar backbone and the crosslinking of the peptidoglycan [59]. The systemic route of administration of vancomycin is oral or intravenous [60]. Vancomycin is often used in the case of $\beta$-lactam resistance $[59,61]$. Another reason for using vancomycin is when the patient is allergic to $\beta$-lactams [17]. Staphylococci, both coagulase negative and coagulase positive are susceptible to vancomycin at levels as low as $\leq 1-5 \mu \mathrm{g} / \mathrm{ml}$, but susceptibility is drastically lowered in vancomycin-resistant Staphylococcus aureus (VRSA) [62].

One potential side effect of high local concentrations of antibiotics is the risk of cytotoxicity. Rathbone et al. showed the effect of the concentration of various antibiotic agents on osteoblast cell viability and activity [63]. Gentamicin concentrations of $10 \mu \mathrm{g} / \mathrm{ml}$ resulted in a decrease of less than $25 \%$ in alkaline phosphatase (ALP) activity and DNA content. At concentrations between $10 \mu \mathrm{g} / \mathrm{ml}$ and $200 \mu \mathrm{g} / \mathrm{ml}$, a decrease in ALP activity and DNA content of $25 \%-50 \%$ was reported, while for concentrations higher than $2000 \mu \mathrm{g} / \mathrm{ml}$ more than $75 \%$ decrease in ALP activity and DNA content was observed [63]. Isefuku et al. used human osteoblast like cells $(\mathrm{HOB})$ to investigate the effect of gentamicin on osteogenesis [64]. ALP activity and DNA content were measured, as well as ${ }^{3} \mathrm{H}$-thymidine incorporation (measure of cell proliferation) after 4 days of culture. Gentamicin concentrations of $30 \mu \mathrm{g} / \mathrm{ml}$ resulted in no decrease in the aforementioned parameters. Gentamicin concentrations of $100 \mu \mathrm{g} / \mathrm{ml}$ and higher showed a decrease in ALP activity, concentrations of $300 \mathrm{\mu g} / \mathrm{ml}$ resulted in less than $50 \%$ decrease of ${ }^{3} \mathrm{H}$ thymidine incorporation and concentrations of $700 \mu \mathrm{g} / \mathrm{ml}$ showed a decrease in DNA content for all HOB cultures. Haleem et al. showed in an in vivo study that systemic administration of gentamicin $(1.5 \mathrm{mg} / \mathrm{kg}$ intramuscularly) or vancomycin $(25 \mathrm{mg} / \mathrm{kg}$ intraperitoneally), both to simulate therapeutic peak serum concentrations, resulted in 30 minutes serum concentration of $4.5 \mu \mathrm{g} / \mathrm{ml}$ for gentamicin and $35.1 \mu \mathrm{g} / \mathrm{ml}$ for vancomycin and did not impair experimental fracture healing in rats [65]. 
Tobramycin can potentially be applied locally at higher concentrations (>500 $\mu \mathrm{g} / \mathrm{ml}$ in vitro) than gentamicin without compromising osteoblast viability $[50,63]$. Vancomycin can be released even at concentrations up to $2000 \mu \mathrm{g} / \mathrm{ml}$ with a decrease of less than $25 \%$ in ALP activity and DNA content. However, such high concentrations may not be required, since glycopeptides display time-dependent activity, rather than concentration dependent activity.

Thus, in the local delivery of antibiotics such as gentamicin it is therefore not only necessary to reach concentration levels above the minimal bactericidal concentration (MBC) in order to prevent bacterial resistance, but it is also important to keep peak concentration at a level which does not affect bone healing $[63,66]$. For instance, local gentamicin levels for prophylaxis against Staphylococcal species (spp.) should be between $128 \mu \mathrm{g} / \mathrm{ml}$ and $200 \mu \mathrm{g} / \mathrm{ml}$ to meet the MIC $_{90 \%}$ value and have a reduction of less than $50 \%$ in ALP activity and DNA content for osteoblasts as determined in vitro $[66,67]$.

Since antibiotics will act for a short term period when injected locally before being cleared, the design of controlled and sustained delivery system is of equal importance as the choice of antibiotic to be used. In 1970, PMMA bone cement was the first polymeric biomaterial which came to the clinic to serve this purpose [68]. Bone cements are prepared by mixing of a liquid phase and a powder phase containing an initiator, which starts the polymerization process. The liquid phase mainly consists of methylmethacrylate (MMA) monomer. The powder phase consists of either a methylmethacrylate (PMMA) or a methylacrylate (PMA) polymer or a copolymer of one of the two previous compounds with butylmethacrylate (BUMA), ethylmethacrylate (EMA), methylacrylate (MA) or styrene. Furthermore, the powder phase contains an initiator, benzoyl peroxide, which cures the cement upon contact with the activator N,N-dimethyl-p-toluidine (DMpT) from the liquid phase. Radiopacifiers such as $\mathrm{BaSO}_{4}$ and $\mathrm{ZrO}_{2}$ may also be added to the powder to increase cement visibility in radiographs. A dye may also be added to the powder or to the liquid or to both. Chlorophyllin is most commonly used; however in Cobalt ${ }^{\mathrm{TM}} \mathrm{G}$ $\mathrm{HV}$ indigo carmine is added. Hydroquinone ( $\mathrm{HQ})$ is added to the liquid monomer as a stabilizer in order to prevent premature polymerization during storage [69]. Obviously, the composition of the polymer powder and the monomer liquid will influence the 
properties of the resulting bone cement after curing, such as hydrophilicity (water uptake), mechanical strength and porosity (created by air inclusions in the cement dough) $[69,70]$. The hydrophilicity of the final polymer components will influence the diffusion of antibiotics from the bone cement into the surrounding tissue and therefore the release rate of the included antibiotic. There are 3 different mechanisms suggested for the release of antibiotics from bone cement in vitro [71]. The antibiotics are either released from the bone cement by a surface phenomenon, (1) by bulkdiffusion through pores and connecting capillaries in the bone cement (2) or by a combination of the two mechanisms, the mixed-mode model, where initially antibiotics are released from the surface followed by bulk-diffusion (3) [71]. However, in all PMMA bone cement compositions, the antibiotics are not completely released [69]. A large amount stays encapsulated within the bone cement and is therefore not released during the lifetime of the implant, which would support the theory that antibiotics are mainly released from the bone cement by a surface phenomenon. In fact, Frutos Cabanillas et al. performed a release study with CMW1 Gentamicin bone cement which supports this phenomenon [72]. The in vitro release was tracked for 8 weeks and it was found that most of the gentamicin was released during the first 2 hours, but then the antibiotic concentration dropped very quickly afterwards to almost no release.

Kühn compared the release of 12 different bone cements in vitro over 7 days [69]. Between the different commercial bone cements there was a large difference in release with a several fold higher release of gentamicin [mg/g bone cement] of the bone cements prepared from MMA/MA copolymer compared to PMMA homopolymer, most likely because of the higher hydrophilicity of the copolymer composition. The gentamicin content in different commercial bone cement powders and the amount of gentamicin released after 7 days from several commercial available bone cements can be seen in Figure 2.1 [69]. 


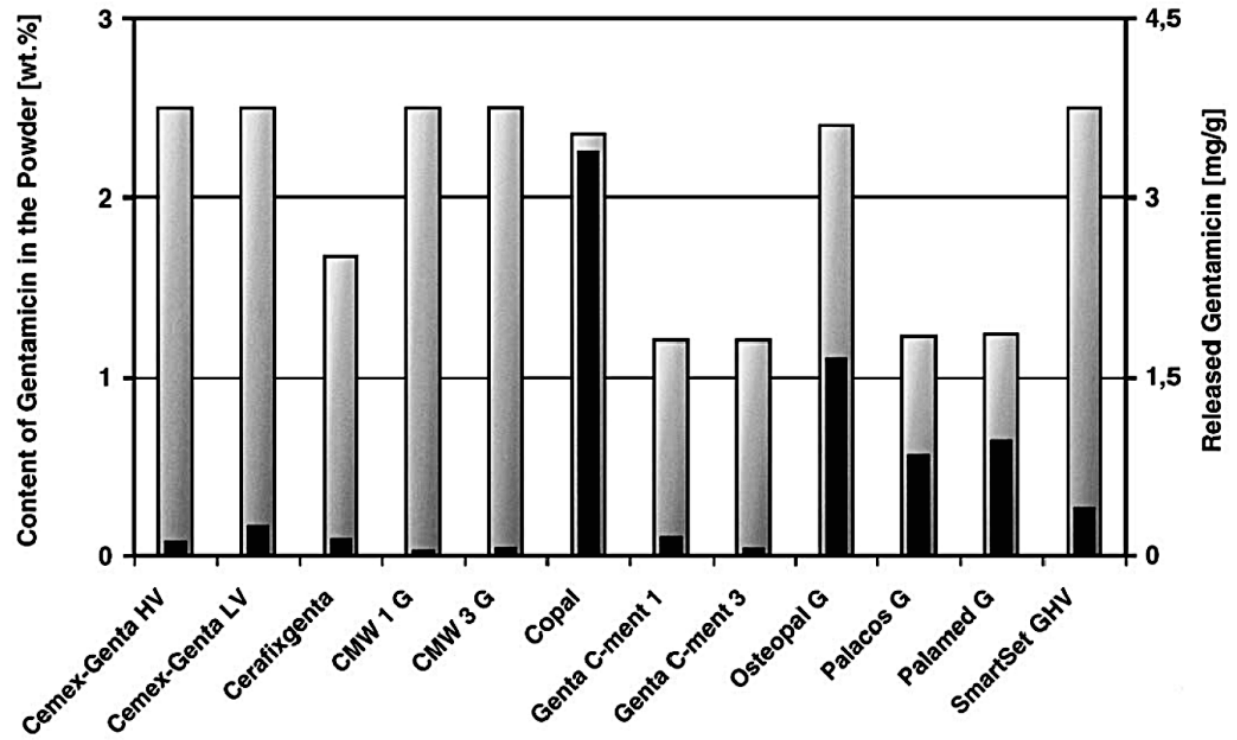

Figure 2.1: Gentamicin content in different commercial bone cement powders (grey bars, yaxis on the left) and the amount of gentamicin released after 7 days in vitro as expressed in $\mathrm{mg} / \mathrm{g}$ bone cement (black bars, $y$-axis on the right) [69].

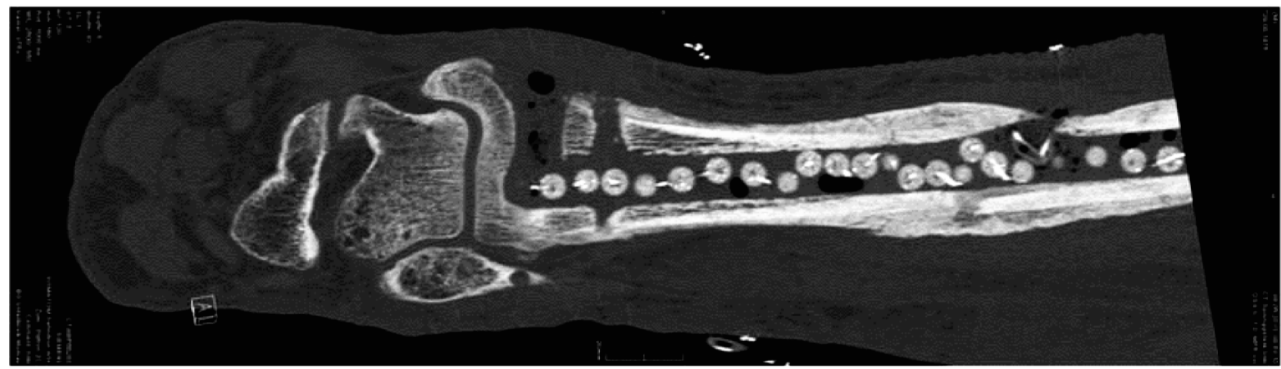

Figure 2.2: Gentamicin loaded PMMA beads, placed after infection of a plated tibial fracture (Image courtesy of Dr. Mario Morgenstern from the BGU Murnau, Germany).

PMMA is used as a carrier material for antibiotics as bead chains (Figure 2.2), blocks (Figure 2.3) and putty. A commercial gentamicin loaded PMMA bead chain is produced by Merck since 1972 under the trading name Septopal囚. These bead 
chains are primarily used in the treatment of infections but they are also used in prophylaxis [55], although this is not standard practice. They are used for treating prosthetic joint infections, septic arthritis and osteomyelitis. In prophylaxis they may be used when there is an elevated risk of SSI [55].

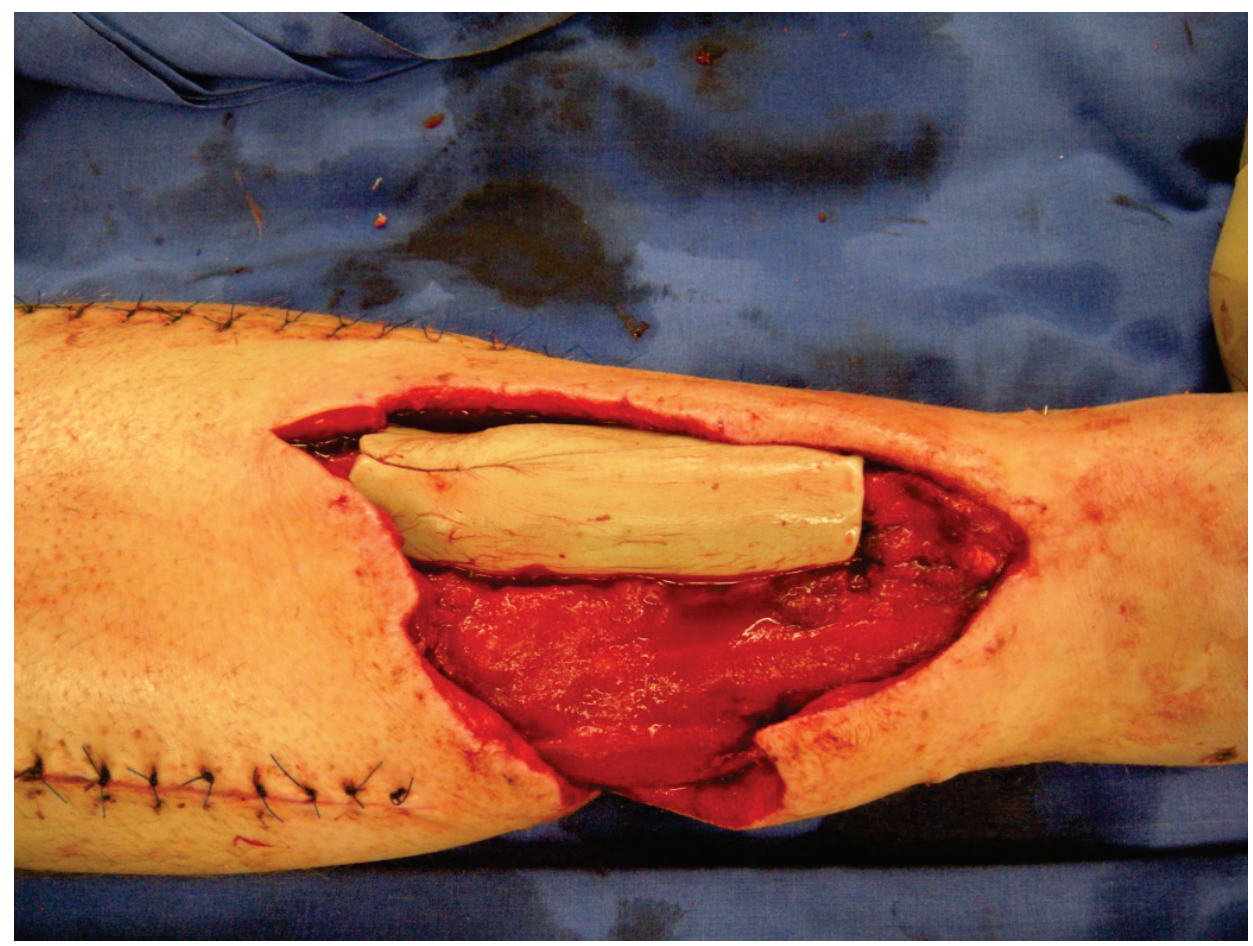

Figure 2.3: Antibiotic loaded PMMA spacer (Image courtesy of Dr. Mario Morgenstern of BGU Murnau, Germany).

The combined action of a systemically administered antibiotic and local delivery using PMMA has been shown to be beneficial in reducing the infection rate upon hip replacement. In a large cohort study of the Norwegian Arthroplasty Register of 22,170 hip replacements, it was shown that local delivery of antibiotics from PMMA bone cement combined with systemic antibiotics had the lowest risk of revision [73]. Patients who received the antibiotics only systemically had a 1.8 times higher revision rate with infection as the endpoint $(p=0.01)$. The systemic antibiotics used were cephalosporins (cephalotin or cefuroxime) or penicillin (cloxacillin or 
dicloxacillin). The antibiotics used in the PMMA were gentamicin in Palacos cement or colistin/erythromycin in Simplex ${ }^{\mathrm{TM}}$ cement [73].

Polymeric bone cement has also several drawbacks as a local delivery vehicle for antibiotics. The drawbacks are primarily the rapidly reducing local antibiotic levels, and the permanent presence of a foreign body, which may be colonized by bacteria. Low, sub-inhibitory antibiotic levels over an extended period can induce bacterial resistance. For example, studies show increased gentamicin resistance after use of impregnated bone cement in patients receiving a hip implant [67]. In a study published by Weber and Lautenbach, the percentage of bacteria resistant to gentamicin increased from $29 \%$ for bacteria which were isolated preoperatively to $41 \%$ for bacteria isolated after surgery in which gentamicin-impregnated cement was used [74]. Furthermore, in a study of 34 cases of revision surgery of hip implants, at least one strain of gentamicin-resistant coagulase negative staphylococci (CNS) was found on $88 \%$ (30) of the implants in which gentamicin-impregnated cement was used. In 57 cases of revision surgery of hip implants where no gentamicin was included in the cement only $16 \%$ (9) grew gentamicin-resistant CNSs [75].

PMMA beads are non-degradable and need to be removed during follow-up surgery, which is an additional risk for acquiring a new intraoperative infection [53]. Unreacted methacrylate monomer can cause toxicity issues, with toxicity directly related to the lipophilicity of the respective methacrylate [76]. Furthermore, the heat generated during polymerization limits the choice of antibiotics: most antibiotics as opposed to gentamicin are heat labile [66]. In vitro maximum temperatures reached according to the standards ISO 5833 and ASTM F 451 for curing of bone cement are between $60^{\circ} \mathrm{C}$ and $80^{\circ} \mathrm{C}$. Clinical trials, however, showed lower temperatures between $40^{\circ} \mathrm{C}$ and $47^{\circ} \mathrm{C}$ at the bone-cement interface in vivo [69]. Although heat necrosis due to high local temperatures, which is suspected to lead to aseptic loosening, might not occur at the interface in vivo, the temperature within the curing bone cement might still be much higher than at the interface and affect heat labile antibiotics [69].

Collagen, in contrast to PMMA, is biodegradable. In the body, collagen is degraded by phagocytosis and enzymatic degradation [10]. Collagen fleece loaded with antibiotics is used in contaminated wounds to prevent infection. Several antibiotic- 
loaded collagen fleeces are commercially available (Figure 2.4) [77], differing in collagen source, amount of antibiotic loaded and type of antibiotic loaded. Controlled randomized clinical studies in which antibiotic-loaded collagen fleece (1 to 3 sponges per case with 200 - $600 \mathrm{mg}$ of gentamicin sulfate) was used for intra-abdominalrelated surgeries or wound infections, had a positive outcome in $95.6 \%$ compared to $72.5 \%$ for standard therapy, in which patients healed by primary intention or without evidence of post-operative infection [78].

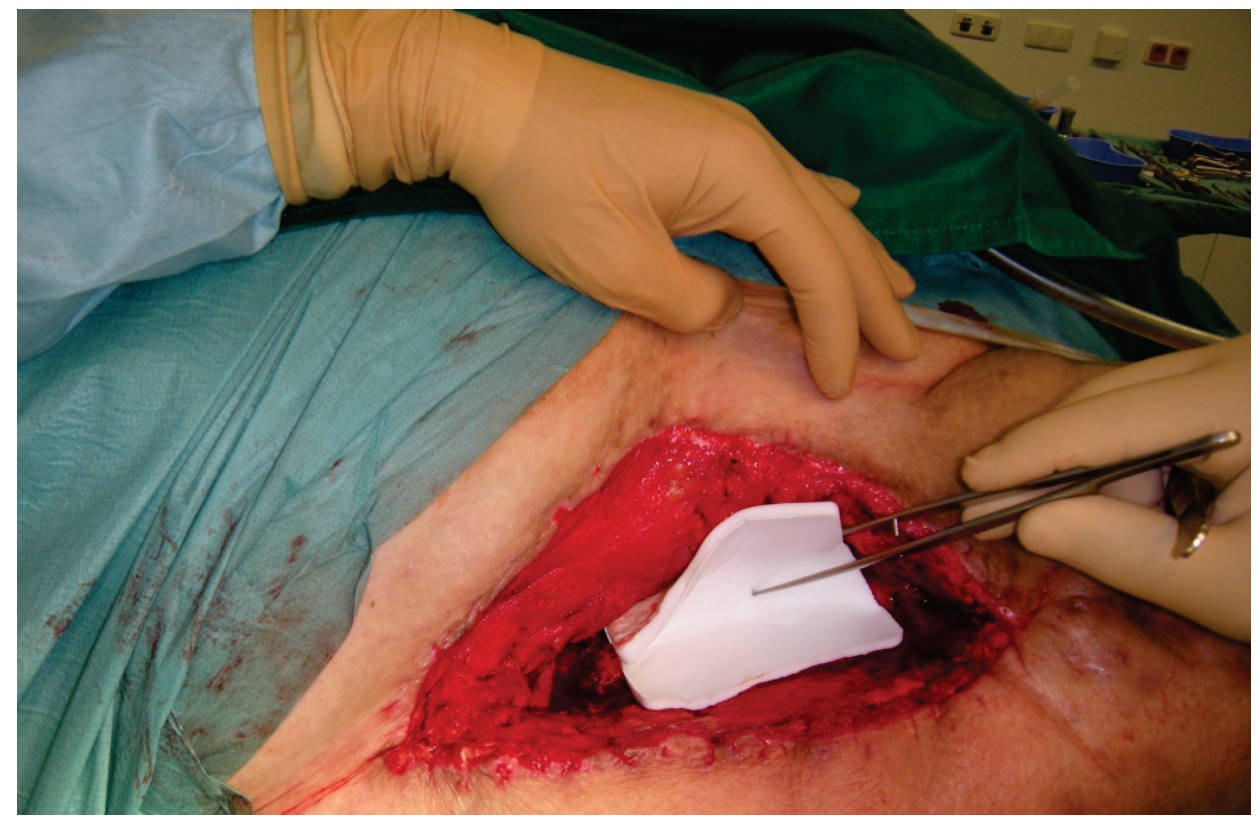

Figure 2.4: Antibiotic loaded collagen fleece applied at the surgical site before insertion of the implant (Image courtesy of Dr. Mario Morgenstern of BGU Murnau, Germany).

When using collagen fleece, the antibiotic is released very rapidly [79]. An in vitro study with pepsin-treated bovine collagen, $0.5 \mathrm{~g}$ of collagen containing $130 \mathrm{mg}$ gentamicin, showed a release of $95 \%$ of the antibiotic in 1.5 hours [79]. However, the full resorption of the collagen carrier takes 8 weeks [80]. Antibiotic delivery rates are highly dependent on the fluid supply in vivo. Effective local concentrations might be reached during less than 24 hours in well perfused sites and up to 1 week in bony structures [81]. In vivo, the mismatch between the rate of antibiotic release and the rate of degradation of the collagen might allow bacteria to attach to the collagen via 
microbial surface components recognizing adhesive matrix molecules (MSCRAMMs) [82], serving as substrate for bacterial adhesion.

High water solubility of particular antibiotics might limit the application and the prolonged release from biomaterials. Therefore, research has also focused on formulations with reduced solubility. One approach is to create lipophilic salts of the antibiotic, e.g. for gentamicin: gentamicin sodium dodecyl sulfate (SDS), gentamicin sodium bis(2-ethylhexyl)sulfosuccinate (AOT), gentamicin crobefate,gentamicin laurate, gentamicin myristate and gentamicin palmitate [83-87].

For the use of collagen fleece longer prophylactic antibiotic levels are maintained, when gentamicin crobefate is incorporated in addition to gentamicin sulphate [88]. A prolonged release period (about 12 days in vivo) is thereby established, since gentamicin crobefate is hydrophobic as opposed to the sulphate salt of gentamicin which is hydrophilic and thus readily diffuses. However, the degradation rate of the fleeces themselves are not modified [80]. Overall, the main drawback of antibiotic loaded collagen fleece is the non-matching degradation rates and release times. Another drawback is the complicated handling of the collagen fleeces, and the covering of all infected areas by the fleece. Furthermore, although rare, biological responses such as localized hypersensitivity to- and circulation of antibodies against bovine collagen can be elicited [89].

The use of biodegradable synthetic implants avoids these biological responses. For instance synthetic coatings containing antibiotics have been applied on metal implants to prevent infection. Coatings can be applied on a wide variety of materials, turning an implant into a drug delivery device. So far, only poly(D,L-lactide) (PDLLA) coatings have made it to the clinic (Figure 2.5). Clinical trials with metal implants coated with PDLLA with gentamicin incorporated were started in July 2003 [54]. Intramedullary nails with a PDLLA coating containing gentamicin were implanted in the tibia of patients with complex fractures. Indications for use of a gentamicincontaining PDLLA coated intramedullary nail were the presence of a type III open fracture or the performance of a re-osteosynthesis, because the incidence of infection is very high for these cases. In a case study of a 17 year old man with a type III open tibia fracture, this PDLLA gentamicin-coated nail was inserted. All the 
wounds healed without complications and after 25 days the patient was fully mobilized. In 2011, this PDLLA gentamicin-coated intramedullary nail was released on the market. In vitro release studies in deionized water showed that these PDLLA gentamicin-coated implants released $40 \%$ of the gentamicin-sulphate payload within $1 \mathrm{~h}, 70 \%$ within 24 hours and $80 \%$ within 48 hours [90].

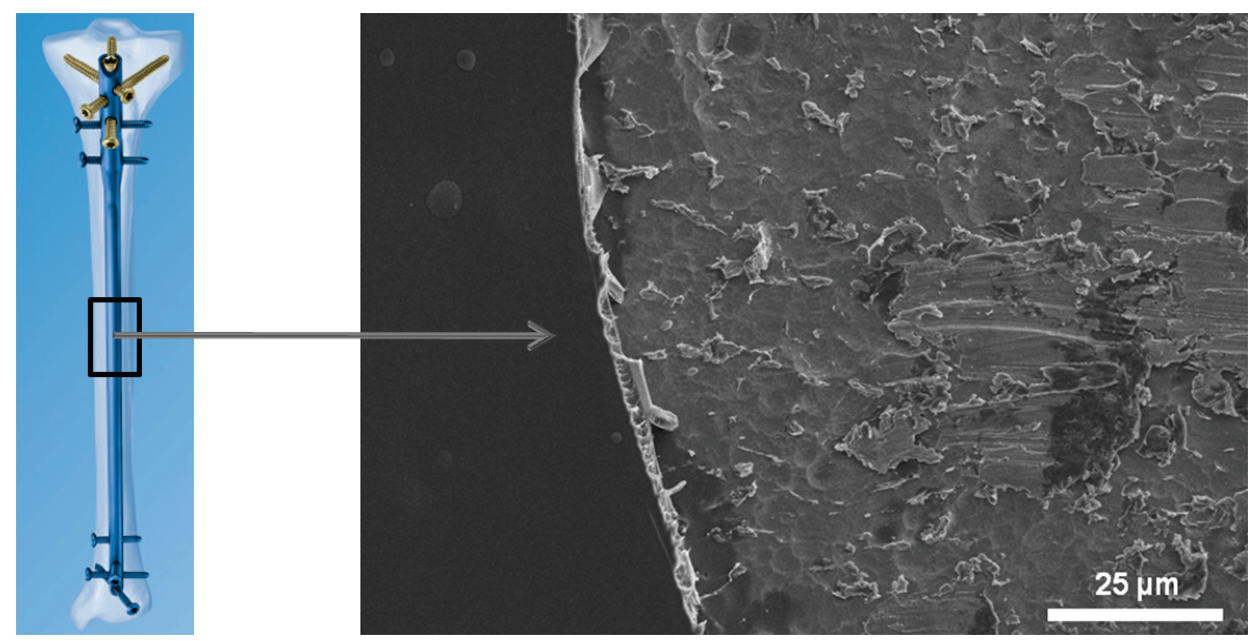

Figure 2.5: Tibial nail with gentamicin sulphate containing PDLLA coating visualized by SEM (Coating on the left of the image (image available from www.synthes.com) and scratched implant surface revealing coating on metal implant on the right).

There are several drawbacks related to the use of coated implants. One of the drawbacks is that part of the coating can delaminate during insertion due to applied forces on the implant. Since coating the implant creates a new medical device, the device needs a separate approval before it can be used in the clinic. Furthermore, antibiotic activity and bone healing can be impaired upon release of acidic degradation products of PDLLA which lower the local $\mathrm{pH}$ [91]. Low $\mathrm{pH}$ values at an implant site might evoke inflammatory foreign body responses with accompanying osteolytic foci in the exposed bone [92]. In vitro degradation studies with poly(lactide) based polymers showed $\mathrm{pH}$ values between $\mathrm{pH} 3.0$ and $\mathrm{pH} 7.0$ depending on the composition of the polymer, experimental conditions and degradation time [93-95]. The minimum $\mathrm{pH}$ is reached at the time that the polymer degrades with the greatest 
rate of weight loss. In vivo, this $\mathrm{pH}$ drop might be less dramatic than that in vitro, since body fluids surround the implant have a buffering effect. This has been shown in vivo in Wistar rats upon implantation of a PDLLA implant. Whereas in vitro the $\mathrm{pH}$ dropped by $4 \mathrm{pH}$ units after 4 weeks in Ringer solution, in vivo the maximum pH drop was $1 \mathrm{pH}$ unit 1 week after implantation [93]. However, buffering the release of these acidic degradation products might not be possible for large size implants or implants located at anatomical regions with restricted access to body fluids [96]. Thus, the development of a better prophylaxis material for implant surfaces and the optimal local delivery of the antibiotics from these surfaces remain major challenges.

\section{New developments in the local delivery of antibiotics}

Different strategies have been pursued by researchers in order to improve systems for the local delivery of antibiotics. For instance, researchers have tried to improve systems already available in the clinics. Besides changing the polymeric carriers, efforts also have been made to incorporate modified antibiotics, to produce polymeric prodrugs based on conventional antibiotics or to entrap silver (nano)particles or to incorporate antimicrobial peptides or antimicrobial peptide elicitors instead of antibiotics. Another new development is the creation of systems that can be applied minimally invasively and have a sustained antimicrobial release profile. And finally, release systems are being investigated which release their antibiotic or antimicrobial compound in response to a biological stimulus related to an infectious state.

\section{Biomaterials loaded with 'new' antimicrobial agents}

Many new antimicrobial compounds have been incorporated into biomaterials. For instance, polymeric prodrugs have been developed based upon conventional antibiotics. An example is given by the work of Marcus et al. who created a prodrug of gentamicin by grafting poly(ethylene glycol) (PEG) to gentamicin with heterobifunctional linkers, which are cleaved by spontaneous hydrolysis [97]. Upon PEGylation, the half-life of the antibiotic increases in vivo. By using reversible PEGylation of gentamicin, $\mathrm{PEG}_{20}$-FMS-gentamicin and $\mathrm{PEG}_{40}-\mathrm{Fmoc}$-gentamicin, the 
inactivated gentamicin becomes active again after the linker has been hydrolytically cleaved, whereas irreversibly bound PEG renders the antibiotic inactive [97].

By covalently grafting the antibiotic to a carrier, additionally to increasing the half-life and retarding the time of release of the antibiotic, special ligands can be incorporated to target the complex towards specific functionalities on cells in order to target intracellular infections (Figure 2.6). As an example, Coessens et al. synthesized a conjugate of streptomycin linked to poly[N-(hydroxyethyl)-L-glutamine] (PHEG) and dextran with glycerine hydrazide as linker and a mannose-terminated side group for intracellular targeting [98]. Streptomycin was coupled via Schiff base formation. The release of streptomycin from the carrier is a hydrolytic process and dependents on the $\mathrm{pH}$ (acidic environments catalyze the hydrolysis of the linker). The authors hypothesized that the lower $\mathrm{pH}(\mathrm{pH} \sim 5.2)$ in endosomes and lysosomes could facilitate the intracellular release of the streptomycin from the prodrug by destruction of the Schiff base. The release of streptomycin from the polyglutamine prodrug was tracked at $\mathrm{pH} 7.4$ and $\mathrm{pH} 5.2$. At pH 5.2 approximately $50 \%$ of the streptomycin was hydrolyzed from the prodrug, whereas at $\mathrm{pH} 7.4$ about $30 \%$ of the streptomycin was released from the prodrug [98].

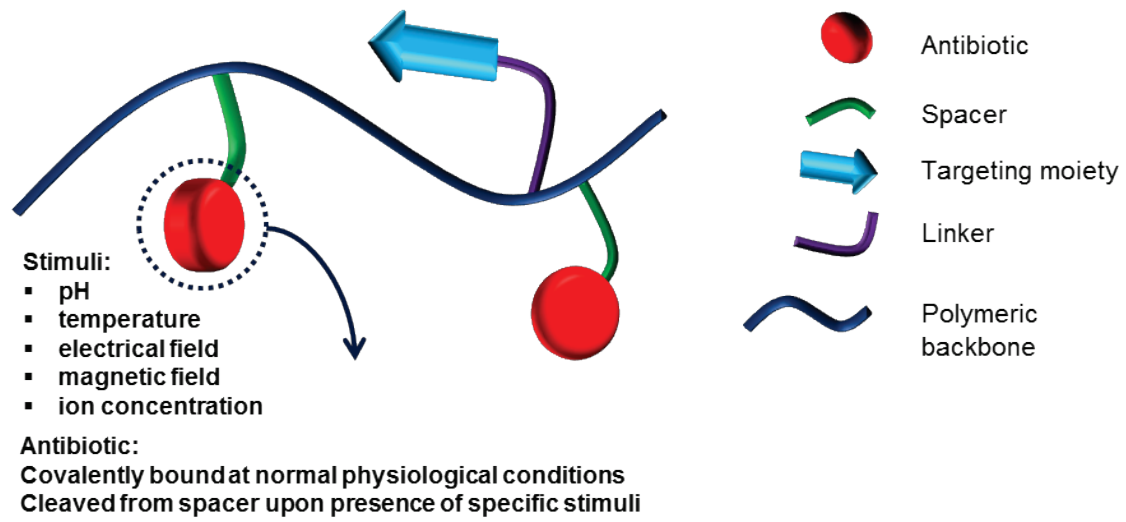

Figure 2.6: Schematic of stimuli-responsive prodrug systems for the targeted delivery of antibiotics. 
Polymeric prodrugs also have been investigated by Choi et al. with the aim of targeting dendrimer-antibiotic conjugates to bacterial cell walls [99]. Poly(amidoamine) (PAMAM) dendrimers of the fifth generation were tethered with vancomycin at the C-terminus. These vancomycin-conjugated PAMAM dendrimers were able to bind to the surface of even vancomycin resistant bacteria in a synthetic model of the bacterial cell wall. Compared to free vancomycin, the PAMAM dendrimer-vancomycin conjugate bound to these synthetic models of the bacterial cell wall tightly through binding to multiple receptor sites, indicating enhancement in avidity of four to five orders of magnitude. In an affinity study by means of surface plasmon resonance spectroscopy, these PAMAM dendrimer-vancomycin conjugates bound tightly to a vancomycin-resistant surface, which shows only weak (millimolar) affinity to free vancomycin [99].

As multi-resistance has become a problem for the use of conventional antibiotics, the use of silver has received new attention in combination with biomaterials. A comprehensive review on the antimicrobial action of silver ions, silver containing compounds and silver nanoparticles in particular has been published by Rai et al. [100]. A book chapter about silver containing biomaterials has been published by Griesser et al. [101]. The bactericidal effect of silver is due to their interaction with biomolecules. Proteins, enzymes and cell-membrane components in bacteria contain nucleophilic functionalities, which are capable of coordinating silver cations $\left(\mathrm{Ag}^{+}\right)$ [102]. Bacterial cell death is induced by silver cations by reacting and disrupting the function of cell membranes, metabolic proteins and enzymes and also by displacing metal ions, like $\mathrm{Zn}^{+}$and $\mathrm{Ca}^{2+}$, which are essential to bacterial cell survival [102]. The antibacterial effect of PMMA bone cement loaded with silver nanoparticles $(0.1 \%$, $0.5 \%$ and $1.0 \%$ ) on S. epidermidis, multi-resistant S. epidermidis (MRSE) and MRSA was compared with PMMA bone cement loaded with gentamicin sulphate (2\%) by Alt et al. [103]. PMMA bone cement loaded with gentamicin or silver nanoparticles both inhibited the proliferation of $S$. epidermidis. Silver nanoparticle-loaded PMMA bone cement was able to clear MRSE and MRSA as well, whereas PMMA bone cement with gentamicin was unable to inhibit the proliferation of the resistant strains.

The advantage of using silver nanoparticles over using larger sized particles is the maximization of the active surface of the silver, while keeping the total amount of 
silver low [104]. Furthermore, the bactericidal effect seems to be dependent on the shape of the silver nanoparticles as well. Truncated triangular shaped silver nanoparticles were more effective in inhibiting bacterial growth of $E$. coli than spherical silver nanoparticles, which were more effective than rod shaped silver nanoparticles in a study performed by $\mathrm{Pal}$ et al. [105]. Although silver-related cytotoxicity towards eukaryotic cells can be limited by using silver with nanodimensions, the preparation of silver nanoparticles is hindered by their tendency to aggregate [106]. To stabilize silver nanoparticles, Travan et al. encapsulated the particles in hydrogels composed of Chitlac (lactose substituted chitosan) and alginate [106]. Microspheres prepared of this composite with encapsulated silver nanoparticles eluted only $2.6 \%$ of the total amount of silver present in the hydrogel over 5 weeks incubation in saline solution, which did not impair the cell viability of 3 different cell lines (mouse fibroblasts, human hepatocarcinoma cells and human osteosarcoma cells). Whereas Chitlac solutions mixed with silver nanoparticles was found to be cytotoxic to all three cell lines, leading to cell death within 24h. Hydrogels and hydrogel extracts prepared from an alginate-Chitlac mixture with the silver nanoparticles entrapped did not show cytotoxicity towards these cell lines as they are shielded from uptake by mammalian cells [106]. Antibacterial testing was done by adding $20 \% \mathrm{MH}$ broth as bacterial nutrition to both alginate and Chitlac solutions. The surfaces of alginate-Chitlac gels with and without silver nanoparticles were smeared with $10^{6} \mathrm{CFU} / \mathrm{ml} \mathrm{S}$. epidermidis. Only the silvernanoparticle loaded gels were free of bacterial colonization [106].

The combination of polymers and nanosilver can solve diverse problems related to the use of nanosilver such as: (1) polymers can prevent aggregation of silver nanoparticles, (2) polymers can act as linker for silver nanoparticles in coatings, (3) silver ion release can be tailored by changing the interaction between the polymer and the silver and changing the silver concentration. Several methods for the preparation of polymer/nanosilver composite coatings have been used to incorporate silver in biomaterials as can be found in an extensive review by Guo et al. [107]. Because of the multiple mechanisms of antimicrobial action exploited by silver nanoparticles they are less likely to suffer from resistance mechanisms in bacteria 
[108], however silver resistance has been observed in clinical isolates from silver exposed sites in patients as well [109].

Antimicrobial peptides (AMPs) have also been incorporated into biomaterials. Antimicrobial peptides are usually rather short peptide sequences, 12 to 100 aminoacids long, positively charged (net charge $+2-+9$ ), are amphiphilic, and have been isolated from single-celled microorganisms, insects and other invertebrates, plants, amphibians, birds, fish and mammals, including humans [110]. A special feature of AMPs is that they target a specific feature of the microbial cellular membrane that distinguishes broad species of bacteria from multicellular plants and animals [111]. Microbial cellular membranes possess negatively charged headgroups on the lipids that form the outermost leaflet of the bilayer which is exposed to the outer world. On the contrary, the outer leaflet of the membranes of plants and animals is composed principally of lipids with no net charge [111]. Although there are large variations in the structure of AMPs, a common feature of cationic AMPs is that they have an amphipatic structure, which allows them to bind to the membrane interface. The interaction with, and finally the disruption of the inner and outer membranes of bacteria leads to the bacterial cell death [112].

Unlike resistance towards antibiotics, acquired resistance towards antimicrobial peptides by sensitive bacterial strains is improbable. However, some bacterial species are resistant by nature, since (1) they lack the appropriate density of acidic lipids to provide peptide-binding sites, (2) Some species produce digestive proteases, which destroy AMPs [111]. Furthermore, degradation by human proteases, unknown toxicity profiles and high costs of production have limited the potential application of AMPs [113]. Only few AMPS have made it to clinical phase testing and none is approved by FDA so far [114]. A promising group of AMPs is the indolicidin-analogues such as MBI-226 (Omiganin) for the treatment of catheterrelated infection, which have been used in a clinical phase III trial [110, 114].

Since development of resistance against AMPs is unlikely, recently the potential of functionalizing biomaterials with AMPs has been explored in research. Issues of short half-lives and cytotoxicity can be circumvented by immobilizing AMPs on the surface of biomaterials. The use of a spacer between a biomaterial and an AMP can 
influence the orientation of the peptide and hence its bactericidal activity. A comprehensive review on the different strategies for immobilization of AMPs onto biomaterials and its effect on activity, cytotoxicity and long-term stability has been published by Costa et al. [115].

\section{Improved polymeric carriers for the passive delivery of antibiotics}

In order to overcome the drawbacks of non-degradable antibiotic loaded biomaterials such as PMMA beads and spacers, biodegradable polymer based materials for the delivery of antibiotics have been investigated [116]. To prepare biodegradable antibiotic loaded beads or spacers, either PMMA copolymerized with degradable blocks or resorbable polymers have been used. For the latter a wide variety of polymers, especially aliphatic polyesters prepared by ring-opening polymerization such as PDLLA [117-127], poly(lactic-co-glycolic acid) PLGA [128, 129] and PCL $[130,131]$ have been used. For example, antibiotic loaded beads from PDLLA and PLGA were prepared by Mader et al. [132]. Clindamycin, tobramycin or vancomycin were released in adequate concentrations for at least 30 days from the PLA and PLGA beads, whereas the PMMA beads released this antibiotics in adequate concentrations for only 12 days [132].

Neut et al. investigated the use of poly(trimethylene carbonate) (PTMC) discs as a delivery system for gentamicin [133]. The advantage of PTMC is that it degrades without acidic degradation products. PTMC degrades primary by enzymatic degradation. Therefore, the degradation in vitro is very slow, whereas the degradation in vivo is much faster due to the presence of enzymes [134]. Furthermore, the degradation of PTMC by surface erosion might facilitate a more gradual and sustained release depending on the shape of the delivery system, with the possibly for zero-order release kinetics, whereas other biodegradable materials usually degrade by bulk erosion and lack this control. Neut et al. compared the performance of these PTMC discs with conventional gentamicin-containing PMMA beads (Septopal $\left.{ }^{\circledR}\right)$. PTMC discs loaded with $10 \mathrm{w} / \mathrm{w} \%$ of gentamicin entrapped were prepared and the in vitro release was assessed by immersing the discs in a PBS solution or in a lipase enzyme solution at $37^{\circ} \mathrm{C}$. In the lipase enzyme solution PTMC 
discs completely degraded in a two week course, whereas the PTMC discs immersed in PBS did not degrade at all. The gentamicin entrapped was released very slowly from the PTMC discs when immersed in PBS solution, with only $10 \%$ of the antibiotic being released over two weeks, however in lipase enzyme solution over $50 \%$ of the antibiotic was released over two weeks [133]. So, the large difference in degradation and release is the result of the combined enzymatic and hydrolytic degradation mechanism of PTMC. In vivo studies of PTMC discs implanted in subcutaneous pockets in the back of rats showed complete degradation of the implant in 1 year [135]. Consequently, in order to find a suitable biodegradable substitute for PMMA beads and spacers, it is important to consider the properties of the material and their mechanism of degradation.

For collagen fleece, most of the research into improvements has focused on sustaining the release of highly water soluble antibiotics. Besides modifying the properties of the antibiotics, the properties of the collagen carrier can be changed to obtain a sustained release. For instance, the release rate of gentamicin from collagen fleece can be modified to a certain extent by varying the porosity of the collagen matrix or by chemical modification, i.e. succinylation of collagen to enhance charge interactions for ionic bonding between the collagen and ciprofloxacin $[78,80,136]$.

Instead of modifying the properties of the collagen fleece itself, a collagen composite can be created by incorporation of microspheres within the collagen matrix. The composite collagen fleece contains antibiotic in the collagen matrix, but also antibiotic entrapped in microparticles. PLGA microspheres made of a 50/50 blend of PLGA of molecular weight (MW) of $13.5 \mathrm{kDa}$ and $36.2 \mathrm{kDa}$ respectively, with gentamicin entrapped were prepared by the water-in-oil-in-water double emulsion technique by Schlapp and Friess [81]. These microspheres were dispersed within a collagen matrix to create the composite fleece. A burst release of $55 \%$ of the entrapped gentamicin was observed in vitro from these fleeces, followed by a more gradual release of the residual gentamicin during the first 7 days upon immersion in PBS at $37^{\circ} \mathrm{C}$. 


\section{New responsive polymeric carriers for the active delivery of antibiotics}

One of the main requirements of a system for the local delivery of antibiotics in prophylaxis is the ability to have a release which is provided over a period of several days. Hydrogels for the delivery of antibiotics combine the advantage of minimally invasive application (injection with needle, through a tube or application of a spray or foam) with the advantage of having a sustained release without the need of frequent re-administration. Hydrogels are polymeric materials with high water content that can be used to entrap antibiotics. The stimuli sensitive hydrogels are a special group of hydrogels that can respond to chemical or physical stimuli as to change their physical properties and cleave attached chemical groups at the site of action. Thermoresponsive hydrogels can respond to changes in the environmental temperature. Thermo-responsive hydrogels are designed to have low viscosity at room temperature, but turn with change of temperature from a viscous state to an elastic state. So, thermo-responsive hydrogels are designed so that they can be injected at room temperature and form a gel at body temperature. Veyries et al. used Poloxamer 407 (Pluronic $\circledast$ F-127) to encapsulate vancomycin [137]. Poloxamer 407 is a triblock co-polymer with the poly(propylene oxide) (PPO) as a hydrophobic central block with on both ends a hydrophilic block of poly(ethylene oxide)(PEO). Poloxamer can, when used in concentrations higher than $20 \mathrm{w} / \mathrm{v} \%$, gel in-situ because of a sol-gel temperature that is lower than the body temperature. However, there is a risk of lipid metabolism alteration because of high doses of Pluronics. Thus, supermolecular structures of Pluronics combined with cyclodextrins have been investigated to decrease the amount of required polymer for gelation while providing a sustain release [138].

Antibiotics can be mixed into these hydrophilic networks at room temperature and become entrapped at higher temperature. Subsequently the drug is released by several mechanisms: diffusion, swelling and erosion. The antibiotics can diffuse out of the hydrogel depending on the concentration difference across the gel and outside the gel and the path length. Swelling of the hydrogel network allows the entrapped antibiotics to more easily diffuse out of the network. Finally, bulk erosion of the hydrogel also causes antibiotics to be released with the eroded parts and decreases the path length for diffusion from the gel. 
Suzuki et al. prepared and studied thermo-responsive hydrogels for infection prophylaxis in vivo, with hydrophilic blocks composed out of p-dioxane (DX) and PEG, the hydrophobic blocks were composed out of PDLLA [123]. This triblock PLADX-PEG hydrogel had a MW of $9.8 \times 10^{3}$ Da and a molar ratio of PLA:DX:PEG equal to $5: 1: 3$. This hydrogel degraded in $2-3$ weeks in PBS at $37^{\circ} \mathrm{C}$. They encapsulated teicoplanin, a glycopeptide antibiotic, within this hydrogel and next to the antibiotic recombinant human bone morphogenetic protein-2 (rhBMP-2). The rationale behind this was to eradicate an infection and at the same time stimulate bone formation. In a release study, $30 \mathrm{mg}$ of the gel with $4 \mu \mathrm{g}$ of teicoplanin was used to track the release of the antibiotic in vitro. Approximately $40 \%$ of the encapsulated teicoplanin was released during the first 24 hours and a level above the $\mathrm{MIC}_{90 \%}$ value for $S$. aureus was maintained for 2 weeks. The polymeric hydrogel was degraded in about 3 weeks. In an in vivo experiment of a rat cranial bone defect, the restored area was measured from CT-scans taken 6 weeks upon implantation of the polymeric implant [123]. The implant with rhBMP-2 had a similar size of restored area as compared with the defect, which had been treated with an implant with rhBMP-2 and teicoplanin. The implant with only teicoplanin encapsulated had a smaller restored area as when rhBMP-2 was used, however this area was larger than for the negative control (only the PLA-DX-PEG implant).

Compositions that respond to enzymes have also been investigated. A poly(esterurethane) based system with covalently bound ciprofloxacin was assessed by Woo et al. [139]. The rationale behind this design is that poly(ester-urethane)s have been shown to be susceptible to degradation by hydrolytic enzymes, which are released by leukocytes and macrophages present at the site of trauma and/or implant site. This way a responsive system would be obtained in which ciprofloxacin would be released from the polymer upon these stimuli. The release was tracked from poly(esterurethane)-ciprofloxacin coated hollow glass tubes in phosphate buffer $(\mathrm{pH} 7)$ and cholesterol esterase (CE) (40 unit/ml) solution for 30 days. Although a higher rate of polymer degradation was observed in the presence of the CE enzyme, there was no difference observed in the release of free ciprofloxacin upon immersion in a CE solution as compared with the phosphate buffer solution. So, the data suggest that the enzyme was unable to specifically cleave the polymer segments required to 
release free ciprofloxacin, and instead inactive ciprofloxacin with poly( $\varepsilon$-caprolactone) or 1,6-hexane diisocyanate fragments attached were released [139]. Another example of such a responsive system was a poly(vinyl alcohol) (PVA) hydrogel system investigated by Suzuki et al. [140]. This hydrogel had gentamicin covalently grafted to it by a peptide linker susceptible to cleavage by bacterial enzymes released by $P$.aeruginosa. Several peptide sequences were tested for their hydrolytic activity, and the most efficient one (Gly-(D)Phe-Pro-Arg-Gly-Phe-Pro-Ala-Gly-Gly) was selected [140]. The peptide linker and the gentamicin were grafted to a succinylated PVA hydrogel. In an in vitro experiment, it was shown that gentamicin was released upon incubation with exudate of a $P$. aeruginosa infected wound, however exudate of a non-infected wound was not able to cleave the peptide linker and release the gentamicin [140].

\section{Conclusion. The ideal polymeric delivery system for infection prophylaxis}

In order for a polymeric biomaterial to be a good candidate for use in infection prophylaxis, the system has to fulfill several requirements. The materials currently available in the clinic contribute to improved infection prophylaxis, by lowering the number of infections in patients. However, all of these materials have their own limitations. For instance PMMA lacks degradability, which is troublesome due to unfavorable release patterns of the antibiotic as well as permanent presence of a foreign body. Collagen on the other hand, can be biodegraded in the human body; however the inability for true sustained release can be an issue for its use. For the PDLLA coatings, the problem lies in the acidic degradation products that hinder bone regeneration and antibiotic action at the same time. Furthermore, all of these systems are rather passive than active in the sense that they are unable to respond and tailor their antibiotic release upon physiological changes in the human body, like temperature or presence of bacterial enzymes. Also the emergence of resistance in bacteria in hospitals worldwide by use and misuse of antibiotics limits the use of delivery systems that are based on conventional antibiotics. Therefore, research has also focused on encapsulating other antimicrobial compounds into biomaterials, such as modified antibiotics, antibiotic prodrugs, silver or antimicrobial peptides. All of 
these should have a broad antibacterial spectrum, with coverage of both Grampositive and Gram-negative organisms.

Finally, a system that can respond to physiological stimuli and therefore can be applied minimal invasively, while sustaining the release of antibiotics over a period of several days can be advantageous. The introduction of linkers in the system, which can be cleaved upon exposure to enzymes produced by bacteria, or other stimuli given by bacterial pathogens, could produce a more effective drug delivery system. In conclusion, there is a wide variety of approaches investigated, all with their specific benefits over traditional delivery systems. But the many requirements for an optimal system make the development of the ideal system a significant challenge.

\section{Acknowledgements}

The authors like to thank Dr Mario Morgenstern from Trauma Center Murnau for the fruitful discussion and for providing the clinical images, Dr Andrea Montali from DePuy Synthes Biomaterials for kindly providing an antibiotic coated tibia nail and Christoph Sprecher from the AO Research Institute Davos for preparation of the SEM image of the antibiotic coated tibia nail. This work was funded as part of the AOTrauma Clinical Priority Program Bone Infection. 


\section{References}

[1] National Center for Biotechnology I. Infection. 2012.

[2] Scottish Intercollegiate Guidelines N. Antibiotic prophylaxis in surgery A national clinical guideline. 2008.

[3] Greene LR. Guide to the elimination of orthopedic surgery surgical site infections: an executive summary of the Association for Professionals in Infection Control and Epidemiology elimination guide. AmJ Infect Control. 2012;40:384-6.

[4] Elek SD, Conen PE. The virulence of Staphylococcus pyogenes for man; a study of the problems of wound infection. BrJ ExpPathol. 1957;38:573-86.

[5] Zimmerli W, Waldvogel FA, Vaudaux P, Nydegger UE. Pathogenesis of foreign body infection: description and characteristics of an animal model. J Infect Dis. 1982;146:487-97.

[6] Busscher HJ, van der Mei HC, Subbiahdoss G, Jutte PC, van den Dungen JJ, Zaat SA, et al. Biomaterial-associated infection: locating the finish line in the race for the surface. SciTransIMed. 2012;4:153rv10.

[7] Rochford ET, Richards RG, Moriarty TF. Influence of material on the development of device-associated infections. ClinMicrobiollnfect. 2012;18:1162-7.

[8] Trampuz A, Zimmerli W. Diagnosis and treatment of infections associated with fracture-fixation devices. Injury. 2006;37:S59-S66.

[9] Trampuz A, Widmer AF. Infections associated with orthopedic implants. Current Opinion in Infectious Diseases. 2006;19:349-56.

[10] Diefenbeck M, Muckley T, Hofmann GO. Prophylaxis and treatment of implantrelated infections by local application of antibiotics. Injury. 2006;37 Suppl 2:S95-104. [11] Schmidmaier G, Lucke M, Wildemann B, Haas NP, Raschke M. Prophylaxis and treatment of implant-related infections by antibiotic-coated implants: a review. Injury. 2006;37:S105-S12.

[12] Weinstein RA, Darouiche RO. Device-Associated Infections: A Macroproblem that Starts with Microadherence. Clinical Infectious Diseases. 2001;33:1567-72.

[13] Mangram AJ, Horan TC, Pearson ML, Silver LC, Jarvis WR. Guideline for Prevention of Surgical Site Infection, 1999. Centers for Disease Control and Prevention (CDC) Hospital Infection Control Practices Advisory Committee. AmJ Infect Control. 1999;27:97-132. 
[14] Zimmerli W. Antibiotic prophylaxis. In: Rüedi TP, Buckley RE, Moran CG, editors. AO Principles of Fracture Management. Davos Platz: AO Publishing; 2007. p. 42533.

[15] Del Pozo JL, Patel R. Infection Associated with Prosthetic Joints. New England Journal of Medicine. 2009;361:787-94.

[16] Boxma H, Broekhuizen T, Patka P, Oosting H. Randomised controlled trial of single-dose antibiotic prophylaxis in surgical treatment of closed fractures: the Dutch Trauma Trial. Lancet. 1996;347:1133-7.

[17] Esposito S, Leone S. Prosthetic joint infections: microbiology, diagnosis, management and prevention. International Journal of Antimicrobial Agents. 2008;32:287-93.

[18] Glenny A, Song F. Antimicrobial prophylaxis in total hip replacement: a systematic review. Health TechnolAssess. 1999;3:1-57.

[19] Tamilvanan S, Venkateshan N, Ludwig A. The potential of lipid- and polymerbased drug delivery carriers for eradicating biofilm consortia on device-related nosocomial infections. Journal of Controlled Release. 2008;128:2-22.

[20] Aarestrup FM. Association between the consumption of antimicrobial agents in animal husbandry and the occurrence of resistant bacteria among food animals. IntJ AntimicrobAgents. 1999;12:279-85.

[21] Kardas P, Devine S, Golembesky A, Roberts C. A systematic review and metaanalysis of misuse of antibiotic therapies in the community. IntJ AntimicrobAgents. 2005;26:106-13.

[22] Tunney MM, Patrick S, Gorman SP, Nixon JR, Anderson N, Davis RI, et al. Improved detection of infection in hip replacements. Journal of Bone \& Joint Surgery, British Volume. 1998;80-B:568-72.

[23] Norden CW. Osteomyelitis. In: Mandell GL, Douglas RG, Bennett JE, editors. Principles and practice of infectious diseases. New York: Churchill Livingstone; 1990. p. 922-30.

[24] Ochsner PE, Sirkin MS, Trampuz A. Acute infection. In: Rüedi TP, Buckley RE, Moran CG, editors. AO Principles of Fracture Management. Davos Platz: AO Publishing; 2007. p. 521-41. 
[25] Johnson EE, Buckley RE. Chronic infection and infected nonunion. In: Rüedi TP, Buckley RE, Moran CG, editors. AO Principles of Fracture Management. Davos Platz: AO Publishing; 2007. p. 543-55.

[26] Patel R. Biofilms and antimicrobial resistance. Clinical Orthopaedics and Related Research. 2005;437:41-7.

[27] Mack D, Fischer W, Krokotsch A, Leopold K, Hartmann R, Egge H, et al. The intercellular adhesin involved in biofilm accumulation of Staphylococcus epidermidis is a linear beta-1,6-linked glucosaminoglycan: purification and structural analysis. Journal of Bacteriology. 1996;178:175-83.

[28] Flemming H-C, Wingender J. The biofilm matrix. Nat Rev Micro. 2010;8:623-33.

[29] Montanaro L, Poggi A, Visai L, Ravaioli S, Campoccia D, Speziale P, et al. Extracellular DNA in biofilms. International Journal of Artificial Organs. 2011;34:82431.

[30] National Center for Biotechnology I. Biofilm. 2013.

[31] Donlan RM. Biofilms and device-associated infections. Emerglnfect Dis. 2001;7:277-81.

[32] Donlan RM. Biofilms: microbial life on surfaces. EmergInfect Dis. 2002;8:881-90.

[33] Anderl JN, Franklin MJ, Stewart PS. Role of antibiotic penetration limitation in Klebsiella pneumoniae biofilm resistance to ampicillin and ciprofloxacin. AntimicrobAgents Chemother. 2000;44:1818-24.

[34] Costerton JW. Biofilm theory can guide the treatment of device-related orthopaedic infections. ClinOrthopRelat Res. 2005:7-11.

[35] von Eiff C, Heilmann C, Peters G. Staphylococcus epidermidis: why is it so successful? Clinical Microbiology and Infection. 1998;4:297-300.

[36] Peng KT, Chen CF, Chu IM, Li YM, Hsu WH, Hsu RWW, et al. Treatment of osteomyelitis with teicoplanin-encapsulated biodegradable thermosensitive hydrogel nanoparticles. Biomaterials. 2010;31:5227-36.

[37] Darouichi RO. Treatment of infections associated with surgical implants. The New England Journal of Medicine. 2004;350:1422-9.

[38] Rubin RJ, Harrington CA, Poon A, Dietrich K, Greene JA, Moiduddin A. The economic impact of Staphylococcus aureus infection in New York City hospitals. EmergInfect Dis. 1999;5:9-17.

[39] National Center for Biotechnology I. Antibiotic prophylaxis. 2012. 
[40] Kaiser AB. Antimicrobial prophylaxis in surgery. New England Journal of Medicine. 1986;315:1129-38.

[41] Haas DW, Kaiser AB. Antimicrobial prophylaxis of infections associated with foreign bodies. In: Waldvogel FA, Bisno AL, editors. Infections Associated with Indwelling Medical Devices. Washington DC: John Wiley \& Sons; 2000. p. 395-406.

[42] Jaeger M, Maier D, Kern WV, Südkamp NP. Antibiotics in trauma and orthopedic surgery - A primer of evidence-based recommendations. Injury. 2006;37:S74-S80.

[43] Gustilo RB, Merkow RL, Templeman D. The management of open fractures. J Bone Joint SurgAm. 1990;72:299-304.

[44] Classen DC, Evans RS, Pestotnik SL, Horn SD, Menlove RL, Burke JP. The timing of prophylactic administration of antibiotics and the risk of surgical-wound infection. New England Journal of Medicine. 1992;326:281-6.

[45] Ito K, Perren SM. Biology and biomechanics in bone healing. In: Rüedi TP, Buckley RE, Moran CG, editors. AO Principles of Fracture Management. Davos Platz: AO Publishing; 2007. p. 9-31.

[46] Deguchi T, Ishi A, Tanaka M. Binding of aminoglycoside antibiotics to acidic mucopolysaccharides. J Antibiot(Tokyo). 1978;31:150-5.

[47] Mingeot-Leclercq MP, Tulkens PM. Aminoglycosides: Nephrotoxicity. Antimicrobial Agents and Chemotherapy. 1999;43:1003-12.

[48] Naughton CA. Drug-induced nephrotoxicity. AmFamPhysician. 2008;78:743-50.

[49] Elyasi S, Khalili H, Dashti-Khavidaki S, Mohammadpour A. Vancomycin-induced nephrotoxicity: mechanism, incidence, risk factors and special populations. A literature review. EurJ ClinPharmacol. 2012;68:1243-55.

[50] Kubin CJ, Ellman TM, Phadke V, Haynes LJ, Calfee DP, Yin MT. Incidence and predictors of acute kidney injury associated with intravenous polymyxin B therapy. $J$ Infect. 2012;65:80-7.

[51] Durante-Mangoni E, Grammatikos A, Utili R, Falagas ME. Do we still need the aminoglycosides? International Journal of Antimicrobial Agents. 2009;33:201-5.

[52] Begg EJ, Barclay ML. Aminoglycosides-50 years on. $\mathrm{Br} \mathrm{J}$ ClinPharmacol. 1995;39:597-603.

[53] Griffis CD, Metcalfe S, Bowling FL, Boulton AJM, Armstrong DG. The use of gentamicin-impregnated foam in the management of diabetic foot infections: a promising delivery system? Expert Opinion Drug Delivery. 2009;6:639-42. 
[54] Raschke MJ, Schmidmaier G. Biologisierung von Implantaten in der Chirurgie des Stütz- und Bewegungsapparates. Der Unfallchirurg. 2004;107:653-63.

[55] Barth RE, Vogely HC, Hoepelman AI, Peters EJ. 'To bead or not to bead?' Treatment of osteomyelitis and prosthetic joint-associated infections with gentamicin bead chains. IntJ AntimicrobAgents. 2011;38:371-5.

[56] Baudoux P, Bles N, Lemaire S, Mingeot-Leclercq M-P, Tulkens PM, Van Bambeke F. Combined effect of $\mathrm{pH}$ and concentration on the activities of gentamicin and oxacillin against Staphylococcus aureus in pharmacodynamic models of extracellular and intracellular infections. Journal of Antimicrobial Chemotherapy. 2007;59:246-53.

[57] Schlessinger D. Failure of aminoglycoside antibiotics to kill anaerobic, low-pH, and resistant cultures. Clinical Microbiology Reviews. 1988;1:54-9.

[58] Madigan MT, Martinko JM, Parker J. Microbial growth control. Brock; Biology of microorganisms2000.

[59] Berger-Bächi B, McCallum N. State of the knowledge of bacterial resistance. Injury. 2006;37:S20-S5.

[60] Lee SH, Lee JE, Baek WY, Lim JO. Regional delivery of vancomycin using pluronic F-127 to inhibit methicillin resistant Staphylococcus aureus (MRSA) growth in chronic otitis media in vitro and in vivo. Journal of Controlled Release. 2004;96:17.

[61] Hajdu S, Lassnigg A, Graninger W, Hirschl AM, Presterl E. Effects of vancomycin, daptomycin, fosfomycin, tigecycline, and ceftriaxone on Staphylococcus epidermidis biofilms. Journal of Orthopaedic Research. 2009:1361-5.

[62] Winkler H, Janata O, Berger C, Wein W, Georgopoulos A. In vitro release of vancomycin and tobramycin from impregnated human and bovine bone grafts. Journal of Antimicrobial Chemotherapy. 2000;46:423-8.

[63] Rathbone CR, Cross JD, Brown KV, Murray CK, Wenke JC. Effect of various concentrations of antibiotics on osteogenic cell viability and activity. Journal of Orthopaedic Research. 2011;29:1070-4.

[64] Isefuku S, Joyner CJ, Simpson AH. Gentamicin may have an adverse effect on osteogenesis. J Orthop Trauma. 2003;17:212-6. 
[65] Halleem AA, Rouse MS, Lewallen DG, Hanssen AD, Steckelberg JM, Patel R. Gentamicin and vancomycin do not impair experimental fracture healing. Clinical Orthopaedics and Related Research. 2004;427:22-4.

[66] McLaren AC. Alternative materials to acrylic bone cement for delivery of depot antibiotics in orthopaedic infections. Clinical Orthopaedics and Related Research. 2004;427:101-6.

[67] Tunney MM, Ramage G, Patrick S, Nixon JR, Murphy PG, Gorman SP. Antimicrobial Susceptibility of Bacteria Isolated from Orthopedic Implants following Revision Hip Surgery. Antimicrobial Agents and Chemotherapy. 1998;42:3002-5.

[68] Buchholz HW, Engelbrecht H. [Depot effects of various antibiotics mixed with Palacos resins]. Chirurg. 1970;41:511-5.

[69] Kuehn KD, Ege W, Gopp U. Acrylic bone cements: composition and properties. Orthop ClinNorth Am. 2005;36:17-28, v.

[70] Serbetci K, Hasirci N. Recent developments in bone cements. Biomaterials in orthopedics2004. p. 241-86.

[71] Lewis G, Janna S. The in vitro elution of gentamicin sulfate from a commercially available gentamicin-loaded acrylic bone cement, VersaBond AB. J BiomedMaterRes B ApplBiomater. 2004;71:77-83.

[72] Frutos CP, Diez PE, Barrales-Rienda JM, Frutos G. Validation and in vitro characterization of antibiotic-loaded bone cement release. IntJ Pharm. 2000;209:1526.

[73] Engesaeter LB, Lie SA, Espehaug B, Furnes O, Vollset SE, Havelin LI. Antibiotic prophylaxis in total hip arthroplasty Effects of antibiotic prophylaxis systemically and in bone cement on the revision rate of 22,170 primary hip replacements followed 014 years in the Norwegian Arthroplasty Register. Acta Orthopaedica. 2003;74:64451.

[74] Weber FA, Lautenbach EEG. Revision of infected total hip arthroplasty. ClinOrthop Relat Res. 1986:108-15.

[75] Hope PG, Kristinsson KG, Norman P, Elson RA. Deep infection of cemented total hip arthroplasties caused by coagulase-negative staphylococci. J Bone Joint SurgBr. 1989;71:851-5.

[76] Yoshii E. Cytotoxic effects of acrylates and methacrylates: relationships of monomer structures and cytotoxicity. J BiomedMaterRes. 1997;37:517-24. 
[77] Kilian O, Hossain H, Flesch I, Sommer U, Nolting H, Chakraborty T, et al. Elution kinetics, antimicrobial efficacy, and degradation and microvasculature of a new gentamicin-loaded collagen fleece. J BiomedMaterRes B ApplBiomater. 2009;90:210-22.

[78] Ruszczak Z, Friess W. Collagen as a carrier for on-site delivery of antibacterial drugs. AdvDrug DelivRev. 2003;55:1679-98.

[79] Sorensen TS, Sorensen Al, Merser S. Rapid release of gentamicin from collagen sponge. In vitro comparison with plastic beads. Acta Orthop Scand. 1990;61:353-6.

[80] El-Husseiny M, Patel S, MacFarlane RJ, Haddad FS. Biodegradable antibiotic delivery systems. Journal of Bone \& Joint Surgery, British Volume. 2011;93-B:151-7. [81] Schlapp M, Friess W. Collagen/PLGA microparticle composites for local controlled delivery of gentamicin. J PharmSci. 2003;92:2145-51.

[82] Campoccia D, Montanaro L, Speziale P, Arciola CR. Antibiotic-loaded biomaterials and the risks for the spread of antibiotic resistance following their prophylactic and therapeutic clinical use. Biomaterials. 2010;31:6363-77.

[83] Imbuluzqueta E, Elizondo E, Gamazo C, Moreno-Calvo E, Veciana J, Ventosa $\mathrm{N}$, et al. Novel bioactive hydrophobic gentamicin carriers for the treatment of intracellular bacterial infections. Acta Biomater. 2011;7:1599-608.

[84] Meyer JD, Falk RF, Kelly RM, Shively JE, Withrow SJ, Dernell WS, et al. Preparation and in vitro characterization of gentamycin-impregnated biodegradable beads suitable for treatment of osteomyelitis. Journal of Pharmaceutical Sciences. 1998;87:1149-54.

[85] Obermeier A, Matl FD, Schwabe J, Zimmermann A, Kuhn KD, Lakemeier S, et al. Novel fatty acid gentamicin salts as slow-release drug carrier systems for antiinfective protection of vascular biomaterials. J MaterSciMaterMed. 2012;23:1675-83.

[86] Schnieders J, Gbureck U, Thull R, Kissel T. Controlled release of gentamicin from calcium phosphate-poly(lactic acid-co-glycolic acid) composite bone cement. Biomaterials. 2006;27:4239-49.

[87] Vogt S, Kühn KD, Gopp U, Schnabelrauch M. Resorbable Antibiotic Coatings for Bone Substitutes and Implantable Devices. Materialwissenschaft und Werkstofftechnik. 2005;36:814-9. 
[88] Holzer B, Grüssner U, Brückner B, Houf M, Kiffner E, Schildberg FW, et al. Efficacy and tolerance of a new gentamicin collagen fleece (Septocoll) after surgical treatment of a pilonidal sinus. Colorectal Disease. 2003;5:222-7.

[89] Friess W. Collagen--biomaterial for drug delivery. EurJ PharmBiopharm. 1998;45:113-36.

[90] Fuchs T, Stange R, Schmidmaier G, Raschke MJ. The use of gentamicin-coated nails in the tibia: preliminary results of a prospective study. Arch Orthop Trauma Surg. 2011;131:1419-25.

[91] Gunatillake PA, Adhikari R. Biodegradable synthetic polymers for tissue engineering. EurCell Mater. 2003;5:1-16.

[92] Bostman OM. Osteolytic changes accompanying degradation of absorbable fracture fixation implants. Journal of Bone \& Joint Surgery, British Volume. 1991;73B:679-82.

[93] Heidemann W, Jeschkeit-Schubbert S, Ruffieux K, Fischer JH, Jung H, Krueger $\mathrm{G}$, et al. pH-stabilization of predegraded PDLLA by an admixture of water-soluble sodiumhydrogenphosphate-results of an in vitro- and in vivo-study. Biomaterials. 2002;23:3567-74.

[94] Sung H-J, Meredith C, Johnson C, Galis ZS. The effect of scaffold degradation rate on three-dimensional cell growth and angiogenesis. Biomaterials. 2004;25:573542.

[95] Wu L, Ding J. In vitro degradation of three-dimensional porous poly(d,l-lactideco-glycolide) scaffolds for tissue engineering. Biomaterials. 2004;25:5821-30.

[96] Agrawal CM, Athanasiou KA. Technique to control $\mathrm{pH}$ in vicinity of biodegrading PLA-PGA implants. Journal of Biomedical Materials Research. 1997;38:105-14.

[97] Marcus Y, Sasson K, Fridkin M, Shechter Y. Turning low-molecular-weight drugs into prolonged acting prodrugs by reversible pegylation: a study with gentamicin. $\mathrm{J}$ Med Chem. 2008;51:4300-5.

[98] Coessens V, Schacht E, Domurado D. Synthesis of polyglutamine and dextran conjugates of streptomycin with an acid-sensitive drug-carrier linkage. Journal of Controlled Release. 1996;38:141-50.

[99] Choi SK, Myc A, Silpe JE, Sumit M, Wong PT, McCarthy K, et al. Dendrimerbased multivalent vancomycin nanoplatform for targeting the drug-resistant bacterial surface. ACS Nano. 2013;7:214-28. 
[100] Rai M, Yadav A, Gade A. Silver nanoparticles as a new generation of antimicrobials. Biotechnology Advances. 2009;27:76-83.

[101] Poulter N, Vasilev K, Griesser SS, Griesser HJ. Silver Containing Biomaterials. In: Moriarty T.F., Zaat S.A.J., H.J. B, editors. Biomaterials Associated Infection. New York: Springer; 2013. p. 355-78.

[102] Hetrick EM, Schoenfisch MH. Reducing implant-related infections: active release strategies. Chemical Society Reviews. 2006;35:780-9.

[103] Alt V, Bechert T, Steinrücke P, Wagener M, Seidel P, Dingeldein E, et al. An in vitro assessment of the antibacterial properties and cytotoxicity of nanoparticulate silver bone cement. Biomaterials. 2004;25:4383-91.

[104] Montali A. Antibacterial coating systems. Injury. 2006;37:S81-S6.

[105] Pal S, Tak YK, Song JM. Does the Antibacterial Activity of Silver Nanoparticles Depend on the Shape of the Nanoparticle? A Study of the Gram-Negative Bacterium Escherichia coli. Applied and Environmental Microbiology. 2007;73:1712-20.

[106] Travan A, Pelillo C, Donati I, Marsich E, Benincasa M, Scarpa T, et al. Noncytotoxic Silver Nanoparticle-Polysaccharide Nanocomposites with Antimicrobial Activity. Biomacromolecules. 2009;10:1429-35.

[107] Guo L, Yuan W, Lu Z, Li CM. Polymer/nanosilver composite coatings for antibacterial applications. Colloids and Surfaces A: Physicochemical and Engineering Aspects. 2013;439:69-83.

[108] Pelgrift RY, Friedman AJ. Nanotechnology as a therapeutic tool to combat microbial resistance. Advanced Drug Delivery Reviews. 2013;65:1803-15.

[109] Silver S. Bacterial silver resistance: molecular biology and uses and misuses of silver compounds. FEMS Microbiology Reviews. 2003;27:341-53.

[110] Jenssen $H$, Hamill P, Hancock RE. Peptide antimicrobial agents. ClinMicrobiolRev. 2006;19:491-511.

[111] Zasloff M. Antimicrobial peptides of multicellular organisms. Nature. 2002;415:389-95.

[112] Epand RM, Vogel HJ. Diversity of antimicrobial peptides and their mechanisms of action. BiochimBiophysActa. 1999;1462:11-28.

[113] Yeung AY, Gellatly S, Hancock RW. Multifunctional cationic host defence peptides and their clinical applications. Cellular and Molecular Life Sciences. 2011;68:2161-76. 
[114] Kang S-J, Park SJ, Mishig-Ochir T, Lee B-J. Antimicrobial peptides: therapeutic potentials. Expert Review of Anti-infective Therapy. 2014;12:1477-86.

[115] Costa F, Carvalho IF, Montelaro RC, Gomes P, Martins MC. Covalent immobilization of antimicrobial peptides (AMPs) onto biomaterial surfaces. Acta Biomater. 2011;7:1431-40.

[116] Daghighi S, Sjollema J, van der Mei HC, Busscher HJ, Rochford ETJ. Infection resistance of degradable versus non-degradable biomaterials: An assessment of the potential mechanisms. Biomaterials. 2013;34:8013-7.

[117] Andreopoulos AG, Hatzi EC, Doxastakis M. Controlled release systems based on poly(lactic acid). An in vitro and in vivo study. Journal of Materials Science: Materials in Medicine. 2000;11:393-7.

[118] Kanellakopoulou K, Galanakis N, Giamarellos-Bourboulis EJ, Rifiotis C, Papakostas K, Andreopoulos A, et al. Treatment of experimental osteomyelitis caused by methicillin-resistant Staphylococcus aureus with a biodegradable system of lactic acid polymer releasing pefloxacin. Journal of Antimicrobial Chemotherapy. 2000;46:311-4.

[119] Koort JK, M,,kinen TJ, Suokas E, Veiranto M, Jalava J, T"rm,I, P, et al. Sustained release of ciprofloxacin from an osteoconductive poly(DL)-lactide implant. Acta Orthopaedica. 2008;79:295-301.

[120] Mauduit J, Bukh N, Vert M. Gentamycin/poly (lactic acid) blends aimed at sustained release local antibiotic therapy administered per-operatively. III. The case of gentamycin sulfate in films prepared from high and low molecular weight poly (DLlactic acids). Journal of Controlled Release. 1993;25:43-9.

[121] Mauduit J, Bukh N, Vert M. Gentamycin/poly(lactic acid) blends aimed at sustained release local antibiotic therapy administered per-operatively. II. The case of gentamycin sulfate in high molecular weight poly(dl-lactic acid) and poly(l-lactic acid). Journal of Controlled Release. 1993;23:221-30.

[122] Mauduit J, Bukh N, Vert M. Gentamycin/poly(lactic acid) blends aimed at sustained release local antibiotic therapy administered per-operatively. I. The case of gentamycin base and gentamycin sulfate in poly(dl-lactic acid) oligomers. Journal of Controlled Release. 1993;23:209-20.

[123] Suzuki A, Terai H, Toyoda H, Namikawa T, Yokota Y, Tsunoda T, et al. A biodegradable delivery system for antibiotics and recombinant human bone 
morphogenetic protein-2: A potential treatment for infected bone defects. Journal of Orthopaedic Research. 2006;24:327-32.

[124] Vogt S, K

Based Release Systems for Local Antibiotic Therapies. Materialwissenschaft und Werkstofftechnik. 2003;34:1041-7.

[125] Wei G, Kotoura Y, Oka M, Yamamuro T, Wada R, Hyon SH, et al. A bioabsorbable delivery system for antibiotic treatment of osteomyelitis. The use of lactic acid oligomer as a carrier. Journal of Bone \& Joint Surgery, British Volume. 1991;73-B:246-52.

[126] Zhang X, Wyss UP, Pichora D, Goosen MFA. A mechanistic study of antibiotic release from biodegradable poly(d,I-lactide) cylinders. Journal of Controlled Release. 1994;31:129-44.

[127] Zhang XICH, Wyss UP, Pichora DAVI, Goosen MFA. Biodegradable Controlled Antibiotic Release Devices for Osteomyelitis: Optimization of Release Properties. Journal of Pharmacy and Pharmacology. 1994;46:718-24.

[128] Garvin KL, Miyano JA, Robinson D, Giger D, Novak J, Radio S. Polylactide/polyglycolide antibiotic implants in the treatment of osteomyelitis. A canine model. J Bone Joint Surg Am. 1994;76:1500-6.

[129] Kim K, Luu YK, Chang C, Fang D, Hsiao BS, Chu B, et al. Incorporation and controlled release of a hydrophilic antibiotic using poly(lactide-co-glycolide)-based electrospun nanofibrous scaffolds. Journal of Controlled Release. 2004;98:47-56.

[130] Chang HI, Perrie Y, Coombes AGA. Delivery of the antibiotic gentamicin sulphate from precipitation cast matrices of polycaprolactone. Journal of Controlled Release. 2006;110:414-21.

[131] Teo EY, Ong SY, Khoon C, Mark S, Zhang Z, Lu J, et al. Polycaprolactonebased fused deposition modeled mesh for delivery of antibacterial agents to infected wounds. Biomaterials. 2011;32:279-87.

[132] Mader JT, Calhoun J, Cobos J. In vitro evaluation of antibiotic diffusion from antibiotic-impregnated biodegradable beads and polymethylmethacrylate beads. Antimicrobial Agents and Chemotherapy. 1997;41:415-8.

[133] Neut D, Kluin OS, Crielaard BJ, van der Mei HC, Busscher HJ, Grijpma DW. A biodegradable antibiotic delivery system based on poly-(trimethylene carbonate) for the treatment of osteomyelitis. Acta Orthopaedica. 2009;80:514-9. 
[134] Zhang Z, Kuijer R, Bulstra SK, Grijpma DW, Feijen J. The in vivo and in vitro degradation behavior of poly(trimethylene carbonate). Biomaterials. 2006;27:1741-8. [135] Pego AP, Van Luyn MJ, Brouwer LA, van Wachem PB, Poot AA, Grijpma DW, et al. In vivo behavior of poly(1,3-trimethylene carbonate) and copolymers of 1,3trimethylene carbonate with D,L-lactide or epsilon-caprolactone: Degradation and tissue response. J BiomedMaterRes A. 2003;67:1044-54.

[136] Sripriya R, Kumar MS, Sehgal PK. Improved collagen bilayer dressing for the controlled release of drugs. J BiomedMaterRes B ApplBiomater. 2004;70:389-96.

[137] Veyries ML, Couarraze G, Geiger S, Agnely F, Massias L, Kunzli B, et al. Controlled release of vancomycin from Poloxamer 407 gels. International Journal of Pharmaceutics. 1999;192:183-93.

[138] Simões SMN, Veiga F, Torres-Labandeira JJ, Ribeiro ACF, Sandez-Macho MI, Concheiro A, et al. Syringeable Pluronic-a-cyclodextrin supramolecular gels for sustained delivery of vancomycin. European Journal of Pharmaceutics and Biopharmaceutics. 2012;80:103-12.

[139] Woo GL, Mittelman MW, Santerre JP. Synthesis and characterization of a novel biodegradable antimicrobial polymer. Biomaterials. 2000;21:1235-46.

[140] Suzuki Y, Tanihara M, Nishimura Y, Suzuki K, Kakimaru Y, Shimizu Y. A new drug delivery system with controlled release of antibiotic only in the presence of infection. Journal of Biomedical Materials Research. 1998;42:112-6. 
Chapter 2 


\section{Chapter 3}

\section{Hyaluronic acid derivatives and its polyelectrolyte complexes with gentamicin as a delivery system for antibiotics}

Gert-Jan A. ter Boo ${ }^{1,2}$, Robert G. Richards ${ }^{1}$, Thomas F. Moriarty ${ }^{1}$, Dirk W. Grijpma ${ }^{2,3}$ David Eglin ${ }^{1}$

${ }^{1}$ AO research institute Davos, Clavadelerstrasse 8, CH 7270 Davos, Switzerland

${ }^{2}$ Department of Biomaterials Science and Technology, University of Twente, Enschede, P.O. Box 217, 7500 AE Enschede, The Netherlands

${ }^{3}$ Department of Biomedical Engineering, W.J. Kolff Institute, University Medical Center Groningen, University of Groningen, P.O. Box 196, 9700 AD Groningen, The Netherlands

* Polym. Adv. Technol. (2016) 


\section{Abstract}

Repeated administration of gentamicin is often necessary to have efficacious pharmacokinetics both in infection prophylaxis and treatment. In order to increase the half-time of gentamicin sulfate and minimize the dosage, the antibiotic can be grafted to polymers as a prodrug or encapsulated within polymers. Gentamicin is positively charged and can interact with negatively charged macromolecules to form polyelectrolyte complexes (PECs). The complexation of gentamicin with hyaluronic acid (HA) was investigated here. Subsequently, several hyaluronic acid conjugates were prepared and screened for their thermo-responsive behavior and their ability to form PECs with gentamicin. PEC formation with HA poly( $N$-isopropylacrylamide $)$ yields an injectable formulation which precipitates out of solution to form micro- or macroscopic gels, depending on its concentration, at temperatures higher than the lower critical solution temperature (LCST).

\section{Introduction}

High infection rates in fracture fixation, especially in grade III open fractures, demand urgent improvement of infection prophylaxis methods [1]. The most common pathogens, responsible for implant-associated infection are Staphylococcus aureus (S. aureus) and coagulase negative staphylococci (CNS) [2, 3]. Aminoglycosides are broad-spectrum antibiotics which cover S. aureus and CNS among a wide spectrum of Gram-positive and Gram-negative bacteria [4]. Gentamicin is a frequently used aminoglycoside for infection prophylaxis, as well as for treatment of an infection after removal of the implant [5]. However, the short half-life of gentamicin (depending on multiple factors, e.g. age, weight and gender) makes repeated administration necessary [6]. In order to increase the half-life, extend the release time and minimize the needed dose, gentamicin can be i) grafted to polymers to create a prodrug [7-11], ii) encapsulated in polymers [12-14], and iii) complexed by macromolecules of opposite charge [15-17]. For example, Marcus et al. created a prodrug based on gentamicin, by grafting the antibiotic to poly(ethylene glycol) (PEG) with heterobifunctional linkers, degradable by hydrolysis [18]. Gentamicin was then released from the prodrug for up to $66 \pm 3 \mathrm{hrs}$, greatly increasing the half-life of native gentamicin. However, prodrug formation is related with several disadvantages. First 
of all the grafted antibiotic should have preferably mono-functional groups, as otherwise network formation will occur. Furthermore, there should be a cleavable leaving group, which does not render the antibiotic inactive or less effective after degradation [19]. The encapsulation of gentamicin sulfate in microspheres is limited by the high hydrophilicity of the sulfate salt, increasing drug loading yields lower encapsulation efficiencies [20]. Complexation of gentamicin by making use of its highly charged nature, would be another approach to increase the half-life and to extend the release time.

Interestingly, as gentamicin possesses 5 positively charged ionisable amino groups [21] (see scheme 3.1) it can interact with negatively charged polysaccharides to form polyelectrolyte complexes (PECs) [22].<smiles>O=S(=O)(O)O</smiles><smiles>[R]C1CC[C@@H](N)[C@H](O[C@@H]2[C@@H](N)C[C@@H](N)[C@H](OC3OC[C@](C)(O)[C@H](NC)[C@H]3O)[C@H]2O)O1</smiles>

Scheme 3.1: Structure of gentamicin sulfate salt

Hyaluronic acid (HA), composed of repeating dimer units of D-glucoronic acid and D$\mathrm{N}$-acetylglucosamine, is a linear polysaccharide present in the extracellular matrix of many tissues and involved in a wide range of biological processes, including wound healing $[23,24]$. Degradation in vivo occurs through the action of 3 enzymes (hyaluronidase, $\beta$-D-glucuronic acid and $\beta$-N-acetyl-D-hexosaminidase)[25] or through hydroxy radicals produced by phagocytic cells [26, 27]. In physiological conditions, HA is solube and negatively charged because of the presence of 
carboxylate groups. Therefore, HA is able to form PECs with positively charged gentamicin. In this paper we investigate the complexation between gentamicin sulfate and HA. Because of the relative instability of PECs between HA and gentamicin, several HA derivatives with or without temperature dependent hydrophilicity/hydrophobicity changes were prepared, and their complexation with gentamicin was investigated to obtain injectable PECs. Finally, the release of gentamicin from these PECs was investigated in vitro.

\section{Experimental}

\section{Materials}

Sodium hyaluronate (HA) from Streptococcus equi was purchased from Contipro Biotech s.r.o. (Dolni Dobrouc, Czech Republic), $M_{n}=170.6 \mathrm{kDa}$ and $\mathrm{M}_{\mathrm{n}} / \mathrm{M}_{\mathrm{w}}=1.73$. Tetrabutylammonium hydroxide solution (TBAOH); 2,2'-azobis(2-methylproprionitrile) (AIBN); methanesulfonic acid (MSA) were purchased from Fluka (Buchs, Switzerland). $N$-isopropylacrylamide (nIPAm) ( $\geq 99 \%)$; cysteamine hydrochloride (AESH) ( $\geq 98 \%$ (titration)); $N, N$-dimethylformamide (DMF) anhydrous (99,8\%); 1,4dioxane; deuterium oxide $\left(\mathrm{D}_{2} \mathrm{O}\right)$; Dowex M-31 cation exchange resin (Dowex CER); 1,1'-carbonyldiimidazole (CDI); dimethyl sulfoxide (DMSO), diethyl ether, gentamicin sulfate salt (GEN), phosphate buffered saline (PBS), sodium tetraborate decahydrate (STDH) $(99.5 \%-100.5 \%)$, ethanol ( $\geq 99.8$ puriss), sulfuric acid $(95 \%-97 \%)\left(\mathrm{H}_{2} \mathrm{SO}_{4}\right)$, carbazole ( $\geq 95 \%(\mathrm{GC})$ ), hyaluronidase type 1-S from bovine testes (400-1000 units $/ \mathrm{mg}$ ), boric acid ( $\geq 99.5 \%$ ) (Bac), o-phthaldialdehyde ( $\geq 99.0 \%$ (HPLC)) (PTH) and methanol (analytical grade (99.8\%)) were purchased from Sigma-Aldrich (St. Louis, MO, USA). Jeffamines (JFMs), amino-terminated polyether copolymers were a gift from Huntsman (Woodlands, TX, USA). The following JFMs were used: M-600 $(\mathrm{PO} / \mathrm{EO}$ ratio $=9 / 1, \mathrm{MW}=600 \mathrm{~g} / \mathrm{mol}) ; \mathrm{M}-1000(\mathrm{PO} / \mathrm{EO}$ ratio $=3 / 19, \mathrm{MW}=1000$ $\mathrm{g} / \mathrm{mol}) ; \mathrm{M}-2005(\mathrm{PO} / \mathrm{EO}$ ratio $=29 / 6, \mathrm{MW}=2000 \mathrm{~g} / \mathrm{mol}) ; \mathrm{M}-2070(\mathrm{PO} / \mathrm{EO}$ ratio $=$ $10 / 31, \mathrm{MW}=2000 \mathrm{~g} / \mathrm{mol}$ ). Amino-terminated methoxy poly(ethylene glycol) (mPEG$\left.\mathrm{NH}_{2}\right)(\mathrm{MW}=5000 \mathrm{~g} / \mathrm{mol})$ was purchased from Jenkem Technology USA (Plano, TX, USA). Sodium hydroxide ( $\geq 99 \%)(\mathrm{NaOH})$ and 2-mercaptoethanol $(99 \%)$ were purchased from Carl Roth (Karlsruhe, Germany). 


\section{Synthesis of HA derivatives}

Sodium hyaluronate was converted into the tetrabutyl ammonium salt (HATBA) by a cationic exchange process [28]. Briefly, sodium hyaluronate was dissolved at $2.73 \%$ $w / v$ in deionised water. Dowex CER was rinsed and subsequently soaked in dionised water. Thereafter, the water was removed from the Dowex CER and covered with TBAOH solution $(85 \mathrm{~g})$ and mildly stirred for $4 \mathrm{hrs}$. Then the supernatant was removed from the Dowex CER and replaced with fresh $\mathrm{TBAOH}$ solution and the solution was stirred overnight. Then again the supernatant was removed with dionised water until the $\mathrm{pH}$ was below 10. Then the resin was moved to a Gooch crucible with vacuum flask and the water was removed from the resin. After removal of the water, the homogeneous sodium hyaluronate solution was passed through the resin in the Gooch crucible into a Büchner flask in about 2 hrs. Finally, the HATBA solution was freeze dried and dessicated under vacuum at $42{ }^{\circ} \mathrm{C}$ for 3 days.

Amino-terminated poly $\left(\mathrm{N}\right.$-isopropylacrylamide) $\left(\mathrm{pN}^{\left.-\mathrm{NH}_{2}\right)}\right.$ polymers with varying molecular weight $(11-41 \mathrm{~kg} / \mathrm{mol})$ were synthesized by radical polymerization of nIPAm in the presence of AESH and AIBN. Different molecular weights were obtained by varying the amount of the radical initiator (AIBN). After degassing by $\mathrm{N}_{2}$ bubbling, $88.4 \mathrm{mmol}$ of monomer was dissolved in $20 \mathrm{ml}$ of DMF. Then, $0.9 \mathrm{mmol}$ of AESH and $0.09-3.00 \mathrm{mmol}$ of AIBN were added to the nIPAm solutions, and the radical polymerization was performed for $6 \mathrm{hrs}$ at $70^{\circ} \mathrm{C}$ under constant $\mathrm{N}_{2}$ bubbling. Then the system was cooled to room temperature (RT). The $\mathrm{pN}-\mathrm{NH}_{2}$ polymers were purified by repeated dissolution in 1,4-dioxane and precipitation in diethyl ether. Analysis of the obtained molecular weight, and molecular weight distribution were determined by size exclusion chromatography (SEC) on a multi-detector SEC system with an Alliance 2695 separation module from Waters (Milford, MA, USA) with 2 online detectors: a MALS Dawn DSP-F photometer from Wyatt (Santa Barbara, CA, USA) and a 2414 differential refractometer from Waters (Milford, MA, USA) used as a concentration detector. To compensate for their intrinsic temporal delay, the signal of the 2 detectors were aligned. The chromatographic column used was a 2PL gel Mixed C from Polymer Laboratories (Shropshire, UK), using DMF + 0.05M LiCl as mobile phase at a flow rate of $0.8 \mathrm{ml} / \mathrm{min}$ at $50^{\circ} \mathrm{C}$ (Sample injection volume: $218.5 \mu \mathrm{l}$, sample concentration: $4 \mathrm{mg} / \mathrm{ml}-8 \mathrm{mg} / \mathrm{ml}$ ). 
Finally, HA derivatives were prepared by a direct amidation reaction. HATBA was dissolved at $1.25 \% \mathrm{w} / \mathrm{v}$ in dry DMSO. For the preparation of $\mathrm{HApN}$, respective $\mathrm{pN}$ $\mathrm{NH}_{2}$ were dissolved at concentrations ranging from $4.4 \% \mathrm{w} / \mathrm{v}-13.2 \% \mathrm{w} / \mathrm{v}$ in dry DMSO. For the preparation of HAJFMs, respective JFMs were dissolved at $8.00 \%$ $\mathrm{w} / \mathrm{v}$ in dry DMSO. The HATBA solution was then warmed to $42^{\circ} \mathrm{C}$, and $225 \mu \mathrm{l}$ of MSA and $270 \mathrm{mg}$ of $\mathrm{CDI}$ were added. For the preparation of HAmPEG, mPEG-NH $\mathrm{N}_{2}$ was dissolved at $9.00 \% \mathrm{w} / \mathrm{v}$ in dry DMSO and the HATBA solution was warmed to $42^{\circ} \mathrm{C}$, and $225 \mu \mathrm{l}$ of MSA and $122 \mathrm{mg}$ of CDI were added to the solution.

All of the solutions were stirred for $1 \mathrm{hr}$, after which the respective amino-terminated species were added to the reaction vials and the solutions were cooled down to RT and left to react for $48 \mathrm{hrs}$. All of the reactions were then quenched by adding a saturated $\mathrm{NaBr}(\mathrm{aq})$ solution to the reaction, and contents were stirred for $2 \mathrm{hrs}$. The solutions were dialysed in cellulose tubing (Spectrapor, MWCO $=50 \mathrm{kDa}$ ) against demineralized cold water for 5 days to remove unreacted low molecular weight polymers. The final HA derivative solutions were frozen and lyophilized.

\section{Characterization of HA derivatives}

Differential scanning calorimetry (DSC): The temperature induced transition from a more hydrophilic to a more hydrophobic conformation of the HA derivatives was assessed by DSC measurements on a Pyris DSC-1 Perkin-Elmer instrument calibrated with indium. HA derivatives were dissolved at $13 \% \mathrm{w} / \mathrm{w}$ in PBS. $25 \mu \mathrm{l}$ of HA derivative was added to $50 \mu$ aluminium crucibles, which were sealed thereafter. Measurements were performed under a dry nitrogen atmosphere at a flow rate of 20 $\mathrm{ml} / \mathrm{min}$. Each measurement was started with holding the sample at $10{ }^{\circ} \mathrm{C}$ for $5 \mathrm{~min}$. Then the sample was heated from $10^{\circ} \mathrm{C}$ to $40^{\circ} \mathrm{C}$, and the sample was held for $5 \mathrm{~min}$ at $40{ }^{\circ} \mathrm{C}$. Finally, the samples were cooled from $40{ }^{\circ} \mathrm{C}$ to $10{ }^{\circ} \mathrm{C}$. This cycle was repeated 6 times for every sample. Both healing and cooling ramps were performed at a rate of $10^{\circ} \mathrm{C} / \mathrm{min}$.

Rheological measurements: Rheology was performed on an Anton Paar Physica MCR 302 rheometer with a Peltier controller with plate-plate geometry $(25 \mathrm{~mm}$ diameter). HA derivatives were dissolved at $13 \% \mathrm{w} / \mathrm{w}$ in PBS. Measurements were 
verified to be run within the viscoelastic region, by running amplitude and frequency sweeps prior to the temperature sweep. Storage modulus $\left(G^{\prime}\right)$ and viscous modulus $\left(G^{\prime \prime}\right)$ were recorded for these HA derivatives subjected to $0.5 \%$ oscillatory strain at 1 $\mathrm{Hz}$ while heating from $20{ }^{\circ} \mathrm{C}$ to $40{ }^{\circ} \mathrm{C}$, at a rate of $1{ }^{\circ} \mathrm{C} / \mathrm{min}$. The borders of the plates were sealed with low viscosity silicone oil, in order to prevent evaporation of water from the hydrogel at the solution-atmosphere interface.

\section{Complexation of HA and HA derivatives and gentamicin}

ATR FTIR: Analysis of the complexation of HA derivatives and gentamicin was performed by Fourier transform-infrared spectroscopy (FT-IR) on a Bruker Tensor 27 spectrophotometer equipped with a single reflection diamond attenuated total reflection (ATR) accessory. Spectra (single measurements with 64 repeated scans per IR spectrum) were recorded for HA, gentamicin sulfate, a physical mixture of HA and gentamicin sulfate, and complexes formed between HA and gentamicin dissolved in dionized water at a w/w ratio of 3:1. Scanning electron microscopy (SEM): Samples were dried on alumina stubs and sputter-coated with Au/Pd. Complex morphology was then investigated by SEM on a Hitachi S-4700 field emission scanning electron microscope operated in secondary electron (SE) detection mode, at an accelerating voltage of $3.0 \mathrm{kV}-5.0 \mathrm{kV}$, and a working distance of 4.3 to $12 \mathrm{~mm}$. UV-Vis spectroscopy: In order to investigate the amount of gentamicin complexed by HA, gentamicin sulfate and HA solutions in MilliQ grade water were mixed at different molar ratios. Immediately after mixing both solutions, precipitation of the complexed material from the solution was observed. After spinning down the vials, the supernatant was collected and new MilliQ grade water was added to the vials, and the vials were vortexed and the second supernatant was collected. The amount of complexed gentamicin in the supernatant was assessed by an absorbance measurements on a spectrophotometer (Multiskan GO, Thermo Scientific) after derivatization with an o-phthaldialdehyde (OP) reagent at $332 \mathrm{~nm}$ [29]. The amount of HA in the supernatant was assessed by a carbazole absorbance assay at $525 \mathrm{~nm}$ [30]. The amounts of gentamicin or HA present within the complex where calculated from the total amount of gentamicin or HA present in the solution prior to complex formation, from which the amounts of gentamicin or HA present in the collected supernatants had been subtracted. 
Gentamicin release from polyelectrolyte complexes of gentamicin and hyaluronic acid or its derivatives

Complexes of hyaluronic acid and its derivatives, with gentamicin were prepared in the $2 \mathrm{ml}$ top compartment of a Slide-A-Lyzer MINI dialysis device (MWCO $=10 \mathrm{kDa})$ (Thermo Scientific). Hyaluronidase was added at $0.5 \mathrm{mg} / \mathrm{ml}$ to the complexes. The total volume of the test tube + top compartment was $30 \mathrm{ml}$. Phosphate buffered saline (PBS) was used as a physiological release medium. PBS was aliquoted and replaced after $0.5,4,24,48,96$ and $120 \mathrm{hrs}$. The amount of released gentamicin was determined by an absorbance assay after derivatization with o-phthaldialdehyde at $332 \mathrm{~nm}$. 


\section{Results and Discussion}

The amount of gentamicin complexed, or HA bound within a polyelectrolyte complex network was calculated for several molar ratio between HA and gentamicin sulfate (Figure 3.1).

The percentage of complexed gentamicin increased as the molar ratio between gentamicin and hyaluronic acid (GS/HA) was decreased. Simultaneously, the amount of bound HA decreased as the molar ratio between gentamicin and hyaluronic acid was decreased (Figure 3.1). The complexes from HA and gentamicin formed a dense precipitated structure, which imaged by SEM, resembled highly porous networks with macropores (Figure 3.2).
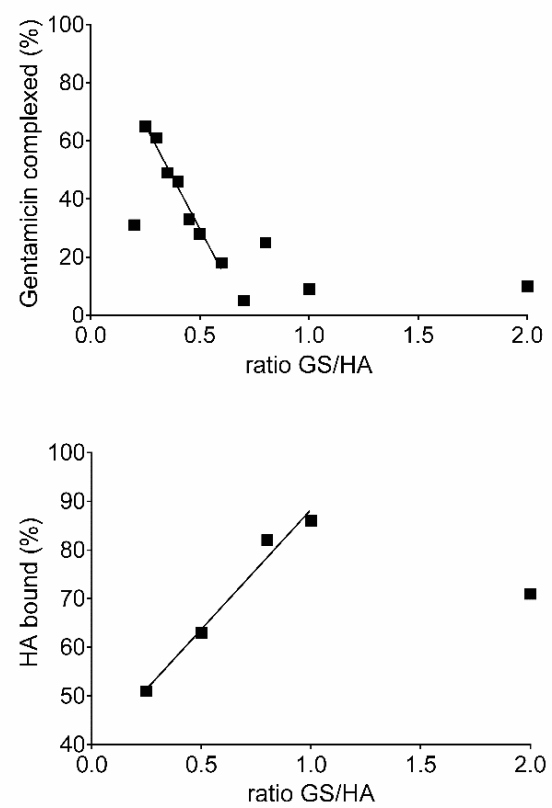

Figure 3.1: The calculated percentage of complexed gentamicin (GS) and bound HA as function of the molar ratio between gentamicin and $H A$. 


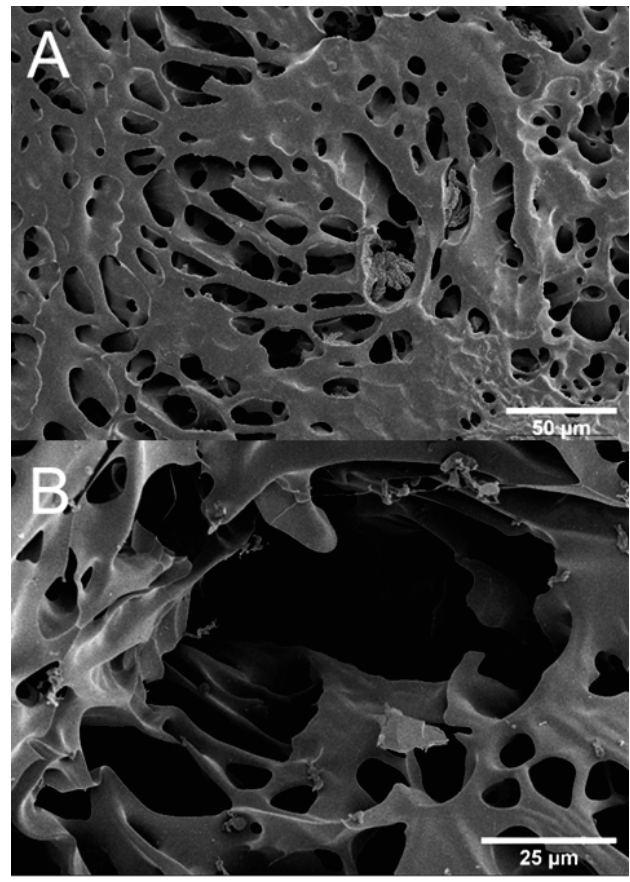

Figure 3.2: Scanning electron microscopy image of sodium hyaluronate $(H A)$ complexed with gentamicin sulfate at $\mathrm{Gen} / H A=0.3$ molar ratio. SEM image $2 B$ is a close up of the network shown in SEM image 2A. Images taken in the secondary electron mode at an accelerating voltage of $3.0 \mathrm{kV}$ and a working distance of $12 \mathrm{~mm}$ in vacuum in the absence of water.

The uniformity of the precipitated structure suggested a microscopically homogeneous complex formation. The precipitate of HA with gentamicin sulfate was then investigated by FTIR (Figure 3.3). 


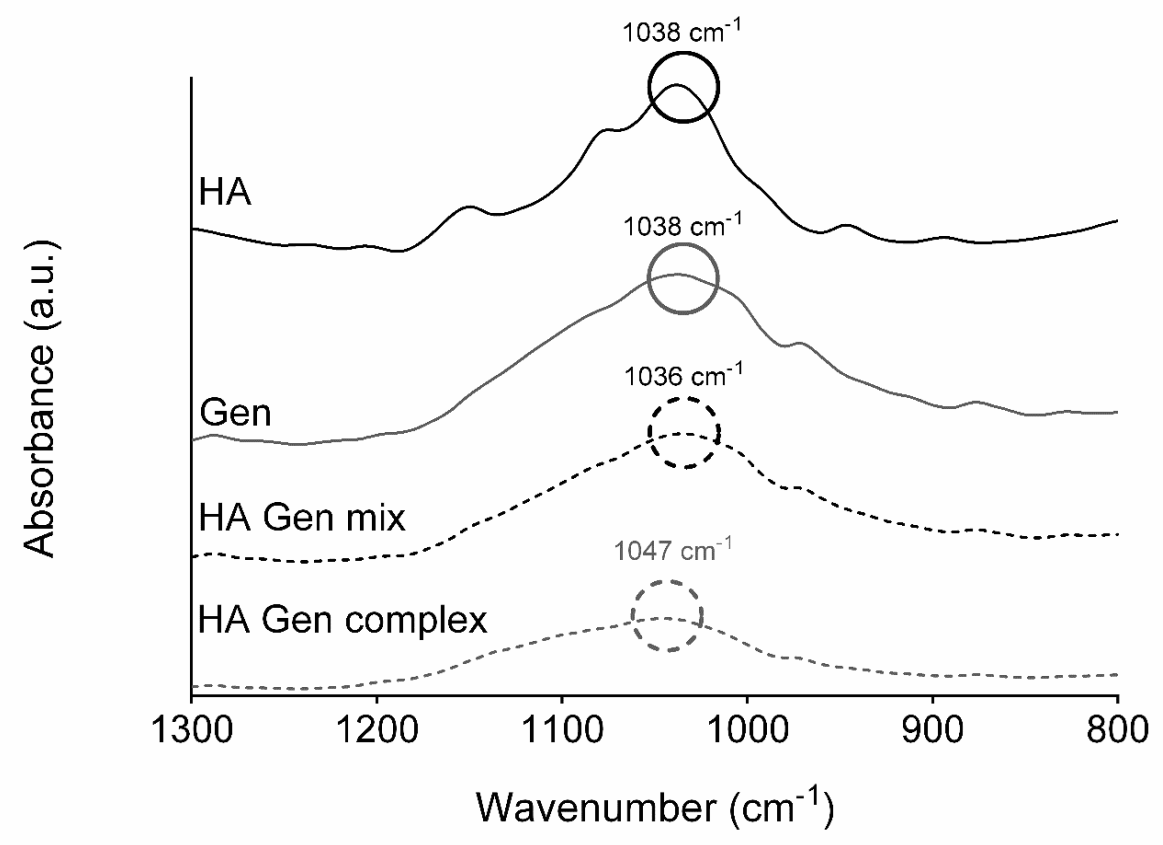

Figure 3.3: IR spectra of HA, gentamicin (Gen), the physical mixture of HA and Gen (mix Gen/HA) by mixing both compounds in the dry state and after drying upon complex formation in solution (Gen/HA).

Upon complexation of $\mathrm{HA}$ and gentamicin, a shift was observed in the $\mathrm{C}-\mathrm{O}$ stretch $\left(\mathrm{v}=1260-1000 \mathrm{~cm}^{-1}\right)$ absorption peak belonging to alcohol groups, both present in HA and gentamicin. The peak for the $\mathrm{C}-\mathrm{O}$ stretch of the alcohol groups of HA shifted to higher wavenumber in the Ge/HA complex in comparison to the original chemicals ant the physical mixture. This was attributed to increases in the energy for stretching the bond in the Gen/HA, suggesting interaction between the negative charged carboxylate groups and the positively charged amine groups and the formation of hydrogen bonds between the hydroxyl and amine groups. 


\section{Synthesis of HA derivatives}

The complexation of $\mathrm{HA}$ and gentamicin yielded an insoluble complex that precipitated from solution (Figure 3.2). Therefore, the ability of derivatives of HA to complex gentamicin into PEC particles that are stable and stay in solution was investigated. In order to form a depot for gentamicin release after injection, several derivatives of HA with and without temperature dependent hydrophilicity and hydrophobicity were investigated. Poly( $N$-isopropylacrylamide $) s$ with different molecular weights, 4 different poly(ether) copolymers with varying hydrophilicity and methoxy poly(ethylene glycol) (mPEG) were grafted to HA. Thermo-responsive poly( $N$-isopropylacrylamide) was prepared by radical polymerization. In order to create a range of molecular weight, the amount of radical initiator (AIBN) was varied. Number average molecular weights $\left(M_{N}\right)$ were obtained in the range of $11-45 \mathrm{kDa}$, as determined by multidetector-SEC (Figure 3.4).

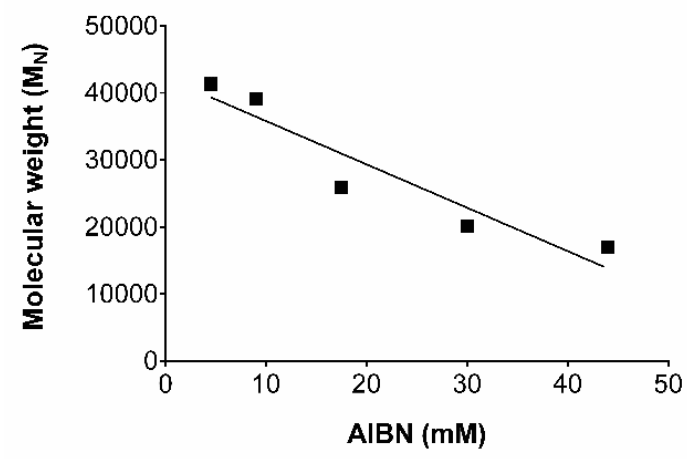

Figure 3.4: Obtained molecular weight of $p N$ as a function of radical initiator in feed $\left(R^{2}=0.89\right)$.

Molecular weight values showed a quasi-linear dependence on radical initiator concentration in the molecular weight range of $17 \mathrm{kDa}-41 \mathrm{kDa}$ (Figure 3.4). The PDI $\left(M_{N} / M_{W}\right)$ does not increase with increasing $M_{N}(P D I=2.71$ for the $17 \mathrm{kDa} p N$ $\mathrm{NH}_{2}$ and $\mathrm{PDI}=2.37$ for the $41 \mathrm{kDa} \mathrm{pN}-\mathrm{NH}_{2}$ ). Subsequently, $\mathrm{HA}$ derivatives were prepared by a direct amidation of the amino-terminated graft polymers to the HA backbone and grafting assessed using NMR (Figure 3.5). 
Hyaluronic acid derivatives and its polyelectrolyte complexes with gentamicin as delivery system for antibiotics

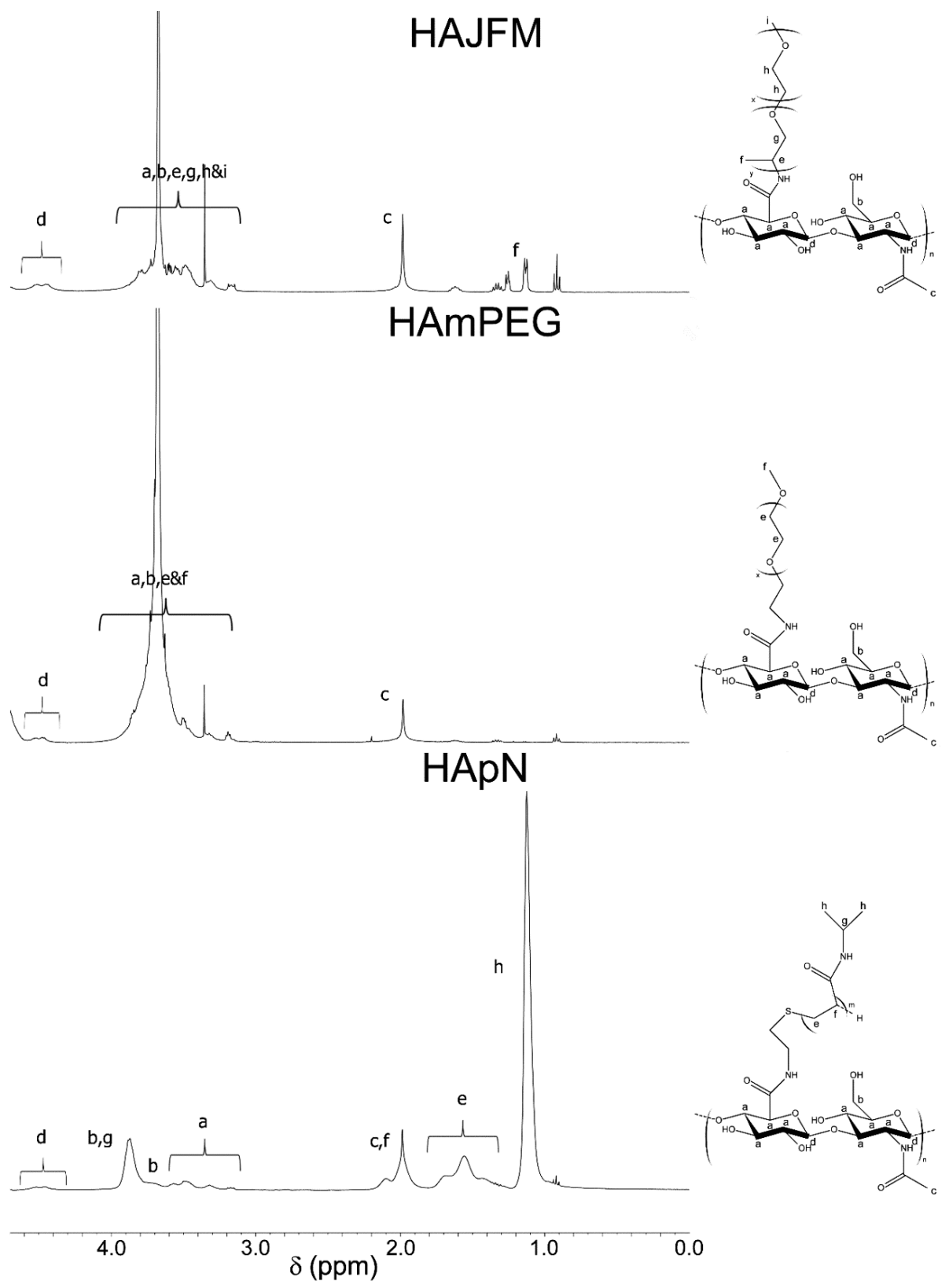

Figure 3.5: HA derivatives prepared by direct amidation of amino-terminated graft polymers (JFM, mPEG-NH $\mathrm{H}_{2}$ and $\mathrm{pN}-\mathrm{NH}_{2}$ ) and their ${ }^{1} \mathrm{H}$ NMR spectrum. 
For each HA derivative synthesis and after dialysis, ${ }^{1} \mathrm{H}$ NMR spectra showed the presence of both signals attributed to $\mathrm{HA}$ and graft polymers and those signals were used to assess the degree of substitution (DOS). The DOS values of the synthesized $\mathrm{HApN}$ calculated from the ${ }^{1} \mathrm{H}$ NMR spectrum are reported in Figure 3.6.
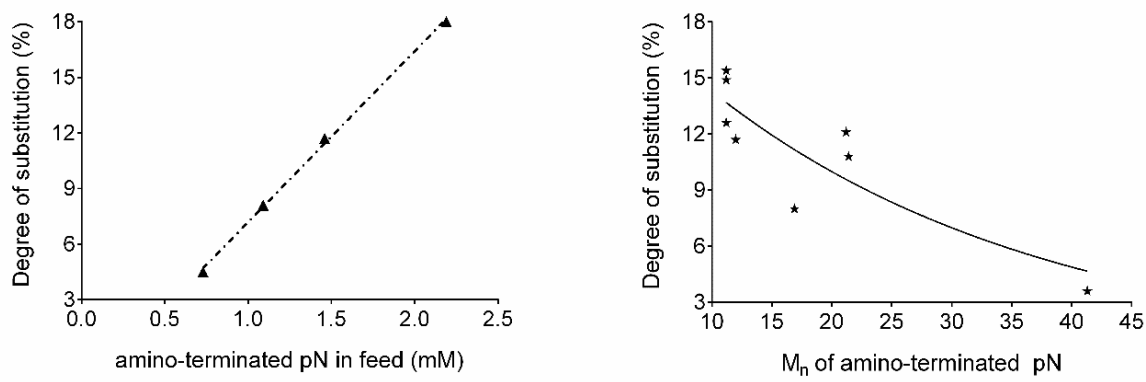

Figure 3.6: Plots of the degree of substitution as a function of $\mathrm{pN}-\mathrm{NH}_{2}$ feed for $\mathrm{pN}-\mathrm{NH}_{2}$ of $\mathrm{M}_{n}$ $=12 \mathrm{kDa}$ (linear fit, $\mathrm{R}^{2}=0.9983$ ) (left) and DOS as a function of the $\mathrm{M}_{n}$ of $\mathrm{pN}-\mathrm{NH}_{2}$ constant feed of $1.75 \mathrm{~g} \mathrm{pN-NH}$ (right).

A high linear correlation between the amount of $\mathrm{pN}-\mathrm{NH}_{2}$ in the feed and the obtained degree of substitution was obtained for a graft polymer of $12 \mathrm{kDa}$ molecular weight within the shown millimolar range. The degree of substitution decreased for a fixed amount of $\mathrm{pN}-\mathrm{NH}_{2}$ in the feed with increasing molecular weight of $\mathrm{pN}-\mathrm{NH}_{2}$.

The DOS for the other HA derivatives are shown in table 3.1.

Table 3.1: The degrees of substitution for the polyether (co)polymer grafts to $H A$.

\begin{tabular}{lccc} 
& $\begin{array}{c}\text { Degree of } \\
\text { substitution }\end{array}$ & $\begin{array}{c}\text { MW graft } \\
(\mathbf{k D a})\end{array}$ & $\begin{array}{c}\text { Ratio } \\
\text { PO/EO }\end{array}$ \\
\hline HAJFM M600 & 30 & 0.6 & 9 \\
HAJFM M1000 & 14 & 1 & 0.2 \\
HAJFM M2005 & 42 & 2 & 4.8 \\
HAJFM M2070 & 30 & 2.1 & 0.3 \\
\hline HAmPEG & 30 & 5 & 0
\end{tabular}


The average degree of substitution values measured by ${ }^{1} \mathrm{H}$ NMR were equal or higher for the HAJFMs and HAmPEG polymers in comparison to HApN. As the molecular weight $\left(\mathrm{M}_{\mathrm{n}}\right)$ of the JFMs and $\mathrm{mPEG}$ were much lower than the $\mathrm{pN}-\mathrm{NH}_{2}$ grafts, steric hindrance could be the main cause of the higher grafting efficiency. No correlation was observed between the JFMs molecular weight and DOS in the HA derivatives. Their hydrophobic/hydrophilic characters at the temperature of the amidation reactions, RT, did not significantly influence the DOS values.

\section{Thermo-responsive behaviour of HA derivatives}

The thermal behavior of HAJFM derivatives in PBS solution was assessed (Figure 3.7).

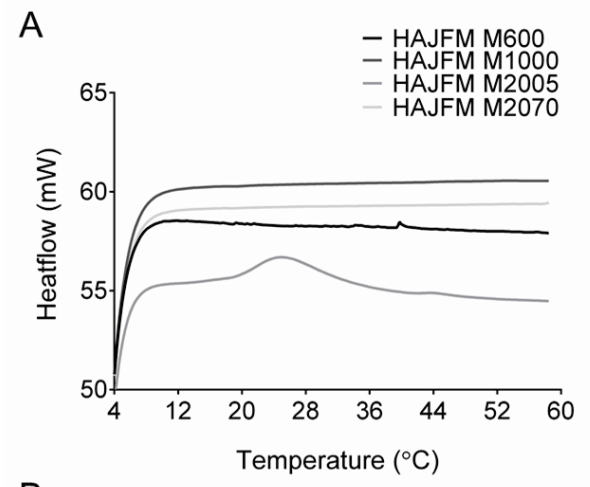

B

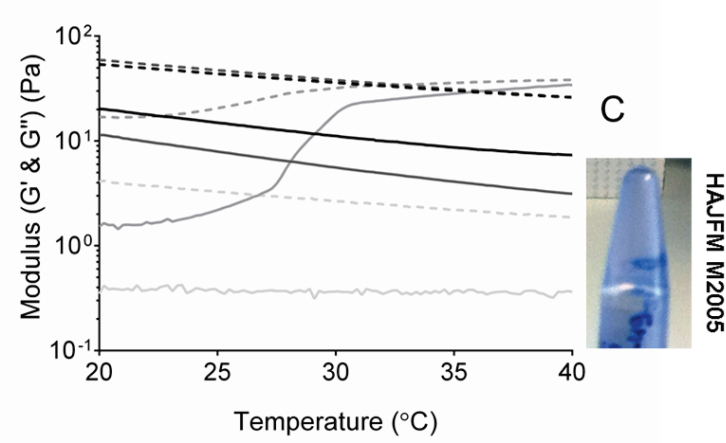

Figure 3.7: Thermo-responsive behavior of HAJFMs. DSC thermogram (A) and rheological temperature sweep (B) for HAJFMs at $13 \% \mathrm{w} / \mathrm{w}$ dissolved in PBS. The vial-inversion test was performed upon heating HAJFM M2005 at $10 \% \mathrm{w} / \mathrm{w}$ to $37^{\circ} \mathrm{C}(\mathrm{C})$. 
Among the 4 different JFM based HA derivatives prepared; only the HAJFM M2005 derivative did not flow upon vial inversion test at $10 \% \mathrm{w} / \mathrm{w}$ in PBS. This was confirmed by DSC measurements which did not reveal any phase transition in 3 of the 4 JFM based derivatives. The HAJFM M2005 derivative was the only derivative which displayed a small and broad endothermal peak at $25{ }^{\circ} \mathrm{C}$ (Figure 3.7). Rheological properties of the HAJFMs during a temperature sweep corresponded well with the calorimetry results and the vial-inversion test. The HAJFM M2005 derivative showed an increase in modulus upon heating to temperatures above $25^{\circ} \mathrm{C}$ suggesting an increase in hydrophobic interactions, while all other HAJFMs showed a slight decrease in moduli with increased temperature suggesting weakening of hydrogen bond interactions between macromolecules in solution (Figure 3.7).

Finally, HAJFM M2005 was the only JFM based derivative that displayed lower critical solution temperature (LCST) behavior, although it was only relatively weak. Most likely, the length of the amphiphilic brushes reduced the gradient of the transition. 
The thermal behavior of HApN derivatives in PBS solution was assessed similarly to the HAJFMs (Figure 3.8).

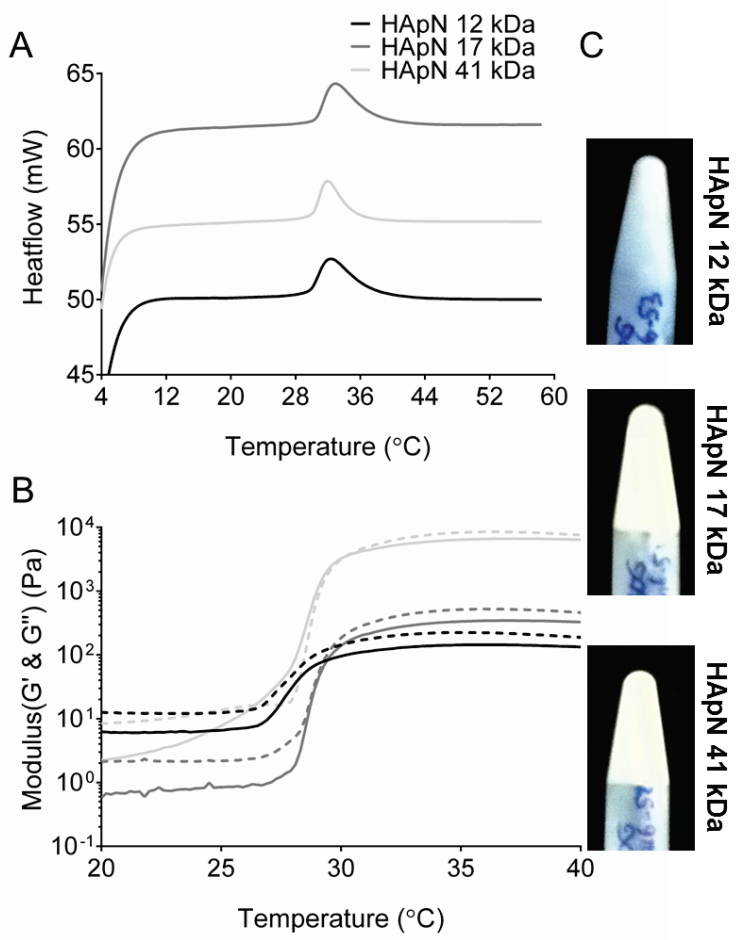

Figure 3.8: Thermo-responsive behavior of HApNs. DSC thermogram (A) and rheological temperature sweep (B) for HApNs at $13 \% \mathrm{w} / \mathrm{w}$ dissolved in PBS. The vial-inversion test was performed upon heating $\mathrm{HApN}$ solutions at $10 \% \mathrm{w} / \mathrm{w}$ to $37^{\circ} \mathrm{C}(\mathrm{C})$.

All HApN derivatives tested presented a LCST behavior which was much more pronounced than for the HAJFMs in the same conditions. In the DSC thermogram of $3 \mathrm{HApNs}$ a peak was observed around $32^{\circ} \mathrm{C}$, corresponding with the endothermic transition from sol to gel phase. Repeated heating and cooling cycles show hysteresis of $\Delta T=5{ }^{\circ} \mathrm{C}$ in the thermogram (not shown) for 6 repeated heating and cooling cycles. Upon heating above the LCST an increase in modulus of several orders was observed for all HApNs independently of the $\mathrm{pN}$ molecular weight. Although HApN $41 \mathrm{kDa}$ had the lowest DOS, upon gelation it had the highest increase in modulus (Figure 3.8). 


\section{Complexation of gentamicin sulfate with HA derivatives}

The ability of HA derivatives to complex gentamicin was assessed, as the complexation of HA with gentamicin sulfate resulted in PEC formation. The molecular weight of the HAJFMs, HApNs and HAmPEG was calculated from the ${ }^{1} \mathrm{H}$ NMR data and the molecular weights of $\mathrm{pN}$ from the multi-detector SEC. Subsequently, an identical 0.3 Gen/ HA derivative molar complex ratio was used for the HA derivatives with gentamicin as for the Gen/HA complexes (Table 3.2) and PEC formation and stability was assessed in comparison to Gen/HA.

All of the HApN polymers formed visible stable complexes with gentamicin, as seen by a slight increase in turbidity of the solutions. No precipitates were observed for at least 1 week in the solutions kept at RT. Increasing the temperature to $37^{\circ} \mathrm{C}$ lead to precipitation of the Gen/HApNs. For the HAJFMs, only 2 out of the 4 derivatives formed similar complexes, the more hydrophilic JFM based HA derivatives formed aggregates upon mixing with gentamicin, as observed by a high turbidity of the solution, followed by precipitation of the complex. The HAmPEG derivative solution stayed clear upon mixing with gentamicin at RT and at $37{ }^{\circ} \mathrm{C}$ (Table 3.2).

Table 3.2: Complex formation between HA derivatives and gentamicin at RT.

\begin{tabular}{lcccc} 
& DOS & $\begin{array}{c}\text { MW graft } \\
(\mathbf{k D a})\end{array}$ & $\begin{array}{c}\text { Ratio } \\
\text { PO/EO }\end{array}$ & Complexation with gentamicin \\
\hline Sodium HA & 0 & NA & NA & Aggregation + precipitation \\
\hline HApN & 12 & 12 & NA & Stable \\
HApN & 8 & 17 & NA & Stable \\
HApN & 4 & 41 & NA & Stable \\
\hline HAJFM M600 & 30 & 0.6 & 9 & Aggregation + Precipitation \\
HAJFM M1000 & 14 & 1 & 0.2 & Stable \\
HAJFM M2005 & 42 & 2 & 4.8 & Aggregation + Precipitation \\
HAJFM M2070 & 30 & 2.1 & 0.3 & Stable \\
\hline HAmPEG & 30 & 5 & NA & Clear solution
\end{tabular}

The dispersed PECs and precipitates were collected and dried in air before imaging by SEM (Figure 3.9). 
Hyaluronic acid derivatives and its polyelectrolyte complexes with gentamicin as delivery system for antibiotics

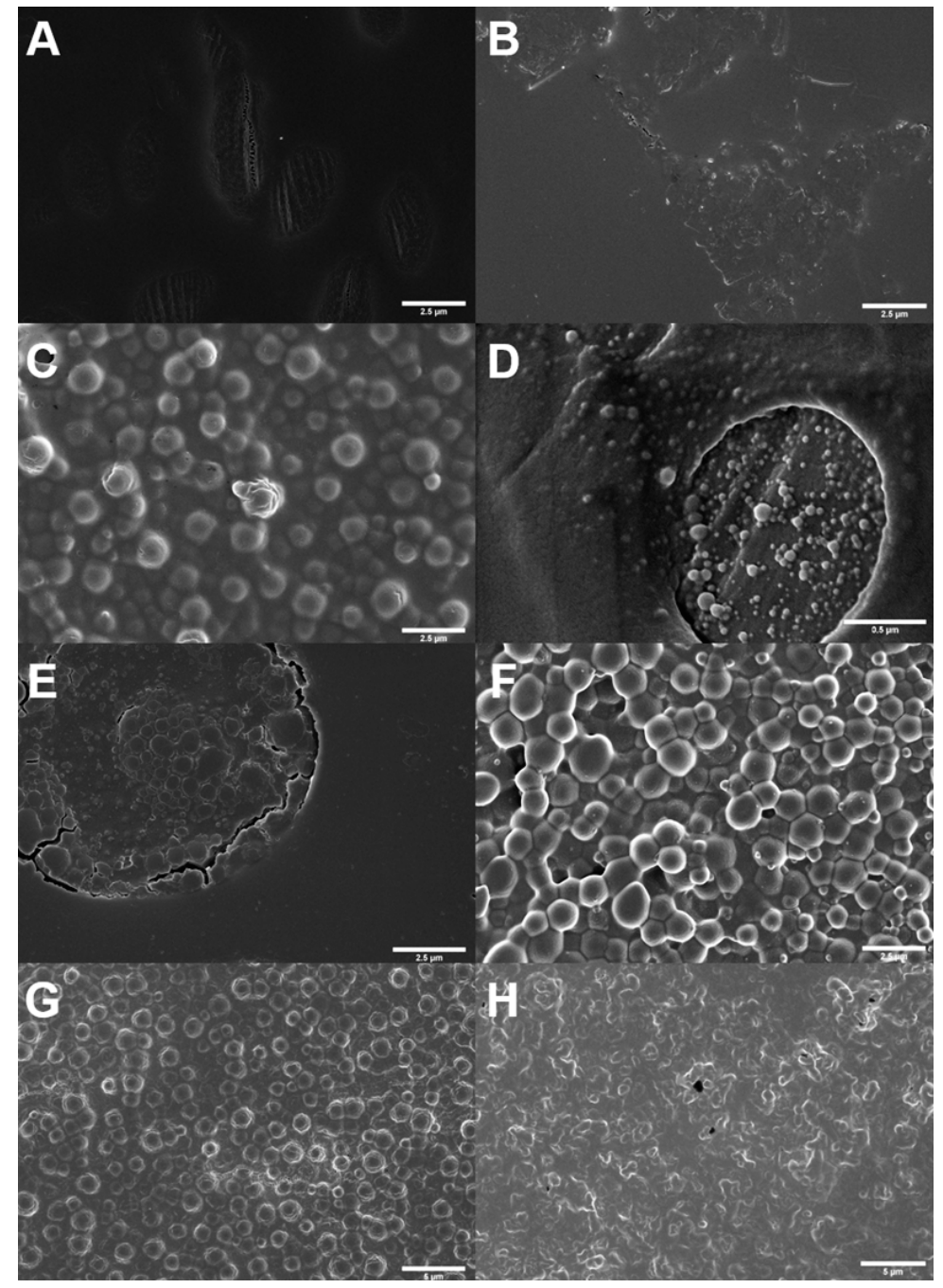

Figure 3.9: Scanning electron microscopy images of $H A p N$ polymer $(12 \mathrm{kDa} p N)(A)$, gentamicin sulfate $(B)$, complex of $H A p N(12 \mathrm{kDa} p N)$ and gentamicin $(C)$, complex of HAJFM M-1000 and gentamicin (D), HAmPEG and gentamicin upon mixing (E), HApN (12 $k D a p N)$ and gentamicin (F) and HApN 12 kDa gentamicin complexes before (G) and after (H) heating from $R T$ to $37^{\circ} \mathrm{C}$. Image taken in the secondary electron mode at an accelerating voltage of $3.0 \mathrm{kV}-5.0 \mathrm{kV}$ and a working distance of $4.3-5.3 \mathrm{~mm}$.

Spherical structures of several microns were observed for Gen/HApN samples at RT, while at $37^{\circ} \mathrm{C}$ an aggregate and less defined structure was imaged. These structures 
were not observed for solutions that only contained HApN or gentamicin (Figure 3.9A and 3.9B). Upon combining the HAJFM M1000 solution with gentamicin, similar sphere like structures were observed, although in smaller quantities (Figure 3.9D). Upon combination of purely hydrophilic HAmPEG and gentamicin, no structures were observed by SEM (Figure 3.9E), most likely because of an absence of hydrophobic regions within the mPEG grafted $\mathrm{HA}$ as opposed to HApN (Figure 3.9F) graft polymers.

\section{Release from poly(electrolyte complexes) of gentamicin and HA derivatives}

As HApN presented the most prominent features for the formation of thermosensitive PECs, the gentamicin release was measured upon formation of Gen/HApN complexes and compared to the release from Gen/HA in the absence or presence of hyaluronidase in PBS at $37^{\circ} \mathrm{C}$ (Figure 3.10).

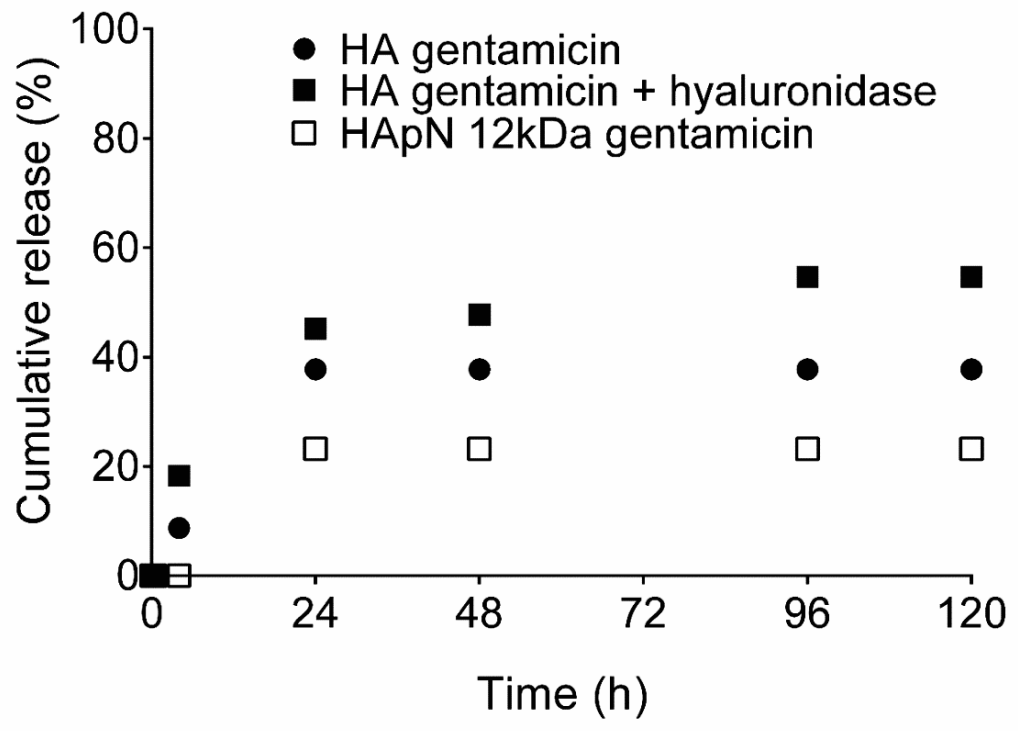

Figure 3.10: Cumulative release of gentamicin from complexes between gentamicin and HA or gentamicin and $\mathrm{HApN}$ over a 1 week course at $37^{\circ} \mathrm{C}$ (hyaluronidase $0.5 \mathrm{mg} / \mathrm{ml}$ ).

Free gentamicin, as control, readily diffused out of the membrane compartment (data not shown). For Gen/HA and Gen/HApN PECs, burst release followed by a plateau at $48 \mathrm{hrs}$ were observed. Degradation of the HA by hyaluronidase caused a faster 
and higher release of gentamicin from the Gen/HA indicating the dependence of gentamicin availability to the degradation of the PEC. The Gen/HApN cumulative release value reached at $48 \mathrm{hrs}$ was lower than the Gen/HA, indicating increased retention of gentamicin in $\mathrm{HApN}$, indicating that the gentamicin/ HA derivative PECs can modulate the availability of the antibiotic.

\section{Conclusions}

Gentamicin and hyaluronic acid form complexes when mixed in solution as a result of opposite ionic charges on both molecules. These complexes have reduced solubility and precipitate out of solution. Several thermo-responsive HA derivatives were synthesized and characterized with respect to thermo-responsive character and complexation with gentamicin. The more hydrophilic HAJFMs precipitated out of solution upon complexation.

HApN polymers were able to form stable complexes that stayed in solution at RT while precipitating at physiological temperature, similar to the more hydrophobic polyether copolymer functionalized HA polymers. HA derivative PECs can modulate the availability of the gentamicin and can potentially increase the half-life and extend the release time of the antibiotic.

\section{Acknowledgements}

This work has been financially supported as part of the AO Clinical Priority Program Bone Infection. 


\section{References}

[1] Trampuz A, Widmer AF. Infections associated with orthopedic implants. Curr Opin Infect Dis. 2006;19:349-56.

[2] Tamilvanan S, Venkateshan N, Ludwig A. The potential of lipid- and polymerbased drug delivery carriers for eradicating biofilm consortia on device-related nosocomial infections. J Control Release. 2008;128:2-22.

[3] Trampuz A, Zimmerli W. Diagnosis and treatment of infections associated with fracture-fixation devices. Injury. 2006;37 Suppl 2:S59-66.

[4] Durante-Mangoni E, Grammatikos A, Utili R, Falagas ME. Do we still need the aminoglycosides? Int J Antimicrob Agents. 2009;33:201-5.

[5] Stengel D, Bauwens K, Sehouli J, Ekkernkamp A, Porzsolt F. Systematic review and meta-analysis of antibiotic therapy for bone and joint infections. Lancet Infect Dis. $2001 ; 1: 175-88$.

[6] Zaske DE, Cipolle RJ, Rotschafer JC, Solem LD, Mosier NR, Strate RG.

Gentamicin pharmacokinetics in 1,640 patients: method for control of serum concentrations. Antimicrob Agents Chemother. 1982;21:407-11.

[7] Bartzatt R, Malesa C. Analysis of an ampicillin propyl ester prodrug which inhibits the growth of Escherichia coli. Biotechnol Appl Biochem. 2002;36:89-93.

[8] Choi SK, Myc A, Silpe JE, Sumit M, Wong PT, McCarthy K, et al. Dendrimerbased multivalent vancomycin nanoplatform for targeting the drug-resistant bacterial surface. ACS Nano. 2013;7:214-28.

[9] Coessens V, Schacht E, Domurado D. Synthesis of polyglutamine and dextran conjugates of streptomycin with an acid-sensitive drug-carrier linkage. Journal of Controlled Release. 1996;38:141-50.

[10] Pereira MP, Shi J, Kelley SO. Peptide Targeting of an Antibiotic Prodrug toward Phagosome-Entrapped Mycobacteria. ACS Infectious Diseases. 2015;1:586-92.

[11] Roseeuw E, Coessens V, Balazuc AM, Lagranderie M, Chavarot P, Pessina A, et al. Synthesis, degradation, and antimicrobial properties of targeted macromolecular prodrugs of norfloxacin. Antimicrob Agents Chemother. 2003;47:3435-41. 
[12] Brin YS, Golenser J, Mizrahi B, Maoz G, Domb AJ, Peddada S, et al. Treatment of osteomyelitis in rats by injection of degradable polymer releasing gentamicin. $J$ Control Release. 2008;131:121-7.

[13] Naraharisetti PK, Lew MD, Fu YC, Lee DJ, Wang CH. Gentamicin-loaded discs and microspheres and their modifications: characterization and in vitro release. $J$ Control Release. 2005;102:345-59.

[14] Virto MR, Elorza B, Torrado S, Elorza Mde L, Frutos G. Improvement of gentamicin poly(D,L-lactic-co-glycolic acid) microspheres for treatment of osteomyelitis induced by orthopedic procedures. Biomaterials. 2007;28:877-85. [15] Chuang HF. Polyelectrolyte multilayers for tunable release of antibiotics and other therapeutics: Massachusetts Institute of Technology; 2008.

[16] Chuang HF, Smith RC, Hammond PT. Polyelectrolyte multilayers for tunable release of antibiotics. Biomacromolecules. 2008;9:1660-8.

[17] Soliman GM, Szychowski J, Hanessian S, Winnik FM. Robust polymeric nanoparticles for the delivery of aminoglycoside antibiotics using carboxymethyldextran-b-poly(ethyleneglycols) lightly grafted with n-dodecyl groups. Soft Matter. 2010;6:4504-14.

[18] Marcus Y, Sasson K, Fridkin M, Shechter Y. Turning low-molecular-weight drugs into prolonged acting prodrugs by reversible pegylation: a study with gentamicin. $J$ Med Chem. 2008;51:4300-5.

[19] Woo GL, Mittelman MW, Santerre JP. Synthesis and characterization of a novel biodegradable antimicrobial polymer. Biomaterials. 2000;21:1235-46.

[20] Prior S, Gamazo C, Irache JM, Merkle HP, Gander B. Gentamicin encapsulation in PLA/PLGA microspheres in view of treating Brucella infections. Int $\mathrm{J}$ Pharm. 2000;196:115-25.

[21] Yoshizawa S, Fourmy D, Puglisi JD. Structural origins of gentamicin antibiotic action. EMBO J. 1998;17:6437-48.

[22] Siyawamwaya M, Choonara YE, Bijukumar D, Kumar P, Du Toit LC, Pillay V. A Review: Overview of Novel Polyelectrolyte Complexes as Prospective Drug Bioavailability Enhancers. International Journal of Polymeric Materials and Polymeric Biomaterials. 2015;64:955-68.

[23] Laurent UB, Fraser JR, Engstrom-Laurent A, Reed RK, Dahl LB, Laurent TC. Catabolism of hyaluronan in the knee joint of the rabbit. Matrix. 1992;12:130-6. 
[24] Stern R, Asari AA, Sugahara KN. Hyaluronan fragments: an information-rich system. Eur J Cell Biol. 2006;85:699-715.

[25] Roden L, Campbell P, Fraser JR, Laurent TC, Pertoft H, Thompson JN. Enzymic pathways of hyaluronan catabolism. Ciba Found Symp. 1989;143:60-76; discussion 86, 281-5.

[26] Girish KS, Kemparaju K. The magic glue hyaluronan and its eraser hyaluronidase: a biological overview. Life Sci. 2007;80:1921-43.

[27] Nobuhiko Y, Teruo O, Yasuhisa S. Inflammation responsive degradation of crosslinked hyaluronic acid gels. Journal of Controlled Release. 1992;22:105-16. [28] Bellini D, Topai A. Amides of hyaluronic acid and derivatives thereof and a process for their preparation. 2000.

[29] Sampath SS, Robinson DH. Comparison of new and existing spectrophotometric methods for the analysis of tobramycin and other aminoglycosides. J Pharm Sci. 1990;79:428-31.

[30] Frazier SB, Roodhouse KA, Hourcade DE, Zhang L. The Quantification of Glycosaminoglycans: A Comparison of HPLC, Carbazole, and Alcian Blue Methods. Open Glycosci. 2008;1:31-9. 


\section{Chapter 4}

\section{Injectable gentamicin-loaded thermo-responsive hyaluronic acid derivative prevents infection in a rabbit model}

Gert-Jan A. ter Boo ${ }^{1,2}$, Daniel Arens ${ }^{1}$, Willem-Jan Metsemakers ${ }^{1,3}$, Stephan Zeiter ${ }^{1}$, Robert G. Richards ${ }^{1}$, Dirk W. Grijpma ${ }^{2,4}$, David Eglin ${ }^{1}$, Thomas F. Moriarty ${ }^{1}$

${ }^{1} \mathrm{AO}$ research institute Davos, Clavadelerstrasse 8, CH 7270 Davos, Switzerland

${ }^{2}$ Department of Biomaterials Science and Technology, University of Twente, Enschede, P.O. Box 217, 7500 AE Enschede, The Netherlands

${ }^{3}$ University Hospitals Leuven, Department of Trauma Surgery, B-3000 Leuven, Belgium

${ }^{4}$ Department of Biomedical Engineering, W.J. Kolff Institute, University Medical Center Groningen, University of Groningen, P.O. Box 196, 9700 AD Groningen, The Netherlands

* Acta Biomaterialia (2016) 185-194 


\section{Abstract}

Despite the use of systemic antibiotic prophylaxis, the surgical fixation of open fractures with osteosynthesis implants is associated with high infection rates. Antibiotic-loaded biomaterials (ALBs) are increasingly used in implant surgeries across medical specialties to deliver high concentrations of antibiotics to the surgical site and reduce the risk of implant-associated infection. ALBs which are either less or not restricted in terms of spatial distribution and which may be applied throughout complex wounds, could offer improved protection against infection in open fracture care.

A thermo-responsive hyaluronic acid derivative (hyaluronic acid- poly $(\mathrm{N}$ isopropylacrylamide) ( $\mathrm{HApN})$ ) was prepared by a direct amidation reaction between the tetrabutyl ammonium (TBA) salt of hyaluronic acid and amine-terminated poly $(\mathrm{N}$ isopropylacrylamide) ( $\mathrm{pN}$ ). The degree of grafting, and gelation properties of this gel were characterized, and the composition was loaded with gentamicin. The rheological- and release properties of this gentamicin-loaded HApN composition were tested in vitro and its efficacy in preventing infection was tested in a rabbit model of osteosynthesis contaminated with Staphylococcus aureus. The gentamicinloaded HApN composition was able to prevent bacterial colonization of the implant site as shown by quantitative bacteriology. This finding was supported by histopathological evaluation of the humeri samples where no bacteria were found in the stained sections.

In conclusion, this gentamicin-loaded HApN hydrogel effectively prevents infection in a complex wound, simulating a contaminated fracture treated with plating osteosynthesis.

\section{Introduction}

Implant-associated infection remains a challenging complication in surgically fixed fractures. On average, $5 \%$ of the patients receiving internal fracture fixation implants develop an infection [1]. In closed fractures, where the protective barrier of the skin is 
intact, the infection rate is between $0.5 \%-2 \%$. However, the infection rate can exceed $30 \%$ in patients with severe open fractures [2]. Contamination of the fracture site prior to or during the surgical intervention can lead to bacterial adhesion and biofilm formation on tissue and implant surfaces [3, 4]. Once developed, the treatment of implant-associated infection is challenging and expensive, and leads to delayed fracture healing and potential loss of limb function $[5,6]$.

In order to reduce infection rates in operative fracture treatment, systemic antibiotic prophylaxis is typically administered pre-operatively and may be continued for a number of days depending upon injury severity. Although appropriate antibiotic prophylaxis reduces infection rates, systemic administration may not be able to provide sufficiently high antibiotic concentrations to locations where distribution is limited by vascular damage or edema $[7,8]$. This may be the case in many fracture sites or contused soft tissues.

Antibiotic-loaded biomaterials (ALBs) offer the prospect of delivering high local concentrations of antibiotics directly to the site of interest, without requiring an intact vasculature. ALBs, such as antibiotic-loaded poly(methylmethacrylate) (PMMA) cement and beads [9, 10], collagen fleece [11] and PDLLA coatings [12-14] with gentamicin have shown their potential in orthopedic and trauma surgery. Nevertheless, currently available ALBs possess certain suboptimal properties. PMMA cement / beads lack degradability often requiring a removal surgery, have poor release kinetics of antibiotics $[10,15,16]$ and their setting can cause heat damage to various antibiotics [10, 17], collagen fleeces have undesirable handling properties, immunogenic potential [18, 19], and coatings of poly(a-hydroxyacid)s form acidic degradation products and have to be approved separately for each type of implant [6]. The complex nature of trauma wounds, i.e. the presence of contamination, inaccessible sites, poorly definable wound margins, and involvement of multiple tissues, demands alternative ALBs that are suited for use in these circumstances. The previously described ALBs have confined dimensions at the time of insertion and may have limited distribution in a complex wound.

Hyaluronan (HA) is a biocompatible and degradable polymer with many biomedical applications, notably as vehicle for drug delivery systems [20]. HA and HA derivative- 
based aqueous formulations can be injectable and subsequently gelate in situ, and are hence good material candidates for delivery of hydrosoluble antibiotics throughout complex wounds [21, 22]. In this study, a direct amidation reaction was performed to graft amine terminated thermo-responsive poly $(N$-isopropylacrylamide $)$ $(\mathrm{pN})$ to HA [23]. The thermo-responsive hyaluronic acid- poly $(\mathrm{N}$-isopropylacrylamide $)$ ( $\mathrm{HApN}$ ) hydrogel was loaded with gentamicin and designed to have a low modulus at room temperature (RT) and easy applicability at the surgical site. Once in contact with tissue and body fluids, the HApN solution shifts from a sol state to a gel state as it heats up to temperatures higher than its lower critical solution temperature (LCST). This property of the hydrogel improves the versatility of its application, since it can be applied at any stage before, during or at completion of the surgery and all potentially contaminated surrounding and overlying tissues, implant surfaces and implant cavities can be covered or filled.

In this preclinical study, a gentamicin-loaded thermo-responsive HApN hydrogel was prepared and characterized in vitro and in vivo. A rabbit humerus model has been established in the past [24], and this model mimics, as close as possible a real trauma case, including an osteotomy and a fracture fixation implant. Additionally, by choosing the humerus the animal's burden can be minimized since rabbits have the opportunity to reduce weight-bearing on the operated limb which is not feasible in their hind limbs. In this study the model was used to assess the efficacy of prophylactic antibiotic delivery.

\section{Experimental}

\section{Materials}

HA sodium salt from Streptococcus equi (HANa) was purchased from Contipro Biotech s.r.o. (Czech Republic), number average molecular weight $\left(M_{n}\right)=170.6 \mathrm{kDa}$ and polydispersity $\left(\mathrm{M}_{\mathrm{w}} / \mathrm{M}_{\mathrm{n}}\right)=1.73$. Tetrabutylammonium hydroxide solution $(\mathrm{TBAOH})$ ( 40\% in $\left.\mathrm{H}_{2} \mathrm{O}, \sim 1.5 \mathrm{M}\right) ; 2$;'-azobis(2-methylpropionitrile) (AIBN) ( $\geq 98.0 \% \mathrm{GC}$ ); methanesulfonic acid (MSA) ( $\geq 99.5 \%)$, methanol (analytical grade $(99.8 \%)$ ), ethanol ( $\geq 99.8 \%$ puriss) and bromophenol blue were purchased from Fluka (Buchs, Switzerland). $N$-isopropylacrylamide (nIPAm) ( $\geq 99 \%) ;$ cysteamine hydrochloride 
(AESH) ( $\geq 98 \%$ (titration)), N,N-dimethylformamide (DMF) anhydrous (99,8\%), 1,4dioxane ( $\geq 99.5 \%$, p.a., ACS); Dowex M-31 cation exchange resin, 1,1'carbonyldiimidazole (CDI) (reagent grade), dimethyl sulfoxide (DMSO) $(\geq 99.5 \%$ for synthesis), sodium carbonate $\left(\mathrm{Na}_{2} \mathrm{CO}_{3}\right)$ (puriss., anhydrous, $99.5 \%-100.5 \%$ calc. on the dried substance), potassium sulfate $\left(\mathrm{K}_{2} \mathrm{SO}_{4}\right)(\geq 99.0 \%)$, gentamicin sulfate salt (GEN) (potency $\geq 590 \mu \mathrm{g}$ gentamicin base per $\mathrm{mg}$ ); boric acid (BAc) ( $\geq 99.5 \%$ ), phthaldialdehyde ( $\geq 99.0$ by high-performance liquid chromatography) and phosphate buffered saline (PBS) were purchased from Sigma-Aldrich (St. Louis, MO, USA). Diethyl ether ( $\geq 99.5 \%$, p.a.), 2-mercaptoethanol (99\%), 2-propanol ( $\geq 99.8 \%)$, glycerol $(\geq 99 \%)$ and sodium bromide $(\mathrm{NaBr})(\geq 99 \%$ p.a., ACS) were purchased from Carl Roth (Karlsruhe, Germany). Blood Agar (BA), Mueller-Hinton broth (MHB), Tryptic Soy Agar (TSA) and Tryptic Soy Broth (TSB) were purchased from Oxoid AG (Basel, Switzerland). Gentamicin sulfate loaded-collagen fleece, Gentafleece $₫$, was purchased from Baxter AG (Volketswil, Switzerland). Blank disks (BBL ${ }^{T M}$ Sensidisc $^{\mathrm{TM}}$ blank disc) and disks with gentamicin (BBL ${ }^{\mathrm{TM}}$ Sensi-disc ${ }^{\mathrm{TM}}$ gentamicin $10 \mu \mathrm{g}$ ) were purchased from BD Diagnostics (Sparks, MD, USA).

\section{Thermo-responsive hyaluronan (HApN) synthesis}

\section{Amino-terminated poly(N-isopropylacrylamide) synthesis}

DMF was degassed by $\mathrm{N}_{2}$ bubbling for 15 mins. Ten grams (88.4 mmol) of nIPAm monomer was then dissolved in $20 \mathrm{ml}$ DMF. $\mathrm{N}_{2}$ bubbling at RT was performed for 2 hrs to remove all oxygen from the solution. Subsequently, $100.2 \mathrm{mg}\left(8.8 \times 10^{-1} \mathrm{mmol}\right)$ AESH and $492.8 \mathrm{mg}(3.0 \mathrm{mmol})$ AIBN were added to the solution. The system was then heated to $70{ }^{\circ} \mathrm{C}$ and the $\mathrm{N}_{2}$ bubbling was continued during the radical polymerization reaction, which proceeded for $6 \mathrm{hrs}$. Then the system was cooled down to RT. Hereafter, the poly( $\mathrm{N}$-isopropylacrylamide) amine $\left(\mathrm{pN}-\mathrm{NH}_{2}\right)$ solution was precipitated in diethyl ether at RT.

After precipitation, the product was redissolved in $35 \mathrm{ml}$ of 1,4-dioxane overnight. Then the $\mathrm{pN}-\mathrm{NH}_{2}$ solution was precipitated again in diethyl ether. The redissolution and precipitation steps were repeated 2-3 times until a fine white precipitate was obtained. The precipitate was collected and dried in a vacuum oven at $32{ }^{\circ} \mathrm{C}$ until all 
residual solvent was removed. The product was characterized by proton nuclear magnetic resonance ( ${ }^{1} \mathrm{H}-\mathrm{NMR}$ ) on a Bruker Avance AV 500 NMR spectrometer using deuterium oxide $\left(\mathrm{D}_{2} \mathrm{O}\right)$ as solvent with 3-(trimethylsilyl)-1-propanesulfonic acid sodium salt (TMS) as a standard to set the zero-shift. The NMR spectra were processed and analysed using Mestrenova ${ }^{\mathrm{TM}}$ software. The molecular weight of the amino-terminated pNs was determined by multi-detector size exclusion chromatography (SEC). The polymers $\mathrm{M}_{\mathrm{n}}$ and polydispersity were determined by a modular multi-detector SEC system with an Alliance 2695 separation module from Waters (Milford, USA) with two on-line detectors: a MALS Dawn DSP-F photometer from Wyatt (Santa Barbara, USA) and a 2414 differential refractometer from Waters (Milford, USA) used as a concentration detector. The different signals from the two detectors were aligned to compensate for their intrinsic temporal delay. Chromatographic column specifications were as follows: Column: 2PL gel Mixed C from Polymer Laboratories (UK); Mobile phase: DMF + 0.05M LiCl; Flow rate: 0.8 $\mathrm{ml} / \mathrm{min}$; Temperature: $50{ }^{\circ} \mathrm{C}$; Injection volume: $218.5 \mu \mathrm{l}$; Sample concentration: 2 $\mathrm{mg} / \mathrm{ml}$.

\section{HApN synthesis}

A cationic exchange process was performed to obtain the tetrabutyl ammonium (TBA) salt of HA (HATBA) from HANa [25]. At RT, $1.0 \mathrm{~g}$ of HATBA was dissolved in $80 \mathrm{ml}$ of dry DMSO under mild stirring. For the synthesis of $\mathrm{HApN}, 2.63 \mathrm{~g}$ of pN-NH was dissolved in $20 \mathrm{ml}$ of DMSO at $25^{\circ} \mathrm{C}$ overnight. HATBA solutions were heated to $42{ }^{\circ} \mathrm{C}$ and $225 \mu \mathrm{l}$ of MSA and $270 \mathrm{mg}$ of CDI were added to the reaction vessel. After $1 \mathrm{hr}$ of stirring at $42^{\circ} \mathrm{C}$ the $\mathrm{pN}-\mathrm{NH}_{2}$ solution was added to the reaction vessel and the constituents were allowed to cool down to $25{ }^{\circ} \mathrm{C}$ and react for $48 \mathrm{hrs}$. A saturated solution of $\mathrm{NaBr}(\mathrm{aq})$ was then added to quench the reaction and the solution was stirred at $25{ }^{\circ} \mathrm{C}$ for $2 \mathrm{hrs}$. At this point, the solution containing the HApN was transferred to cellulose dialysis tubing with a molecular weight cut-off (MWCO) of 50 $\mathrm{kDa}$ (Spectrapor no 6, $34 \mathrm{~mm}$ flat width). The products were dialyzed against demineralized water for 5 days. The HApN solutions were frozen and lyophilized. The samples were finally kept under vacuum for 3 days and sterilized using a cold ethylene oxide cycle and further degassed for 5 days. The degree of substitution of 
the HApN was then determined by ${ }^{1} \mathrm{H}$ NMR [23]. Residual TBA content in the final HApN samples was quantified by a Bromophenol Blue Assay [26].

\section{Rheological behavior of gentamicin-loaded HApN formulations}

The temperature-induced sol-gel transition of the HApN was assessed by the vial inversion method. HApN was dissolved in phosphate buffer saline (PBS; pH 7.4) at $13 \% \mathrm{w} / \mathrm{w}$ in hermetically closed vials. The flowability of the solutions was assessed visually using a vial inversion test at $22 \pm 2{ }^{\circ} \mathrm{C}$ and after 5 minutes incubation at 37 ${ }^{\circ} \mathrm{C}$.

Rheological measurements were performed on an Anton Paar Physica MCR 302 rheometer with a Peltier controller with plate-plate geometry ( $\varnothing 25 \mathrm{~mm}$ ). HApN samples were dissolved at $13 \% \mathrm{w} / \mathrm{w}$ in PBS or in PBS containing $1 \% \mathrm{w} / \mathrm{w}$ gentamicin sulfate. The shear moduli $\left(G^{\prime}\right)$ and loss moduli $\left(G^{\prime \prime}\right)$ were recorded as a function of the temperature for these HApN polymers. Solutions were then subjected to $0.5 \%$ oscillatory strain at $1 \mathrm{~Hz}$ while heating from $20^{\circ} \mathrm{C}$ to $40{ }^{\circ} \mathrm{C}$ at a rate of $1{ }^{\circ} \mathrm{C} / \mathrm{min}$. In order to avoid evaporation of water from the hydrogel composition at the solutionatmosphere interface, low viscosity silicone oil was applied along the border of the plates after sample placement. Measurements were assured to be run within the viscoelastic linear region.

The effect of the sulfate salt of gentamicin on the LCST of HApN was investigated for HApN (derived from high MW HANa; $M_{n}=952.5 \mathrm{kDa}, M_{w} / M_{n}=1.65$ ) solutions with increasing concentrations of sulfate from gentamicin sulfate dissolved in PBS $(0,26$, 52 and $104 \mathrm{mM}$ sulfate). In order to verify that the shift could be attributed to the sulfate salt in the gentamicin sulfate molecule, HApN solutions dissolved in PBS with increasing concentrations of potassium sulfate $\left(\mathrm{K}_{2} \mathrm{SO}_{4}\right)$ were also screened. In order to make a valid comparison, the amount of $\mathrm{K}_{2} \mathrm{SO}_{4}$ that needed to be dissolved to obtain a stoichiometric equivalent of sulfate ions in the final solution was calculated as compared to the HApN solutions with gentamicin sulfate. Shear moduli and viscous moduli were again recorded as a function of the temperature, as described above. 


\section{Gentamicin release in vitro}

Release of gentamicin from the $\mathrm{HApN}$ hydrogel was assessed in vitro. For the preparation of the gentamicin-loaded $\mathrm{HApN}$, either a $1 \% \mathrm{w} / \mathrm{w}$ or a $2 \% \mathrm{w} / \mathrm{w}$ gentamicin solution in PBS was used to dissolve $\mathrm{HApN}$ at $13 \% \mathrm{w} / \mathrm{w}$. To keep the total gentamicin payload equal (8 $\mathrm{mg}$ gentamicin sulfate in total), $800 \mu \mathrm{l}$ of the $1 \% \mathrm{w} / \mathrm{w}$ gentamicinloaded HApN or $400 \mu$ l of the $2 \%$ w/w gentamicin-loaded HApN were injected into 8 $\mathrm{ml}$ of pre-warmed PBS $\left(37^{\circ} \mathrm{C}\right)$ to form single hydrogel spheres. Vials were then incubated at $37^{\circ} \mathrm{C}$ in an incubator, while shaking at 20 rotations/min on a shaker plate (New Brunswick Scientific co. Inc. Classic C1, Edison, New Jersey, US). Supernatants $(1 \mathrm{ml})$ were collected after $1 \mathrm{hr}, 3 \mathrm{hrs}, 6 \mathrm{hrs}, 1$ day, 2 days, 4 days and 7 days, and $1 \mathrm{ml}$ of fresh PBS was added to the vials. Each condition was performed in triplicate. The amount of gentamicin released was quantified by a modified absorbance assay measured at $\lambda=332 \mathrm{~nm}$ on a spectrophotometer (Multiskan GO, Thermo Scientific) as reported by Sampath and Robinson, after derivatization with ophthaldialdehyde (OPDA) reagent [27]. The detection limit was calculated to be 94 $\mu \mathrm{g} / \mathrm{ml}$ for this assay [28].

Gentamicin-loaded collagen fleece $(4 \mathrm{~cm} \times 1 \mathrm{~cm} \times 0.5 \mathrm{~cm})$, containing $8 \mathrm{mg}$ gentamicin sulfate, was used as a clinically available comparator in the in vitro release study. The release was expressed as cumulative percentage (\%) of the total payload, the removal of $1 \mathrm{ml}$ of supernatant and dilution with $1 \mathrm{ml}$ of fresh PBS was accounted for in the calculation. 


\section{In vivo assessment of a gentamicin-loaded HApN formulation in a contaminated plated fracture model in rabbits}

\section{Study design}

An overview is provided with a description of the 3 study groups in Table 4.1. Bacteriological evaluations were performed on 8 animals of each group, and the remaining 2 animals per group were used for histological evaluation.

Table 4.1: in vivo study plan

\begin{tabular}{ccc}
\hline Group name & ALB & Gentamicin sulfate* \\
\hline 1. Untreated control & - & - \\
2. Collagen Gen & Collagen fleece & + \\
3. HApN Gen & HApN \\
\hline
\end{tabular}

*Amount of gentamicin sulfate in ALB is $8 \mathrm{mg}, \mathrm{n}=10$ per study group

\section{Institutional animal care and use committee approvals}

The in vivo study was approved by the Ethical Committee of the Canton of Grisons, Switzerland (TVB number 28/2014). All procedures were performed in an AAALAC (Association for Assessment and Accreditation of Laboratory Animal Care) International approved facility and according to Swiss animal protection law and regulations. Thirty skeletally mature, specific pathogen free (SPF) female New Zealand white rabbits (Charles River, Suzfeld, Germany) older than 24 weeks of age and a mean body weight of $3.6 \mathrm{~kg} \pm 0.2 \mathrm{~kg}$ were included in this study. All rabbits were assessed by a veterinarian and determined to be healthy prior to inclusion in this study and were allowed to acclimatize to their surroundings for two weeks prior to the start of the study. During the acclimatization period, they were group-housed with a 12 hrs dark/ 12 hrs light cycle, fed with hay, lettuce and supplemental feed for 
rabbits (Biomill, Switzerland). After the surgical intervention, the animals were singlehoused until euthanasia.

For the first five postoperative days, each animal was checked using a score sheet at least twice daily by a veterinarian or an experienced animal caretaker, thereafter the rabbits were checked at least once a day for the rest of the study duration.

\section{Bacteria}

A gentamicin sensitive Staphylococcus aureus strain (JAR 060131), isolated from a male patient with a knee prosthesis infection was used in the present study [29]. Bacteria were stored in MHB supplemented with $20 \%$ of glycerol for long-term preservation at $-20^{\circ} \mathrm{C}$.

Bacterial inocula were prepared in PBS as previously described [30], with a target inoculum of $2.0 \times 10^{6}$ colony-forming units (CFU) of S. aureus. Quantitative culture of each inoculum was performed immediately after preparation to assure the accuracy of the used inocula.

\section{Antibiotic-loaded biomaterials}

Gentamicin sulfate loaded collagen fleece was cut into $4 \mathrm{~cm} \times 1 \mathrm{~cm}$ pieces using a sterile custom-made steel template. These dimensions were selected in order to allow the fleece to completely overlay the implants used in the in vivo study. All the sterile HApN samples were reconstituted at $13 \% \mathrm{w} / \mathrm{w}$ overnight in $1 \% \mathrm{w} / \mathrm{w}$ gentamicin sulfate in sterile PBS at $4^{\circ} \mathrm{C}, 1$ day prior to surgery. The HApN hydrogel samples with gentamicin were chilled on ice prior to administration. During the surgery, $800 \mu \mathrm{l}$ of the gentamicin-loaded HApN hydrogel was injected over the implant. In order to speed up the gelation process, an infrared lamp was used to pre-heat the surgical site. This lamp was removed prior to injection of the hydrogel. The total payload was $8 \mathrm{mg}$ gentamicin sulfate in both the hydrogel and the fleece groups. 


\section{Operative procedure}

The surgical anesthesia, plating procedure and pre-operative and post-operative analgesia regimens have been described previously elsewhere [24].

Inoculation of the rabbits was performed after creation of the osteotomy with a 0.45 $\mathrm{mm}$ Gigly saw, as three separate $34 \mu \mathrm{l}$ injections into the central screw hole overlying the osteotomy and onto the adjacent proximal and distal screw holes. Subsequently, the wounds were closed without any local antibiotic prophylaxis (group 1), or after gentamicin-loaded collagen fleece was placed (group 2) or HApN hydrogel with gentamicin (group 3) was injected over the 7-hole locking plate (Figure 4.1).

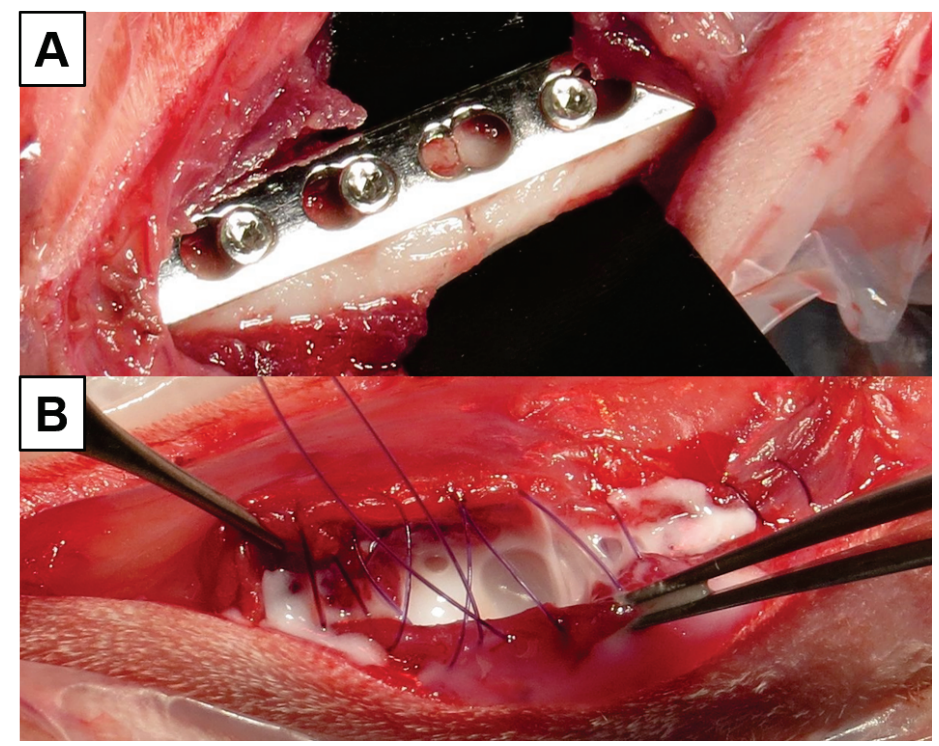

Figure 4.1: Intra-operative image before $(A)$ and after application of the gentamicin-loaded $H A p N$ hydrogel (B) within the surgical field. The HApN hydrogel (white color) fills the surgical field and turns from a sol to a gel state upon contact with the tissue. 


\section{Evaluation of the in vivo study}

Post-operative care and radiological analyses

Weight was measured at surgery, and 3 and 7 days postoperatively. Radiographs of the operated limb were taken in two planes (lateromedial and caudocranial) after surgery and postmortem to assess proper implant positioning. Animal exclusion criteria were set at a weight loss exceeding $15 \%$ of the initial body weight, local infection with severe lameness, persistent swelling and discharge, or signs of systemic infection such as fever, depression and anorexia. One of the rabbits of study group 2, which received the gentamicin-loaded collagen fleece, died during anesthesia due to cardiac arrest and was excluded from the study. The rabbit was intended to be used for histology and was not replaced. Upon completion of the observation period (7 days), all animals were euthanized using intravenously administered Pentobarbital (200 mg/kg, Esconarkon ${ }^{\circledR}$, Streuli Pharma AG, Switzerland).

\section{Blood analyses}

Blood samples were drawn from all included rabbits pre-operatively, 3 and 6 hrs, 1 day post-operatively and then every day until the end of the study. White blood cell (WBC) count was measured at each time point (Vet ABC, Scil animal care, Germany). C-reactive protein (Rabbit CRP Elisa Kit, ICL Inc. Portland, OR, USA) and gentamicin concentrations were measured in serum samples at the same time points. Serum gentamicin levels were quantified by a fluorescence polarization immunoassay (FPIA, lower limit of detection, $0.5 \mu \mathrm{g} / \mathrm{ml}$ ) on a Cobas Integra ${ }^{\circledR} 400$ plus analyzer (Roche Diagnostics AG, Switzerland) using reagents from Roche Diagnostics. Test solutions and calibration standards were diluted with human plasma. 


\section{Bacteriology}

The soft tissue covering the locking plate and any abscess material were removed using a scalpel, weighed, and then placed into a sterile receptacle containing $10 \mathrm{ml}$ of PBS. The soft tissue samples were then homogenized using an Omni-TH handheld homogenizer (LabForce AG, Switzerland) with sterile Omni-tip plastic probes. All hardware (plates and screws) were transferred to sterile glass test tubes containing $10 \mathrm{ml}$ of PBS. Plates and screws were sonicated (Bandelin Ultrasonic waterbath RK $510 \mathrm{H}$, Bandelin, Germany) for $3 \mathrm{~min}$, thereafter they were vortexed for $10 \mathrm{sec}$. Humerus bone samples were crushed into small fragments with a sterile luer and immediately homogenized in $40 \mathrm{ml}$ of PBS using a Polytron PT3100 homogenizer (Kinematica AG, Switzerland).

All tissue and implant samples were serially diluted (10-fold steps) and plated on BA plates. Agar plates were incubated at $37^{\circ} \mathrm{C}$ and colonies were counted after $24 \mathrm{hrs}$ and $48 \mathrm{hrs}$. The limit of detection of $S$. aureus colonies was $5 \times 10^{1} \mathrm{CFU}$ for soft tissue and hardware samples and $2 \times 10^{2} \mathrm{CFU}$ for bone samples. All S. aureus bacterial growth was tested by a latex agglutination test (Staphaurex ${ }^{\mathrm{TM}}$ Plus Latex Agglutination Test, Remel, UK). In case of a negative test result (i.e. infection with organism other than $S$. aureus), isolates were identified using a Vitek2 machine (bioMérieux Vitek Inc., Hazelwood, MO, USA). The susceptibility of the S. aureus strain used for inoculation and the susceptibility of other isolated organisms to gentamicin were assessed by the disk diffusion method. For $S$. aureus the disk

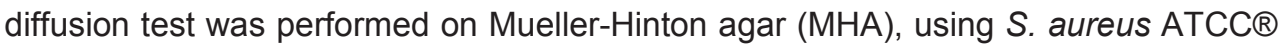
25923 as quality control strain. All zone of inhibition (ZOI) tests were performed in triplicate for each bacterial species. Bacterial suspensions were adjusted to a 0.5 McFarland standard before use. Susceptibility to gentamicin was tested by using discs with $10 \mu \mathrm{g}$ gentamicin. The bacterial strain was determined to be susceptible, intermediate or resistant according to the clinical and laboratory standards institute (CLSI) guidelines M100-S25 (2015) [31]. 


\section{Histology}

Rabbit humeri, including implant and adjacent soft tissue, were fixed in $70 \%(\mathrm{v} / \mathrm{v})$ methanol for a minimum of 2 weeks with fresh methanol changes weekly. Contact radiographs (full thickness) were taken using high resolution technical film (D4 Structurix DW ETE, Agfa, Belgium) and a cabinet X-ray system (Model No. 4385A, Faxitron X-ray Corporation, AZ, USA). After fixation, samples were dehydrated by an ascending series of ethanol and were transferred to xylene. Finally, they were infiltrated and embedded in methylmethacrylate (MMA). The polymerized MMA blocks were trimmed using a butcher saw (Bizerba FK 22, Bizerba AG, Switzerland) prior to cutting with an annular diamond saw (Leitz 1600 saw microtome, Leica AG, Switzerland). The samples were glued with cyanoacrylate onto Beracryl holders for sectioning. Contact radiographs of the sections were taken as described previously. Two sections of each sample were selected, which were glued onto opaque Plexiglass ${ }^{\circledR}$ slides, ground and fine polished. Sections were stained with GiemsaEosin and histopathological analysis of the slides was performed using a transmission light microscope (BX40, Olympus, Switzerland). Histological findings were described, wherever possible, according to distribution (focal, multifocal, diffuse), morphological character and to severity by a veterinary pathologist. 


\section{Results}

Preparation and characterization of gentamicin-loaded HApN formulations

The $\mathrm{M}_{\mathrm{n}}$ of the $\mathrm{pN}-\mathrm{NH}_{2}$ was determined to be $11.2 \mathrm{kDa}$ with a polydispersity index of 3.85 , and a recovered mass of $95.2 \%$. The average degree of substitution of $\mathrm{pN}$ for the carboxylate group on hyaluronic acid was $15 \%$ as verified by integration of the HA proton NMR signals between $\delta=3.00 \mathrm{ppm}$ and $3.77 \mathrm{ppm}$ (equivalent to $9 \mathrm{HA}$ protons) and integration of the $\mathrm{pN}$ signal at $\delta=1.14 \mathrm{ppm}$ (6 protons, $-\mathrm{CH}_{3}$ ) [23]. Residual TBA content in the HApN polymer was low and quantified to be $0.1 \%$.

A vial inversion test of the HApN composition in PBS showed that at concentrations above $9 \% \mathrm{w} / \mathrm{w}$ the composition flowed easily at RT, upon heating to $37{ }^{\circ} \mathrm{C}$ the composition did not flow anymore. A $13 \% \mathrm{w} / \mathrm{w}$ concentration was selected as it has the required temperature dependent gelation for this study. Rheology was performed on the $13 \% \mathrm{w} / \mathrm{w} \mathrm{HApN}$, dissolved in PBS alone or in PBS with $1 \% \mathrm{w} / \mathrm{w}$ gentamicin sulfate (Figure 4.2A).

The 13\% w/w HApN composition in PBS (Figure 4.2A, black circles) was found to be a flowing sol at RT, with moderate shear and viscous moduli below $1 \mathrm{~Pa}$. Upon heating above the lower critical solution temperature where the shear modulus $G^{\prime}$ over take the viscous modulus G", the shear moduli of all the HApN compositions (with and without gentamicin) increased more than 3 orders of magnitude up to 10 $\mathrm{kPa}$ at $37^{\circ} \mathrm{C}$. The onset of gelation for the $\mathrm{HApN}$ without gentamicin added, was approximately $28{ }^{\circ} \mathrm{C}$. Upon addition of $1 \% \mathrm{w} / \mathrm{w}$ gentamicin sulfate the LCST decreases to $25^{\circ} \mathrm{C}$.

As can be seen from Figures 4.2B and 4.2C, the shift in LCST is proportional to the gentamicin sulfate concentration in the PBS, with the largest shift observed for the highest concentration. The same effect is observed when HApN is dissolved in $\mathrm{K}_{2} \mathrm{SO}_{4}$ at stoichiometric equal concentrations. However, the effect is stronger for $\mathrm{K}_{2} \mathrm{SO}_{4}$ than for gentamicin sulfate. 


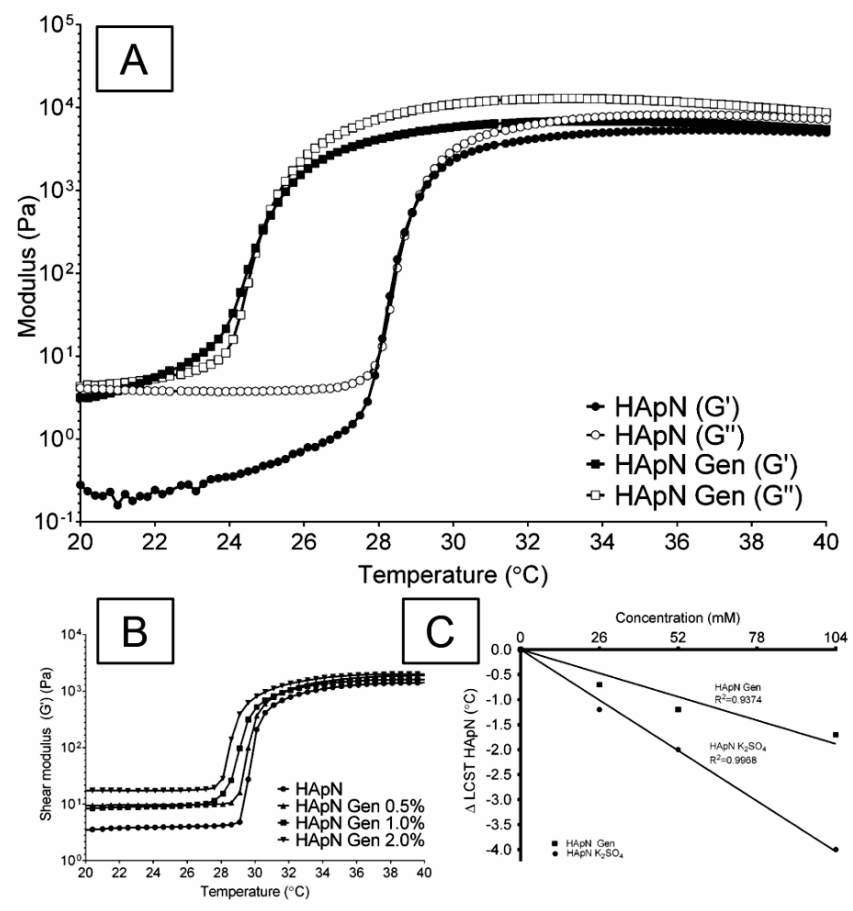

Figure 4.2: Viscoelastic shear moduli of $13 \%$ w/w HApN solution in PBS, without or with addition of $1 \% \mathrm{w} / \mathrm{w}$ of gentamicin sulfate $(A)$. Shear moduli of a $13 \% \mathrm{w} / \mathrm{w}$ HApN solution in $P B S$ with increasing gentamicin sulfate content $(B)$. Concentration dependent LCST shift $(\triangle T)$ for $H A p N(13 \% w / w)$ solutions in PBS with increasing sulfate content from gentamicin sulfate (0 - $104 \mathrm{mM}$ sulfate) or increasing stoichiometric equal concentration of sulfate ions from potassium sulfate $\left(\mathrm{K}_{2} \mathrm{SO}_{4}\right)(\mathrm{C})$.

In vitro gentamicin release

The cumulative release of gentamicin sulfate from collagen fleece and HApN hydrogels with $1 \%$ and $2 \% \mathrm{w} / \mathrm{w}$ gentamicin over a 1 week period were measured in vitro at $37^{\circ} \mathrm{C}$ (Figure 4.3).

An initial burst release of gentamicin was observed for all the tested ALBs (Figure 4.3). After $1 \mathrm{hr}, 67 \%$ of the gentamicin incorporated in the collagen fleece was released, whereas for the $\mathrm{HApN}$ hydrogel with $1 \% \mathrm{w} / \mathrm{w}$ gentamicin and $2 \% \mathrm{w} / \mathrm{w}, 47 \%$ 
and $62 \%$ of the total gentamicin payload was released, respectively. After $24 \mathrm{hrs}$, $88 \%$ of the total amount of gentamicin was released from the collagen fleece, and $86 \%$ and $96 \%$ respectively for the $1 \% \mathrm{w} / \mathrm{w}$ and $2 \% \mathrm{w} / \mathrm{w}$ gentamicin containing HApN hydrogels. After 7 days incubation in PBS, all ALBs had released their entire gentamicin payload. The HApN hydrogel $(800 \mu \mathrm{l})$ with $1 \% \mathrm{w} / \mathrm{w}$ gentamicin sulfate was chosen for the in vivo study as it matches more closely the volume of the applied collagen fleece in the in vivo study $\left(2 \mathrm{~cm}^{3}\right)$ and because of its slightly slower initial release of gentamicin as compared to the $2 \% \mathrm{w} / \mathrm{w}$ gentamicin sulfate containing HApN hydrogel.

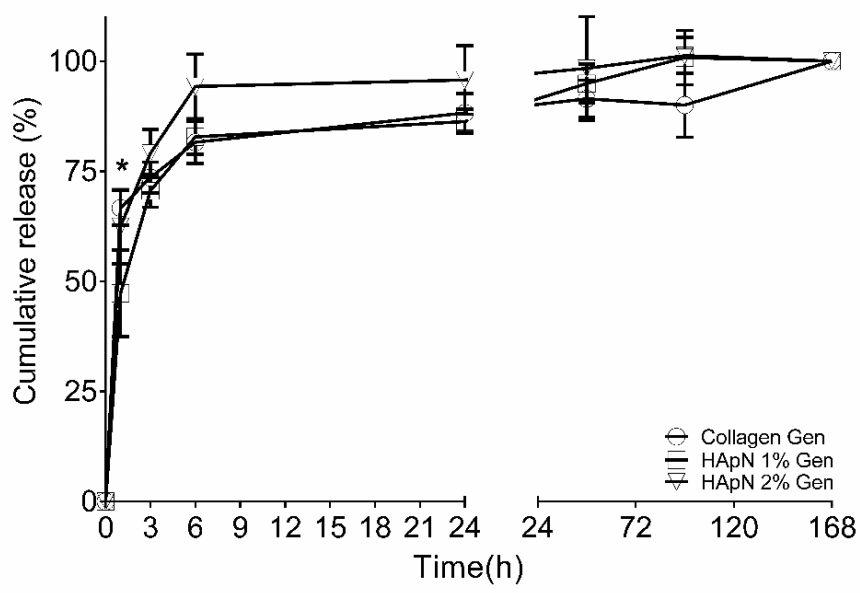

Figure 4.3: Gentamicin cumulative release profile of collagen-gentamicin fleece and $H A p N$ hydrogels loaded with $1 \% \mathrm{w} / \mathrm{w}$ and $2 \% \mathrm{w} / \mathrm{w}$ gentamicin incubated at $37^{\circ} \mathrm{C}$ for 1 week in $\mathrm{PBS}$. $n=3$, error bars represent standard deviation. 


\section{In vivo observations}

Between the rabbits from the 3 study groups no difference in weight development was observed over the course of the observation period. Rabbit weights were $3.4 \mathrm{~kg}$ $( \pm 0.2 \mathrm{~kg})$ (untreated control group rabbits), $3.5 \mathrm{~kg}( \pm 0.2 \mathrm{~kg})$ (gentamicin loaded collagen fleece treated rabbits) and $3.4 \mathrm{~kg}( \pm 0.3 \mathrm{~kg})$ (gentamicin loaded HApN hydrogel treated rabbits) after 1 wk, respectively.

C-reactive protein \& white blood cell count

After surgery the C-reactive protein (CRP) levels in plasma were elevated in all 3 study groups (Figure 4.4).
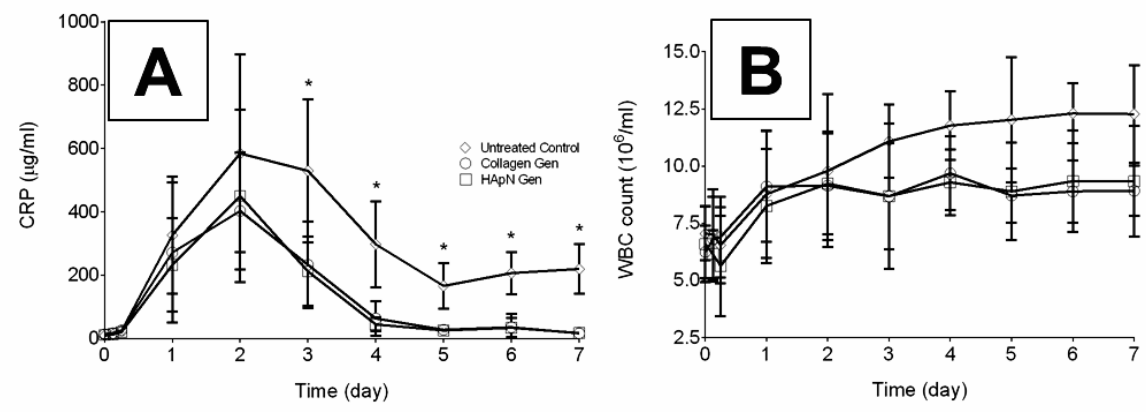

Figure 4.4: Plasma C-reactive protein (CRP) levels $(A)$ and white blood cell $(W B C)$ values $(B)$ for the untreated group, gentamicin-loaded collagen fleece (Collagen Gen) treated group and the gentamicin-loaded HApN hydrogel (HApN Gen) treated group. Values are expressed as mean value per group $(n=10) \pm$ standard deviations. Statistical analysis on the CRP levels was performed by Mann-Whitney test $\left({ }^{*}, P \leq 0.05\right)$.

The peak in CRP production is found 2 days after surgery, after which CRP levels started to decrease for all 3 study groups. For the 2 groups treated with either the Collagen Gen or the HApN Gen, CRP levels returned to base line values. However, after day 3 the CRP levels of the untreated group stayed significantly elevated until the end of the study (Figure 4.4). A similar trend is observed for the white blood cell (WBC) counts in the rabbit plasma, where 7 days after surgery rabbits of the untreated group have $12.3 \times 10^{6} \mathrm{WBCs} / \mathrm{ml}$ as opposed to $8.9 \times 10^{6}$ (Collagen Gen) and $9.3 \times 10^{6}$ (HApN Gen) WBCs/ml in the treated groups (Figure 4.4). 
In vivo systemic gentamicin concentrations

The plasma concentration of gentamicin sulfate released from both HApN and Collagen fleece was measured over a 1 week period (Figure 4.5).

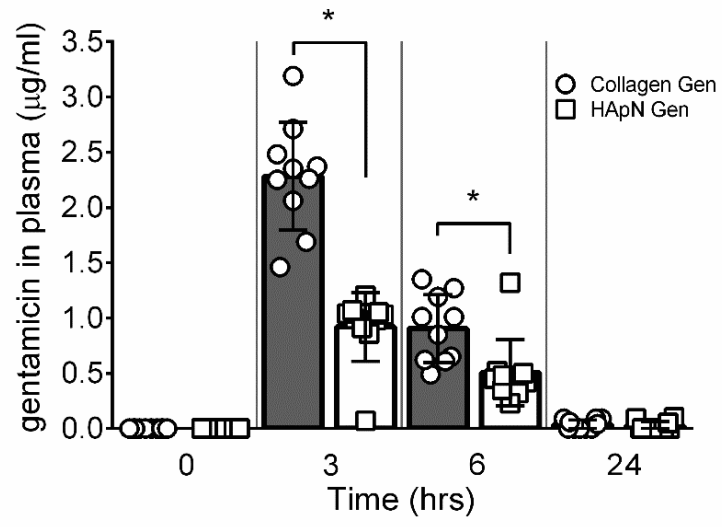

Figure 4.5: Plasma concentrations of gentamicin after application of antibiotic loaded ALBs in vivo: Collagen Gen and HApN Gen at 0, 3, 6, 24 hrs. Values for the plasma concentrations of gentamicin are expressed as the mean value per group $(n=10) \pm$ standard deviations. Statistical analysis on the gentamicin concentrations was performed by Mann-Whitney test $\left({ }^{*}, P \leq 0.05\right)$.

Systemic gentamicin concentrations at $3 \mathrm{hrs}$ upon administration were found to be $2.3 \mu \mathrm{g} / \mathrm{ml}$ for Collagen Gen, and $0.9 \mu \mathrm{g} / \mathrm{ml}$ for the HApN Gen, respectively. After 24 hrs no gentamicin could be traced in the plasma from both ALBs (Figure 4.5).

\section{Bacteriology}

Quantitative culture of each inoculum, showed that CFU counts ranged from $1.2 \mathrm{x}$ $10^{6} \mathrm{CFU}-3.5 \times 10^{6} \mathrm{CFU}$ for the inocula administered to the rabbits. Bacteriological quantification for harvested tissues and implant is shown in Figure 4.6. 


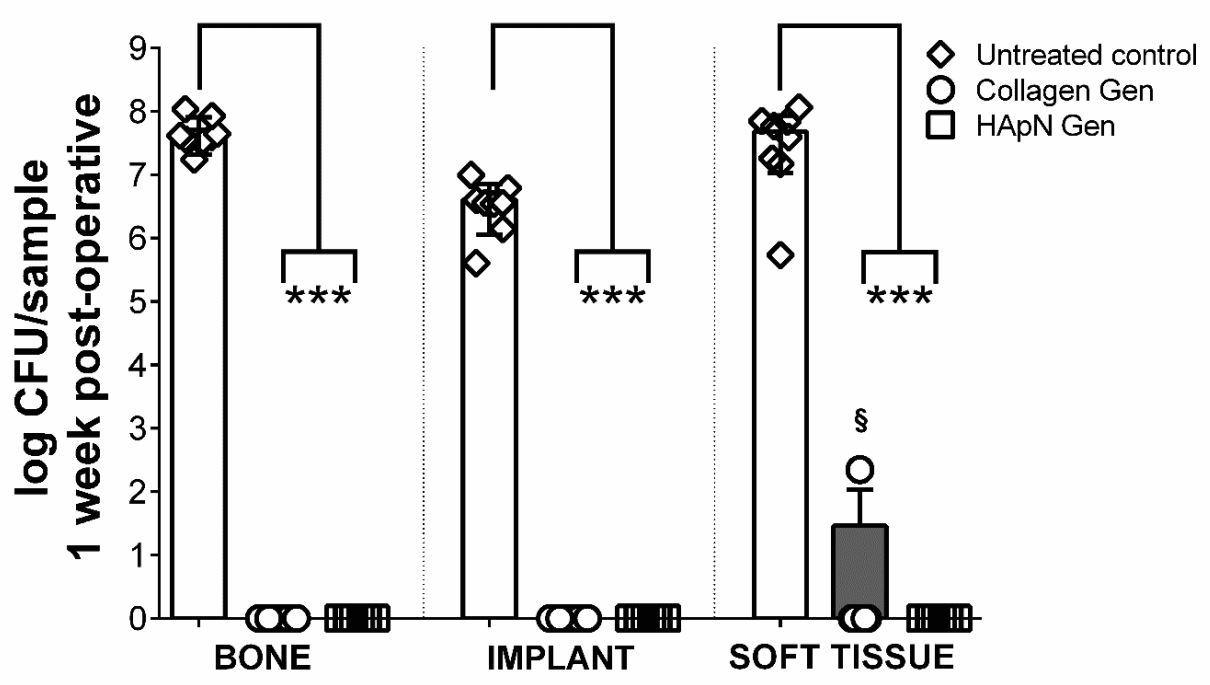

Figure 4.6: Bacteriological quantification of harvested tissues and implant 1 week post-operatively from: Untreated control group (Untreated Control); Collagen fleece with gentamicin (Collagen Gen); HApN hydrogel with gentamicin (HApN Gen). § indicates causative organism other than $S$. aureus. $n=8$, error bars represent standard deviation. Statistical analysis on the number of CFUs was performed by Mann-Whitney test ( $\left.{ }^{* * *}, P \leq 0.001\right)$.

All rabbits (8/8) that did not receive any antibiotic treatment (untreated control) developed an infection (Figure 4.6). Bone, soft tissues and implant material of these rabbits were all colonized by $S$. aureus, as proven by a positive latex agglutination test for $S$. aureus. The $S$. aureus strain used in this in vivo study was found to be susceptible to gentamicin (average zone diameter for S. aureus JAR 060131 was 20 $\mathrm{mm}$ and for the quality control strain, the average zone diameter for $S$. aureus ATCC® 25923 was $22 \mathrm{~mm}$ indicating the test was performed correctly). In the group of rabbits treated with the collagen fleece with gentamicin (Collagen Gen), all tissues and implant material, except for the soft tissue of one rabbit (1/8), stayed free from bacterial colonization. The soft tissue sample of the infected rabbit was negative for the $S$. aureus latex agglutination test and was identified as Streptococcus salivarius (S. salivarius). This strain was at least intermediately susceptible to gentamicin as determined by the disk diffusion method (average zone diameter was $19.5 \mathrm{~mm} \pm 0.9$ 
$\mathrm{mm})$. None of the rabbits $(0 / 8)$ of the group that received the HApN hydrogel with gentamicin (HApN Gen) developed an infection. Bone, soft tissue and implant were free of bacteria.

\section{Histological evaluation}

Images of Giemsa Eosin stained sections of the operated humerus, including implants and surrounding soft tissues, are shown in Figure 4.7.
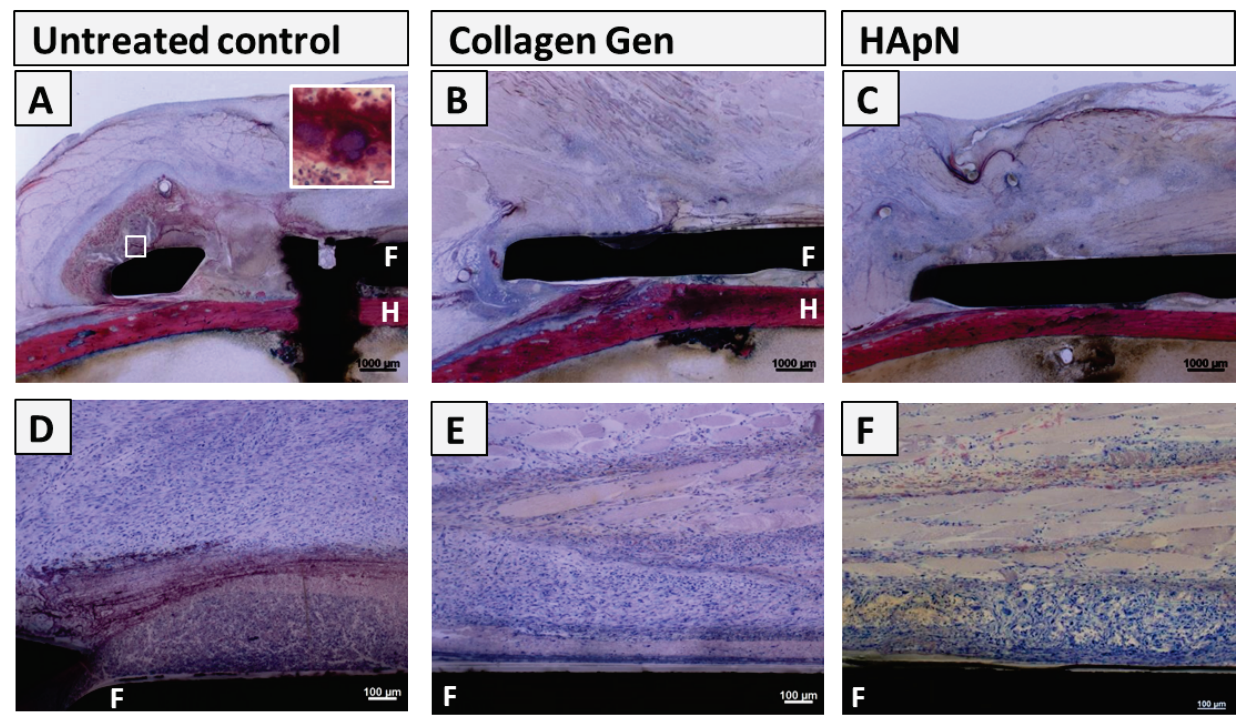

Figure 4.7. Microphotographs of histological humerus samples (incl. stainless steel implant and soft tissue $(A, B, C)$ ) at day 7 after inoculation with S. aureus (Giemsa-Eosin stained thicksections; objective lens [A, B, C]: 1.25x; [D, E, F]: 10x; [inset Figure A]: $100 x$ oil immersion). Fracture fixation implant $(F)$ and the cortex of the humerus $(H)$ are indicated in the image. The inset in figure $A$ represents a magnification of the area within the white bordered box. The scale bar in the inset in figure A represents $10 \mu \mathrm{m}$. Histological changes: see text.

All three groups displayed signs of surgery-induced damage at the 7-day euthanasia time point, such as fibrin formation and muscle necrosis. However, some distinctions between treated and untreated groups were evident. In the untreated control group (Figure 4.7, left column), obvious suppurative inflammation was observed surrounding the implant. At high magnification, Giemsa-positive coccoid bacterial 
micro-colonies were identified in the untreated control group, and seen to be embedded in fibrin and surrounded by polymorphonuclear granulocytes at the periphery of a micro-abscess (Figure 4.7 D, inset).

In comparison, the Collagen Gen and HApN groups (center and right columns, respectively) displayed a more physiological response at the implant interface and there were early signs of muscle regeneration (Figure 4.7 E and F).

\section{Discussion}

Open fracture treatment has been shown to benefit from the local application of ALBs $[12,32]$. However, improvements in the development of ALBs may offer the possibility of further reducing the infection rates associated with operative fracture care [2, 33]. Hydrogels are attractive ALBs as they offer the prospect of a less invasive application than non-injectable materials such as PMMA or collagen fleece. Hydrogels also offer versatility in that they can be applied as an anti-infective adjunct to any fracture fixation system and can protect the entire surgical site regardless of the size or extent of tissue damage and regardless of the $3 \mathrm{D}$ geometry of the repaired fracture [34-36]. Furthermore, hydrogels based on biodegrabable polymers do not require removal. Coated implants or bone cement beads may not achieve these particular performance targets, especially in cases where tissue damage and contamination extends beyond the immediate vicinity of the implant/ALB.

Previously described hydrogel systems that were based on hydrated polymer matrices with already formed networks, are applied as highly viscous compositions prior to surgery to coat the implant [37]. Therefore, there is a risk of retaining only a low percentage of the starting amount of gel on the implant during the insertion procedure. This high viscosity may also result in a suboptimal dispersion within the surgical field. The gentamicin-loaded HApN formulation characterized in this study showed liquid-like behavior at RT, enabling distribution throughout the contaminated surgical site. Once placed within the wound, the gentamicin-loaded HApN dispersed throughout the wound, gelated soon thereafter, and effectively prevented bacterial infection. The treatment was also shown to prevent infection-induced CRP increases 
over time in all rabbits and prevented the appearance of suppurative abscess formation adjacent to the implant.

The addition of gentamicin sulfate to the HApN resulted in a reduction in LCST (from $28^{\circ} \mathrm{C}$ to $25^{\circ} \mathrm{C}$ ). The temperature-induced phase transition of thermo-responsive polymers is influenced by the presence of co-solutes, such as salts [38], and their position in the Hoffmeister series [39]. Of all anions, sulfate has the strongest saltingout potential [38]. In addition, anions like $\mathrm{SO}_{4}{ }^{2-}$ have shown to increase the viscosity of polysaccharide solutions, as observed as an increase in G" at temperatures below the LCST for HApN [40]. As the temperature of tissues in the extremities of the body is ordinarily much lower than $37^{\circ} \mathrm{C}$, the shift in LCST is beneficial for their application to obtain fast gelation in traumatic wounds.

The HApN Gen showed an initial and rapid burst release of antibiotic, followed soon thereafter by complete exhaustion of the antibiotic from the material. This release profile favorable in terms of reducing toxicity concerns, but also in terms of optimal pharmacodynamics of gentamicin, which is a concentration dependent antibiotic. In vitro, the gentamicin released at $1 \mathrm{hr}$ was significantly lower for the HApN Gen hydrogel than the collagen fleece, and this was also seen in the plasma measurements of rabbits three and six hours after surgery. This may indicate a slightly lower burst release of gentamicin upon application of the thermo-responsive HApN Gen than for the Collagen Gen. This is, however, difficult to verify as the halflife of gentamicin in the blood circulation of the rabbit is very short and accurate assessment of the pharmacokinetics with such few time-points is therefore a challenge [41, 42]. Nevertheless, the peak plasma gentamicin levels measured in both groups are much lower than the commonly observed maximum concentration $\left(\mathrm{C}_{\max }\right)$ of gentamicin in the human serum $(18 \mu \mathrm{g} / \mathrm{ml})$ upon intravenous administration of a conventional dose of $6 \mathrm{mg}$ gentamicin/ $\mathrm{kg}$ body weight [43], indicating systemic toxicity is not a concern after application of either ALB. Clearly, both the thermoresponsive $\mathrm{HApN}$ hydrogel and collagen fleece with gentamicin provided adequate protection against infection, despite the low total amount of gentamicin applied, highlighting the fact that local delivery is a highly effective prophylactic strategy. 
Although numerous publications have described hydrogels as antibiotic or antifungal delivery systems, few hydrogels have been tested for their efficacy in in vivo models $[36,37,44-51]$, and those that have done so present varied success in their primary goal of infection prevention. Giavaresi et al. tested a non-responsive HA hydrogel with poly-D,L-lactic acid grafted as side groups, and loaded with vancomycin in an in vivo model with methicillin-resistant $S$. aureus (MRSA) in the rabbit femur. The vancomycin loaded hydrogel reduced, but was not able to clear the MRSA infection [37], possibly due to the high bacterial load of MRSA $\left(10^{4} \mathrm{CFU}\right.$ and $\left.10^{6} \mathrm{CFU}\right)$ used in the study. Jia et al. tested a platelet-rich plasma derived leucocyte gel in a rabbit tibia model with $S$. aureus inoculation without the presence of a fracture fixation implant. Again, however, 4 out of 9 treated rabbits became infected [47], although as a nonconventional antibacterial agent, this result is nevertheless of interest. Taken together, none of these in vivo studies showed complete clearance of the bacterial burden, as opposed to the present study, in which the bacterial burden is completely cleared. Soon after inoculation of bacteria into the surgical site, the innate immune defenses will be activated and begin to combat the contaminating bacteria. Although the amount of bacteria killed by the innate defense system relative to those killed by the antibiotic cannot be estimated, in the absence of antibiotic, this dose of bacteria will consistently achieve a longstanding infection for up to at least ten weeks in this model [24]. This indicates that the antibiotic delivery is a critical feature in the eradication of infection by the hydrogel. In using the HApN hydrogel for prophylaxis, we prove that a flowable degradable thermo-responsive hydrogel loaded with gentamicin can eliminate a single species $S$. aureus contamination. As such, the efficacy against other pathogens such as Gram-negative or resistant bacteria is not shown. Furthermore, the bacteria in this model are planktonic and so are more easily targeted than for example bacteria within a biofilm. However, gentamicin does retain activity against many Gram-negative pathogens, and gentamicin has even been selected as the antibiotic of choice for the only commercially available antibiotic coated trauma implant on the market, which is used prophylactically in the same clinical context as intended use for the HApN.

Should the HApN hydrogel be required to treat an infection, it would present a much more formidable challenge, considering that the bacteria will likely have formed 
biofilm on implanted hardware rendering them highly resistant to antibiotics. Additionally, the local tissues will likely be inflamed, with granulation tissue and abscess formation possible. The antibiotic distribution and concentrations required to achieve eradication in this situation may well require greater control over, or greater amounts of release from, the hydrogel than is achieved with the tested formulation. Therefore, the data presented should not be extrapolated to any claim of efficacy in the treatment of established infection. Overstreet et al. investigated the efficacy of a gentamicin loaded poly( $N$-isopropylacrylamide-co-dimethyl-y-butyrolactone acrylateco-Jeffamine $^{\circledR} \mathrm{M}-1000$ acrylamide) (G-PNDJ) viscous hydrogel as treatment of established infection in a rabbit model [36]. The G-PNDJ hydrogel, with an average $30 \mathrm{mg}$ gentamicin, was able to treat the infection in combination with debridement. Future work with the HApN hydrogel described here may involve evaluating the efficacy as a treatment option in a similar in vivo model.

Collagen fleece is a benchmark delivery product used for the local delivery of gentamicin in infection prophylaxis and was chosen as an ideal comparison for the hydrogel in the absence of any commercially available, gentamicin loaded hydrogels. The systemic gentamicin concentration observed in the collagen fleece group is in accordance with previous published work by Mehta et al. [52], where collagen fleece resulted in an average systemic gentamicin concentration of $3.2 \mu \mathrm{g} / \mathrm{ml}$. The single rabbit in the collagen gen group that was found to have a superinfection with a streptococcus (of intermediate gentamicin resistance $[53,54]$ ), is believed to be due to the rabbit licking the wound and delivery of oral microflora after the initial gentamicin is released from the collagen. This highlights the importance of proper post-surgical wound care and the need to protect the surgical field until wound closure, rather than as a particular failing of the collagen fleece. Several clinical cases have been published where collagen fleece with gentamicin was applied to prevent infection: e.g. after major or minor amputations in patients with diabetes or diabetic complications; before insertion of plate osteosynthetic hardware; and at the site of the removed disc after discectomy in spinal surgery [55]. In a case series report of 35 patients with open fractures, the efficacy of applying the gentamicinloaded collagen fleece during the plating procedure was investigated. The majority of the fractures were considered to have united 40 weeks post-surgery. Local wound 
complications were observed in $10 \%$ of the patients, and $7 \%$ of the patients had deep tissue infections following the procedure [55]. In general, the wound healing time was shorter after application of the gentamicin-loaded collagen fleece and no patient progressed to non-union or implant failure during long-term follow-up.

Although similarly effective in preventing infection, the collagen fleece lacks many of the handling features of HApN. HApN may therefore be expected to be equally effective as collagen fleece, however, with greater ease of use and greater distribution throughout even complex wounds. Furthermore, there is the possibility to reconstitute the HApN hydrogel with different antibiotics for loading. This may eventually result in greater clinical uptake, should such a material become clinically available. Prior to clinical implementation however, the effect of the HApN hydrogel with gentamicin on the bone healing process should be investigated.

\section{Conclusions}

The described gentamicin-loaded HApN hydrogel is designed for complex trauma cases, where contamination may have spread throughout complex wound sites. The gentamicin-loaded HApN hydrogel was effective in preventing $S$. aureus infection in a rabbit prophylaxis model in the presence of osteosynthesis material. The HApN hydrogel offers comparable prophylaxis against a current clinical product, yet promises greater versatility in terms of application. 


\section{Acknowledgements}

The authors would like to thank Dr. med. vet. Tanja Schmid for performing all the rabbit surgeries. Furthermore, the authors like to thank Katharina Kluge, Christian Günther, Jennifer Hagen for their contribution to the rabbit surgeries, Iris KellerStoddart for assisting with the bacteriology work and the CRP quantification in particular, Nora Goudsouzian for preparing the histological sections, Pamela Furlong for taking images of the stained histology sections and Dirk Nehrbass for describing the histological findings (All from AO Research Institute Davos, Davos, Switzerland). Prof. Dr. Laurent Decosterd (Laboratory of Clinical Pharmacology, University Hospital Lausanne, Lausanne, Switzerland) is thanked for performing the immuno-assay to quantify gentamicin in the rabbit plasma. This work was funded as part of the AOTrauma Clinical Priorirty Program Bone Infection. 


\section{References}

[1] Darouiche RO. Treatment of infections associated with surgical implants. N Engl J Med. 2004;350:1422-9.

[2] Trampuz A, Widmer AF. Infections associated with orthopedic implants. Current Opinion in Infectious Diseases. 2006;19:349-56.

[3] Busscher HJ, van der Mei HC, Subbiahdoss G, Jutte PC, van den Dungen JJAM, Zaat SAJ, et al. Biomaterial-Associated Infection: Locating the Finish Line in the Race for the Surface. Science Translational Medicine. 2012;4:153rv10.

[4] Rochford ETJ, Richards RG, Moriarty TF. Influence of material on the development of device-associated infections. Clinical Microbiology and Infection. 2012;18:1162-7.

[5] Inzana JA, Schwarz EM, Kates SL, Awad HA. Biomaterials approaches to treating implant-associated osteomyelitis. Biomaterials. 2016;81:58-71.

[6] ter Boo G-JA, Grijpma DW, Moriarty TF, Richards RG, Eglin D. Antimicrobial delivery systems for local infection prophylaxis in orthopedic- and trauma surgery. Biomaterials. 2015;52:113-25.

[7] Boxma H, Broekhuizen T, Patka P, Oosting H. Randomised controlled trial of single-dose antibiotic prophylaxis in surgical treatment of closed fractures: the Dutch Trauma Trial. Lancet. 1996;347:1133-7.

[8] Ito KP, S.M. Biology and biomechanics in bone healing. In: Rüedi TPB, R.E.; Moran, C.G., editor. AO Principles of Fracture Management. Davos Platz: AO Publishing; 2007. p. 9-31.

[9] Engesaeter LB, Lie SA, Espehaug B, Furnes O, Vollset SE, Havelin LI. Antibiotic prophylaxis in total hip arthroplasty: effects of antibiotic prophylaxis systemically and in bone cement on the revision rate of 22,170 primary hip replacements followed 014 years in the Norwegian Arthroplasty Register. Acta Orthop Scand. 2003;74:64451.

[10] Kuehn KD, Ege W, Gopp U. Acrylic bone cements: composition and properties. Orthop Clin North Am. 2005;36:17-28, v.

[11] Ruszczak Z, Friess W. Collagen as a carrier for on-site delivery of antibacterial drugs. Adv Drug Deliv Rev. 2003;55:1679-98. 
[12] Fuchs T, Stange R, Schmidmaier G, Raschke MJ. The use of gentamicin-coated nails in the tibia: preliminary results of a prospective study. Arch Orthop Trauma Surg. 2011;131:1419-25.

[13] Metsemakers WJ, Reul M, Nijs S. The use of gentamicin-coated nails in complex open tibia fracture and revision cases: A retrospective analysis of a single centre case series and review of the literature. Injury. 2015;46:2433-7.

[14] Raschke M, Vordemvenne T, Fuchs T. Limb salvage or amputation? The use of a gentamicin coated nail in a severe, grade Illc tibia fracture. Eur J Trauma Emerg Surg. 2010;36:605-8.

[15] Tunney MM, Ramage G, Patrick S, Nixon JR, Murphy PG, Gorman SP. Antimicrobial susceptibility of bacteria isolated from orthopedic implants following revision hip surgery. Antimicrob Agents Chemother. 1998;42:3002-5.

[16] Weber FA, Lautenbach EE. Revision of infected total hip arthroplasty. Clin Orthop Relat Res. 1986:108-15.

[17] McLaren AC. Alternative materials to acrylic bone cement for delivery of depot antibiotics in orthopaedic infections. Clin Orthop Relat Res. 2004:101-6.

[18] Friess W. Collagen--biomaterial for drug delivery. Eur J Pharm Biopharm. 1998;45:113-36.

[19] Lynn AK, Yannas IV, Bonfield W. Antigenicity and immunogenicity of collagen. J Biomed Mater Res B Appl Biomater. 2004;71:343-54.

[20] Prestwich GD. Hyaluronic acid-based clinical biomaterials derived for cell and molecule delivery in regenerative medicine. J Control Release. 2011;155:193-9. [21] Mortisen D, Peroglio M, Alini M, Eglin D. Tailoring thermoreversible hyaluronan hydrogels by "click" chemistry and RAFT polymerization for cell and drug therapy. Biomacromolecules. 2010;11:1261-72.

[22] Schanté CE, Zuber G, Herlin C, Vandamme TF. Chemical modifications of hyaluronic acid for the synthesis of derivatives for a broad range of biomedical applications. Carbohydrate Polymers. 2011;85:469-89.

[23] D’Este M, Alini M, Eglin D. Single step synthesis and characterization of thermoresponsive hyaluronan hydrogels. Carbohydrate Polymers. 2012;90:1378-85. [24] Arens D, Wilke M, Calabro L, Hackl S, Zeiter S, Zderic I, et al. A rabbit humerus model of plating and nailing osteosynthesis with and without Staphylococcus aureus osteomyelitis. Eur Cell Mater. 2015;30:148-61; discussion 61-2. 
[25] Bellini D, Topai A. Amides of hyaluronic acid and derivatives thereof and a process for their preparation. 2000.

[26] Yamamoto K. Sensitive determination of quaternary ammonium salts by extraction-spectrophotometry of ion associates with bromophenol blue anion and coextraction. Analytica Chimica Acta. 1995;302:75-9.

[27] Sampath SS, Robinson DH. Comparison of new and existing spectrophotometric methods for the analysis of tobramycin and other aminoglycosides. J Pharm Sci. 1990;79:428-31.

[28] Morelli B. Determination of iron(III) and copper(II) by zeroth, first and second derivative spectrophotometry with 2-thiobarbituric acid (4,6-dihydroxy-2mercaptopyrimidine) as reagent. Analyst. 1983;108:870-9.

[29] Campoccia D, Montanaro L, Moriarty TF, Richards RG, Ravaioli S, Arciola CR. The selection of appropriate bacterial strains in preclinical evaluation of infectionresistant biomaterials. Int J Artif Organs. 2008;31:841-7.

[30] Moriarty TF, Campoccia D, Nees SK, Boure LP, Richards RG. In vivo evaluation of the effect of intramedullary nail microtopography on the development of local infection in rabbits. Int J Artif Organs. 2010;33:667-75.

[31] CLSI. Performance Standards for Antimicrobial Susceptibility Testing. TwentyFifth Informational Supplement. Wayne, Pa (USA): Clinical and Laboratory Standards Institute; 2015.

[32] Evans RP, Nelson CL. Gentamicin-impregnated polymethylmethacrylate beads compared with systemic antibiotic therapy in the treatment of chronic osteomyelitis. Clin Orthop Relat Res. 1993:37-42.

[33] Ostermann PA, Seligson D, Henry SL. Local antibiotic therapy for severe open fractures. A review of 1085 consecutive cases. J Bone Joint Surg Br. 1995;77:93-7. [34] Drago L, Boot W, Dimas K, Malizos K, Hansch GM, Stuyck J, et al. Does implant coating with antibacterial-loaded hydrogel reduce bacterial colonization and biofilm formation in vitro? Clin Orthop Relat Res. 2014;472:3311-23.

[35] Risbud MV, Hardikar AA, Bhat SV, Bhonde RR. pH-sensitive freeze-dried chitosan-polyvinyl pyrrolidone hydrogels as controlled release system for antibiotic delivery. J Control Release. 2000;68:23-30. 
[36] Overstreet D, McLaren A, Calara F, Vernon B, McLemore R. Local gentamicin delivery from resorbable viscous hydrogels is therapeutically effective. Clin Orthop Relat Res. 2015;473:337-47.

[37] Giavaresi G, Meani E, Sartori M, Ferrari A, Bellini D, Sacchetta AC, et al. Efficacy of antibacterial-loaded coating in an in vivo model of acutely highly contaminated implant. Int Orthop. 2014;38:1505-12.

[38] Freitag R, Garret-Flaudy F. Salt Effects on the Thermoprecipitation of Poly-(Nisopropylacrylamide) Oligomers from Aqueous Solution. Langmuir. 2002;18:3434-40. [39] Hofmeister F. Zur Lehre von der Wirkung der Salze. Archiv f experiment Pathol u Pharmakol. 1888;25:1-30.

[40] Yin W, Zhang H, Huang L, Nishinari K. Effects of the lyotropic series salts on the gelation of konjac glucomannan in aqueous solutions. Carbohydrate Polymers. 2008;74:68-78.

[41] Curl JL, Curl JS. Pharmacokinetics of gentamicin in laboratory rabbits. Am J Vet Res. 1988;49:2065-7.

[42] Dube L, Caillon J, Gras-Le Guen C, Jacqueline C, Kergueris MF, Granry JC, et al. Simulation of human gentamicin pharmacokinetics in an experimental Enterococcus faecalis endocarditis model. Antimicrob Agents Chemother. 2003;47:3663-6.

[43] Barcia-Macay M, Seral C, Mingeot-Leclercq MP, Tulkens PM, Van Bambeke F. Pharmacodynamic evaluation of the intracellular activities of antibiotics against Staphylococcus aureus in a model of THP-1 macrophages. Antimicrob Agents Chemother. 2006;50:841-51.

[44] Anumolu SS, Menjoge AR, Deshmukh M, Gerecke D, Stein S, Laskin J, et al. Doxycycline hydrogels with reversible disulfide crosslinks for dermal wound healing of mustard injuries. Biomaterials. 2011;32:1204-17.

[45] Changez M, Koul V, Dinda AK. Efficacy of antibiotics-loaded interpenetrating network (IPNs) hydrogel based on poly(acrylic acid) and gelatin for treatment of experimental osteomyelitis: in vivo study. Biomaterials. 2005;26:2095-104.

[46] Hudson SP, Langer R, Fink GR, Kohane DS. Injectable in situ cross-linking hydrogels for local antifungal therapy. Biomaterials. 2010;31:1444-52. 
[47] Jia WT, Zhang CQ, Wang JQ, Feng Y, Ai ZS. The prophylactic effects of platelet-leucocyte gel in osteomyelitis: an experimental study in a rabbit model. $J$ Bone Joint Surg Br. 2010;92:304-10.

[48] Krasko MY, Golenser J, Nyska A, Nyska M, Brin YS, Domb AJ. Gentamicin extended release from an injectable polymeric implant. J Control Release. 2007;117:90-6.

[49] Li P, Poon YF, Li W, Zhu HY, Yeap SH, Cao Y, et al. A polycationic antimicrobial and biocompatible hydrogel with microbe membrane suctioning ability. Nat Mater. 2011;10:149-56.

[50] Matsuno H, Yudoh K, Hashimoto M, Himeda Y, Miyoshi T, Yoshida K, et al. A new antibacterial carrier of hyaluronic acid gel. J Orthop Sci. 2006;11:497-504. [51] Veyries ML, Couarraze G, Geiger S, Agnely F, Massias L, Kunzli B, et al. Controlled release of vancomycin from poloxamer 407 gels. Int J Pharm. 1999;192:183-93.

[52] Mehta S, Humphrey JS, Schenkman DI, Seaber AV, Vail TP. Gentamicin distribution from a collagen carrier. J Orthop Res. 1996;14:749-54.

[53] Barbour A, Philip K. Variable characteristics of bacteriocin-producing Streptococcus salivarius strains isolated from Malaysian subjects. PLoS One. 2014;9:e100541.

[54] Burton JP, Wescombe PA, Moore CJ, Chilcott CN, Tagg JR. Safety assessment of the oral cavity probiotic Streptococcus salivarius K12. Appl Environ Microbiol. 2006;72:3050-3.

[55] Knaepler H. Local application of gentamicin-containing collagen implant in the prophylaxis and treatment of surgical site infection in orthopaedic surgery. Int J Surg. 2012;10 Suppl 1:S15-20. 


\section{Chapter 5}

\section{Local application of a gentamicin-loaded thermo-responsive hydrogel allows fracture healing upon clearance of a high Staphylococcus aureus load}

Gert-Jan A. ter Boo ${ }^{1,2}$, Tanja Schmid ${ }^{1}$, Ivan Zderic ${ }^{1}$, Dirk Nehrbass ${ }^{1}$, Karin Camenisch ${ }^{1}$, Robert G. Richards ${ }^{1}$, Dirk W. Grijpma ${ }^{2,3}$, Thomas F. Moriarty ${ }^{1}$, David Eglin ${ }^{1}$

${ }^{1} \mathrm{AO}$ research institute Davos, Clavadelerstrasse 8, CH 7270 Davos, Switzerland

${ }^{2}$ Department of Biomaterials Science and Technology, University of Twente, Enschede, P.O. Box 217, 7500 AE Enschede, The Netherlands

${ }^{3}$ Department of Biomedical Engineering, W.J. Kolff Institute, University Medical Center Groningen, University of Groningen, P.O. Box 196, 9700 AD Groningen, The Netherlands

* Submitted for publication in Eur Cell Mater 


\section{Abstract}

Antibiotic loaded biomaterials (ALBs) have emerged as a useful adjunctive antimicrobial measure for the prevention of infection in high risk cases, such as the surgical fixation of open fractures. A biodegradable thermo-responsive poly $(\mathrm{N}$ isopropylacrylamide) grafted hyaluronic acid (HApN) hydrogel loaded with gentamicin has recently been shown to prevent implant-related infection in an osteosynthesis model in the rabbit. The aim of this study was to determine the influence of this HApN hydrogel on bone healing. A rabbit humeral osteotomy model with plating osteosynthesis was used to compare fracture healing in rabbits receiving the hydrogel versus the controls, both with and without bacterial inoculation. Outcome measures were mechanical stability and histological score.

Application of the HApN hydrogel did not significantly influence mechanical stability or histological evaluation of fracture healing in the non-inoculated group relative to controls. In the inoculated groups, control animals receiving the bacterial inoculum without hydrogel were culture positive at euthanasia and were found to display weaker mechanical stability and higher histopathological scores in comparison with equivalents receiving the gentamicin-loaded $\mathrm{HApN}$ hydrogel who cleared the bacterial load.

Therefore, the presented hydrogel is an effective antibiotic carrier that does not affect fracture healing. Addition of an osteopromotive compound in the hydrogel may accelerate fracture healing upon successful prophylaxis.

\section{Introduction}

Infection is one of the most common complications associated with operative fracture fixation [1-3]. As the number of patients receiving implants increases year on year [4], the number of implant associated infections is also set to increase. Systemic administered prophylactic antibiotics have been shown to reduce the number of infections. In the primary fracture fixation of both closed [5] and open fractures [6] antibiotic prophylaxis reduced the infection rate in comparison with patients receiving either a placebo or no antibiotic. However, the fact that infections still occur indicates systemic antibiotic prophylaxis is not completely effective in all cases. The failure of 
systemic antibiotic therapy may be due to compromised vasculature, tissue deconstruction and edema preventing antibiotic delivery when applied intravenously [7]. The delivery of antibiotics directly to the intended site of action using antibiotic loaded biomaterials (ALBs) is an attractive option to overcome this problem [8]. Degradable ALBs offer advantages over some of the conventional ALBs such as antibiotic loaded bone cement beads or spacers due to the need for surgical removal of the latter.

A thermo-responsive formulation of a hyaluronic acid (HA) derivative loaded with gentamicin, which is injected and gelates in vivo, could successfully prevent bacterial colonization of a contaminated implant site in rabbits in a one-week study [9]. The physically crosslinked hydrogel is composed of HA, a linear polysaccharide, that degrades enzymatically in the body. Although its relatively simple primary structure, it is involved in a plethora of biological processes [10-13] and its derivatives have been widely used as injectable carriers for drug delivery [14, 15].

A critical feature for such an ALB that may be added directly to a fracture site is the effect on fracture healing. Few reports are available on bone healing after delivery of antibiotics by a biodegradable ALB and clearance of a bacterial load [16-18]. In particular, bone healing data in the context of an appropriate release profile and subsequent or simultaneous degradation of the delivery vehicle is lacking. The foreign material itself, the time to degrade and the effect of high local concentrations of antibiotics may potentially influence fracture healing [19, 20]. In addition, the dead bacterial contaminants will still have some potential to induce bone resorption due to upregulation of osteoclast activity [21, 22].

Bone healing in the presence of an ALB has also been investigated by Peng et al. and by Ambrose et al., however these were not prophylactic studies, but rather treatment studies investigating the treatment of osteomyelitis with antibiotic-loaded non-degradable poly(methylmethacrylate) (PMMA) and biodegradable thermosensitive hydrogel nanoparticles or polyester microspheres, respectively [23, 24]. Upon establishment of an acute infection and subsequent debridement and treatment with either antibiotic loaded PMMA beads or an MPEG-PLGA based hydrogel, no histological differences in bone healing were observed between the two 
ALBs four and eight weeks post-operatively. However, a higher degree of bone healing in the defect treated with the antibiotic-loaded biodegradable polyester microspheres was observed at four weeks compared to animals treated with antibiotic loaded PMMA. In a prophylaxis model, biodegradable antibiotic-loaded injectable microspheres composed of a blend of poly(lactic-co-glycolic acid) with poly(ethylene glycol) dry-mixed with $\beta$-tricalcium phosphate and subsequently mixed with $0.5 \%$ carboxymethyl cellulose in saline to make a paste, were shown to effectively prevent infection in a large animal model [17]. However, the lack of positive and negative control groups prevented the assessment of bone healing. None of these studies included a quantitative measure of bone healing, such as bending stiffness.

In this study, the effect of the injectable thermo-responsive physical crosslinked hydrogel on the bone healing process was assessed. A rabbit humeral osteotomy model with plating osteosynthesis was used to compare fracture healing in animals receiving the hydrogel versus the controls, both with and without bacterial inoculation. Outcome measures in assessing new bone formation were given by the mechanical stability and histological scores. Bacterial colonization and potential foreign body reaction were assessed by quantitative bacteriology and histopathological analysis, respectively.

\section{Experimental}

\section{Materials}

Hyaluronic acid sodium salt (HANa) from Streptococcus equi was purchased from Contipro Biotech s.r.o. (Dolni Dobrouc, Czech Republic), number average molecular weight $\left(M_{n}\right)=170.6 \mathrm{kDa}$ and polydispersity $\left(\mathrm{M}_{n} / \mathrm{M}_{\mathrm{w})}=1.73\right.$. Tetrabutylammonium hydroxide solution (TBAOH) $\left(\sim 40 \% \quad\right.$ in $\left.\mathrm{H}_{2} \mathrm{O}, \quad \sim 1.5 \quad \mathrm{M}\right), \quad 2,2$-azobis(2methylpropionitrile) (AIBN) ( $\geq 98.0 \%$ GC), methanesulfonic acid (MSA) $(\geq 99.5 \%$ ), methanol (analytical grade (99.8\%)) and ethanol ( $\geq 99.8 \%$ puriss) were purchased from Fluka (Buchs, Switzerland). N-isopropylacrylamide (nIPAm) ( $\geq 99 \%)$, cysteamine hydrochloride (AESH) ( $\geq 98 \%$ (titration)), N,N-dimethylformamide (DMF) anhydrous $(99,8 \%)$, 1,4-dioxane ( $\geq 99.5 \%$, p.a., ACS), deuterium oxide $\left(D_{2} O\right)(99.9$ atom\% $D)$, Dowex M-31 cation exchange resin, 1,1'-carbonyldiimidazole (CDI) (reagent grade), 
dimethyl sulfoxide (DMSO) ( $\geq 99.5 \%$ for synthesis), gentamicin sulfate salt (Gen) (potency $\geq 590 \mu \mathrm{g}$ gentamicin base per $\mathrm{mg}$ ) and phosphate buffered saline (PBS) were purchased from Sigma-Aldrich (St. Louis, MO, USA). Diethylether $(\geq 99.5 \%$, p.a.), glycerol ( $\geq 99 \%$ ) and sodium bromide ( $\mathrm{NaBr})$ ( $\geq 99 \%$ p.a., ACS) were purchased from Carl Roth (Karlsruhe, Germany). Blood Agar (BA), Tryptone Soya Agar (TSA), Tryptic Soy Broth (TSB) and Mueller-Hinton broth (MHB) were purchased from Oxoid AG (Basel, Switzerland).

\section{In vivo study design}

Four study groups were included in this study, both non-inoculated and inoculated, with the relevant control group. Comparison groups involved bacterial inoculation or not, and groups with or without (antibiotic loaded) hydrogel. The 4 study groups within this study are listed in Table 5.1.

Table 5.1: List of the in vivo study groups, including presence of inoculum, thermoresponsive hydrogel and gentamicin sulfate.

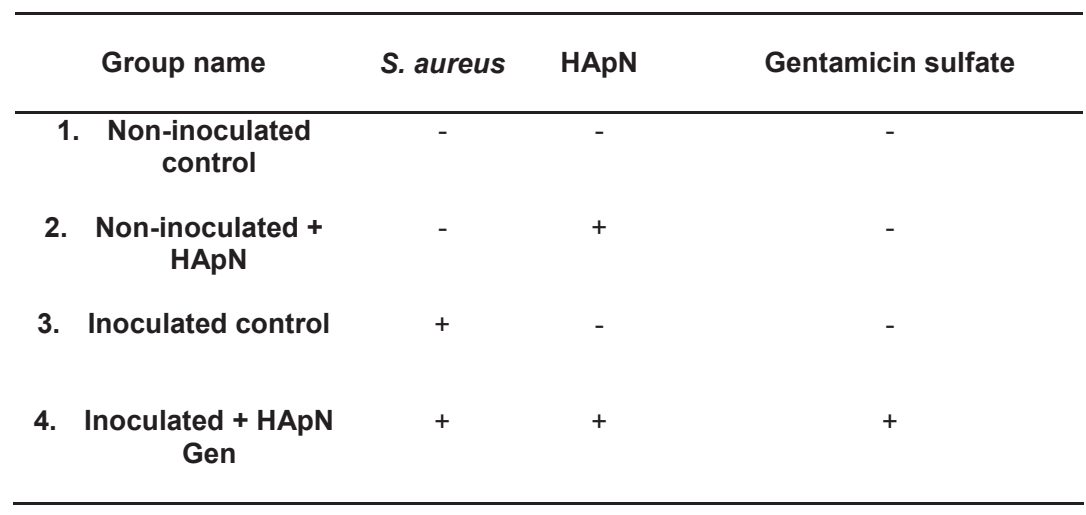

$\mathrm{n}=10$ per study group. Target inoculum was $2.0 \times 10^{6}$ colony forming units (CFU) per rabbit. Volume of HApN hydrogel applied is $800 \mu \mathrm{l}(13 \% \mathrm{w} / \mathrm{w})$ per rabbit. Total payload of gentamicin sulfate in the hydrogel is $8 \mathrm{mg}$ per rabbit. 


\section{Preparation of gentamicin-loaded thermo-responsive hydrogel}

Amino-terminated poly $(\mathrm{N}$-isopropylacrylamide $) \quad\left(\mathrm{pN}^{\left.-\mathrm{NH}_{2}\right)}\right.$ was prepared and characterized with respect to its molecular weight as described previously [9]. The molecular weight $\left(\mathrm{M}_{\mathrm{n}}\right)$ of the $\mathrm{pN}-\mathrm{NH}_{2}$ obtained was between $21.2-21.4 \mathrm{~kg} / \mathrm{mol}$, the polydispersity index $\left(\mathrm{M}_{\mathrm{w}} / \mathrm{M}_{\mathrm{n}}\right)$ was between 2.32 and 2.63 , and the recovered mass was between $82.2 \%$ and $83.4 \%$ for the two batches synthesized under the same condition, which were subsequently used in the synthesis of the $2 \mathrm{HApN}$ batches used during the in vivo study.

Subsequently, NaHA was converted into its tetrabutyl ammonium salt (HATBA) by a cationic exchange process described by Bellini and Topai [25]. Subsequently, pN$\mathrm{NH}_{2}$ was grafted to the HATBA in a direct amidation reaction [9]. The degree of substitution of $\mathrm{pN}-\mathrm{NH}$ for the carboxyl group on the HA backbone was then determined by proton nuclear magnetic resonance ( $\left.{ }^{1} \mathrm{H}-\mathrm{NMR}\right)$ by integration of the HA proton NMR signals between $\delta=3.00 \mathrm{ppm}$ and $3.77 \mathrm{ppm}$, equivalent to 9 protons belonging to the $\mathrm{HA}$ dimer and integration of the $\mathrm{pN}$ signal at $\delta=1.14 \mathrm{ppm}$, deriving from 6 protons on the two methyl groups of $\mathrm{pN}$ [26]. The degree of grafting of $\mathrm{pN}$ to $\mathrm{HA}$ for the HApN batches used in this study was calculated to be $11 \%-12 \%$.

\section{In vivo study}

The in vivo study was approved by the Ethical Committee of the Canton of Grisons, Switzerland (TVB numbers 2015_06F and 2015_13E). All procedures were performed in AAALAC (Association for Assessment and Accreditation of Laboratory Animal Care International) approved facility and according to Swiss animal protection law and regulations. Forty skeletally mature, pathogen free (SPF) female New Zealand white rabbits (Charles River Laboratoris International, Inc, Sulzfeld, Germany) older than 24 weeks of age and a mean body weight of $3.9 \pm 0.4 \mathrm{~kg}$ were included in this study. 


\section{Animal welfare}

All rabbits were assessed by a veterinarian and determined to be healthy prior to inclusion in this study. Rabbits were group-housed and allowed to acclimatize to their surroundings for two weeks prior to the start of the study. After the surgical intervention, animals were single-housed until euthanasia. After surgery, each animal was checked at least twice daily for the first five postoperative days by a veterinarian or an experienced animal care taker. Thereafter, the animals were checked once daily at day six and seven postoperative and finally bi-weekly for the remainder of the study. Five of the forty rabbits used in this study had to be excluded during the observation period, and were replaced.

\section{Pre-operative bacterial inoculum and hydrogel preparation}

A gentamicin sensitive S. aureus (JAR 060131) isolated from a 68-year old male patient with an infected total knee arthroplasty was used in the present study [27]. Bacteria were stored in MHB supplemented with $20 \%$ of glycerol for long term preservation at $-20^{\circ} \mathrm{C}$. Bacterial inocula were prepared in PBS as previously described [28], with a target inoculum of $2.0 \times 10^{6}$ colony forming units (CFU) of $S$. aureus. Quantitative culture of each inoculum was performed immediately after preparation to assure the accuracy of the used inocula.

The sterile HApN samples were reconstituted at $13 \% \mathrm{w} / \mathrm{w} 1$ day prior to surgery. For study group 2 (non-inoculated + HApN), reconstitution was in sterile PBS, whilst for study group 4 (inoculated $+\mathrm{HApN}+\mathrm{Gen}$ ), reconstitution was in sterile PBS containing $1 \% \mathrm{w} / \mathrm{w}$ gentamicin sulfate. The total payload of the antibiotic loaded HApN hydrogel was $8 \mathrm{mg}$ gentamicin sulfate in $800 \mu \mathrm{l}$ of the hydrogel, which was the volume injected over the implant. 


\section{Surgical procedure}

Surgical anesthesia, pre- and post-operative analgesia were administered to the operated rabbits and the plating procedure was performed as described elsewhere [29]. Rabbits belonging to study group 1 (non-inoculated control) and study group 2 (non-inoculated $+\mathrm{HApN}$ ) did not receive a bacterial inoculum, whereas rabbits belonging to study group 3 (inoculated control) and study group 4 (inoculated + $\mathrm{HApN}+\mathrm{Gen}$ ) received a bacterial inoculum after creation of the osteotomy with a $0.45 \mathrm{~mm}$ Gigli saw. The inoculum consisted of three separate injections of $34 \mu \mathrm{l}$ bacterial suspension into the empty screw hole overlying the osteotomy, and onto the adjacent proximal and distal screw holes. Rabbits belonging to study group 2 (noninoculated $+\mathrm{HApN}$ ) received a $\mathrm{HApN}$ hydrogel injected over the 7-hole locking plate, but no inoculum. Rabbits of study group 4 (inoculated $+\mathrm{HApN}+\mathrm{Gen}$ ) received the gentamicin-loaded HApN hydrogel after obtaining the inoculum. The wounds were closed immediately after application of the hydrogel. A schematic overview of the rabbit humerus osteotomy model including fracture fixation hardware is found in figure 5.1 .

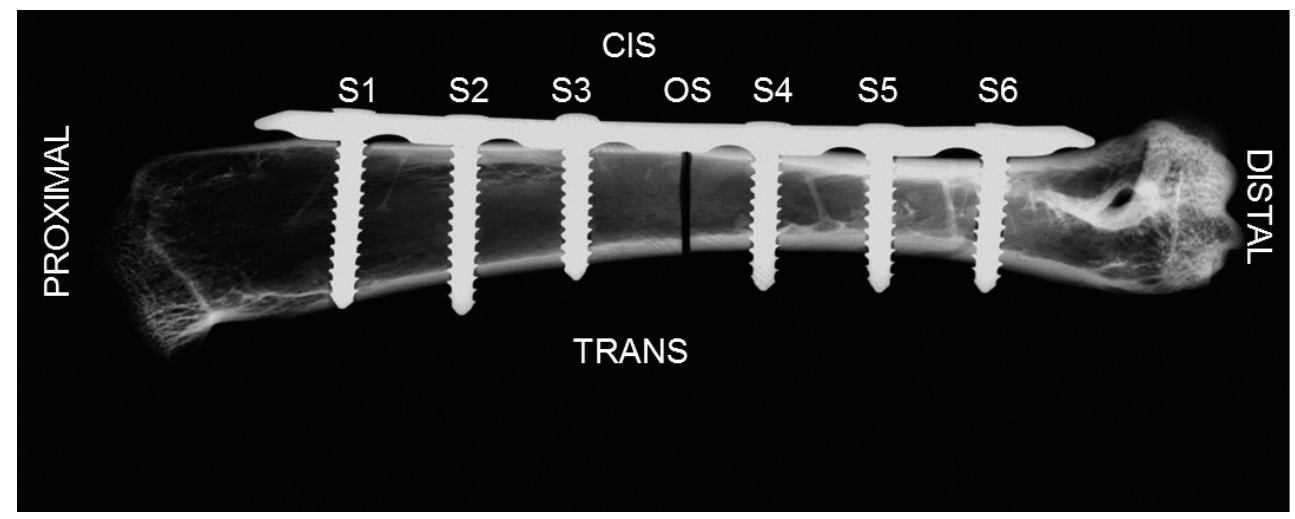

Figure 5.1: Contact radiograph depicting the rabbit humerus osteotomy model including: screw postions (S1-S6), osteotomy (OS), inoculation points is performed on top of S3,S4 and in the OS, the HApN hydrogel spreads around the fracture fixation plate and in the osteotomy gap. 


\section{Observation}

Blood samples were withdrawn from all included rabbits pre-operatively, $3 \mathrm{hrs}, 6 \mathrm{hrs}$, then once daily until day 7 post-operatively, and then on a weekly basis until the end of the study. White blood cell (WBC) count was measured at each time point (Vet ABC, Scil animal care, Viernheim, Germany). C-reactive protein (CRP) concentrations were quantified by ELISA (Rabbit CRP Elisa Kit, ICL Inc. Portland, OR, USA) for each time point until day 7 post-operatively. Serum gentamicin levels were quantified by a fluorescence polarization immunoassay (FPIA, lower limit of detection, $0.5 \mu \mathrm{g} / \mathrm{ml}$ ) on a Cobas Integra ${ }^{\circledR} 400$ plus analyzer (Roche Diagnostics AG, Risch, Switzerland) using reagents from Roche Diagnostics. Test solutions and calibration standards were diluted with human plasma. Weight of the rabbits was measured at surgery, 3 days and 7 days post-operatively and then weekly for the duration of the study. Radiographs of the operated limbs were taken in two planes (lateromedial and caudocranial) from all operated rabbits directly after surgery and then weekly until the end of the study. Animal exclusion criteria were: signs of systemic infection such as fever, depression and anorexia, local infection with severe lameness, persistent swelling and discharge or a weight loss exceeding $15 \%$ of the initial body weight. All rabbits were euthanized at the end of the observation period using intravenously administered Pentobarbital (Esconarkon ${ }^{\circledR}$, Streuli Pharma AG, Switzerland).

\section{Bacteriology}

The soft tissues including all large muscles covering the implant, and any abscess material if present, were removed using a scalpel, weighed, and then placed into a sterile receptacle containing $10 \mathrm{ml}$ of PBS. These samples were then homogenized using an Omni-TH hand-held homogenizer (LabForce AG, Switzerland) with sterile Omni-tip plastic probes. All implant samples were transferred to sterile glass test tubes containing $10 \mathrm{ml}$ of PBS. Implant samples were then sonicated (Bandelin Ultrasonic waterbath RK $510 \mathrm{H}$, Bandelin, Germany) for 3 min, thereafter they were vortexed for $10 \mathrm{sec}$. Further processing of the samples for quantitative bacteriology was performed as described elsewhere [9]. 


\section{Mechanical testing of rabbit humeri}

After removal of the plate and screws of the operated humeri, the bending stiffness of the bone was determined via a non-destructive four-point bending test according to ISO 9585 (1990), using a material testing machine (Instron 5866, Instron, Norwood, MA, USA) equipped with a $1 \mathrm{kN}$ load cell. Axial compression along the machine axis was applied to the bone by two loading pins of $10 \mathrm{~mm}$ diameter and $25 \mathrm{~mm}$ distance in between them, attached to the machine actuator. With the posterior side of the humerus facing towards the machine actuator, each specimen was supported by two pins of $10 \mathrm{~mm}$ diameter connected to the machine base at $50 \mathrm{~mm}$ distance between each other. The supporting points were defined by letting each specimen settle according to its anatomical landmarks.

The setup with a specimen mounted for biomechanical testing is shown in figure 5.2. Prior to testing the specimens, the load necessary to fracture intact non-operated rabbit humeri was determined for cadaveric humeri of age-matched rabbits (circa 400 $\mathrm{N})$. Both the operated humerus and the contralateral humerus of each rabbit included in the study were then loaded to $100 \mathrm{~N}$ at a rate of $1 \mathrm{~mm} / \mathrm{min}$. Axial stiffness of the rabbit humeri was derived from the ascending linear slope of the load-displacement curve in the interval between $50 \mathrm{~N}$ and $100 \mathrm{~N}$. Finally, the stiffness was expressed as the normalized stiffness of the operated humerus compared to the stiffness of the intact contralateral humerus of the same rabbit. 


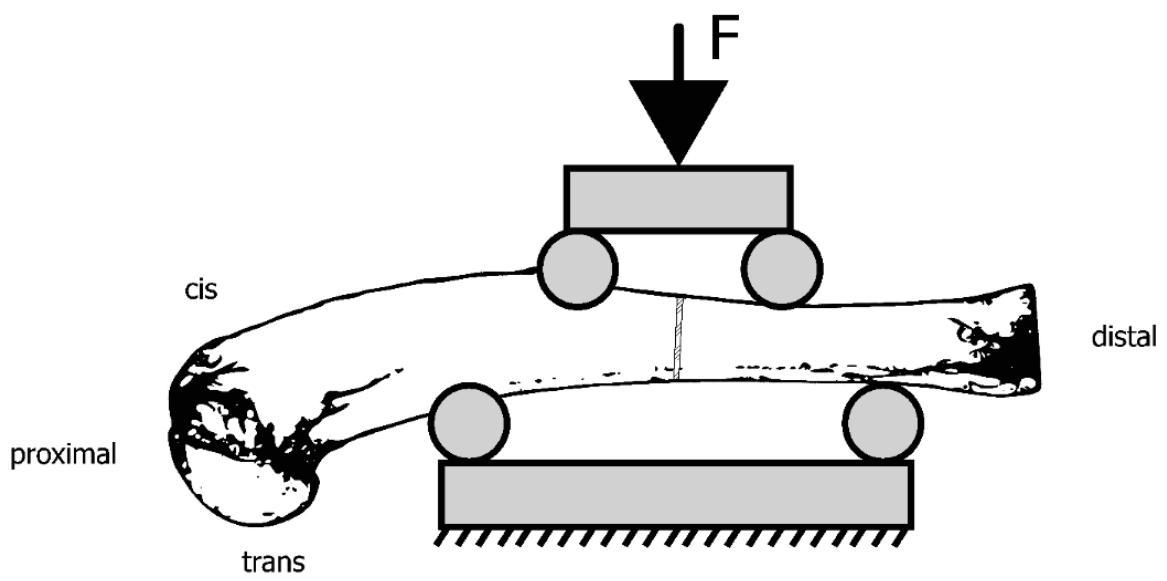

Figure 5.2: Mechanical testing setup showing the positioning of the mounted operated rabbit humerus. Distance between the two loading pins $(\varnothing=10 \mathrm{~mm})$ attached to the actuator was 25 $\mathrm{mm}$, and between the two loading pins $(\varnothing=10 \mathrm{~mm})$ at the machine base was $50 \mathrm{~mm}$. The relative stiffness was calculated as the stiffness of the operated humerus divided by the stiffness of the contralateral humerus of the same rabbit.

\section{Histopathological evaluation}

Full thickness contact radiographs were taken in two planes (lateromedial and caudocranial) using high resolution technical film (D4 Structurix DW ETE, Agfa, Belgium) and a cabinet X-ray system (Model No. 4385A, Faxitron X-ray Corporation, USA) to document the state of the humeri after biomechanical testing. Rabbit humeri were then fixed in $70 \%(\mathrm{v} / \mathrm{v})$ methanol for a minimum of two weeks, with fresh methanol changes weekly. After fixation, samples were dehydrated through an ascending series of ethanol and transferred to xylene and finally the samples were infiltrated and embedded in methylmethacrylate (MMA). Polymerized MMA blocks were trimmed using a butcher saw (Bizerba FK 22, Bizerba AG, Switzerland) and after that cut with an annular diamond saw (Leitz 1600 saw microtome, Leica AG, Switzerland). The samples were glued with cyanoacrylate onto Beracryl holders for sectioning. Contact radiographs of the sections were taken as described previously. The two sections to be stained were selected from as close as possible to the midline 
of the humerus, including the empty screw holes. Sections were glued onto opaque plexiglas slides, ground and fine polished. One of the sections of the humeri was stained with Giemsa-Eosin, and the other was stained with Brown and Brenn for bacteria. The Giemsa-Eosin stained sections were used for semi-quantitative histopathological evaluation with a focus on tissue repair and/or fracture healing. Histological findings were described according to distribution, morphological character and severity using a semi-quantitative grading scheme (5-point scale) [29, 30]. The graded parameters were specially selected for this model by a veterinary pathologist. The Brown and Brenn stained sections were used to confirm the presence of bacteria. The histopathological analysis included osteotomy gap filling, endosteal and periostal callus formation, presence of inflammation, presence of multinuclear histiocytes and presence and amount of Brown and Brenn positive coccoid bacteria.

\section{Statistical analysis}

Statistical evaluation was performed using IBM SPSS Statistics software, vs 23. Results are presented as mean of each group with standard deviation (SD). Data was screened for normality of distribution with the Shapiwo-Wilk test. An independent T-test was run to compare the values of the bacterial inoculum in the two inoculated groups. One-way Analysis of Variance (ANOVA) test with Tukey post-hoc correction for multiple comparisons was conducted to compare the outcome measures for quantitative bacteriology data, normalized stiffness and periosteal callus formation between the four study groups. Finally, two-way ANOVA test with Tukey post-hoc correction was performed to detect significant influence of the treatments on the hematological values and weight change data in the four study groups. Level of significance was set to ${ }^{*} p<0.05$ for all statistical tests. 


\section{Results}

\section{Prevention of infection by gentamicin-loaded HApN hydrogel at 4 weeks}

Total viable counts of the bacterial inocula given to each rabbit in both inoculated groups (group 3 and 4) are shown in Figure 5.3 A. There was no statistically significant difference in the inocula given to the two groups. The implant and fibrous capsule samples from rabbits belonging to study groups 1 \& 2 (both non-inoculated) were all culture negative, and none of the humeri contained any visible abscesses. The implant and fibrous capsule samples of rabbits belonging to study group 4 (inoculated $+\mathrm{HApN}+$ Gen) were culture negative for bacteria (Figure $5.3 \mathrm{~B}$ ). In 1 out of the 10 rabbits from study group 4, small abscesses were observed close to the osteotomy site, however these abscesses were found to be culture negative.
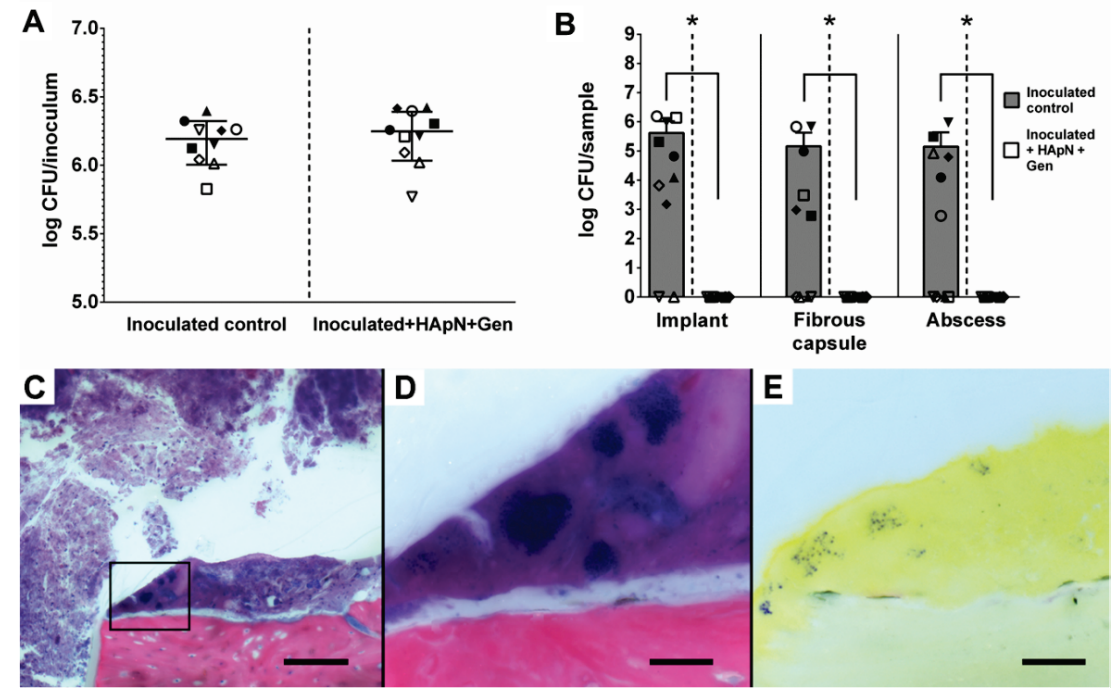

Figure 5.3: A) Quantification of bacterial inocula used during rabbit surgeries B) Bacterial quantification of implant, fibrous capsule and if present of abscess material, $n=10$ per study group, error bars indicate standard deviation (SD). Each of the 10 rabbits per study group is represented by a different symbol (5 closed and 5 open symbols) C) Microphotographs of Giemsa-Eosin (C, D) and Brown and Brenn-stained (E) humeri sections at the trans side near the osteotomy of an infected rabbit (study group 3). The blue dots visible in both Giemsa-Eosin and Brown and Brenn sections are Gram-positive bacteria. Figure $D$ and $E$ are close ups of the area within the square in figure $C$. 
One rabbit belonging to study group 3 was culture negative for bacterial growth, however a low amount of Gram-positive bacteria were found in the Brown and Brenn stained section of this animal. Generally, the stained sections of the humeri from rabbits from the inoculated control group showed high amounts of bacteria visible in Giemsa-Eosin (Figure 5.3 C, 5.3 D) and Brown and Brenn stained sections (Figure $5.3 \mathrm{E}$ ). Furthermore, empty osteocytic lacuna were observed in the cortex (focal osteonecrosis near the osteotomy) and a large amount of acellular debris was observed in the bone marrow (diffuse necrotizing osteomyelitis) (Figure 5.3 C). The presence of bacteria was accompanied by large amounts of inflammatory cells. Most bacteria were found in the proximity of the S3 screw (proximal screw, next to osteotomy site) and in the osteotomy, locally where the bacterial inoculation had been performed.

Rabbits from the inoculated control group that were negative for the Brown and Brenn staining, showed Gram-positive bacterial growth for the quantitative bacteriology.

In none of the humeri from rabbits that belonged to the group of rabbits that received a bacterial inoculum and subsequently the gentamicin-loaded HApN hydrogel (inoculated + HApN + Gen) Gram-positive bacteria were detected microscopically.

CRP concentrations, WBC counts and weight of the rabbits were quantified and the lymphocyte/granulocyte ratios were calculated throughout the observation period and are shown in Figure 5.4. Rabbits from the inoculated control group and the inoculated $+\mathrm{HApN}+$ Gen group in this study had normal pre-operative CRP levels. Seven days post-operative CRP levels for these groups in this study were matching with historical data (Figure 5.4) [9].

For the rabbits belonging to the non-inoculated control group and the non-inoculated + HApN group, CRP levels increased to a maximum value at 2 days post-operatively and returned back to pre-operative levels.

The lymphocyte/granulocyte ratio was significantly lower for the inoculated control rabbits in comparison to the ratio in the rabbits that successfully cleared the bacterial load (inoculated $+\mathrm{HApN}+$ Gen group) at day 28 (Figure 5.4). There was no 
significant difference in lymphocyte/ granulocyte ratio between rabbits belonging to the 2 study groups that did not receive an inoculum (Figure 5.4).

The gentamicin concentration in the plasma of the rabbits was assessed 3 hrs postoperative, which has previously been shown to display an approximate peak serum concentration [9]. The rabbits from the inoculated + HApN +Gen group had a $3 \mathrm{hrs}$ post-operative gentamicin plasma concentration of $1.11 \pm 0.32 \mu \mathrm{g} / \mathrm{ml}$.
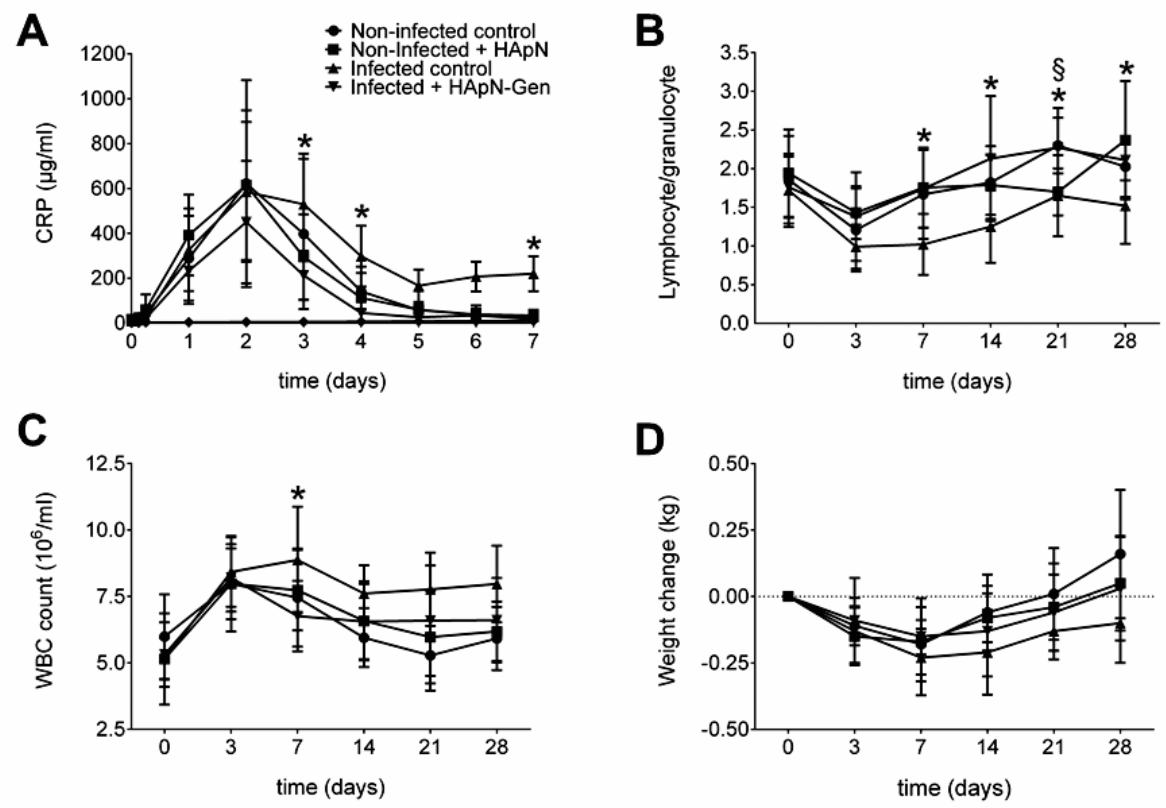

Figure 5.4: Haematological and clinical observations of rabbits from non-inoculated control group, non-inoculated + HApN hydrogel group, inoculated control group and inoculated + $H A p N+$ Gen group. Presented is the CRP concentration in rabbit serum (data from inoculated control group and inoculated $+H A p N+$ Gen was collected in a previous in vivo study [9] ; the ratio of lymphocytes to granulocytes; WBC count and weight change in comparison to pre-operative weight. In all cases $n=10$, and data is represented as mean \pm $S D$. (§-sign represents significance between the non-inoculated groups 1 and 2, *- sign represents significance between the inoculated study groups 3 and 4). 
A similar trend as for the lymphocyte/granulocyte ratio could be observed for the WBC count. At day 7 the inoculated control rabbits had a significantly higher WBC count than rabbits from the inoculated $+\mathrm{HApN}+$ Gen group.

\section{Fracture healing in the presence of the gentamicin-loaded HApN hydrogel at 4 weeks}

Bone healing of the operated rabbit humeri was visualized by contact radiographs of the humerus sections, as well as by staining sections of the operated humeri with Giemsa-Eosin (Figure 5.5). In the non-inoculated control group, there was lots of new periosteal callus formation around the osteotomy gap, leading to the closure of the osteotomy gap (Figure 5.5 \& 5.6). Bone was formed both at the cis and trans site of the bone, though somewhat more on the trans site than on the cis site because of the presence of the fracture fixation plate. The presence of the fracture fixation plate leads to local stress shielding and diminishes formation of new callus at the cis site of the bone [31, 32]. Also new bone formation was observed in the screw holes proximal and distal to the osteotomy site leading to high osteo-integration of all screws. Bone was formed by osteochondral ossification, as can be seen by small amounts of bluish stained cartilage tissue in the osteotomy where the bone is bridging (Figure 5.5) in the non-inoculated control rabbits. The humeri from the rabbits that received the HApN hydrogel in the absence of bacterial inoculation (Figure 5.5) showed also a large amount of new periosteal callus formation, both at the cis and trans site of the bone and in the screw holes proximal and distal of the osteotomy site, however the amount of endosteal and periosteal callus formation was slightly lower, especially at the cis site (Figure 5.6). 

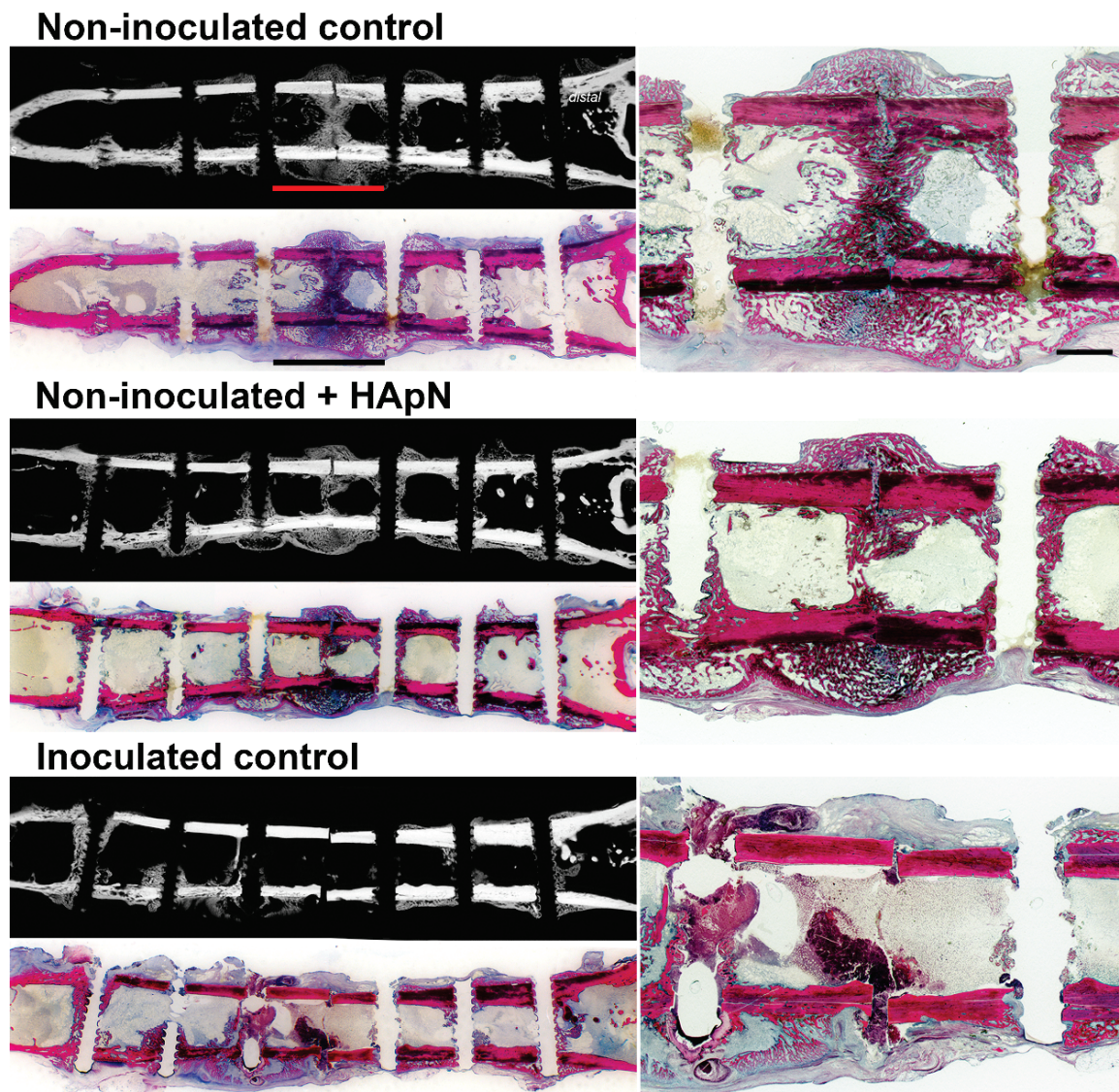

\section{Inoculated + HApN + Gen}

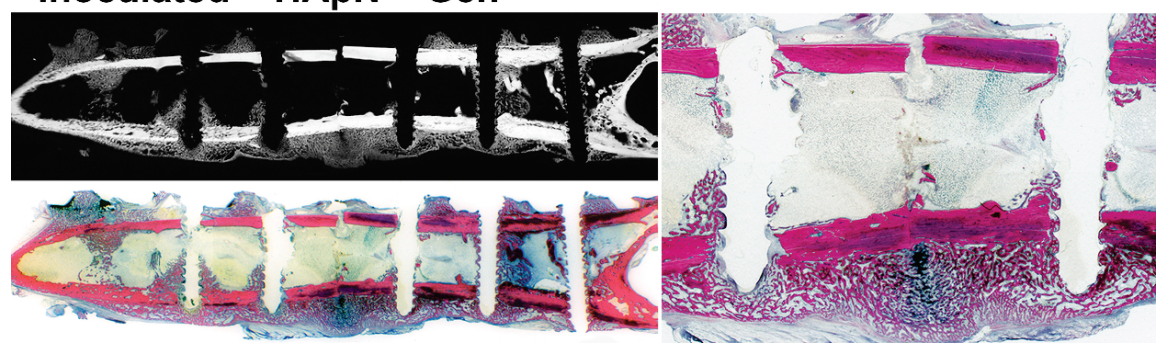

Figure 5.5: $\quad$ Contact radiographs and Giemsa-Eosin-stained overview microphotographs (left, scale bar represents $10 \mathrm{~mm}$ ) of the complete operated rabbit humeri depicting the osteotomy site (OS) and all six screw holes (S1 - S6, 4 weeks post-operative, longitudinal cutting plane, fracture fixation implants removed, situation after mechanical testing), as well as magnified details of the humerus osteotomy site (right, scale bar represents $2 \mathrm{~mm}$ ) including the two adjacent screw holes (S3, left and S4, right). 
In the case of an established localized infection in the humerus, as was the case for rabbits from the inoculated control group, there was no callus formation and no bone formation is seen at the anatomical sites where the inoculation was performed (in the osteotomy and the S3 and S4 screw holes) (Figure 5.5). Large amounts of necrotic tissue can be seen in the medulla at the osteotomy site and at the S3 screw. Screws more distant to the inoculation site, showed better osteo-integration. Humeri from rabbits that received the inoculum, but that were treated with the HApN hydrogel with gentamicin, showed new callus formation (Figure 5.5). Opposed to the inoculated control rabbits, no necrotic tissue was observed. The new formed callus was localized at the trans site of the humerus and at the screw holes, while the cis callus and the endosteal bone formation at the osteotomy site was relatively low (Figure 5.6).

A

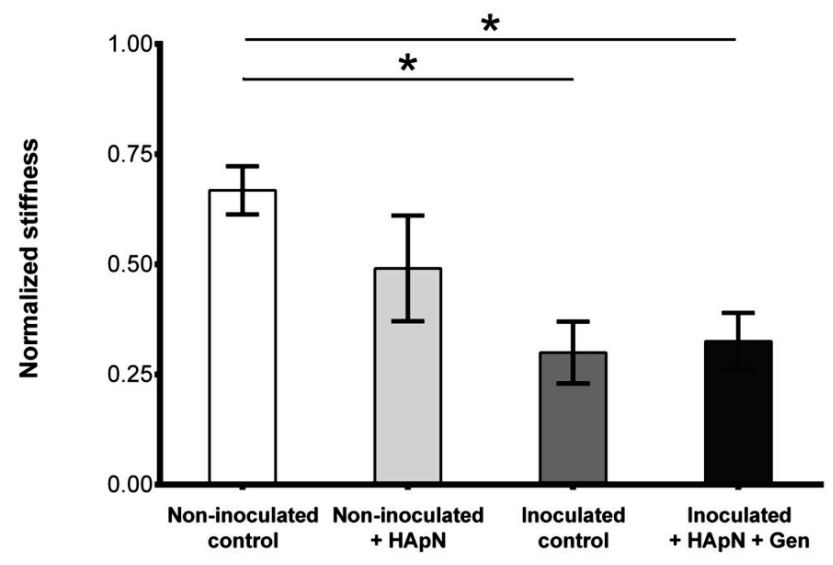

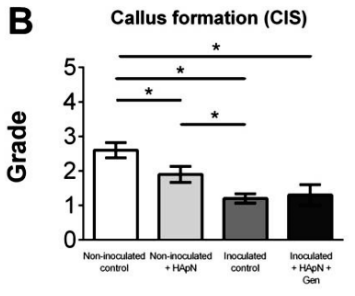

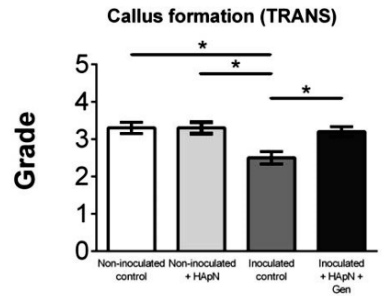

Figure 5.6: Results of mechanical testing by four-point bending test of operated and contralateral humeri $(A)$ and of histopathological scoring for new callus formation, at the cis and at the trans site of the humerus $(B)$.

As the presence of remaining biomaterial upon unfinished degradation can delay fracture healing, histopathological evaluation of the rabbit humeri sections also focused on localizing any reaction to remaining hydrogel components. 
In the sections of the rabbits from both groups receiving the hydrogel (Figure 5.7), there are large amounts of mono- and multinucleated histiocytes with foamy bluish cytoplasm present. Cells with similar morphology are absent in sections from the rabbits of other groups which did not receive the HApN hydrogel (Figure 5.7). Furthermore, similar to Figure 5.7 large amounts of bony callus formation could be observed in the humeri from both non-inoculated groups at the osteotomy site and fibrous incapsulaton of the implant was observed. Soft tissue near the osteotomy in the inoculated control group showed acellular necrotic debris, fibrin and a mixed population of inflammatory cells due to inflammation below the plate which was not observed in the inoculated rabbits that were treated with the gentamicin-loaded HApN hydrogel. 

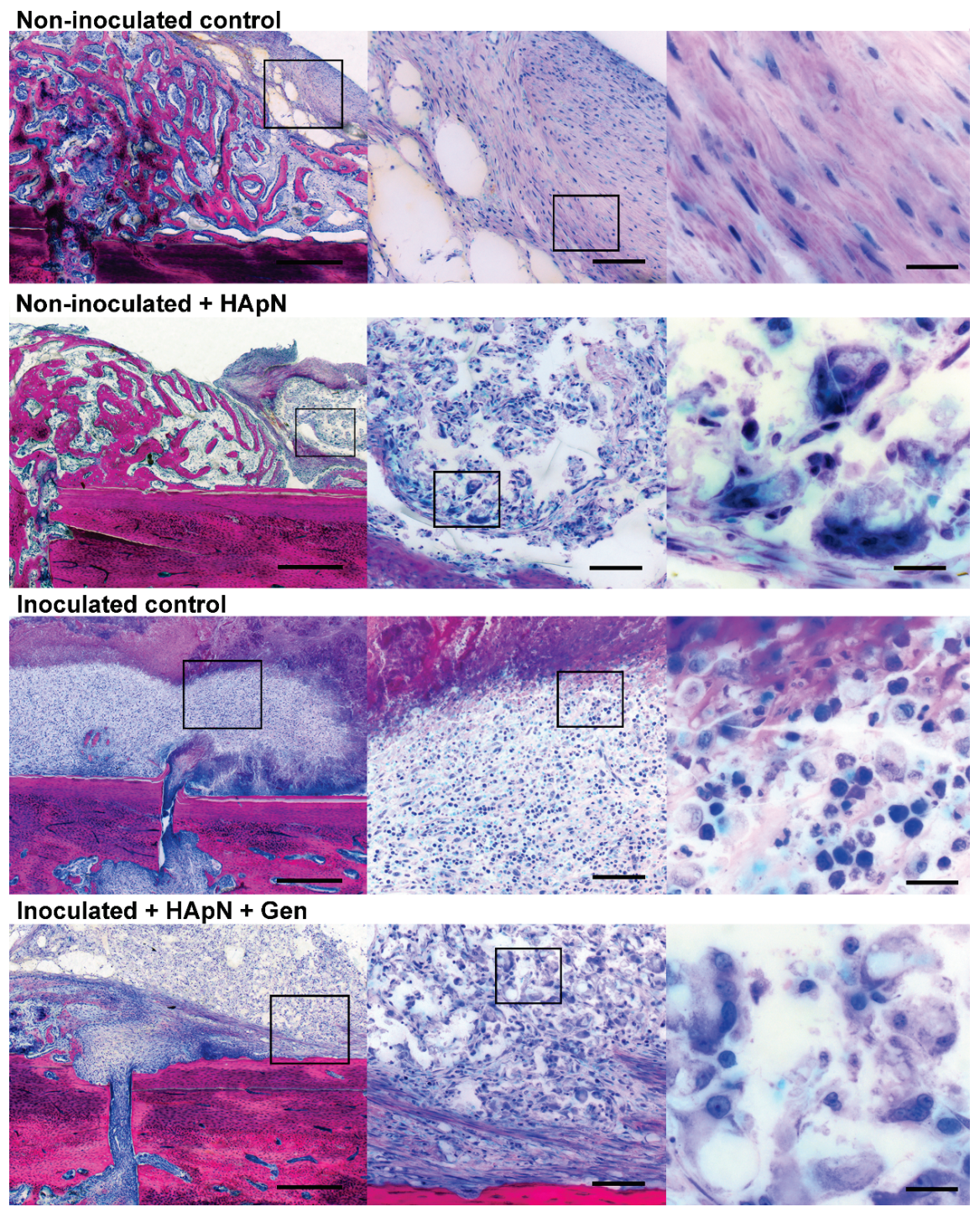

Figure 5.7: Microphotographs of Giemsa-Eosin stained sections of the rabbit humeri at the cis site of the osteotomy site (left column, scale bar represents $500 \mu \mathrm{m}$ ), cellular details of the tissues below the plate (marked by black frames) are shown (middle column: scale bar represents $100 \mu \mathrm{m}$; right column: scale bar represents $20 \mu \mathrm{m}$ ). No callus formation is recorded in the inoculated control group which instead shows necrosis and a mixed-cellular inflammation. The two HApN-treated groups (with and without gentamicin) both show formation of multinucleated histiocytes with foamy bluish cytoplasm. 
The normalized stiffness value of the operated humeri was $67 \%$ of the stiffness of the contralateral humerus in the non-inoculated group without hydrogel, indicating that fracture healing has not yet achieved complete healing at 4 weeks, while complete healing was achieved 10 weeks post-operatively [29]. There was no statistical difference between the non-inoculated control and the non-inoculated + HApN group. Still, the bone stiffness was still lower for the latter, $49 \%$ of the stiffness of the contralateral humerus, in comparison to the rabbits that were only operated (Figure 5.6).

The humeri from rabbits that received the bacterial inoculum, whether they were treated with the HApN hydrogel with gentamicin or not, showed to have significantly lower stiffness than the two non-inoculated groups. The inoculated control group having a mean normalized stiffness of 0.30 and the inoculated + HApN + Gen group 0.33 of the stiffness of the contralateral humerus.

\section{Discussion}

The osteotomy-model including fracture fixation implant used in this in vivo study represents a realistic simulation of fracture healing after trauma, by incorporating all the factors that might influence bone healing or occurrence of an infection (i.e. antibiotics, bacteria, fracture and implant) [29]. In this model, the gentamicin-loaded HApN hydrogel successfully prevented infection during a 4 week post-operative period.

It is known that the created osteotomy in the presence of plating fixation heals in approximately 10 weeks [29, 33, 34]. In this study we used the model to assess the influence of a degradable ALB on bone healing, both under sterile and contaminated conditions at 4 weeks as the largest variations between the study groups were anticipated in this early bone healing phase. Both mechanical testing and histopathological evaluation of the operated humeri showed that the presence of the HApN hydrogel does not significantly influence bone healing in comparison to rabbits that only had surgery.

Four weeks upon surgery rabbit humeri that only underwent surgery (non-inoculated control group) partially healed and gained back $67 \%$ of the stiffness in comparison to 
the non-operated contralateral humeri. In the histological sections this was observed as the formation of callus, both on the cis and trans site of the bone, as well as periost around the osteotomy.

The thermo-responsive HApN hydrogel was injected as a flowable sol with low viscoelastic moduli at room temperature, and upon heating above the lower critical solution temperature it forms a gel over the fracture fixation plate and all the contaminated tissues in the surgical site. The presence of the HApN hydrogel did not significantly affect bone healing in terms of relative stiffness. The relative stiffness of the humeri that received the HApN hydrogel was $49 \%, 4$ weeks post-operatively, and not significantly reduced in comparison to humeri that only had surgery. In the histological sections callus formation was observed at both cis and trans site of the humerus, although the amount of callus formation was slightly decreased at the cis site.

Whereas in mammals degradation of HA usually takes 0.5 day up to several days depending on the anatomical location [35], conjugation of moieties to the HA dimer may alter its degradation behavior [36] and prolongs its presence in vivo [37] and the delivery of the entrapped drugs [38]. Indeed it is known that chemically crosslinked methacrylated hyaluronan hydrogels with differential in vitro enzymatic degradation profile modulate the formation of bone in vivo [39]. The HA formulation used in this in vivo study was rendered thermo-responsive by poly( $N$-isopropylacrylamide) $(\mathrm{pN})$ grafts. Moderate chain length $\mathrm{pN}$, as the $20 \mathrm{kDa}$ graft used in this in vivo study does not decrease cell viability in vitro [40]. Presence of remnants of the HApN hydrogel, suggested by the occurrence of moderate amounts of mono- and multinucleated histiocytes where the hydrogel was applied, suggests ongoing and incomplete resorption of the HApN hydrogel 4 weeks post-operatively. The CRP values, WBC counts and also the final body weight change in the non-inoculated rabbits that received the HApN hydrogel were similar to the rabbits that only had surgery.

In the rabbits that received the $S$. aureus inoculum, but where no treatment was provided (inoculated control) no bone healing was observed. Implants and fibrous capsule samples from 9 out of the 10 rabbits were culture positive for $S$. aureus. Whereas in all the other study groups, new bone formation was observed around the 
osteotomy, as well as in the S3 and S4 screw holes, no bone formation was observed in the humeri from the inoculated control rabbits. An inflammatory reaction to staphylococcal infection leads to disruption of the homeostatic balance of bone matrix production and resorption leading to bone loss [41, 42]. CRP values and WBC count were elevated in the rabbits that established a localized infection in the humerus.

Implant and fibrous capsule samples of rabbits that received the HApN hydrogel with gentamicin after inoculation were all culture negative. Also no bacteria were found in the Brown and Brenn stained images. CRP levels and WBC count were comparable to the values observed in the plasma of non-inoculated rabbits. Callus formation around the osteotomy was predominantly located at the trans site of the humerus in the rabbits that had received the HApN hydrogel with gentamicin. Large amounts of mono- and multinucleated histiocytes could be observed at the cis site of the humerus near the osteotomy suggesting ongoing $\mathrm{HApN}$ hydrogel clearance, similar to rabbits in the study group that only received the hydrogel. Osteoblast viability can be lowered by high concentrations of aminoglycosides when exposure takes place over an extended time in vitro [19, 20]. However, in vivo such an effect is not necessarily seen [43] and systemic gentamicin levels $3 \mathrm{hrs}$ post-operatively in this study were low, as was intended by local application of the hydrogel, and were comparable to previously measured values [9].

Operated humeri from the rabbits that cleared the infection by the HApN hydrogel with gentamicin had a significant lower stiffness than the rabbits that only had surgery. Although these rabbits had a significantly larger amount of new callus formed at the trans site of the humerus as observed in infected rabbits, a limited amount of bone was formed at the site of the humerus where the HApN hydrogel with gentamicin had cleared the bacterial load. This limited callus formation at the cis site of the humerus concealed the difference in healing status between humeri from the gentamicin-loaded HApN treated and infected rabbits in the mechanical testing data.

As the bacterial load in this study was high $\left(2 \times 10^{6} \mathrm{CFU}\right)$, and much higher than the normal amount of contamination found in wounds, a large amount of dead bacteria might remain in the inoculated area. The presence of this dead bacteria, killed by the 
gentamicin released from the HApN hydrogel might influence bone healing, as was shown in mice $[44,45]$. In mice, this surface-associated material from $S$. aureus cell wall preparations stimulates the production of TNFa and IL-6, leading to increased bone resorption and osteoclast formation [44, 45].

However, on the long term fracture healing is anticipated as after the clearance of the high bacterial load with the gentamicin-loaded HApN hydrogel callus formation was observed which might make bridging of the osteotomy possible on the long term. A potential solution to speed-up the bone healing process could consist of the addition of osteopromotive factors [46-49].

\section{Conclusion}

In this in vivo fracture model including osteotomy, plate fixation and bacterial inoculum, the gentamicin-loaded HApN hydrogel was successful in preventing an infection. The HApN hydrogel itself did not evoke any systemic response as was shown by the absence of differences in hematological values between the rabbits that were only operated and the rabbits that were additionally injected with the HApN hydrogel. Bone formation is not significantly hindered by application of the HApN hydrogel itself as can be seen from the mechanical testing results, as well as from the evaluated stained humeri sections. However, there is a delay in bone healing which might likely be resolved at a later time point. In the group where rabbits got inoculated with $S$. aureus and which received the HApN hydrogel with gentamicin, additional factors such as the presence of dead bacteria might further slowdown bone healing. However, on the long term were the infected humeri showed lots of necrosis and a total absence of callus formation round the osteotomy and the S3 and S4 screw holes, it is to be expected that the humeri of the inoculated rabbits that got treated with the HApN hydrogel with gentamicin would heal. Thus, the thermoresponsive HApN hydrogel is an effective delivery system for prophylactic antibiotics which does not affect fracture healing itself, and will be evaluated in a large animal model in the future. 


\section{Acknowledgements}

The authors like to thank Dr. med. vet. Stephan Zeiter and Dr. med. vet. Daniel Arens for assistance during the planning and execution of the rabbit surgeries, Iris Keller for assisting with the bacteriology work, Nora Goudsouzian and Mauro Bluvol for preparing the histological sections (All from the AO Research Institute Davos, Davos, Switzerland). Dr. Wouter Potters (Amsterdam Medical Center, Amsterdam, The Netherlands) is thanked for his support with the schematic image displaying the general set-up for performing the 4-point bending test. Prof. Dr. Laurent Decosterd (Laboratory of Clinical Pharmacology, University Hospital Lausanne, Lausanne, Switzerland) is thanked for performing the immuno-assay to quantify gentamicin in the rabbit plasma. This work was funded as part of the AOTrauma Clinical Priority Program Bone Infection. 


\section{References}

[1] Darouiche RO. Treatment of infections associated with surgical implants. N Engl J Med. 2004;350:1422-9.

[2] Inzana JA, Schwarz EM, Kates SL, Awad HA. Biomaterials approaches to treating implant-associated osteomyelitis. Biomaterials. 2016;81:58-71.

[3] Metsemakers WJ, Handojo K, Reynders P, Sermon A, Vanderschot P, Nijs S. Individual risk factors for deep infection and compromised fracture healing after intramedullary nailing of tibial shaft fractures: a single centre experience of 480 patients. Injury. 2015;46:740-5.

[4] Darouiche RO. Device-associated infections: a macroproblem that starts with microadherence. Clin Infect Dis. 2001;33:1567-72.

[5] Boxma H, Broekhuizen T, Patka P, Oosting H. Randomised controlled trial of single-dose antibiotic prophylaxis in surgical treatment of closed fractures: the Dutch Trauma Trial. Lancet. 1996;347:1133-7.

[6] Gosselin RA, Roberts I, Gillespie WJ. Antibiotics for preventing infection in open limb fractures. Cochrane Database Syst Rev. 2004:CD003764.

[7] Metsemakers WJ, Emanuel N, Cohen O, Reichart M, Potapova I, Schmid T, et al. A doxycycline-loaded polymer-lipid encapsulation matrix coating for the prevention of implant-related osteomyelitis due to doxycycline-resistant methicillin-resistant Staphylococcus aureus. J Control Release. 2015;209:47-56.

[8] ter Boo GJ, Grijpma DW, Moriarty TF, Richards RG, Eglin D. Antimicrobial delivery systems for local infection prophylaxis in orthopedic- and trauma surgery. Biomaterials. 2015;52:113-25.

[9] ter Boo G-JA, Arens D, Metsemakers W-J, Zeiter S, Geoff Richards R, Grijpma DW, et al. Injectable gentamicin-loaded thermo-responsive hyaluronic acid derivative prevents infection in a rabbit model. Acta Biomaterialia.

[10] Aya KL, Stern R. Hyaluronan in wound healing: rediscovering a major player. Wound Repair Regen. 2014;22:579-93.

[11] Fraser JR, Laurent TC, Laurent UB. Hyaluronan: its nature, distribution, functions and turnover. J Intern Med. 1997;242:27-33. 
[12] Schanté CE, Zuber G, Herlin C, Vandamme TF. Chemical modifications of hyaluronic acid for the synthesis of derivatives for a broad range of biomedical applications. Carbohydrate Polymers. 2011;85:469-89.

[13] Stern R, Asari AA, Sugahara KN. Hyaluronan fragments: an information-rich system. Eur J Cell Biol. 2006;85:699-715.

[14] Oh EJ, Park K, Kim KS, Kim J, Yang JA, Kong JH, et al. Target specific and long-acting delivery of protein, peptide, and nucleotide therapeutics using hyaluronic acid derivatives. J Control Release. 2010;141:2-12.

[15] Tripodo G, Trapani A, Torre ML, Giammona G, Trapani G, Mandracchia D. Hyaluronic acid and its derivatives in drug delivery and imaging: Recent advances and challenges. Eur J Pharm Biopharm. 2015;97:400-16.

[16] Ferguson JY, Dudareva M, Riley ND, Stubbs D, Atkins BL, McNally MA. The use of a biodegradable antibiotic-loaded calcium sulphate carrier containing tobramycin for the treatment of chronic osteomyelitis: a series of 195 cases. Bone Joint J. 2014;96-B:829-36.

[17] McLaren JS, White LJ, Cox HC, Ashraf W, Rahman CV, Blunn GW, et al. A biodegradable antibiotic-impregnated scaffold to prevent osteomyelitis in a contaminated in vivo bone defect model. Eur Cell Mater. 2014;27:332-49.

[18] Stewart RL, Cox JT, Volgas D, Stannard J, Duffy L, Waites KB, et al. The use of a biodegradable, load-bearing scaffold as a carrier for antibiotics in an infected open fracture model. J Orthop Trauma. 2010;24:587-91.

[19] Isefuku S, Joyner CJ, Simpson AH. Gentamicin may have an adverse effect on osteogenesis. J Orthop Trauma. 2003;17:212-6.

[20] Rathbone CR, Cross JD, Brown KV, Murray CK, Wenke JC. Effect of various concentrations of antibiotics on osteogenic cell viability and activity. J Orthop Res. 2011;29:1070-4.

[21] Meghji S, Crean SJ, Hill PA, Sheikh M, Nair SP, Heron K, et al. Surfaceassociated protein from Staphylococcus aureus stimulates osteoclastogenesis: possible role in S. aureus-induced bone pathology. Br J Rheumatol. 1998;37:1095101.

[22] Nair SP, Meghji S, Wilson M, Nugent I, Ross A, Ismael A, et al. Clinical isolates of Staphylococcus aureus have osteolytic surface proteins and a proportion of the 
population have antibodies that block this activity: is this of prognostic significance? Br J Rheumatol. 1997;36:328-32.

[23] Ambrose CG, Gogola GR, Clyburn TA, Raymond AK, Peng AS, Mikos AG. Antibiotic microspheres: preliminary testing for potential treatment of osteomyelitis. Clin Orthop Relat Res. 2003:279-85.

[24] Peng KT, Chen CF, Chu IM, Li YM, Hsu WH, Hsu RW, et al. Treatment of osteomyelitis with teicoplanin-encapsulated biodegradable thermosensitive hydrogel nanoparticles. Biomaterials. 2010;31:5227-36.

[25] Bellini D, Topai A. Amides of hyaluronic acid and the derivatives thereof and a process for their preparation. 2000.

[26] D'Este M, Alini M, Eglin D. Single step synthesis and characterization of thermoresponsive hyaluronan hydrogels. Carbohydr Polym. 2012;90:1378-85.

[27] Campoccia D, Montanaro L, Moriarty TF, Richards RG, Ravaioli S, Arciola CR. The selection of appropriate bacterial strains in preclinical evaluation of infectionresistant biomaterials. Int J Artif Organs. 2008;31:841-7.

[28] Moriarty TF, Campoccia D, Nees SK, Boure LP, Richards RG. In vivo evaluation of the effect of intramedullary nail microtopography on the development of local infection in rabbits. Int J Artif Organs. 2010;33:667-75.

[29] Arens D, Wilke M, Calabro L, Hackl S, Zeiter S, Zderic I, et al. A rabbit humerus model of plating and nailing osteosynthesis with and without Staphylococcus aureus osteomyelitis. Eur Cell Mater. 2015;30:148-61; discussion 61-2.

[30] D'Este M, Sprecher CM, Milz S, Nehrbass D, Dresing I, Zeiter S, et al. Evaluation of an injectable thermoresponsive hyaluronan hydrogel in a rabbit osteochondral defect model. J Biomed Mater Res A. 2016;104:1469-78.

[31] Sha M, Guo Z, Fu J, Li J, Yuan CF, Shi L, et al. The effects of nail rigidity on fracture healing in rats with osteoporosis. Acta Orthop. 2009;80:135-8.

[32] Stoffel K, Klaue K, Perren SM. Functional load of plates in fracture fixation in vivo and its correlate in bone healing. Injury. 2000;31 Suppl 2:S-B37-50.

[33] Terjesen T. Plate fixation of tibial fractures in the rabbit. Correlation of bone strength with duration of fixation. Acta Orthop Scand. 1984;55:452-6.

[34] Wang XP, Zhang XL, Li ZG, Yu XG. A first order system model of fracture healing. J Zhejiang Univ Sci B. 2005;6:926-30.

[35] Laurent TC, Fraser JR. Hyaluronan. FASEB J. 1992;6:2397-404. 
[36] Leone G, Consumi M, Lamponi S, Magnani A. New hyaluroran derivative with prolonged half-life for ophthalmogical formulation. Carbohydrate Polymers. 2012;88:799-808.

[37] Holloway JL, Ma H, Rai R, Burdick JA. Modulating hydrogel crosslink density and degradation to control bone morphogenetic protein delivery and in vivo bone formation. J Control Release. 2014;191:63-70.

[38] Purcell BP, Kim IL, Chuo V, Guinen T, Dorsey SM, Burdick JA. Incorporation of Sulfated Hyaluronic Acid Macromers into Degradable Hydrogel Scaffolds for Sustained Molecule Delivery. Biomater Sci. 2014;2:693-702.

[39] Patterson J, Siew R, Herring SW, Lin AS, Guldberg R, Stayton PS. Hyaluronic acid hydrogels with controlled degradation properties for oriented bone regeneration. Biomaterials. 2010;31:6772-81.

[40] Mellati A, Valizadeh Kiamahalleh M, Dai S, Bi J, Jin B, Zhang H. Influence of polymer molecular weight on the in vitro cytotoxicity of poly ( $\mathrm{N}$-isopropylacrylamide). Mater Sci Eng C Mater Biol Appl. 2016;59:509-13.

[41] Henderson B, Nair SP. Hard labour: bacterial infection of the skeleton. Trends Microbiol. 2003;11:570-7.

[42] Matsuo K, Irie N. Osteoclast-osteoblast communication. Arch Biochem Biophys. 2008;473:201-9.

[43] Haleem AA, Rouse MS, Lewallen DG, Hanssen AD, Steckelberg JM, Patel R. Gentamicin and vancomycin do not impair experimental fracture healing. Clin Orthop Relat Res. 2004:22-4.

[44] Takeuchi O, Hoshino K, Akira S. Cutting edge: TLR2-deficient and MyD88deficient mice are highly susceptible to Staphylococcus aureus infection. J Immunol. 2000;165:5392-6.

[45] Takeuchi O, Hoshino K, Kawai T, Sanjo H, Takada H, Ogawa T, et al. Differential roles of TLR2 and TLR4 in recognition of gram-negative and grampositive bacterial cell wall components. Immunity. 1999;11:443-51.

[46] Doty HA, Leedy MR, Courtney HS, Haggard WO, Bumgardner JD. Composite chitosan and calcium sulfate scaffold for dual delivery of vancomycin and recombinant human bone morphogenetic protein-2. J Mater Sci Mater Med. 2014;25:1449-59. 
[47] Mantripragada VP, Jayasuriya AC. Effect of dual delivery of antibiotics (vancomycin and cefazolin) and BMP-7 from chitosan microparticles on Staphylococcus epidermidis and pre-osteoblasts in vitro. Mater Sci Eng C Mater Biol Appl. 2016;67:409-17.

[48] Strobel C, Bormann N, Kadow-Romacker A, Schmidmaier G, Wildemann B. Sequential release kinetics of two (gentamicin and BMP-2) or three (gentamicin, IGFI and BMP-2) substances from a one-component polymeric coating on implants. J Control Release. 2011;156:37-45.

[49] Suzuki A, Terai H, Toyoda H, Namikawa T, Yokota Y, Tsunoda T, et al. A biodegradable delivery system for antibiotics and recombinant human bone morphogenetic protein-2: A potential treatment for infected bone defects. J Orthop Res. 2006;24:327-32. 


\section{Chapter 6}

\section{Preparation of gentamicin dioctyl sulfosuccinate loaded poly(trimethylene carbonate) matrices intended for the treatment of orthopedic infections}

Gert-Jan A. ter Boo ${ }^{1,2}$, Dirk W. Grijpma ${ }^{2,3}$, Robert G. Richards ${ }^{1}$, Thomas F. Moriarty ${ }^{1}$, David Eglin $^{1}$

${ }^{1}$ AO research institute Davos, Clavadelerstrasse 8, CH 7270 Davos, Switzerland

${ }^{2}$ Department of Biomaterials Science and Technology, University of Twente, Enschede, P.O. Box 217, 7500 AE Enschede, The Netherlands

${ }^{3}$ Department of Biomedical Engineering, W.J. Kolff Institute, University Medical Cente Groningen, University of Groningen, P.O. Box 196, 9700 AD Groningen, The Netherlands

* Clin Hemorheol Microcirc. 60 (2015) 89-98 


\section{Abstract}

Infection is a common problem in trauma- and orthopaedic surgery. Antibiotic-loaded biomaterials are used locally to clear infections as an adjunct to systemic antibiotics. Gentamicin-sulphate (GEN-SULPH) is commonly used in antibiotic-loaded biomaterials, although it displays high water solubility resulting in quick diffusion from the carrier. The objective of this study was the preparation of a lipophilic derivative of gentamicin to reduce solubility and obtain a slower release. Subsequently, this lipophilic gentamicin was entrapped within poly(trimethylene carbonate) (PTMC) matrices. Hydrophobic ion-pairing was used to prepare lipophilic gentamicin (GENAOT). The susceptibility of Staphylococcus aureus NCTC 12973 and Staphylococcus epidermidis 103.1 for GEN-AOT was tested and the viability of fibroblasts upon exposure to GEN-AOT was assessed. GEN-AOT was then loaded into PTMC films. GEN-AOT was successfully prepared as confirmed by FTIR-spectroscopy. GEN-AOT was bactericidal for $S$. epidermidis and $S$. aureus at $0.5 \mu \mathrm{M}$ and $8.5 \mu \mathrm{M}$, respectively. At $1.1 \mu \mathrm{M}$ GEN-AOT no reduction in fibroblast viability was observed. At $11 \mu \mathrm{M}$ the reduction was $\sim 50 \%$. PTMC discs loaded with GEN-AOT were prepared by compression molding. Therefore, it could be concluded that lipophilic GEN-AOT was at least as potent as GEN-SULPH. For S. epidermidis it was even more potent than GEN-SULPH. More than $50 \%$ fibroblast cell viability was maintained at bactericidal concentration for both bacterial strains.

\section{Introduction}

The incidence of infection seriously threatens modern-day advances in the field of orthopaedics and traumatology. Most infections related to implanted fracture fixation devices and orthopaedic implants are caused by Staphylococci [1,2]. Bacteria present in a biofilm on the surface of an implant, necrotic bone or living tissue can enter a state of reduced growth and become less susceptible to killing by growthdependent antimicrobials [3]. Treatment of these infections is therefore difficult, and usually involves systemic administration of antibiotics over an extended time of approximately 6 weeks. Antibiotic-loaded biomaterials are used as an adjunct treatment for clearing these infections. Two types of antibiotic-loaded biomaterials are used in the clinic: Non-degradable poly(methyl methacrylate) (PMMA) blocks and 
beads, which need to be removed after the treatment has finished [4] (these PMMA based materials have a poor antibiotic release profile [5]), and degradable biomaterials such as calcium phosphate cements [6] or collagen fleece [7]. The latter may be advantageous as they do not need removal. However, usually antibiotic release is not simultaneous with degradation $[8,9]$. Often this leads to a suboptimal antibiotic release profile and the presence of a biomaterial without antibiotic action.

Many antibiotic-loaded biomaterials used in the clinic are loaded with gentamicin [10]. However, the sulphate salt of gentamicin, gentamicin-sulphate (GEN-SULPH) is highly soluble, which results in fast diffusion from the carrier [9]. A less soluble salt, gentamicin crobefate, has been combined with collagen fleece, extending the release kinetics, but simultaneous resorption of the carrier and antibiotic release was not achieved [8].

Poly(trimethylene carbonate) (PTMC) as opposed to other biodegradable polymers synthesized by ring-opening polymerization (ROP), degrades by enzymatic surface erosion [11,12]. Other biodegradable polymers, like poly(lactic acid) (PLA), poly(glycolic acid) (PGA) and poly(caprolactone) (PCL) and their copolymers degrade by bulk erosion into acidic degradation products. So, PTMC has the advantage of degrading in a more controlled fashion which could be beneficial for the release profile of antibiotics from the material. PTMC based carriers will gradually reduce their thickness when degrading, so the diffusion pathway for antibiotics entrapped closer to the core of the carrier will be become shorter, leading to a more gradual release as compared to release from a bulk degrading matrix. Furthermore, the degradation products of PTMC are non-acidic (predominantly cyclic TMC monomer, cyclic and linear oligomers of TMC and 1,3-propanediol) [13], so these will not interfere with aminoglycoside activity and bone healing, which are impaired at low $\mathrm{pH}$.

Therefore, it was hypothesized that a delivery system based on PTMC, and entrapping a lipophilic gentamicin complex, could be advantageous for a sustained antibiotic release and would be able to achieve this in the absence of negative stimuli that impair antibiotic action and bone healing. 
Hence, a lipophilic complex of gentamicin was prepared by hydrophobic ion-pairing with dioctyl sodium sulfosuccinate (tradename Aerosol OT (AOT)) and characterized by means of Fourier Transform Infrared Spectroscopy (FTIR). Minimal inhibitory concentrations (MIC) and minimal bactericidal concentrations (MBC) for relevant bacterial species, as well as cell viability upon exposure, were assessed for this lipophilic gentamicin. High molecular weight linear PTMC was prepared by ROP and characterized by means of gel permeation chromatography (GPC). Finally, PTMC films loaded with GEN-SULPH and GEN-AOT were prepared by compression molding, demonstrating the ability to produce PTMC membranes homogeneously loaded with lipophilic gentamicin for a sustained and controlled antibiotic release.

\section{Experimental}

\section{Materials:}

TMC monomer was obtained from Huizhou Foryou Medical Devices (China). Stannous octoate $\left(\mathrm{Sn}(\mathrm{Oct})_{2}\right)$, dioctyl sodium sulfosuccinate, gentamicin sulphate salt and sodium chloride were purchased from Sigma-Aldrich (St. Louis, MO, USA). Sodium acetate, potassium chloride, calcium chloride dehydrate and tyrode buffer saline solution (TBSS) were purchased from Fluka (Buchs, Switzerland). Dimethyl sulfoxide (DMSO) $(\geq 99.5 \%)$ was purchased from Carl Roth (Karlsruhe, Germany). Staphylococcus Aureus (S. aureus) NCTC 12973 was purchased from the National Collection of Type Cultures (NCTC). Staphylococcus epidermidis (S. epidermidis) 103.1 was obtained as clinical isolate from a patient with an infected plate osteosynthesis at the BGU Murnau, Germany. Tryptone soy agar (casein soy bean digest agar, CM0131) and Mueller Hinton (MH) broth (CM0405, LOT\# 970220) were purchased from OXOID (Basel, Switzerland). Cation adjusted Mueller Hinton (CAMH) broth was prepared by adding $\mathrm{Ca}^{2+}$ and $\mathrm{Mg}^{2+}$ to the $\mathrm{MH}$ broth to obtain a final cation content of $20-25 \mathrm{mg} / \mathrm{L} \mathrm{Ca}^{2+}$ and $10-12.5 \mathrm{mg} / \mathrm{L} \mathrm{Mg}^{2+}$. The cation containing solutions were sterile filtered before addition to the broth. Dulbecco's modified Eagles medium (DMEM), L-glutamine, sodium pyruvate, foetal calf serum (FCS) and Trypsin/Ethylenediaminetetraacetic acid (EDTA) were purchased from Gibco Life 
Technologies (Waltham, MA, USA). Cell titer blue $\AA$ was purchased from Promega (Madison, WI, USA).

\section{Preparation of lipophilic gentamicin-dioctyl sulfosuccinate (GEN-AOT)}

AOT was used for hydrophobic ion pairing (HIP) with GEN-SULPH. Equal volumes of GEN-SULPH in buffer (10 mM sodium acetate, $\mathrm{KCl}$ and $\mathrm{CaCl}_{2}(\mathrm{pH} 5)(0.40 \% \mathrm{w} / \mathrm{v})$ ) and $\mathrm{AOT}$ in $\mathrm{CH}_{2} \mathrm{Cl}_{2}(1.25 \% \mathrm{w} / \mathrm{v})$ were mixed by vigorous stirring for $3 \mathrm{~h}$ and left for $0.5 \mathrm{~h}$ to separate the 2 phases. GEN-AOT was isolated from $\mathrm{CH}_{2} \mathrm{Cl}_{2}$ by evaporation of the solvent. Both structures for GEN-SULPH and GEN-AOT are depicted in figure 6.1 .

GEN-SULPH<smiles>O=S(=O)(O)O</smiles><smiles>[2H]C1CC[C@@H](N)[C@H](C[C@@H]2[C@H](N)C[C@@H](N)[C@@H](OC3OC[C@](C)(O)[C@H](NC)[C@H]3O)[C@@H]2O)O1</smiles><smiles>CCNCC(C)NCC(C)NC</smiles>

GEN-AOT<smiles>CCCCC(CC)COC(=O)CC(CC(=O)OCC(CC)CCCC)S(=O)(=O)OC</smiles>

$\mathrm{R}=$<smiles>CCNCC(C)NCC(C)NC</smiles>

Figure 6.1: Structure of gentamicin sulfate (GEN-SULPH) and gentamicin AOT (GEN-AOT)

\section{Characterization of gentamicin-dioctyl sulfosuccinate (GEN-AOT)}

The successful hydrophobic ion pairing of GEN-SULPH with AOT was confirmed by Fourier Transform Infrared Spectroscopy (FTIR) on a Bruker Tensor 27 
spectrophotometer equipped with a single reflection diamond attenuated total reflection (ATR) accessory. Spectra (single measurements with 128 repeated scans per IR spectrum) were recorded for both starting compounds, GEN-SULPH and AOT, and for the GEN-AOT isolated from the $\mathrm{CH}_{2} \mathrm{Cl}_{2}$ layer after the HIP process. Additional to the previous stated compounds, also the spectrum for a physical mixture of GENSULPH and AOT was recorded.

\section{Antimicrobial susceptibility testing}

2 clinical relevant bacterial strains were selected for susceptibility testing of GENAOT. The used strains were: S. aureus NCTC 12973 (SA) and S. epidermidis 103.1 $(S E)$. Antibiotic solutions were prepared in $\mathrm{CAMH}$ broth by doubling dilution in a concentration range from $271 \mu \mathrm{M}-0.06 \mu \mathrm{M}$. The minimal inhibitory concentrations (MIC), the concentration for which bacterial growth is inhibited and the minimal bactericidal concentrations (MBC), the concentration for which bacteria are killed, were determined according CLSI guidelines M7-A9 (2012) [14]. All concentrations of the antibiotic solutions were measured in triplicate, as well as the positive control (no antibiotic + inoculum), DMSO control (10\% v/v DMSO in broth + inoculum) and the sterility control (no antibiotic + no inoculum). For the susceptibility testing, GENSULPH and AOT were solubilized and diluted directly in CAMH broth. In order to solubilize GEN-AOT and to prepare the dilution range, GEN-AOT was first dissolved in DMSO at 10x the final concentration, after which $10 \mu$ of this solution was added to $90 \mu \mathrm{l} \mathrm{CAMH}$ broth in the wells of a 96 -wells plate. Solubilisation of GEN-AOT in $10 \% \mathrm{v} / \mathrm{v}$ DMSO did not impair viability of the bacterial strains (data not shown). Although, an end concentration of $5 \% \mathrm{v} / \mathrm{v}$ DMSO in the wells did not inhibit bacterial growth, it cannot be excluded that there is a synergistic effect between GEN-AOT and DMSO [15]. Finally, $100 \mu$ inoculum $\left(5 \times 10^{5} \mathrm{CFU} / \mathrm{ml}\right)$ of the respective bacterial strain was added to every well, to reach a final volume of $200 \mu \mathrm{l} /$ well.

\section{Viability testing for fibroblast cell line}

The hTERT fibroblast BJ-1 cell line was used for viability testing upon exposure to the antibiotics following the basic rules as prescribed in ISO-10993-5 [16]. Viability was assessed after $24 \mathrm{~h}$ and $72 \mathrm{~h}$ of exposure of the cells to the antibiotics. An 
antibiotic concentration range from $0.53 \mu \mathrm{M}-2.12 \mathrm{mM}$ was prepared for viability testing. After $24 \mathrm{~h}$ and $72 \mathrm{~h}$ respectively, cell media containing the antibiotics was removed from the wells of the 96-wells plate and the cells were incubated for $2.5 \mathrm{~h}$ with cell titer blue after which the fluorescence intensity $(\mathrm{FI})$ was measured $\left(\lambda_{\text {excitation }}=\right.$ $\left.560 \mathrm{~nm}, \lambda_{\text {emission }}=590 \mathrm{~nm}\right)$. FI was measured with a Perkin Elmer Victor 3 1420-012 multi-label microplate reader. All sample concentrations, including the controls, were measured in quadruplicate. Viability was expressed as relative percentage with respect to the untreated control. Viability $=\left(\mathrm{Fl}_{\text {sample }}-\mathrm{FI}_{\text {negative control }}\right) /\left(\mathrm{Fl}_{\text {positive control }}\right.$ $\mathrm{FI}_{\text {negative control) }} \times 100$.

\section{Polymer synthesis and characterization:}

High molecular weight (HMW) PTMC was synthesized by ROP of trimethylene carbonate in the presence stannous octoate $\left(\mathrm{Sn}(\mathrm{Oct})_{2}\right)\left(2 \times 10^{-4} \mathrm{~mol} \mathrm{Sn}(\mathrm{Oct})_{2}\right.$ per mol TMC) as catalyst (Figure 6.2). No initiator was added to obtain a high molecular weight polymer. Polymerization was performed in the melt in dry vacuum sealed silanized glass ampoules for $48 \mathrm{~h}$ at $130^{\circ} \mathrm{C}$. Number average molecular weight $\left(\mathrm{M}_{\mathrm{n}}\right)$ and intrinsic viscosity (IV) were determined by gel permeation chromatography (GPC, Viscotek (US)). Chloroform was used as eluent at a flow rate of $1.0 \mathrm{ml} / \mathrm{min}$. The GPC system was equipped with ViscoGEL I-guard-0478, ViscoGEL I-MBHMW3078 and ViscoGEL I-MBLMW-3078 columns in series and a TDA 302 triple detector array with refractometer-, viscometer-, and light scattering detectors to determine the absolute molecular weights.

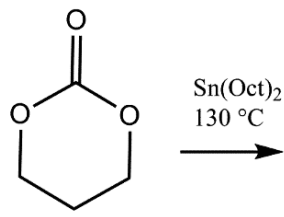

trimethylene carbonate

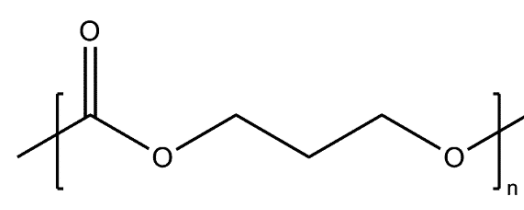

poly(trimethylene carbonate)

Figure 6.2: Ring opening polymerization of trimethylene carbonate 


\section{Preparation of GEN-AOT loaded PTMC discs}

PTMC was dissolved in $\mathrm{CH}_{2} \mathrm{Cl}_{2}$ at a concentration of $4 \% \mathrm{w} / \mathrm{v}$. Then either no antibiotic or $10 \% \mathrm{w} / \mathrm{w}$ GEN-SULPH or $10 \% \mathrm{w} / \mathrm{w}$ GEN-AOT was added to this solution. GEN-SULPH was dispersed through the PTMC solution by ultrasonication for $5 \mathrm{~min}$. Since GEN-AOT is soluble in the PTMC solution it was not sonicated. Subsequently, the GEN-SULPH or GEN-AOT containing PTMC solutions were stirred for 24h. The GEN-SULPH containing solutions were then precipitated in diethyl ether and the GEN-AOT containing solutions were poured in petri-dishes after which the $\mathrm{CH}_{2} \mathrm{Cl}_{2}$ was allowed to evaporate for 1 week. Finally, PTMC, PTMC with $10 \% \mathrm{w} / \mathrm{w}$ GEN-SULPH and PTMC with $10 \% \mathrm{w} / \mathrm{w}$ GEN-AOT were compression moulded in stainless steel molds at $70^{\circ} \mathrm{C}$ and $300 \mathrm{kN}$ force with a laboratory press (Fonteijne THB008, The Netherlands). The antibiotic-containing polymer films were cooled to room temperature using cold water. $500 \mu \mathrm{m}$ thick films were obtained, and $\varnothing 8 \mathrm{~mm}$ discs were punched out of these films.

\section{Characterization of GEN-AOT loaded PTMC discs}

Differential Scanning Calorimetry was performed on a Pyris DSC-1 Perkin-Elmer instrument calibrated with indium. PTMC, PTMC-GEN-SULPH and PTMC-GEN-AOT samples were weighed in hermetically closed aluminium pans. Measurements performed in triplicate, were carried out under a dry nitrogen atmosphere at a flow rate of $20 \mathrm{~mL} / \mathrm{min}$. Each measurement was run heating the sample from $-30^{\circ} \mathrm{C}$ to $100^{\circ} \mathrm{C}$. The sample was held for $1 \mathrm{~min}$ at $100^{\circ} \mathrm{C}$ and cooled to the initial temperature. Heating and cooling ramps were run at a rate of $5^{\circ} \mathrm{C} / \mathrm{min}$.

\section{Optical microscopy}

Optical microscopy was performed to assess the antibiotic distribution throughout the GEN-SULPH and GEN-AOT loaded PTMC films. Images of the films were captured using a Zeiss CCD camera (Axiocam HRc, Jena, Germany) attached to an optical microscope in diffuse illumination mode with a macrolens (Leica, Macrofluo, Wetzlar, Germany) using Zeiss Axiovision Vs40 (v4.6.3.0) image acquisition software. Gray values (GVs) of circular areas of the specimens with $3200 \mu \mathrm{m}$ radius were recorded 
and analysed. Average GVs and standard deviation were calculated for the PTMC, PTMC-GEN-SULPH and PTMC-GEN-AOT films for this area.

\section{Results}

The composition of the product of the HIP process of GEN-SULPH and AOT was determined by FTIR. The FTIR spectrum of GEN-SULPH, AOT and the product of the HIP (GEN-AOT) can be found in Figure 6.3. An absorption band at $1734 \mathrm{~cm}^{-1}$ (Figure 6.3) in the FTIR spectrum can be both observed for AOT and GEN-AOT. This band can be attributed to the stretching of the $\mathrm{C}=\mathrm{O}$ groups of the ester of the AOT molecule. The absorption band between $1620 \mathrm{~cm}^{-1}$ and $1610 \mathrm{~cm}^{-1}$ (Figure 6.3) present in both GEN-SULPH and GEN-AOT can be attributed to the primary amine groups present on the gentamicin molecule (Figure 6.3). Vibrational bands attributed solely to GEN-SULPH and AOT can be identified in the spectrum of GEN-AOT. As GEN-SULPH is not soluble in $\mathrm{CH}_{2} \mathrm{Cl}_{2}$, these features suggest the successful ionpaired GEN-AOT complex formation. Furthermore, the absorption wavenumber for the stretching vibration for the amine groups present in the gentamicin-sulphate complex is located at $1620 \mathrm{~cm}^{-1}$. The same stretching vibration in the physical mixture of GEN-SULPH and AOT was observed. For the amine groups present in the GEN-AOT complex this vibrational band is located at $1608 \mathrm{~cm}^{-1}$. 


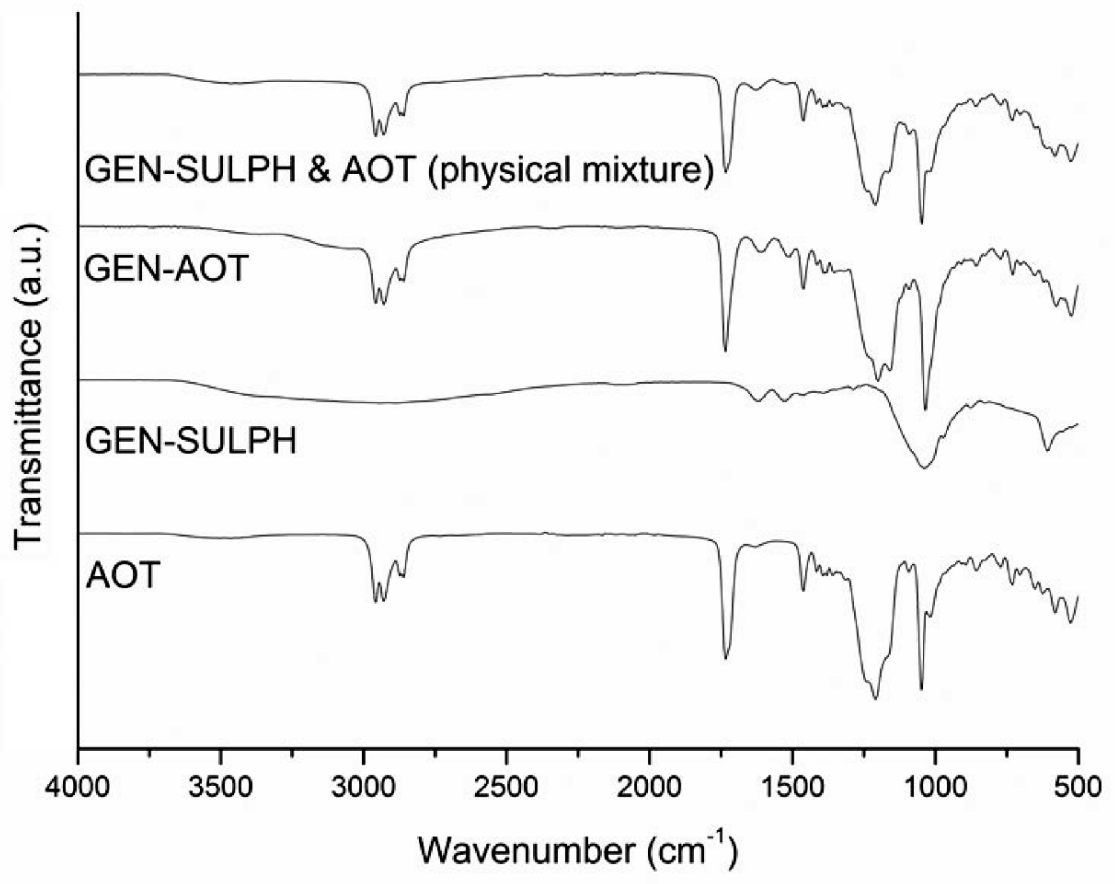

Figure 6.3: FTIR spectra of GEN-SULPH, AOT, physical mixture of GEN-SULPH and AOT and GEN-AOT.

The susceptibility of SA and SE for GEN-AOT and GEN-SULPH as represented in MIC and MBC values can be found in Table 6.1.

Table 6.1: Susceptibility of S. aureus and S.epidermidis for GEN-SULPH, GEN-AOT and $A O T$.

\begin{tabular}{lcccc}
\hline \multicolumn{4}{c}{ Gram-positive } \\
\hline & S. aureus & NCTC 12973 & S. epidermidis 103.1 \\
\hline & MIC $(\mu \mathrm{M})$ & MBC $(\mu \mathrm{M})$ & MIC $(\mu \mathrm{M})$ & MBC $(\mu \mathrm{M})$ \\
\hline GEN-SULPH & 2.1 & 8.5 & 0.5 & 4.2 \\
GEN-AOT & 2.1 & 8.5 & 0.5 & 0.5 \\
AOT & 544 & 544 & 544 & $>544$ \\
\hline
\end{tabular}


As can be seen from Table 6.1, GEN-AOT was at least as effective as GEN-SULPH in inhibiting and killing both Staphylococcal species. Towards S. epidermidis 103.1 it is more bactericidal than GEN-SULPH. AOT itself has no antimicrobial effect as can be seen from the high MIC and MBC values.

The cell viability data reported in Figure 6.4 indicated that GEN-SULPH did not impair fibroblast viability. Even at high concentration of $2.1 \times 10^{3} \mu \mathrm{M}$ GEN-SULPH, $75 \%$ fibroblast cell viability was observed. For GEN-AOT, concentrations up to $1.1 \mu \mathrm{M}$ did not negatively influence fibroblast cell viability. At $11 \mu \mathrm{M}$ GEN-AOT fibroblast cell viability was reduced to $\sim 50 \%$. For free AOT, a sharp decrease in viability is seen when the concentration in the medium is increased from $11 \times 10^{2} \mu \mathrm{M}$ to $21 \times 10^{2}$. This decrease in fibroblast cell viability appears at a higher concentration than for GENAOT. HMW PTMC with $M_{n}=272 \mathrm{~kg} / \mathrm{mol}$ and IV= 2.3 was obtained, which was used for preparation of the antibiotic loaded PTMC discs. PTMC discs, PTMC discs with GEN-SULPH and PTMC discs with GEN-AOT prepared by compression molding were prepared (Figure 6.5). Both the PTMC discs and PTMC discs with GEN-AOT were transparent while the PTMC discs containing GEN-SULPH were opaque indicating a dispersion of the salt in the polymer matrix. 


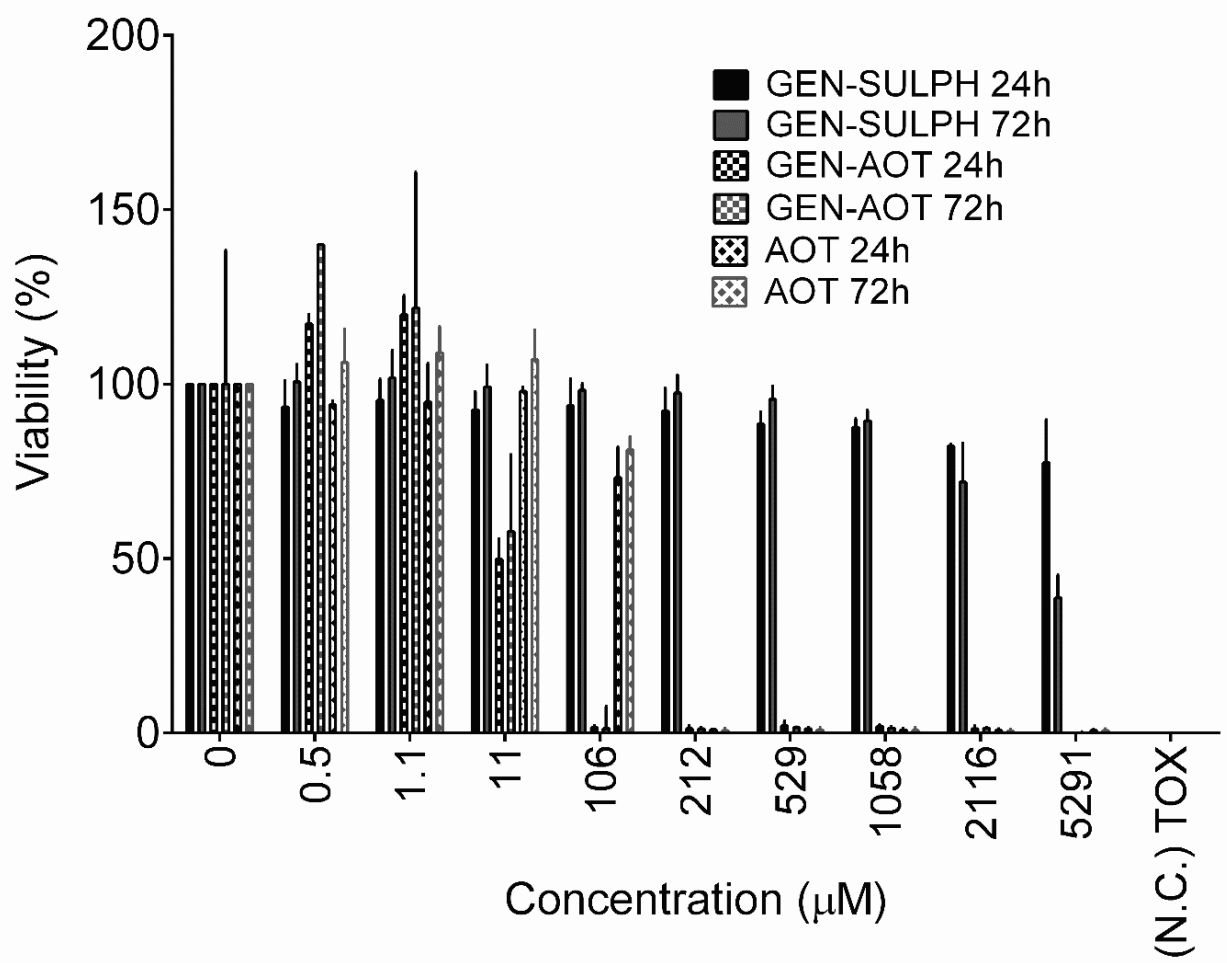

Figure 6.4: $h$ TERT fibroblast cell viability upon $24 h$ and $72 h$ of exposure to GEN-SULPH and GEN-AOT ( $n=4 \pm S D$, and N.C. is negative control).

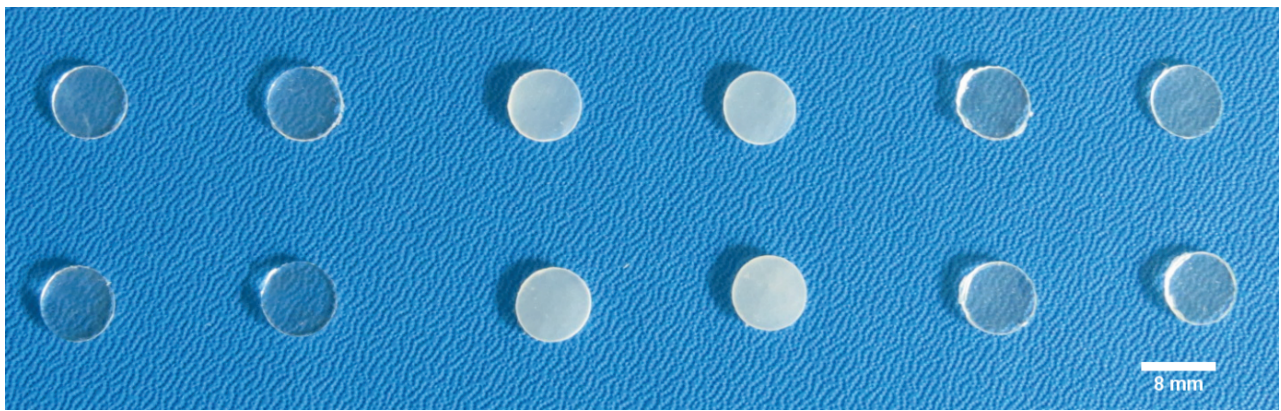

Figure 6.5: ø $8 \mathrm{~mm}$ PTMC discs (left 4), PTMC discs with GEN-SULPH (middle 4) and PTMC discs with GEN-AOT (right 4) prepared by compression molding. 
Table 6.2: Glass transition temperature $\left(T_{g}\right)$ for PTMC, PTMC-GEN-SULPH and PTMCGEN-AOT samples.

\begin{tabular}{lrr}
\hline & \multicolumn{2}{c}{ Peak $\left(\mathrm{T}_{\mathrm{g}}\right)$} \\
\hline Specimen & Heating $\operatorname{ramp}\left(\mathrm{T}\left({ }^{\circ} \mathrm{C}\right)\right)$ & Cooling ramp $\left(\mathrm{T}\left({ }^{\circ} \mathrm{C}\right)\right)$ \\
Pure PTMC & -14.2 & -16.1 \\
PTMC + GEN-SULPH & -12.5 & -13.7 \\
PTMC + GEN-AOT & -12.4 & -14.5 \\
\hline
\end{tabular}

Figure 6.6: Gray values obtained for PTMC discs, PTMC discs with GEN-SULPH and PTMC discs with GEN-AOT by optical microscopy in diffuse illumination mode.

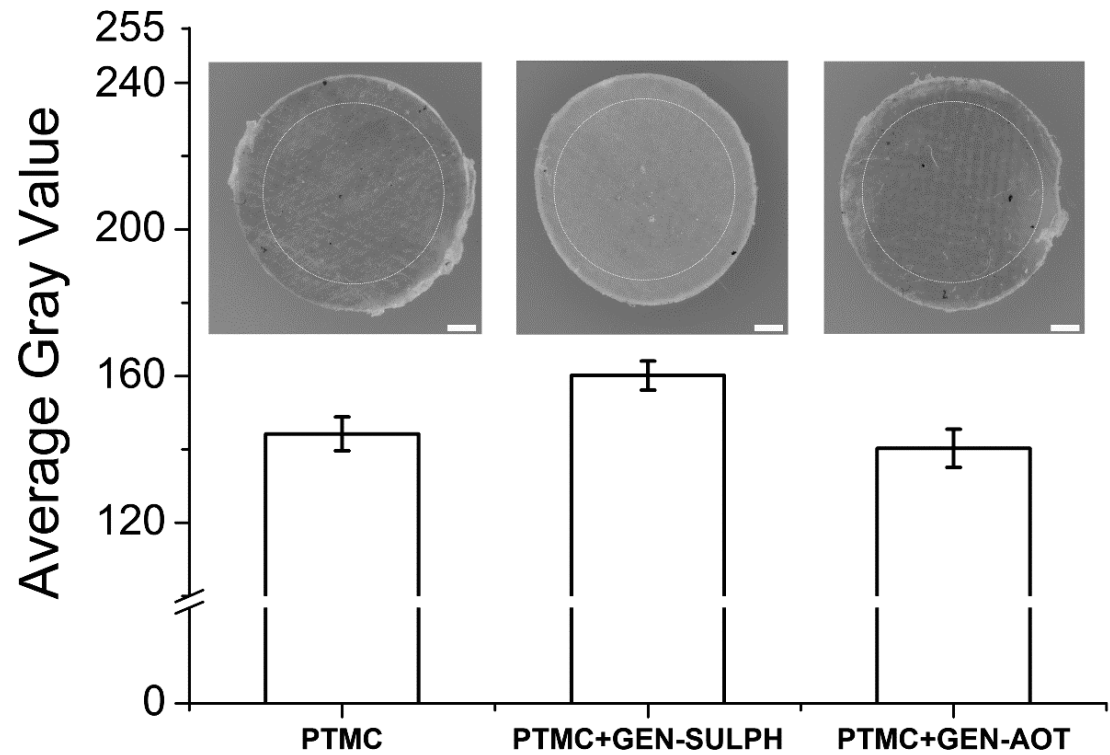

The glass transition temperature $\left(\mathrm{T}_{\mathrm{g}}\right)$ for the PTMC, PTMC-GEN-SULPH and PTMCGEN-AOT discs can be found in table 6.2. The GEN-SULPH and GEN-AOT loaded PTMC samples show a slight decrease of the glass transition temperature, which could be explained by the presence of a relatively high concentration of gentamicin 
$(10 \% \mathrm{w} / \mathrm{w})$. This decrease is due to a possible enhanced interaction between the PTMC chains, established in the presence of the gentamicin.

The homogeneous dispersion of GEN-SULPH and GEN-AOT through the PTMC matrix was assessed by optical microscopy. Average gray values were recorded for all the specimens (Figure 6.6). A significant higher gray value (more reflection due to scattering of larger antibiotic particles) was observed for the PTMC-GEN-SULPH specimens. For all of the films, the standard deviation of the GVs was low, indicating a homogenous dispersion/dissolution of the antibiotic through the films.

\section{Discussion and conclusion}

GEN-SULPH and GEN-AOT inhibit S. aureus and S. epidermidis and kill S. aureus at the same molar concentration. GEN-AOT kills $S$. epidermidis even at lower molar concentration than GEN-SULPH. This indicates that the ion pairing with dioctyl sodium sulfosuccinate does not affect the potency of the antibiotic. Even more, in the case of $S$. epidermidis GEN-AOT seems to be more effective than the sulfate salt of gentamicin; potentially it is more effective in destabilizing the bacterial membrane. Besides the susceptibility of relevant bacterial species for the hydrophobic modified gentamicin, its toxicity towards eukaryotic cells should be taken into account. The modified gentamicin should kill relevant bacterial species, but at the same time it should not impair cell viability. GEN-SULPH has limited effect on fibroblast viability. Only at very high concentration $\left(2.1 \times 10^{3} \mu \mathrm{M}\right)$ viability is reduced to $~ 75 \%$ compared to the untreated control. AOT has an effect on fibroblast cell viability when the concentration is increased from $11 \times 10^{2} \mu \mathrm{M}$ to $21 \times 10^{2} \mu \mathrm{M}$. In the presence of $11 \mu \mathrm{M}$ GEN-AOT, cell viability was reduced to $\sim 50 \%$. Reduction of fibroblast cell viability is observed at lower concentration for GEN-AOT than for AOT. Possibly, the effect of AOT on cell viability is combined with the lipophilic character of GEN-AOT which makes it possible for the GEN-AOT to cross the cell membrane and have a stronger effect on cell viability than AOT alone. However, GEN-AOT killed S. epidermidis at a molar concentration of $0.5 \mu \mathrm{M}$ and killed $S$. aureus at $8.5 \mu \mathrm{M}$, which is below the concentration for which cell viability was reduced with 50\%. HMW PTMC was successfully synthesized and was used for the preparation of GEN-SULPH and 
GEN-AOT loaded discs. In the PTMC the GEN-AOT was well solubilized, while the GEN-SULPH was dispersed through the polymeric matrix.

\section{Acknowledgements}

The authors thank Christoph Sprecher, MSc. for help with optical microscopy. Trimethylene carbonate monomer was a kind gift of Huizhou Foryou Medical Devices (China). This work was funded as part of the AOTrauma Clinical Priority Program Bone Infection. 


\section{References}

[1] Trampuz A, Zimmerli W, Diagnosis and treatment of infections associated with fracture-fixation devices, Injury 2006 (37): S59

[2] Esposito S., Leone S., Prosthetic joint infections: microbiology, diagnosis, management and prevention, Int J Antimicrob Ag 2008 (32): 287

[3] Patel R., Biofilms and antimicrobial resistance, Cli Orthop Relat R 2005 (437): 41

[4] Griffis C.D., Metcalfe S., Bowling F.L., Boulton A.J.M., Armstrong D.G., The use of gentamicin-impregnated foam in the management of diabetic foot infections: a promising delivery system?, Expert Opin Drug Deliv 2009 (6): 639

[5] Frutos Cabanillas P., Diez Pena E., Barrales-Rienda J.M., Frutos G., Validation and in vitro characterization of antibiotic-loaded bone cement release, Int $\mathrm{J}$ Pharm 2000 (209): 15

[6] Silverman L.D., Lukashova L., Herman O.T., Lane J.M., Boskey A.L., Release of gentamicin from a tricalcium phosphate bone implant, J Orthop Res 2007 (25): 23

[7] Friess W., Collagen - biomaterial for drug delivery, Eur J Pharm Biopharm 1998 (45): 113

[8] Kilian O., Hossain H., Flesch I., Sommer U., Nolting H., Chakraborty T., et al. Elution kinetics, antimicrobial efficacy, and degradation and microvasculature of a new gentamicin-loaded collagen fleece, J Biomed Mater Res B 2009 (90): 210

[9] Sørensen T.S., Sørensen A.I., Merser S., Rapid release of gentamicin from collagen sponge In vitro comparison with plastic beads, Act Orthop Scand 1990 (61): 353

[10] Diefenbeck M., Mückley T., Hofmann G.O., Prophylaxis and treatment of implant-related infections by local applications of antibiotics, Injury 2006 (37): S95 [11] Zhang Z., Kuijer R., Bulstra S.K., Grijpma D.W., Feijen J., The in vivo and in vitro degradation behavior of poly(trimethylene carbonate), Biomaterials 2006 (27): 1741 [12] Bat E., van Kooten T.G., Feijen J., Grijpma D.W., Macrophage-mediated erosion of gamma irradiated poly(trimethylene carbonate) films, Biomaterials 2009 (30): 3652 [13] Matsumura S., Harai S., Toshima K., Lipase-catalyzed transformation of Poly(trimethylene carbonate) into cyclic monomer, Trimethylene carbonate; A new strategy for sustainable polymer recycling using an enzyme, Macromol rapid comm 2001 (22): 215 
[14] Clinical and Laboratory Standards Institute: Methods for dilution antimicrobial susceptibility tests for bacteria that grow aerobically. In Approved standard M7-A9 $9^{\text {th }}$ edition. CLSI, Wayne, Pa: 2012

[15] Tarrand J.J, LaSala P.R., Han X.Y., Rolston K.V., Kontoyiannis D.P., Dimethyl sulfoxide enhances effectiveness of skin antiseptics and reduces contamination rates of blood cultures, J Clin Microbiol 2012 (50): 1552

[16] I.S.O., 10993-5, Part 5: 1999 
Chapter 6 


\section{Chapter 7}

\section{Polymer microparticles with low dispersity loaded with gentamicin sulfate and hydrophobic gentamicin}

Gert-Jan A. ter Boo ${ }^{1,2}$, Dirk W. Grijpma ${ }^{2,3}$, Robert G. Richards ${ }^{1}$, Thomas F. Moriarty ${ }^{1}$, David Eglin ${ }^{1}$

${ }^{1} \mathrm{AO}$ research institute Davos, Clavadelerstrasse 8, CH 7270 Davos, Switzerland

${ }^{2}$ Department of Biomaterials Science and Technology, University of Twente, Enschede, P.O.

Box 217, 7500 AE Enschede, The Netherlands

${ }^{3}$ Department of Biomedical Engineering, W.J. Kolff Institute, University Medical Cente

Groningen, University of Groningen, P.O. Box 196, 9700 AD Groningen, The Netherlands 


\section{Abstract}

Extended local release of antibiotics is required for the treatment of infection. Biodegradable polymeric microparticles can extend the release of hydrophilic gentamicin sulfate, therefore it was incorporated in microparticles. Furthermore, the hydrophilicity of gentamicin was also lowered by a hydrophobic ion pairing process to potentially further extend the release, as well as to be able to incorporate the antibiotic in the same phase as the polymer during the encapsulation process. Membrane emulsification yielded monodisperse gentamicin AOT loaded PDLLA and PTMC microparticles when the polymer and antibiotic were dissolved in the same solvent as dispersed phase in the cross flow membrane emulsification process. These monodisperse antibiotic loaded particles could be interesting for the sustained controlled release of antibiotics.

\section{Introduction}

The treatment of bone infections involves systemic administration of antibiotics over an extended time frame, usually a 4-6 weeks period. It is complemented by the application of ALBs to increase further the local concentration of antibiotic without reaching toxic systemic concentrations and clear the affected tissues from contamination [1, 2]. The high hydrophilicity of several antibiotics, such as gentamicin sulfate commonly used in ALBs limits the time of antibiotic release when encapsulated in injectable hydrophilic polymeric networks, such as hydrogels or nano- or microgels as the antibiotic readily diffuses out. Therefore, these systems usually allow for short term release of antibiotics, suitable for infection prophylaxis, but not for treatment purposes. In order to extend the release and keep the advantages of an injectable system, a so called 'plum pudding' composite hydrogel can be prepared by the incorporation of the antibiotic in hydrophobic biodegradable polymer micro- or nanoparticles dispersed in the hydrogel network [3]. Entrapment of drugs or antibiotics is commonly performed by emulsion solvent evaporation or emulsion solvent extraction processes [7-10]. However, applying these conventional techniques leads to a wide size distribution of the microparticles. 


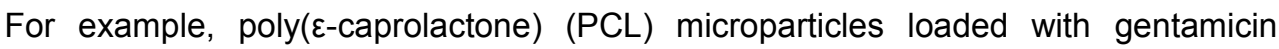
sulfate have been prepared by an emulsion solvent evaporation technique. PCL microparticles produced with a range of initial PCL concentration in the oil phase showed an increase size and large size distribution (Figure 7.1).

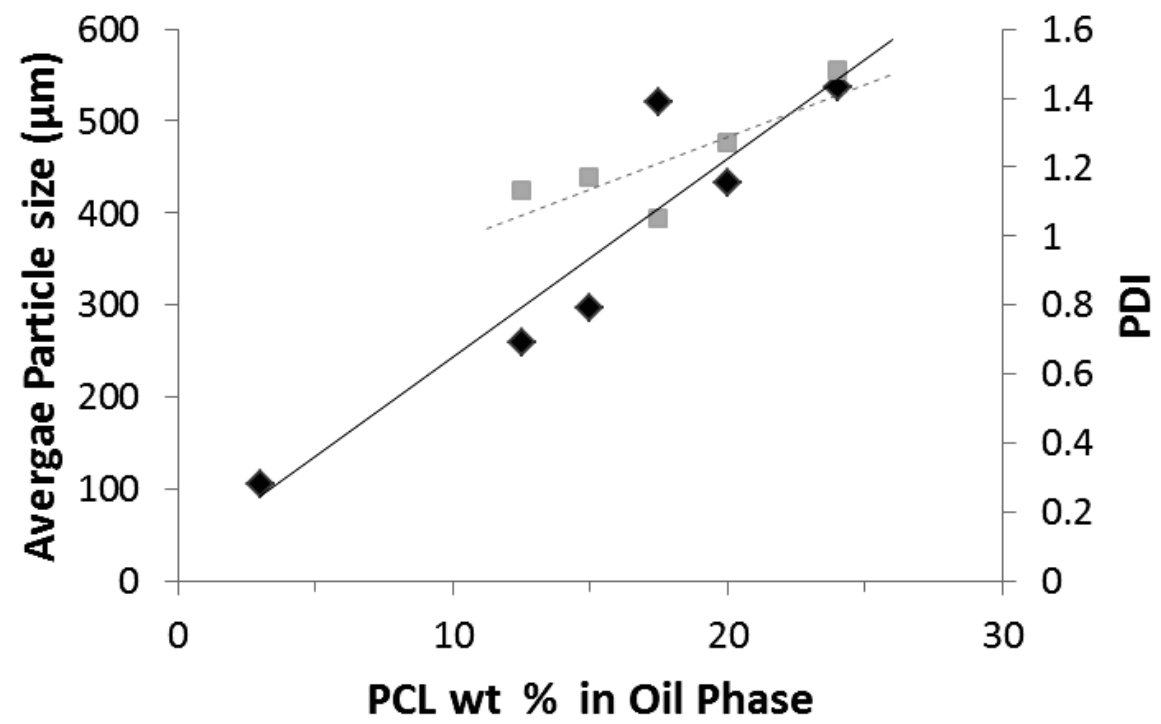

Figure 7.1: Plot of the average microparticle size and polydispersity (PDI) as a function of $P C L(M n=80.000 \mathrm{~g} / \mathrm{mol}(G P C))$ concentration in the oil phase of a single emulsion. PCL was dissolved in $9 \mathrm{ml}$ of dichloromethane (DCM). Subsequently, the emulsion was injected at a rate of $0.5 \mathrm{ml} / \mathrm{min}$ in $250 \mathrm{ml}$ PBS with $0.5 \% \mathrm{w} / \mathrm{w}$ PVA, under magnetic stirring. After addition of the total volume of emulsion, stirring was continued for $1 \mathrm{hr}$, during which the DCM was allowed to evaporate and the particles could harden out. Finally, particles were washed with ultrapure water and spun down (3x), collected and lyophilized. Data point at 3 wt \% PCL is from [4].

Importantly, the gentamicin sulfate can only be dispersed at low concentration, circa $0.3 \% \mathrm{w} / \mathrm{w}$ in the PCL/DCM solution. A gentamicin sulfate dispersion in the PCL microparticles is obtained with relatively low encapsulation efficiency of $39.5 \%$ [4]. The relatively high PDI will together with the heterogeneous dispersion of gentamicin sulfate, result in different release rates of the incorporated antibiotic, with a faster release from smaller particles due to the larger surface area of the particles and the shorter diffusion pathways of the antibiotic from the particles [5]. These lead to a 
release profile consisting in a burst release followed by a sustain release of 30 days [4]. Improved dispersion of gentamicin can potentially be achieved using a water in oil in water emulsion process [6].

In order to better control the size of, and hence the release from the microparticles, efforts have been made to develop techniques which yield monodisperse microparticles such as obtained by membrane, microchannel and microfluidic emulsification devices $[5,7,8]$. In addition, increasing the availability of antibiotic over time can also be achieved by hydrophobic ion pairing, extending its availability via a reduced water solubility of the antibiotic $[9,10]$. Besides extending the release, the hydrophobic modification also simplifies the microencapsulation process of the antibiotic in the hydrophobic polymeric matrix, as only a single emulsion has to be prepared [9], increases drug encapsulation efficiency and drug loading and minimizes the burst release [11].

Here we first describe the preparation of a hydrophobic gentamicin dioctyl sulfosuccinate. Then, poly(D,L-lactide) (PDLLA) and poly(trimethyl carbonate) (PTMC) microparticles with low size dispersion using a microfluidic emulsification device is reported. The degradation rate of PCL was deemed too slow, up to years in vivo and therefore was not assessed further [12]. The influence of the gentamicin sulfate added via a double water/oil/water emulsion process and the hydrophobic salt of gentamicin, gentamicin dioctyl sulfosuccinate, solubilised directly in the PDLLA and the PTMC oil phase, on the produced microspheres size and PDI is finally reported. 


\section{Experimental}

\section{Materials}

Stannous octoate (92.5\%-100\%), gentamicin sulfate (potency $\geq 590 \mu \mathrm{g}$ gentamicin base per mg), dioctyl sodium sulfosuccinate (AOT) and poly(vinyl alcohol) (fully hydrolysed), sucrose ( $\geq 99.5 \%(\mathrm{GC})$ ) were obtained from Sigma-aldrich (St. Louis, MO, USA). D,L-lactide was purchased from Purac Biochem (Gorinchem, The Netherlands). Trimethylene carbonate was a gift from Huizhou Foryou Medical Devices (Huizhou, China). Sodium acetate, potassium chloride and calcium chloride dehydrate were purchased from Fluka (Buchs, Switzerland). Dichloromethane (DCM) was purchased from Carl Roth (Karlsruhe, Germany).

\section{Synthesis and characterization of polymers for encapsulation}

Linear poly(trimethylene carbonate) (PTMC) and poly(D,L-lactide) (PDLLA) were prepared by ring opening polymerization of the corresponding monomers under argon at $130^{\circ} \mathrm{C}$ and using stannous octoate as catalyst. The obtained polymers were purified by dissolution in chloroform and subsequent precipitation in ethanol. Finally, the polymers were dried at RT under vacuum. Number average- and weight average molecular weights $\left(M_{N}\right.$ and $\left.M_{W}\right)$ and polydispersity $\left(M_{W} / M_{N}\right)$ of the polymers were determined by gel permeation chromatography (GPC) (Viscotek, USA) using chloroform as the eluent at a flow rate of $1.0 \mathrm{ml} / \mathrm{min}$. The GPC setup was equipped with a series of ViscoGEL columns and a TDA 302 Triple Detector Array including refractometer-, viscometer- and light scattering detectors for the determination of absolute molecular weights. The obtained molecular weights, were $\mathrm{Mn}=274 \mathrm{~kg} / \mathrm{mol}$ with a PDI value of 1.35 for PTMC and $\mathrm{Mn}=187 \mathrm{~kg} / \mathrm{mol}$ with a PDI value of 1.38 for PDLLA. 


\section{Preparation of hydrophobic modified gentamicin}

Dioctyl sodium sulfosuccinate (AOT) was used for the hydrophobic ion pairing with gentamicin sulfate. Equal volumes of gentamicin sulfate in buffer ( $(10 \mathrm{mM}$ sodium acetate, $\mathrm{KCl}$ and $\left.\mathrm{CaCl}_{2}(\mathrm{pH} 5)(0.40 \% \mathrm{w} / \mathrm{v})\right)$ and $\mathrm{AOT}$ in $\mathrm{DCM}(1.25 \% \mathrm{w} / \mathrm{v})$ were mixed by vigorously stirring for $3 \mathrm{~h}$ and left for $0.5 \mathrm{~h}$ to separate the two phases. Hydrophobic modified gentamicin (gentamicin AOT) was isolated from the DCM fraction by evaporation of the solvent. Fourier Transform Infrared Spectroscopy (FTIR) was performed on a Bruker Tensor 27 spectrophotometer equipped with a single reflection diamond attenuated total reflection (ATR) set-up. Spectra were recorded for gentamicin sulfate, AOT and the gentamicin AOT isolated from the DCM layer, as a control the spectrum for a physical mixture of gentamicin sulfate and AOT was recorded.

\section{Preparation of antibiotic loaded microparticles}

For the preparation of monodisperse antibiotic loaded microparticles a membrane emulsification technology (microsieve ${ }^{\mathrm{TM}}$ ) of Nanomi monosphere technology (Oldenzaal, The Netherlands) was applied. Shortly, a $1 \% \mathrm{w} / \mathrm{w}$ PTMC or a $1 \% \mathrm{w} / \mathrm{w}$ PDLLA solution in DCM were prepared and given into the feed as the dispersed phase. The dispersed phase was injected through the microsieve ${ }^{\mathrm{TM}}$ membrane at a flowrate of $4 \mathrm{ml} / \mathrm{h}$ by a syringe pump. The continuous phase consisting of ultrapure water with $2 \% \mathrm{w} / \mathrm{w}$ of PVA, was flushed through the collection compartment below the membrane at a flowrate of $63 \mathrm{ml} / \mathrm{h}$ by a peristaltic pump (Figure 7.2).

In order to prepare hydrophobic antibiotic loaded microparticles, $20 \% \mathrm{w} / \mathrm{w}$ gentamicin AOT with respect to the polymer content was dissolved into the DCM solution containing the polymer before injection through the membrane.

Gentamicin-sulfate loaded microparticles were prepared by creating a first emulsion prior to membrane emulsification. By mixing a small volume of gentamicin-sulfate dissolved in ultrapure water in a larger volume of polymer dissolved in DCM by ultrasonication with an ultrasonic probe.

Finally, microparticles were collected in a beaker glass and allowed to harden out during mild stirring. Finally, the collected dispersions containing the hardened microparticles were freeze dried in the presence of $5 \%$ sucrose, as a cryoprotectant. 


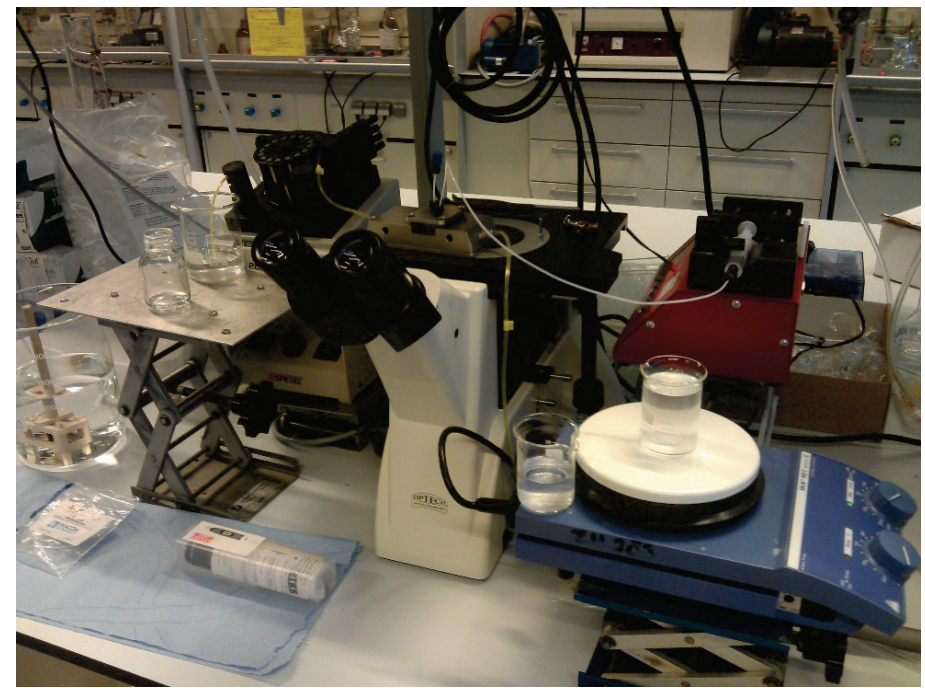

Figure 7.2: General setup for microparticles production with a membrane emulsification device. The dispersed phase is injected through the microsieve membrane by an injection pump and the continuous phase is flow through the channel below the membrane by a peristaltic pump.

\section{Characterization of antibiotic loaded microparticles}

Microparticles were imaged using a light microscope (Nikon Eclipse Fluorescence Microscope). Microparticle sizes were determined with ImageJ software, a public domain, Java-based image processing program developed by the National Institutes of Health (Bethesda, MD, USA). The average size and size distribution of the microparticles prepared by the emulsion solvent evaporation method was determined by measuring 10 spheres each time for the different concentration of PCL used. Finally, PDLLA and PTMC microparticle sizes obtained by membrane emulsification were determined by measuring 100 particles for each of the applied conditions. The mean diameters (number mean $\left(D_{n}\right)$, volume mean $\left(D_{v}\right)$ and polydispersity (PDI) of the microparticles were calculated according to the following equations:
$D_{n}=\frac{\sum_{i=1}^{k} n_{i} D_{i}}{\sum_{i=1}^{k} n_{i}}$
$\mathrm{D}_{\mathrm{v}}=\frac{\sum_{\mathrm{i}=1}^{\mathrm{k}} \mathrm{n}_{\mathrm{i}} \mathrm{D}_{\mathrm{i}}^{4}}{\sum_{\mathrm{i}=1}^{\mathrm{k}} \mathrm{n}_{\mathrm{i}} \mathrm{D}_{\mathrm{i}}^{3}}$
$\mathrm{PDI}=\frac{\mathrm{D}_{\mathrm{v}}}{\mathrm{D}_{\mathrm{n}}}$ 


\section{Results}

\section{Preparation of hydrophobic modified gentamicin}

The successful hydrophobic ion pairing was confirmed by FTIR measurements. An absorption band at $1734 \mathrm{~cm}^{-1}$ was observed for both AOT and gentamicin AOT. This band belongs to the energy of stretching the $\mathrm{C}=\mathrm{O}$ group of the ester of the AOT molecule. Between $1620 \mathrm{~cm}^{-1}$ and $1610 \mathrm{~cm}^{-1}$ an absorption band is observed associated with the primary amine groups present both in gentamicin sulfate and gentamicin AOT. In the spectrum vibrational bands solely associated with gentamicin sulfate or AOT could be identified in the spectrum of gentamicin AOT. Since gentamicin sulfate is not soluble in DCM, these had to derive from the ion paired complex. Furthermore, a shift in absorption wavenumber for the stretching of the amine group present on the gentamicin molecule has been observed from $1620 \mathrm{~cm}^{-1}$ for gentamicin sulfate to $1608 \mathrm{~cm}^{-1}$ for gentamicin AOT.

\section{Polymeric microparticles fabrication using a membrane emulsification method}

PDLLA particles were prepared with low PDI by the membrane emulsification method. Incorporating hydrophobic modified gentamicin in the same phase as the polymer yields smaller particle sizes. Encapsulating gentamicin sulfate in another water phase results in bigger particles again, as well as increase in polydispersity. PTMC particles were prepared, incorporating gentamicin AOT resulted in a drop in particle size as well as PDI. Again, incorporation of gentamicin sulfate increase microparticle size (Table 7.2). Gentamicin AOT loaded monodisperse microparticles are shown in figure 7.3 . 
Table 7.2: Microparticle size and polydispersity of microparticles prepared by microsieve membrane emulsification

\begin{tabular}{lccc}
\hline $\begin{array}{l}\text { Microparticle } \\
\text { composition }\end{array}$ & $\mathbf{D}_{\mathrm{n}}(\boldsymbol{\mu m})$ & $\mathrm{D}_{\mathrm{w}}(\boldsymbol{\mu m})$ & PDI \\
\hline PDLLA & 20 & 21 & 1.06 \\
\hline PDLLA + Gentamicin AOT & 11 & 11 & 1.04 \\
\hline PDLLA + Gentamicin sulfate & 20 & 31 & 1.52 \\
\hline PTMC & 40 & 62 & 1.56 \\
\hline PTMC + Gentamicin AOT & 11 & 12 & 1.06 \\
\hline PTMC + Gentamicin sulfate & 20 & 24 & 1.24 \\
\hline
\end{tabular}

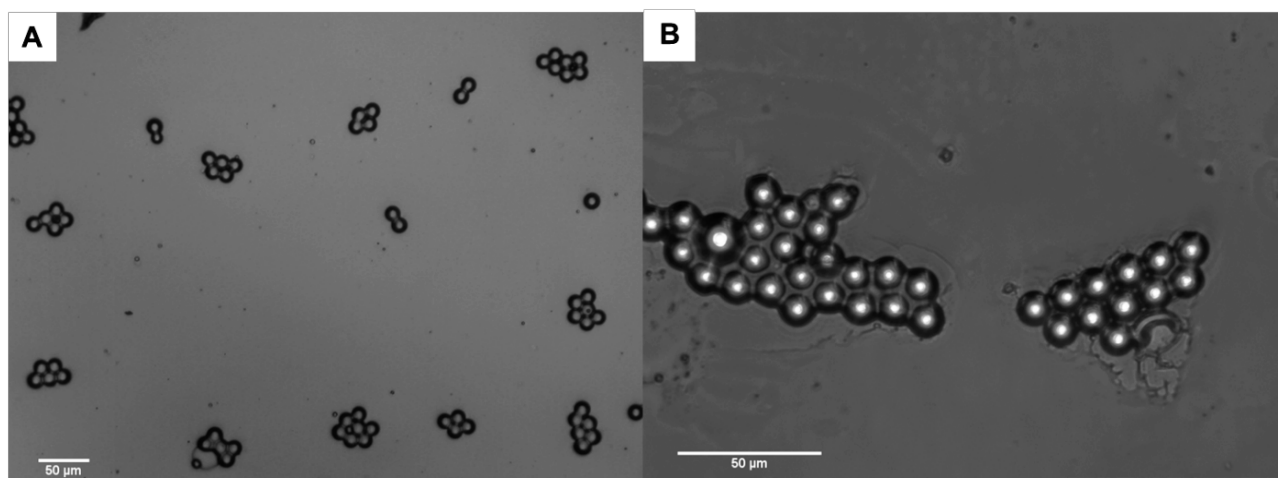

Figure 7.3: Gentamicin AOT loaded PDDLA microparticles $(A)$ and gentamicin AOT loaded PTMC microparticles $(B)$ were prepared with low dispersity $(P D I<1.1)$. 


\section{Discussion}

Generally, the size distribution for microparticles obtained by the classical emulsion solvent evaporation method is broad. By increasing the polymer concentration, and hence the viscosity of the oil phase, larger particles are obtained. Wide size distributions limits the predictability of the release, as the surface area of the particles and the diffusion pathway of the antibiotic from the particle differs between microparticles with different sizes. Furthermore, antibiotic particles dispersion in the polymeric oil phase leads to much larger diameter than the average microparticle size and might cloak injection needles when trying to decrease particle size. Membrane emulsification allowed for the preparation of monodisperse PDLLA and PTMC microparticles. However, when a first water phase containing the gentamicin sulfate was mixed with the oil phase to obtain gentamicin-sulfate loaded microparticles higher PDI values were obtained independently of the polymer used. The reason for the larger PDI for the gentamicin-sulfate containing microparticles could be an improper size of the emulsion droplets of the first emulsion flowing through the pores of the membrane, leading to a variety of particle size and shapes. Incorporation and solubilisation of gentamicin AOT directly in the oil phase creates significantly smaller particles with conserved low PDI, in comparison to the polymers only microparticles. This can be hypothetically attributed to a decrease in the viscosity of the polymer solution loaded with gentamicin AOT in the dispersed phase.

\section{Conclusion}

Preparation of monodisperse PDLLA and PTMC microparticles was achieved by membrane emulsification. By hydrophobic modification of water soluble gentamicin sulfate using ion pairing, the antibiotic was soluble in the oil phase (DCM) of the emulsion in which also the polymer was dissolved. By this method monodisperse gentamicin loaded microparticles of around 10 microns diameter were obtained. These microparticles are suitable for the development of an injectable controlled release antibiotic formulation. Further investigations will consist in assessing the antibiotic loading efficiency, the antibiotic release kinetic from the microparticles in vitro and antimicrobial activity over period of time relevant for the treatment of infection. 


\section{Acknowledgements}

We would like to thank Anita Bijsterveld for performing the GPC measurements. The microsieve ${ }^{\mathrm{TM}}$ equipment was kindly provided by Nanomi monosphere technology (Oldenzaal, The Netherlands). 


\section{References}

[1] Inzana JA, Schwarz EM, Kates SL, Awad HA. Biomaterials approaches to treating implant-associated osteomyelitis. Biomaterials. 2016;81:58-71.

[2] ter Boo GJ, Grijpma DW, Moriarty TF, Richards RG, Eglin D. Antimicrobial delivery systems for local infection prophylaxis in orthopedic- and trauma surgery. Biomaterials. 2015;52:113-25.

[3] Hoare TR, Kohane DS. Hydrogels in drug delivery: Progress and challenges. Polymer. 2008;49:1993-2007.

[4] Ryu T-K, Kim SE, Kim J-H, Moon S-K, Choi S-W. Biodegradable uniform microspheres based on solid-in-oil-in-water emulsion for drug delivery: A comparison of homogenization and fluidic device. Journal of Bioactive and Compatible Polymers: Biomedical Applications. 2014.

[5] Tran V-T, Benoît J-P, Venier-Julienne M-C. Why and how to prepare biodegradable, monodispersed, polymeric microparticles in the field of pharmacy? International Journal of Pharmaceutics. 2011;407:1-11.

[6] Abdelghany SM, Quinn DJ, Ingram RJ, Gilmore BF, Donnelly RF, Taggart CC, et al. Gentamicin-loaded nanoparticles show improved antimicrobial effects towards Pseudomonas aeruginosa infection. Int J Nanomedicine. 2012;7:4053-63.

[7] Berkland C, Kim K, Pack DW. Fabrication of PLG microspheres with precisely controlled and monodisperse size distributions. J Control Release. 2001;73:59-74. [8] Vladisavljević GT, Kobayashi I, Nakajima M. Production of uniform droplets using membrane, microchannel and microfluidic emulsification devices. Microfluidics and Nanofluidics. 2012;13:151-78.

[9] Choi SH, Park TG. Hydrophobic ion pair formation between leuprolide and sodium oleate for sustained release from biodegradable polymeric microspheres. Int $\mathrm{J}$ Pharm. 2000;203:193-202.

[10] Meyer JD, Manning MC. Hydrophobic ion pairing: altering the solubility properties of biomolecules. Pharm Res. 1998;15:188-93.

[11] Dai WG, Dong LC. Characterization of physiochemical and biological properties of an insulin/lauryl sulfate complex formed by hydrophobic ion pairing. Int J Pharm. 2007;336:58-66. 
Polymeric microparticles with low dispersity loaded with gentamicin sulfate and hydrophobic gentamicin

[12] Labet M, Thielemans W. Synthesis of polycaprolactone: a review. Chem Soc Rev. 2009;38:3484-504. 
Chapter 8

Future perspectives 


\section{Conclusions and Future perspectives}

Millions of fracture fixation devices are implanted annually, and their number is expected to grow further in the future. Due to the fact that implant-associated infection has emerged as one of the most challenging complications after osteosynthesis, research in the field of antibiotic loaded biomaterials (ALBs) aimed at prophylaxis or treatment of these infections has expended tremendously over the last decades.

The local delivery of antibiotics circumvents the issue of systemic toxicity and makes it possible to deliver high concentrations of antibiotics at vascular comprised regions. Furthermore, the short half-life of systemic administered antibiotics can be improved by incorporating the antibiotic into a biomaterial. Despite the recent advances in ALB delivery systems, numerous opportunities for improvement present themselves.

\section{ALBs for infection prophylaxis}

\section{Antimicrobials beyond gentamicin-sulfate}

ALBs should be able to provide protection under complex circumstances specific for traumatic wounds such as: high bacterial contamination of unknown origin (Grampositive, Gram-negative, multi-species, (multi-)resistant species), inaccessibility of part of the contaminated areas, poorly defined wound margins and involvement of multiple tissues. One of the requirements therefore is that the incorporated agent, either an antibiotic, or another antimicrobial such as antimicrobial peptides or antibacterial metals should have a broad antimicrobial spectrum. Therefore, it would be important to assess how such diverse antimicrobials agents would be released from stimuli-responsive hydrogels.

\section{Facilitating bone repair}

Locally delivered antibiotics from an ALB can have an effect on cell viability of osteoblasts and other eukaryotic cell types if concentrations are high and exposure times are long. In order to counteract any potential deleterious effect, osteopromotive 
factors such as bone morphogenetic proteins could be co-introduced in order to improve bone healing in fracture fixation in which an ALB is used.

The in vivo fate of thermo-responsive materials

Stimuli-responsive hydrogels represent an attractive ALB, as they have low viscoelastic moduli before administration, and therefore can easily cover all the contaminated exposed areas of the traumatic anatomical site. Several cues can be used to induce the phase transition from sol to gel, temperature being one of them. Although there is a large amount of polymers or block (co)polymers that display LCST behaviour, only a few have gained particular interest as they gelate at temperatures just below physiological relevant temperature. Amongst them poly $(\mathrm{N}-$ isopropylacrylamide), poly( $N, N$-diethylacrylamide) and block copolymers of poly(ethylene oxide) and poly(propylene oxide) or poly(ethylene oxide) and poly(lactic-co-glycolic acid). Amongst these poly( $N$-isopropylacrylamide) is the one that shows the sharpest transition between sol and gel state, needed for a fast gelation of the hydrogel.

However, a concern for the use of thermo-responsive polymers based upon (co) polymers of $N$-isopropylacrylamide is their fate in the body, which has not yet been clarified. After degradation, the thermo-responsive grafts stay behind and have to leave the body by renal excretion when they should resolubilize upon shortening of the chain. So far, toxicity testing for $N$-isopropylacrylamide and different molecular weight (co)polymers from the monomer have been performed only in vivo for acute or subacute toxicity. However, the exact fate and excretion process of the material still need to be defined within test animals, potentially through specific labelling and quantification in vivo. This is crucial for their safe application in to the patients. 


\section{ALBs for infection treatment}

Delivery systems with a more sustained release are needed for treatment of established infections as clearance takes place over an extended time.

The "Plum pudding" approach

Antibiotic release could potentially be extended through encapsulation in hydrophobic polymer microcarriers dispersed in a stimuli responsive hydrogel. In order to achieve a more predictable release, monodisperse particles can be used. When using hydrophobic polymers which degrade by surface erosion rather than bulk degradation, even zero-order release kinetics can be obtained depending on the dimensions of the implant.

\section{Prodrugs approach}

Another approach could be the development of prodrugs, in which the antibiotic attached to a macromolecule through cleavable linkers is released upon exposure to bacterial enzymes or other infection cues.

Furthermore, MICs for bacteria located in a biofilm are multiple times higher than their planktonic counterparts, so also the local concentrations delivered by an ALB should be considerably higher than in the case of infection prophylaxis. Infection with $S$. aureus can even be more complex to treat as the species also tends to invade cells and become intracellular, where many antibiotic are unable to reach them as the cell membrane has low permeability for them. Therefore, either the antibiotics should be modified so they can be internalized easier or targeting ligands which will target the antibiotic loaded vehicle to bone cells could be used in order to effectively clear these pathogens from colonized tissues.

Finally, the efficacy of the emerging ALBs from the ongoing developments have to be assessed in relevant in vivo prophylactic and treatment models, in order to be able to successfully move on into clinical trials. This is the only way patients at risk or suffering from implant-associated osteomyelitis can benefit from all these developments. 
Summary 
This thesis describes the development of gentamicin loaded resorbable polymeric carriers as anti-infective strategy for implant-associated osteomyelitis and their in vitro and in vivo evaluation. Local delivery of antibiotics has several advantages in the case of trauma to the bone and surrounding tissues. It can deliver high amounts of antibiotics directly to the target site, without inducing toxicity in non-target organs. Furthermore, sufficient antibiotic levels can be reached by local application at sites where the vasculature is disturbed.

A general background with regard to the work in the thesis and antibiotic loaded biomaterials is provided in Chapter 1. In Chapter 2 the problem of implantassociated infection is described and an overview of polymeric carriers for antibiotics delivery is given. These can be passive polymeric carriers, that release their antibiotics by diffusion and/or upon degradation, and active polymeric carriers that release antibiotics upon stimuli provided by bacterial pathogens. Additionally, some polymeric carriers are able to gelate in-situ in response to physiological stimuli to form a depot for antibiotics release. Besides antibiotics, also other anti-infectives such as silver and antimicrobial peptides have been incorporated into biomaterials in the response to emerging antibiotic resistance. Chapter 3 describes the complexation of gentamicin with negatively charged hyaluronic acid (HA) to form polyelectrolyte complexes (PECs). These complexes have reduced solubility and precipitate out of solution. Several HA conjugates were prepared and screened for their thermo-responsive behaviour and their ability to form polyelectrolyte complexes with gentamicin. The more hydrophilic HA-Jeffamines precipitated out of solution upon complexation. HApN polymers were able to form stable complexes that stayed in solution at RT while precipitating out at $37^{\circ} \mathrm{C}$, similar to the more hydrophobic Jeffamine functionalized HA polymers. Hereby the HA derivative based PECs can modulate the availability of gentamicin and potentially increase the half-life and extend the release time of the antibiotic. In Chapter 4 the preparation and characterization of gentamicin-loaded thermo-responsive HA-poly $(\mathrm{N}$ isopropylacrylamide) ( $\mathrm{HApN}$ ) hydrogels is described. At a concentration of $13 \% \mathrm{w} / \mathrm{w}$ the hydrogel had suitable gelation properties, being a moderate viscous fluid at $20^{\circ} \mathrm{C}$, whereas at physiological temperatures viscoelastic moduli were in the $\mathrm{KPa}$ range. The HApN hydrogel showed an initial burst release of gentamicin in vitro, however 
the burst was lower than for collagen fleece containing an equal amount of the same antibiotic. In an in vivo rabbit humerus model of plating osteosynthesis contaminated with Staphylococcus aureus the HApN hydrogel with gentamicin successfully protected the implant site from bacterial colonization at 1 week post-operative. All samples from taken from the implant, bone and surrounding soft tissues from the rabbits to which the HApN hydrogel with gentamicin was administered were culture negative for bacteria. Bone, soft tissue and implant samples deriving from the untreated rabbits on the contrary were colonized by high amounts of Gram-positive bacteria. Histology data showed an absence of bacteria in the humeri of rabbits treated with the HApN hydrogel with gentamicin. Fracture healing upon clearance of a high bacterial load in the presence of the gentamicin-loaded HApN hydrogel is described in Chapter 5. Although healing has progressed, bridging of the created osteotomy is not complete 4 weeks post-operatively, as was observed in rabbits that only had surgery. Mechanical testing and histopathological evaluation of the operated humeri showed that the presence of the HApN hydrogel does not significantly influence bone healing in comparison to rabbits that only had surgery. In the histological sections this was observed as the formation of callus both on the cis and trans site of the bone, as well as periost around the osteotomy. Neither did the HApN hydrogel evoke a systemic response as was shown by the absence of differences in haematological values between the rabbits that were operated and the rabbits that were additionally injected with the $\mathrm{HApN}$ hydrogel. Humeri of inoculated rabbits that did not receive treatment showed a high degree of necrosis and absence of callus formation in the inoculated area. In the group of rabbits that got inoculated with $S$. aureus and which received the HApN hydrogel with gentamicin bone healing is delayed at the site where the bacteria and the hydrogel had been applied. The presence of dead bacteria might slow down bone healing. However on the contrary to the infected rabbits, callus formation was observed and there was an absence of necrosis. On the long term bone healing in these rabbits is anticipated. In Chapter 6 the preparation of a lipophilic salt of gentamicin, gentamicin dioctyl sulfosuccinate and its encapsulation in poly(trimethylene carbonate) (PTMC) matrices is described. It was shown that ion-pairing with dioctyl sodium sulfosuccinate does not affect the potency of the antibiotic. The in vitro viability was affected negatively at lower molar 
concentrations for the gentamicin dioctyl sulfosuccinate as compared to the sulfate salt of gentamicin. However, the lipophilic modified gentamicin was bactericidal towards $S$. epidermidis and $S$. aureus at molar concentrations lower than the concentration for which cell viability was reduced with $50 \%$. The lipophilic modified gentamicin was well solubilized in the PTMC matrix, while gentamicin sulfate was dispersed to the polymer matrix and antibiotic loaded PTMC discs were obtained by compression molding. Chapter $\mathbf{7}$ describes the preparation of polymeric microparticles with low dispersity and loaded with gentamicin sulfate or lipophilic modified gentamicin. Membrane emulsification yielded monodisperse gentamicin dioctyl sulfosuccinate loaded PDLLA and PTMC microparticles when polymer and antibiotic were dissolved in the same solvent as dispersed phase in the cross flow membrane emulsification process. By this method monodisperse lipophilic modified gentamicin loaded microparticles with an average diameter of $10 \mu \mathrm{m}$ and polydispersity index $(\mathrm{PDI})<1.1$ were obtained. Finally, in Chapter 8 final conclusions are drawn and future perspectives of antibiotic loaded biomaterials are discussed. Issues such as bacterial resistance, lowered viability of osteoblasts and other eukaryotic cells in the presence of antibiotics, the in vivo fate of thermo-responsive polymers, additional requirements for infection treatment, delivery in response to bacterial presence and targeting of antimicrobials are addressed. 
Samenvatting 
Dit proefschrift beschrijft de ontwikkeling van degradeerbare polymere afgiftesystemen geladen met gentamicin als infectiewerende strategie tegen implantaat gerelateerde osteomyelitis en hun in vitro en in vivo evaluatie. Lokale afgifte van antibiotica heeft verschillende voordelen ten opzichte van systemische afgifte in het geval van trauma aan bot en omliggende weefsels. Hoge lokale antibiotica concentraties kunnen worden bewerkstelligd zonder dat andere organen beschadigen door middel van lokale afgifte. Verder kunnen voldoende hoge antibiotica concentraties worden gehaald in weefsels waar de vasculatuur is beschadigd.

De achtergrond met betrekking tot het werk in deze thesis en antibiotica geladen biomaterialen is beschreven in Hoofdstuk 1. In Hoofdstuk 2 wordt het probleem dat implantaat gerelateerde osteomyelitis vormt beschreven, samen met een overzicht van de polymere afgifte systemen voor antibiotica. Een overzicht wordt gegeven van de passieve polymere afgifte sytemen voor antibiotica die hun lading afgeven door middel van diffusie/ of na degradatie, en actieve polymere afgifte systemen die antibiotica afgeven naar aanleiding van stimuli die worden geproduceerd door de aanwezigheid van bacteriën. Verder kunnen sommige polymere afgifte systemen insitu een gel vormen, als reactie op fysiologische stimuli en als depot voor antibiotica afgifte dienen. Naast antibiotica, zijn er ook andere infectiewerende middelen zoals zilver en antimicrobiële peptiden geladen in biomaterialen als antwoord op een toename in antibiotica resistentie in bacteriën. Hoofdstuk 3 beschrijft de complexatie van gentamicin met negatief geladen hyaluronan zuur (HA) in polyelectrolyte complexen (PECs). Deze complexen hebben een gereduceerde oplosbaarheid en precipiteren uit de oplossing. Verschillende HA derivaten werden gesynthetiseerd en gescreend op thermoresponsiviteit en de mogelijkheid om PECs te vormen met gentamicin. De meer hydrofiele HA-Jeffamines precipiteerden uit de oplossing na complexatie. HApN polymeren waren in staat complexen te vormen die in oplossing bleven bij kamertemperatuur, terwijl ze precipiteerden bij $37^{\circ} \mathrm{C}$, net als de meer hydrophobe Jeffamine gefunctionaliseerde HA polymeren. Op deze manier kunnen PECs op basis van HA derivaten de beschikbaarheid van gentamicin moduleren en potentieel de halfwaardetijd vergroten en de afgiftetijd verlengen. In Hoofdstuk 4 wordt de synthese en de karakterisatie van gentamicin geladen thermoresponsieve 
HA-poly( $N$-isopropylacrylamide) (HApN) hydrogelen beschreven. Goede gelvormende eigenschappen werden bereikt bij een concentratie van $13 \% \mathrm{w} / \mathrm{w}$. Bij kamertemperatuur $\left(20^{\circ} \mathrm{C}\right)$ was de $\mathrm{HApN}$ een matig visceuze oplossing, en bij lichaamstemperatuur waren de viscoelastische moduli in het $\mathrm{kPa}$ bereik. De HApN hydrogel gaf initieel een grote hoeveelheid gentamicin af, hoewel de hoeveelheid kleiner was dan voor collageen fleece geladen met een gelijke hoeveelheid antibiotica. De HApN hydrogel met gentamicin beschermde het implantaat en de omliggende weefsel succesvol tegen bacteriële contaminatie 1 week postoperatief in een in vivo fractuur model in de humerus van het konijn met osteosynthese hardware en Staphylococcus Aureus contaminatie. Alle monsters die werden genomen van het implantaat, het bot en de omringende zachte weefsels van de met de gentamicin geladen HApN hydrogel behandelde konijnen waren vrij van bacteriegroei. Daarentegen, de monsters van het implantaat, het bot en de omringende weefses van onbehandelde konijnen uit de controle groep waren gekoloniseerd door grote hoeveelheden Gram-positieve bacteriën. Histologie ondersteunde deze resultaten en toonde afwezigheid van bacteriën aan in de met de gentamicin geladen HApN hydrogel behandelde konijnen. Het helen van een fractuur na het afdoden van een grote hoeveelheid bacteriën door de gentamicin geladen HApN hydrogel is beschreven in Hoofdstuk 5. De gecreëerde osteotomie geneest niet totaal in de 4 weken die deze studie duurde. Mechanische testen en histopathalogisch onderzoek van de geopereerde humeri toonde aan dat de $\mathrm{HApN}$ hydrogel geen significant effect heeft op de bot genezing in vergelijking met konijnen die alleen werden geopereerd. Dit kon worden gezien in de vorm van callus formatie aan de cis en trans zijde van het bot, en het vormen van periost rondom de osteotomie. Ook had de toediening van de HApN hydrogel geen systemische reactie tot gevolg, hetgeen kon worden gezien aan de hand van gelijke bloedwaardes voor de groep die alleen geopereerd werd en de groep die de HApN hydrogel toegediend kreeg. De humeri van konijnen die enkel werden geinoculeerd met bacteriën toonden necrose en afwezigheid van nieuw gevormde callus. Tot slot, de heling van de breuk was vertraagd in de groep die werd geinoculeerd met $S$. aureus en die de HApN hydrogel met gentamicin toegediend kreeg. De aanwezigheid van afgedode bacteriën kan het genezingsproces hebben vertraagd. Echter in tegenstelling tot de geinfecteerde konijnen was er nieuwe callus gevormd in deze konijnen en werd er geen necrotisch 
weefsel aangetroffen. Op de lange termijn mag verwacht worden dat het bot heelt in deze konijnen. In Hoofdstuk 6 wordt het bereiden van een lipofiel zout van gentamicin, gentamicin dioctyl sulfosuccinaat en het incapsuleren van dit lipofiele molecuul in poly(trimethyleen carbonaat) (PTMC) matrices beschreven. Er werd aangetoond dat het uitwisselen van het dioctyl sulfosuccinaat voor sulfaat geen effect had op de uiteindelijke antibacteriële capaciteit van het antibioticum. De levensvatbaarheid van cellen wanneer deze aan de antibiotica werden blootgesteld werd negatief beïnvloed in vitro bij lagere concentraties voor gentamicin dioctyl sulfosuccinaat dan voor het sulfaat zout van gentamicin. Echter de lipofiel gemodificeerde gentamicin doodde $S$. epidermidis en $S$. aureus bij lagere molaire concentraties dan voor welke de levensvatbaarheid van de cellen met $50 \%$ werd gereduceerd. Het lipofiel gemodificeerde gentamicin losde goed op in de PTMC matrix, terwijl het gentamicin sulfaat als dispersie in de polymere matrix werd opgesloten, en antibiotica geladen PTMC schijven konden worden gemaakt met behulp van een pers. Hoofdstuk 7 beschrijft het vervaardigen van polymere nanodeeltjes met lage dispersiteit en geladen met gentamicin sulfaat of lipofiel gemodificeerd gentamicin. Met behulp van membraan emulsificatie konden monodisperse gentamicin dioctyl sulfosuccinaat geladen PDLLA en PTMC micropartikels worden gemaakt door het antibioticum en het polymer in hetzelfde oplosmiddel als gedispergeerde fase te gebruiken in het kruisstroom membraan emulsificatie proces. Monodisperse lipofiel gentamicin geladen micropartikels konden worden verkregen met een gemiddelde diameter van $10 \mu \mathrm{m}$ en een polydispersiteit $(\mathrm{PDI})<1.1$. Tenslotte werd de balans opgemaakt in Hoofdstuk 8 en de toekomstperspectieven van antibiotica geladen biomaterialen werden geschetst. Kwesties met betrekking tot resistentie, verlaagde levensvatbaarheid van osteoblasten, het in vivo lot van thermoresponsieve polymeren, verdere eisen aan afgifte systemen wanneer het de behandeling van infectie betreft, afgifte in repons op aanwezigheid van bacteriën en het gericht afgeven van antibiotica in bepaalde weefsels werden besproken. 


\section{Acknowledgements}

I still remember the end of 2011, I had just finished my masters Biomedical Engineering and I was looking for a PhD position. As I always have loved travelling and I had stayed 3 months in Tokyo for my internship, Prof. Dirk Grijpma suggested me to contact Dr. David Eglin in the AO Research Institute in Davos, Switzerland because he had heard there was a position available. I went for a two day job interview and meeting with David Eglin, head of the Polymers group, and Fintan Moriarty, head of the Musculoskeletal Infection group. Before I knew I moved to Davos and started my PhD in the AO Research Institute in January 2012. The four and a half years following have passed increasingly fast over time, both because of the projects that were running, but certainly because of all the social contacts as well. I have a long list of people to thank, for helping me out with the research, as well as for making me feel at home in Davos, and it felt like home because of them. The people I have to thank first are Prof. Dirk Grijpma, Dr. David Eglin and Dr. Fintan Moriarty.

Dirk thanks for giving me the opportunity to do a PhD abroad and for keeping me on track. I had a tendency to get lost in details some time and you always helped me to find back the bigger picture, helped keeping a clear structure and you got me back on track again. Although the contact moments were somewhat limited because of the physical distance, this was of great help.

Dear David, I really appreciated that you have given me the opportunity to come to Davos and do my $\mathrm{PhD}$ in the $\mathrm{AO}$ research institute. You have given me a lot of support over the past years. Your door has always been open to discuss small or bigger issues and to decide how to move on. I have learned a lot from your creative way of thinking and problem solving. If I got stuck in an experiment or during the writing, you helped me finding a solution.

And of course Fintan, I have to say a big thanks to you too. Firstly, you have introduced me in a field to which I was new, the world of infection. Especially, in the later years that more bacteriology work was involved and we conducted the in vivo studies you invested a lot of time to support me with the work and the writing. We 
had often a lot of correction rounds before the manuscript was send for review to the journal, but with your accuracy and eye for detail the amount of comments and corrections from the reviewers were always limited.

Furthermore, I would like to express my gratitude to my promotion committee for accepting their participation, their precious time spent on reading the thesis and their presence during the defence. Prof. H.B.J. Karperien, prof. D.B.F. Saris, prof. H.C. van der Mei, prof. R.R.M. Bos and dr. S.A.J. Zaat, it is a great privilege that you agreed to be members of my promotion committee.

My gratitude of course goes also out to Prof. Geoff Richards, for his valuable advice during the $\mathrm{PhD}$ and recommendations on all manuscripts before they were sent in for review to the respective journals. A big thanks as well to Prof. Mauro Alini, as head of the Musculoskeletal Regeneration you take very well care of your team and I think that is one of the reasons that the work atmosphere is so good.

Thank you so much Karin Hendriks, for the help with the arrangements all the times I came from Davos to Twente to perform experiments or to discuss with Dirk. And furthermore, I would like to thank you for the help with all the arrangements and the paperwork prior to the defence.

Here I would also like to thank the people which became very close friends, almost like a family to me. Dear Ana-Maria, Dalila and Marina thanks so much for all the good times spend together, within the $\mathrm{AO}$ and outside $\mathrm{AO}$, during dinners, drinks, conferences, parties, in the weekends and during the holidays. And of course often together with Adriano, Fabian and Isaac. Most recently was the very nice trip to Puglia, where I was treated so well by the Rucci and Petta families, thanks again :) ! You were there in the good and in the bad times. We have been to so many places together, that it will be difficult now we all continue in different directions. But we will keep meeting regularly, I am sure. Life in Davos would not have been the same without you.

Ryan, I also would like to thank you and Sarah of course for the nice time I had in Davos. You are a great couple, and it was great to have been to your wedding in 
Barcelona. Good we could meet recently in Amsterdam. I hope you will settle feel at home with your son Nelson in Boston, and hope we meet soon again.

During the $41 / 2$ years the polymers group composition has changed, and I have seen people coming and going. I would like to thank Matteo D' Este for the assistance and advice during all these years. I could always consult you with questions regarding polymer synthesis or characterization and I admire your knowledge and insight. And of course also thanks for all the great dinner parties at your place. Markus, thank you for the help in the polymer lab at the start of my PhD. And of course your sense of humor that cheered up the whole lab. Later, Flavio took over. Flavio I would also like to thank you for your help in the lab, and assisting me with part of the work. Olivier, Angela and Laura Kyllönen thanks for all the discussions during work, and Olivier thanks for presenting my work in Groningen during the Biofilm conference. Also thanks to Christoph for help with the scanning electron microscope. Stijn, you have just started in the polymer group. You are the second Twente PhD candidate in Davos. I wish you all the best for your PhD career and hope you will enjoy these years.

During this 4 and a half years, I was also part of the Musculoskeletal Infection group. Next to Fintan, I have to give a big thanks to Iris Keller. She taught me all the basic bacteriology skills and with her precise way of working and teaching I am sure I will still remember those forever! And of course thanks a lot as well for organizing a lot of social events within the group.

Furthermore, I would like to thank my colleagues and former colleagues in the infection group: Barbara, Jan P., Keith, Pamela, Stoyan and Virginia for their help and discussions with me. Next to the polymer group and the infection group, there is many other colleague to thank for their help especially during the 2 in vivo studies that were part of the PhD. Thanks a lot: Daniel Arens, Dirk Nehrbass, Ivan Zderic, Karin Camenisch, Mauro Bluvol, Nora Goudsouzian, Stephan Zeiter, Tanja Schmid and Willem-Jan Metsemakers.

Ivan more than a good colleague in both the professional and personal sense, you have been a wonderful friend. I remember all the good times spent together during 
dinners, the trip we did with Rukmanikanthan Shanmugam (Kanthan) to Copenhagen, being present at your wedding with Slavica in Croatia together with Dirk Nehrbass and the recent dinners together with you, Slavica and your daughter Nicole and son Gabriel. I hope we will be able to meet often in future as well.

Thanks as well Catarina Leite Pereira, we started more or less at the same time in the $\mathrm{AO}$, and we did many trips, and many weekends of skiing, sledging and trips together. It was nice to visit you and João back in Porto, and I hope to return for your wedding!

I want to thank all the people with which we had together the 'lunchgroup' started as a small group when I began in order to be more efficient and to have to cook less, and of course because eating with a group is more fun. It started as a small group, but in the more busy times it grew towards 10-15 people. Thanks Adrian, Beata, Dimitar, Dominik, Fabrizio, Jan P., Lourdes, Martin H., Meret, Nina, Robert O., Rose, Shan, Silvia, Ying, Yishan and forgive me if I have forgotten any past members.

Thanks also Ugo, Inesa and Marta for the nice drinks and dinners. And of course for our nice trip to the Netherlands. Unfortunately, Marta, you could not be there. But it was great that we were both at the group excursion to Sicily! And of course to meet Giuseppe Musumeci again in Sicily after spending time together in the AO in 2012. Hope we all can keep meeting in future, although we are a bit spread.

Thanks Fatemeh Safari and Reihane Ziadlou for getting to know a bit more of Iran and of course for teaching me some useful words in Persian ;-) and for making kuku, samosa and of course the wonderful shashlik and hike to Sertig when your parents and sister were visiting Reihane :). Thanks as well Andre Arruda for the good times, if you come ever to visit, I will make sure there are chocolate sprinkles and also in future I will keep updating you about our dog Heros in the Netherlands :). Thanks Janek also for the discussions and for the grilling! And it was very nice to meet you again both in Davos and Bangkok, Stephanie Caprez, after your time in Davos! We had such a good fun during our trip. Cassie thanks as well for all the dinners and lunches and your visits back to Davos and of course for joining us for our trip to Thailand and Cambodia. 
My gratitude goes also out to Walter 'Tico' Ocampo. After your fellowship in AO in 2013 we have been meeting regularly, often short and during a travel when I was in Basel. Nevertheless this was great and thank you so much for hosting!

Kerstin Schneider thanks as well for all the nice moments and gatherings during the AO courses in Davos or for going for a drink in Zurich!. Daniel Wagner, also thanks to you! It is always nice meeting when you are back in Davos, or when we meet at a wedding in Barcelona ;-). I have to visit you in Germany at some point in the future!

Koen Dullaert ook bedankt voor de gezellige tijd in Davos en voor alle parties en pilsjes!, laten we ook snel een keer een pilsje in Nederland doen! Mario Morgenstern, thanks for the trips with the BuBu (transporter) to your place in Rosenheim and to Milan and the lake of Como with Catarina and Joseph! And of course thanks a lot for all the clinical input at the start of my project! Thanks Andrea for all you effort to organize tango lessons in AO! Willemijn, nice that there was a bit more of dutchness in the AO during my last months. I hope you will enjoy the years in Davos like I did. Federico and Letizia thanks for the (dinner) parties, movies and all the funny moments. Niamh thanks as well for the nice times and the Guinness.

I also would like to thank my other $\mathrm{AO}$ colleagues for the nice chats during coffee and lunchbreaks as well as during $\mathrm{AO}$ trips and in 'regular' weekends: Alexander, Bojun, Catherine, Corina, Dragica, Ewa, Fernanda, Gaston, Girish, Jason, Jessi, Linda, Luisa, Marco Bruderer, Matti, Oliver, Peter Varga, Robert P., Samina, Sebastian, Viktor, Zahira and Zhen.

Also I would like to thank my friends from the other research institute in Davos, the Swiss Institute of Allergy and Asthma Research (SIAF): Thanks Arturo and Weronika for the nice party we had this year! And of course thanks to Kirsten as well.

Staying far away from home, it was nice to have so often visitors from the Netherlands. That made my stay especially in the start much easier.

Thanks Mark Smeets, in January 2012 you helped me move all my stuff to Davos and we did a bit of exploration of the area before I started in AO. You have been visiting several times, and it was a lot of fun. I appreciate having you as a friend very much!. 
Thanks as well to Derk-Jan for visiting me several times during my $\mathrm{PhD}$. Also thanks to Jos Wennink, Sytze Buwalda and Niels Sijbrandi for visiting and our trip to the Stelvio pass. Thanks Wim and Catalina for visiting me multiple times in Davos, and it was great I could visit you guys back in Vancouver. And of course for the nice days of skiing we had together with Bas and Caroline and with Menno. Gijs en Sabine for visiting me in the summer of the first year, we had some nice tour through Davos with a matras ;-). And of course for meeting all the times in Deventer or De Klomp I was back in the Netherlands. Also Sten and Miriam, it was nice that you could visit me when you came to Switzerland on holiday! Thank you for being part of your wedding day!.

Sjoerd and Jurgen, we have been friends from highschool and it is great we could meet so often during the last 4,5 years. In the first year we did some holidays in and around Davos. The trips we did to Romania, Moldova and Transnistria recently I enjoyed a lot. And the short trip with Johan Hiemstra to Manchester after quite a bit of trouble with congress travelling to Liverpool. Next time it will be your defense Sjoerd $(-)$. And thanks Jurgen en Sarah to be present at your wedding in Belgium, it was a fantastic day. Thanks as well to Gerto, Marieke and Jonathan for meeting at least once a year in the Netherlands!

Wouter many thanks as well, you came several times to Davos when you were staying half a year at the ETH in Zurich during your own $\mathrm{PhD}$. And later for the nice weekend together with Mechteld and Willemijn! And of course during all the trips we did with our 'corrupte trip' group from the University. Thanks for these nice trips and other wonderful moments: Aniek, Jan, Jan-Philip, Jasper, Johannes, Mark, Renee en Wouter. Furthermore also thanks Yabin for the dinners in Zurich and Davos, and that you came over for skiing in the winter. I am looking forward to come for your big day to China. Thanks Gerbert and Jelle as well for making a 'slight detour' from your holiday in Vienna back to the Netherlands and having dinner with me in Davos. Remko Hofsteenge, nice you came all the way by motorcycle. Jun Ishihara, it was nice that you came from Lausanne to Davos after we had met during my internship in Tokyo, hope one day we'll meet again. Tante Ada en oom Johan, ook hartelijk dank voor het bezoek en de sportieve dagen in Davos en omgeving. Thanks as well Björn for visiting, and some nice dinners we had in Enschede. 
Lukas and Ing-Ing, it is fantastic that I got to know you in Davos, and all the nice events we had together. You guys have a real good sense of humour! Fantastic highlight was to be present on your wedding in Zug this year, it was an amazing day with my 'sisters'.

I got a long list of people from Twente to thank as well. Aga, thanks a lot for all the nice dinners, you were always one of the driving forces between all the socializing in twente :-). The dinners we had at Matteo's and your place were awesome and the quick coffee sometimes, like that time on Schiphol as well. And as Sint I could not have had a better Piet to assist me when Sinterklaas visited the Zuidhorst ;-). Kasia thanks for all the coffee breaks and lunches in the Waaier! And of course thanks to you and Emi for all the nice dinners as well. I still have your 'We wish you...' poster it has been all these years on the wall of the office in the $A O$ to also have my twente friends and colleagues there :). Thanks to you too Natalia! for all the stroopwafels and dinners. I was really impressed hoe jij in een zeer klein tijdsbestek zo goed Nederlands hebt leren spreken!!! :). Thanks as well Lia, you were short time my office mate in Twente and Denys of course, Mister, I will keep with the tradition to eat now and then a straciatella yoghurt ;-). Xiaolin, we became friends during our masters. It was nice that although you were in the AMC in Amsterdam already when I came back to Twente from Davos the first time that we always found time to meet in Schiphol or in one of the several nice Chinese restaurants in Amsterdam. I wish you all the best for your PhD too and hope I can soon attend yours. Guoying, also known as Mr. Si or Gijs, it was also a pleasure to meet you in Enschede again during the $\mathrm{PhD}$. It was a pleasure having regular talks and updates, I hope you found 'a home' in Cork, Ireland just as you did in Twente. Bas and Pia it was nice that you came to visit in Davos, and that eventually everybody survived the weekend. It was also the time that Mike was there. Mike it was nice that you also spend time in the lab in Davos for RAPIDOS, and on the sledging track :) of Rinerhorn. Thanks as well to Shariar, your passion for research and your knowledge is really something to admire. Thanks for your discussions and suggestions. And Mr. Blanquer, sebastien, we had a great time together in the office in twente, and if there were no scientific discussions in the office, than for sure politics was on the table. It was great you were in Davos as well. You now settled in Montpellier, were we met recently. All the best for you, 
Marilyn and Haile! Thanks as well Vincent Verdoold for your help in the lab and the nice conversations! Thanks Janine Jansen for supervising me during the master assignment in BST, it was nice to meet again in Enschede recently. I would like to thank Anita Bijsterveld, Hetty ten Hoopen, Lydia Bolhuis, Marc Ankone, and Zlata Rekenji for their support with technical issues and supplies. It was great to be back in the lab in Twente, surely also because of all of you! And of course there are much more people to thank from the BST group or which used to be in BST: Andriy, Aysun, Bade, Dmitriy, Erwin, Frits, Ilaria Geremia, llaria de Napoli, Jos Paulusse, Suvi and Tony. And also thanks to Barbara and Bram.

And of course I have to thank my group of friends from the University of Twente, which I have known for many years. Thanks for all your efforts and the nice weekends and trips and that you have been trying to keep the group together although we are spread over several countries and many of us have now their own families. In these years I have had the pleasure to visit the wedding of Sten and Miriam, and later to the one of Karin and Emiel. First I want to thank all the guys :), it has been a pleasure to go out with you guys or shoot at people in bunny suits and do a beer tasting afterwards during a bachelor party! Bedankt Emiel, Gijs, Han, Hannes, Joost, Pim, Sjoerd en Sten!. En natuurlijk ook de vrouwen: Ellen, Karin, Lianne, Marjolein, Miriam en Sabine.

En natuurlijk wil ik ook heel hartelijk mijn familie bedanken, ooms en tantes en neven en nichten. Ondanks dat we een kleine familie zijn, zien en spreken we elkaar toch met enige regelmaat en is het fijn om met de feest- en verjaardagen iedereen weer tezien. En tot slotte wil ik hier de personen waar ik het meest aan te danken heb noemen, mijn ouders. Ondanks een moeilijke start, hebben zij er met al hun inspanningen op jeugdige leeftijd voor gezorgd dat ik uiteindelijk het tot de universiteit heb kunnen brengen en uiteindelijk heb kunnen beginnen met een promotie onderzoek. Ik weet dat we het nooit tegen elkaar zeggen, maar ik hou van jullie en bewonder jullie enorm voor wat jullie voor me gedaan hebben. Zonder jullie had ik het niet gered, hartelijk dank daarvoor.

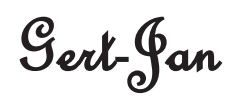

